\title{
Caracterización y potencial probiótico de bacterias lácticas aisladas de leche de oveja Guirra
}

Claudia Milena Amorocho Cruz 


\section{UNIVERSITAT POLITÈCNICA DE VALÈNCIA}

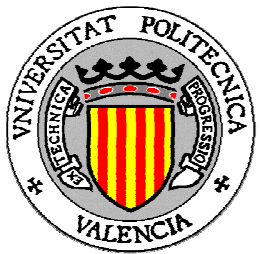

\section{DEPARTAMENTO DE BIOTECNOLOGÍA}

CARACTERIZACIÓN Y POTENCIAL PROBIÓTICO DE BACTERIAS LÁCTICAS AISLADAS DE LECHE DE OVEJA GUIRRA

TESIS DOCTORAL

Presentada por

Claudia Milena Amorocho Cruz

Dirigida por Dr. Manuel Hernández Pérez Dra. Yolanda Moreno Trigos 


\section{Esta editorial es miembro de la UNE, lo que garantiza la difusión y comercialización de sus publicaciones a nivel

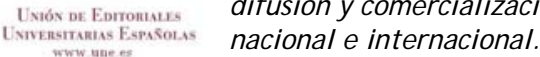

(c) Claudia Milena Amorocho Cruz, 2011

Primera edición, 2011

(c) de la presente edición:

Editorial Universitat Politècnica de València

www.editorial. upv.es

ISBN: 978-84-695-2327-8

Ref. editorial: 5515

Queda prohibida la reproducción, distribución, comercialización, transformación, y en general, cualquier otra forma de explotación, por cualquier procedimiento, de todo o parte de los contenidos de esta obra sin autorización expresa y por escrito de sus autores. 


\title{
UNIVERSIDAD POLITECNICA DE VALENCIA
}

\section{ESCUELA TECNICA SUPERIOR DE INGENIERIA AGRONÓMICA Y DEL MEDIO NATURAL}

\author{
DEPARTAMENTO DE BIOTECNOLOGIA
}

ÁREA DE MICROBIOLOGÍA

D. Manuel Hernández Pérez, profesor titular y Dña. Yolanda Moreno Trigos, profesor asociado, pertenecientes al Departamento de Biotecnología (Área de Microbiología) de la Universidad Politécnica de Valencia,

\section{CERTIFICAN:}

Que la tesis doctoral titulada "CARACTERIZACIÓN Y POTENCIAL PROBIÓTICO DE BACTERIAS LÁCTICAS AISLADAS DE LECHE DE OVEJA GUIRRA", que presenta Dña. Claudia Milena Amorocho Cruz para optar al grado de Doctor por la Universidad Politécnica de Valencia, ha sido realizada bajo su dirección y reúne los requisitos adecuados para ser presentada como tesis doctoral ante el tribunal correspondiente para su lectura y defensa.

Y para que conste a los efectos oportunos, firman el presente certificado,

Valencia, 14 de octubre de 2011 
A mis padres Rodrigo y Rosa Edilma, A mis hermanos Alexander, Erika, Fabian y Santiago. 
Doy gracias a Dios por mi vida y la de cada una de las personas que me han acompañado durante este tiempo, de cada uno de ustedes me llevo gratos recuerdos. Agradezco al Dr. Manuel Hernández por su dirección, apoyo y darme la oportunidad de trabajar en el laboratorio durante esta etapa, a la Dra. Yolanda Moreno por su dirección, enseñanza y dedicación. A Dr. Enrique Hernández por su gentileza. Al Dr. Javier Hernández por su cordialidad. A la Dra. Ma Angeles Castillo por su escucha y generosidad. A la Dra. Ma Antonia Ferrús por su colaboración incondicional. Al Dr. Luis Roig por su atención y pedagogía. A la Dra. Salut por su acogida. A la Dra. Rosa por su ayuda desinteresada. Al Dr. Gonzalo por compartir de su experiencia en el laboratorio y por las dudas que me ayudó a solucionar. A la Dra. Ana G por su franqueza. A la Dra. Ana J por su atención. Al Dr. Rafael por su amabilidad y al Dr. Jorge G por su sinceridad. A Nancy por su buena disposición y ayuda.

Del departamento de Bioquímica, agradezco a la Dra. Ma Jesús Ibañez su colaboración y a la Dra. Consuelo por su confianza y cooperación en la última etapa de la investigación.

A mis compañeros de laboratorio Veronica Belenguer y Susana por su buena energía y amistad. A Pilar, Rocío, Ana de la Hoz, Myriam, Eyder, Gloria, Paula, Javier, Irene, Lorena, Albert y muchos otros, por cada uno de los buenos detalles.

A mis amigos de los buenos y los malos ratos y que llevo en el corazón Juan Pablo, Anicia, S. Francisca, Javier Eduardo, Amanda del Pilar, Nelly Condori, Alejandro, Marcos, Liliana, Daniel, Pilar Angarita, Liliana del Pilar, Claudia Yaneth y Nelly Alvarez por ser tan especiales, bellos y alegrar mi vida con cada uno de los momentos compartidos.

A Begoña por su buen ánimo y ternura, a María Sancho por su generosidad. A los hermanos de la Parroquia de San Martín, en especial la cuarta comunidad por compartir el camino de Fé. A mi familia fuente de mi inspiración por su amor, a quienes llevo en mi mente, mi corazón y mi ser. 
ÍNDICES Y RESUMENES

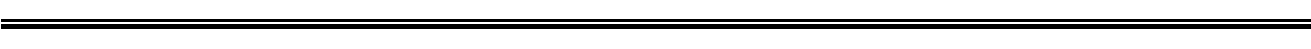




\section{INTRODUCCIÓN}

1. Alimentos funcionales. .1

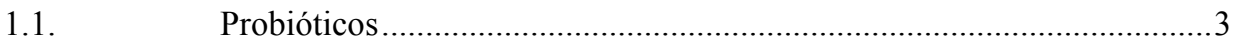

1.1.1. Antecedentes de los probióticos ............................................ 4

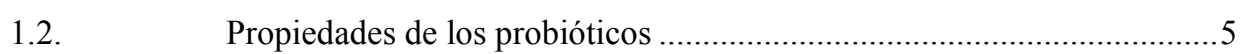

1.3. Efectos beneficiosos de los probióticos ..........................................

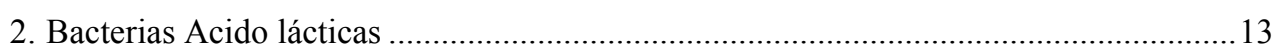

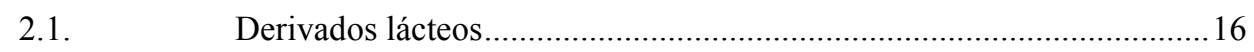

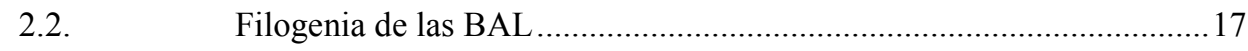

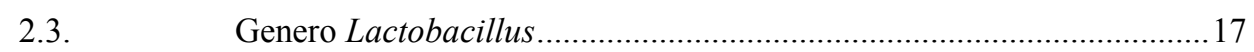

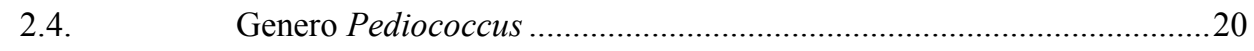

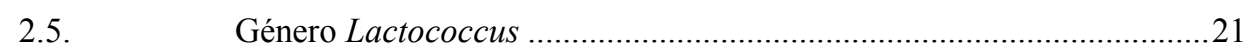

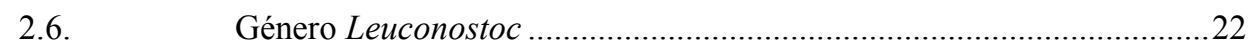

2.7. Especies presentes en leche de oveja Guirra.....................................23

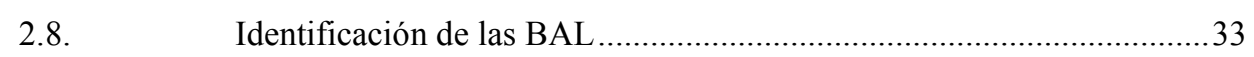

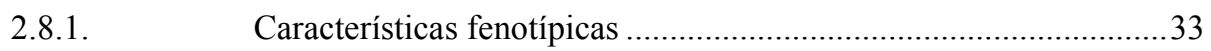

2.8.2. Características genotípicas...................................................... 34

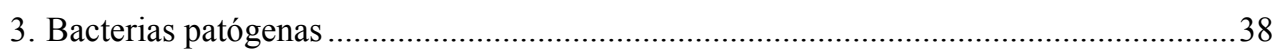

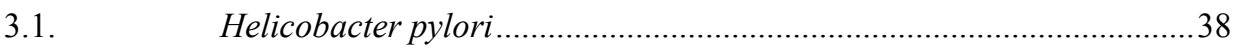

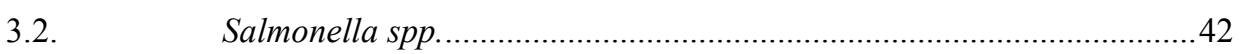

\section{CAPITULO I}

IDENTIFICACIÓN FENOTIPICA DE BACTERIAS ÁCIDO LÁCTICAS AISLADAS DE

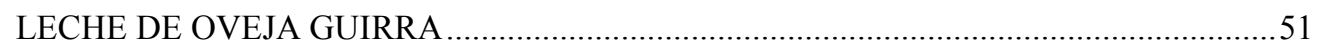

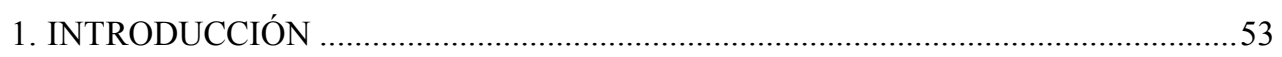

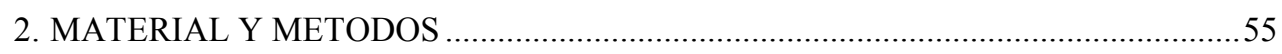

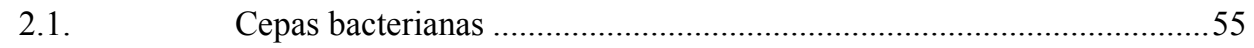

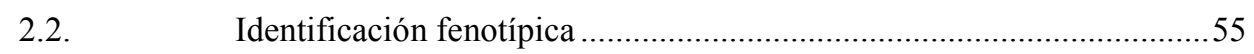

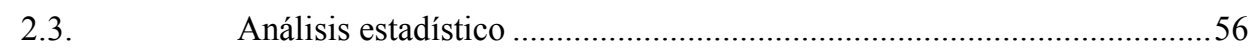

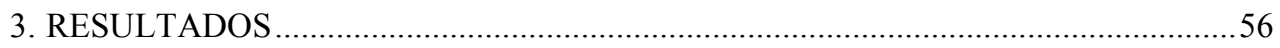




\section{CAPITULO II}

EVALUACION DE LA ACTIVIDAD ANTIMICROBIANA DE BACTERIAS ÁCIDO LÁCTICAS AISLADAS DE LECHE DE OVEJA GUIRRA....................................................63

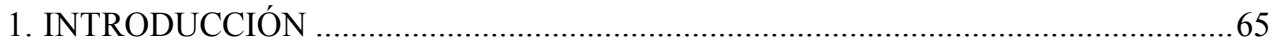

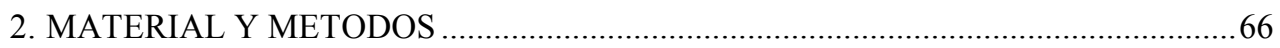

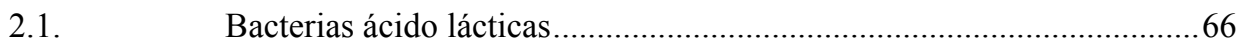

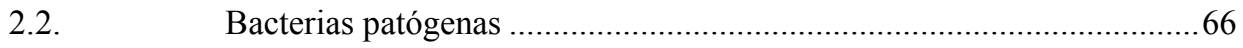

2.3. Evaluación de actividad antimicrobiana de las BAL ..............................67

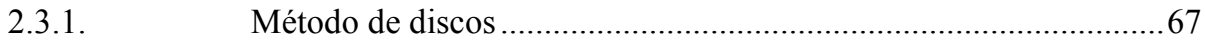

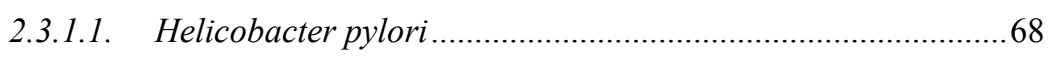

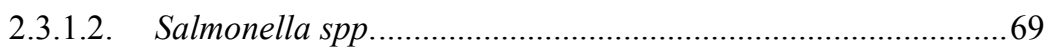

2.3.2. Método del sobrenadante en pocillos............................................. 70

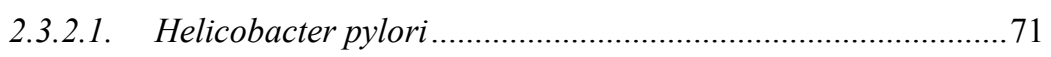

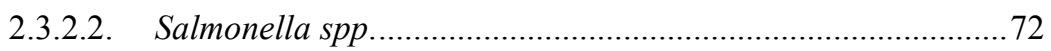

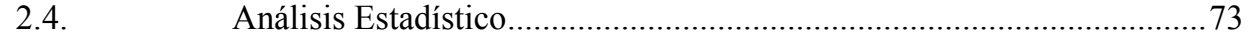

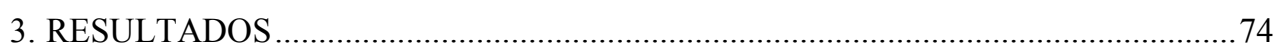

3.1. Actividad antimicrobiana frente a H. pylori …….................................... 74

3.2. Actividad antimicrobiana frente a Salmonella spp .................................. 84

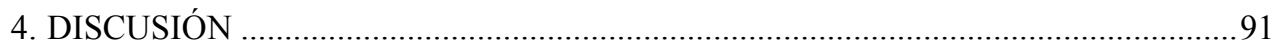

\section{CAPITULO III}

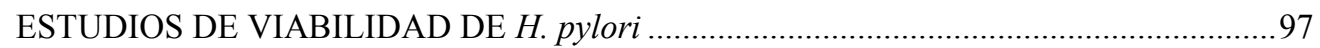

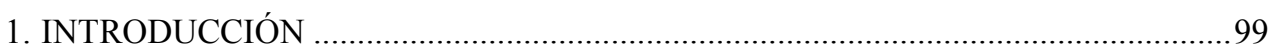

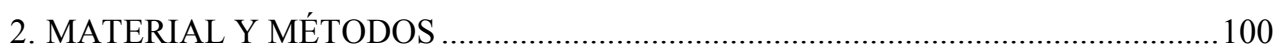

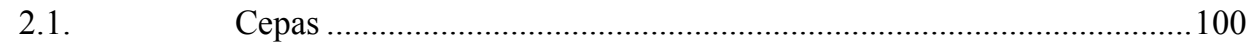




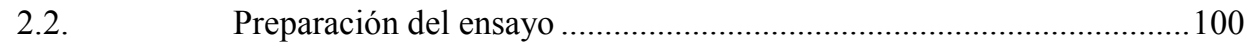

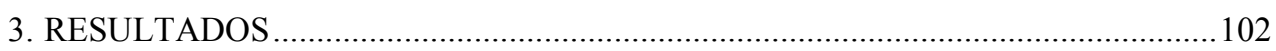

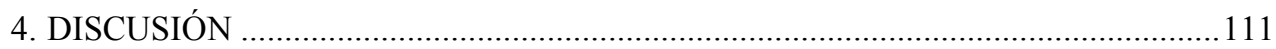

\section{CAPITULO IV}

\begin{tabular}{|c|c|}
\hline \multicolumn{2}{|c|}{ 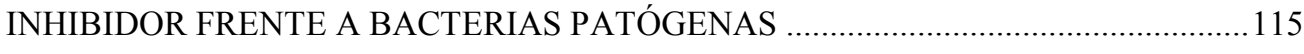 } \\
\hline \multicolumn{2}{|c|}{ 1. INTRODUCCIÓN } \\
\hline \multicolumn{2}{|c|}{ 2. MATERIALES Y METODOS } \\
\hline 2.1. & Caracterización molecular por RAPD …............................................. 118 \\
\hline 2.1.1. & 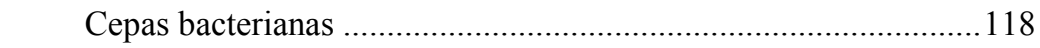 \\
\hline 2.1.2. & 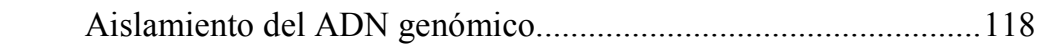 \\
\hline \multirow[t]{2}{*}{ 2.1.3. } & RAPD (Amplificación del DNA mediante iniciadores aleatorios) \\
\hline & $\ldots 119$ \\
\hline 2.1.4. & Análisis de los datos ... \\
\hline 2.2 . & Antibiogramas .................. \\
\hline 2.2.1. & Cepas bacterianas ............................... \\
\hline \multicolumn{2}{|c|}{ 3. RESULTADOS..... } \\
\hline 3.1. & Caracterización molecular por RAPD .. \\
\hline 3.2. & Antibiogramas ..... \\
\hline 3.2.1. & Cepas bacterianas .. \\
\hline 4. DISCUS & $\ldots 137$ \\
\hline
\end{tabular}

\section{CAPITULO V}

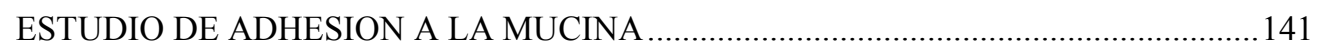

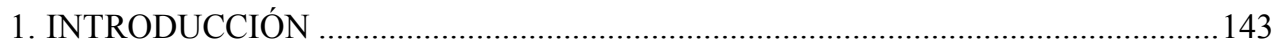

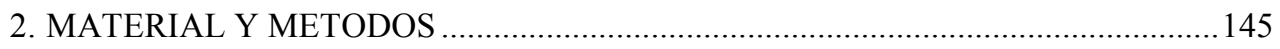


2.1. Cepas bacterianas y condiciones de crecimiento ............................. 145

2.2. Tratamiento de la mucina …............................................................. 145

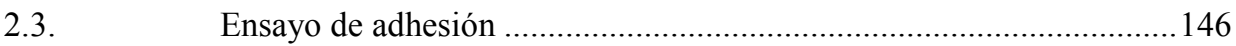

2.4. Análisis Estadístico.............................................................................. 147

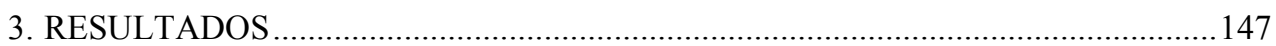

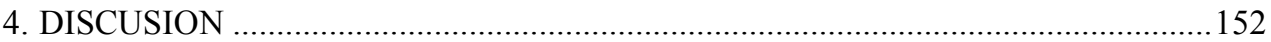

\section{CAPITULO VI}

\section{ESTUDIO DE VIABILIDAD CELULAR DE LAS BAL FRENTE A CONDICIONES}

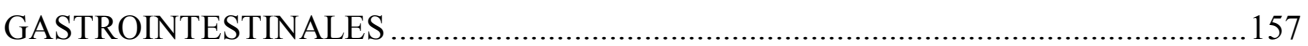

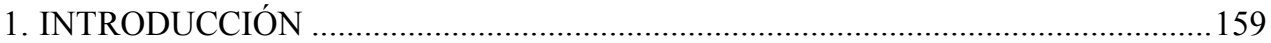

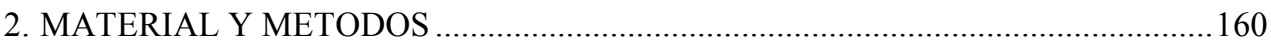

2.1. Estudio in vitro de la supervivencia frente a los jugos gástricos .........160

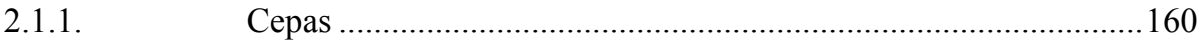

2.1.2. Preparación de los jugos gástricos y pancreáticos ......................... 160

2.1.3. Determinación de la supervivencia “in vitro” al tránsito

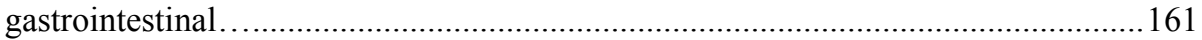

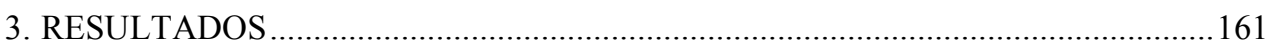

3.1. Determinación de la tolerancia gastrointestinal .................................. 161

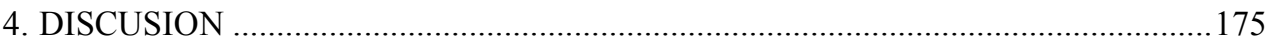

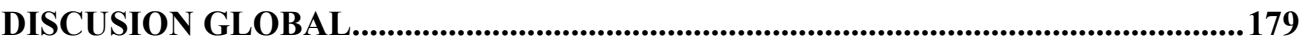

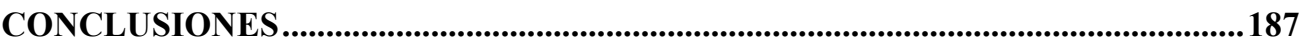

BIBLIOGRAFIA ....................193 


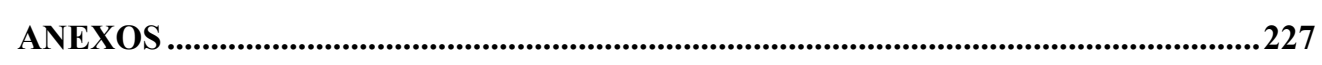

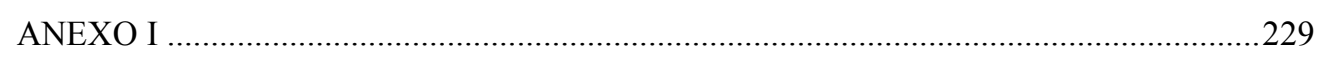

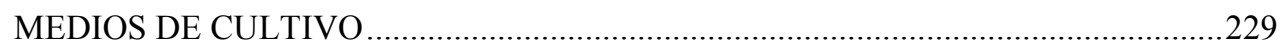

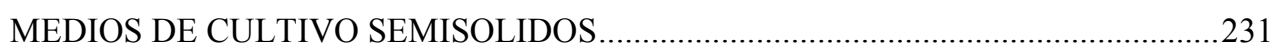

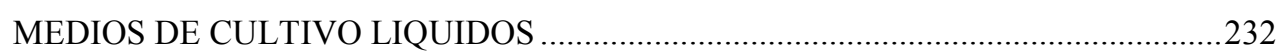

ANEXO 2 2

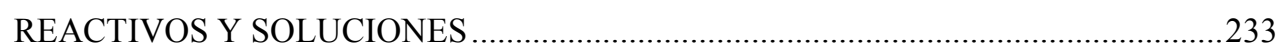

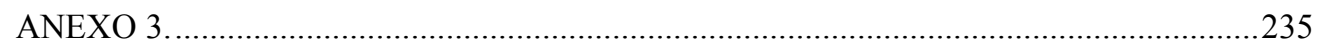

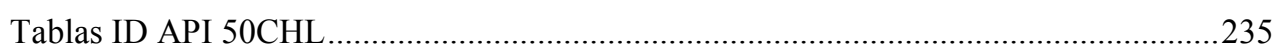

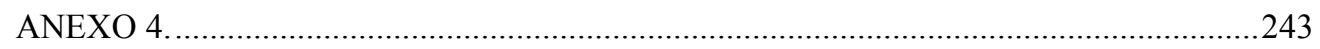

ACTIVIDAD ANTIMICROBIANA DE LAS BAL FRENTE A Helicobacter pylori y

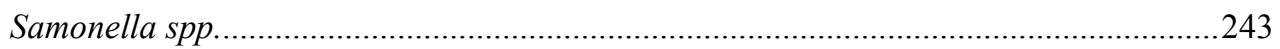

CONGRESOS Y PUBLICACIONES.......................................................................251 


\section{INTRODUCCIÓN}

Tabla 1. Aislados y usos de especies de Lactobacillus 19

Tabla 2. Características del género Lactobacillus.

\section{CAPITULO I}

Tabla 1. Identificación de Bacterias Acido Lácticas de la CECT y aisladas de leche de oveja Guirra mediante el sistema comercial API-50CHL .58

Tabla 2. Matriz de componentes rotados.

\section{CAPITULO II}

Tabla 1. Cepas de H. pylori

Tabla 2. Cepas de Salmonella spp.

Tabla 3. Porcentaje de inhibición de las BAL aisladas de leche de oveja y de cepas de la CECT frente a la cepa B6 de H. pylori en cada método.

Tabla 4. Porcentaje de inhibición de las BAL aisladas de leche de oveja y la CECT frente a la cepa NCTC11637 de H. pylori en cada método.

Tabla 5. Porcentaje de inhibición de las BAL frente a las cepas de H. pylori B6 y NCTC11637

Tabla 6. Porcentaje de inhibición de las BAL frente a la cepa S134 en cada método. .86

Tabla 7. Porcentaje de inhibición de las BAL frente a la cepa S58 en cada método. .86

Tabla 8. Porcentaje de inhibición de las BAL frente a la cepa S135 en cada método. .86 
Tabla 9. Porcentaje de inhibición de las BAL frente a la cepa CECT915 en cada método....87

Tabla 10. Porcentaje inhibición de las BAL frente a las cepas S58, CECT915, S134, S135.91

\section{CAPITULO III}

Tabla 1. Viabilidad de H. pylori B6 en contacto con sobrenadantes de BAL aisladas de leche de oveja guirra mediante técnicas de cultivo en placa y recuento de epifluorescencia empleando el kit de viabilidad LIVE/DEAD. Media \pm (SEM) Error estándar de la media.. 104

\section{CAPITULO IV}

Tabla 1. BAL con actividad antimicrobiana frente a H. pylori y Salmonella spp. 119

Tabla 2. Iniciadores

Tabla 3. Condiciones PCR. Iniciador 1254 120

Tabla 4. Condiciones PCR - iniciador 7254

Tabla 5. Antibióticos 123

Tabla 6. Antibiograma de las cepas aisladas de leche de oveja Guirra y CECT con actividad antimicrobiana frente a H. pylori y Salmonella. Media en mm y (SEM) error estándar de la media de dos análisis. 


\section{CAPITULO V}

Tabla 1. Adhesión de las BAL a mucina y tratamiento sin mucina. Densidad bacteriana inicial de cada muestra en placa $\log \mathrm{UFC} / \mathrm{ml}$. (-) valor no observado. Media de tres observaciones y error estándar (SD).

\section{CAPITULO VI}

Tabla 1. Tinción con los fluorocromos SYTO9 y PI de BAL antes y después del tratamiento con pepsina $\mathrm{pH} 2$.

Tabla 2. Tinción con los fluorocromos SYTO9 y PI de BAL antes y después del tratamiento con pancreatina $\mathrm{pH} 8$ 


\section{CAPITULO I}

Figura 1. Identificación API 50 CHL .56

Figura 2. Distribución por especie de las cepas aisladas de leche de oveja Guirra........57

Figura 3. Agrupación de las cepas estudiadas de acuerdo al análisis de componentes principales 61

\section{CAPITULO II}

Figura 1. Diseño del ensayo de actividad antimicrobiana contra H. pylori en presencia de células viables de BAL.

Figura 2. Diseño del ensayo de actividad antimicrobiana contra Salmonella en presencia de células viables de BAL

Figura 3. Diseño del ensayo de actividad antimicrobiana en ausencia de células. $H$. pylori frente a las sustancias producidas por BAL

Figura 4. Diseño del ensayo de actividad antimicrobiana en ausencia de células. Salmonella frente a las sustancias producidas por BAL....

Figura 5. Ensayo de inhibición H. pylori B6 en presencia células de las BAL 75

Figura 6. Inhibición de H. pylori B6 por presencia de células de las BAL aisladas de leche de oveja. 75

Figura 7. Inhibición de H. pylori NCTC11637 en presencia de células por las BAL aisladas de leche de oveja. .76

Figura 8. Ensayo de inhibición H. pylori B6 ausencia células de las BAL .77 
Figura 9. Inhibición de $H$. pylori B6 en ausencia de células de las BAL aisladas de leche de oveja.

Figura 10. Actividad antimicrobiana de las BAL en presencia, ausencia de células sobre H. pylori $\mathrm{B} 6$ a $\mathrm{pH} 4.5$ y 7.

Figura 11. Comparación entre métodos aplicados a la inhibición de las BAL frente a $H$. pylori B6. No Método: 1: Presencia de células. 2: Ausencia de células pH 4.5. 3: Ausencia de células pH 7.

Figura 12. Inhibición de H. pylori NCTC11637 en ausencia de células de las BAL aisladas de leche de oveja.

Figura 13. Actividad antimicrobiana de las BAL aisladas de leche de oveja en presencia y ausencia de células a pH 4.5 y 7 sobre $H$. pylori NCTC11637.

Figura 14. Inhibición H. pylori B6 y NCTC11637 por las BAL aisladas de leche de oveja.......

Figura 15. Ensayo de inhibición Salmonella spp. en ausencia células de las BAL.......85

Figura 16. Inhibición de las BAL sobre Salmonella spp. Los resultados son la media de tres experimentos independientes. 89

\section{CAPITULO III}

Figura 1. Variación de la cultivabilidad para cada muestra respecto del tiempo 0. No: Tiempo 0. N: Tiempo 0, 5, 19, 24 horas.

Figura 2. Variación del número de células viables para cada muestra respecto del tiempo 0. No: Tiempo 0. N: Tiempo 0, 5, 19, 24 h. 
Figura 3. Variación del número de células viables, no viables (cel/ $/ \mathrm{ml})$ y cultivables (UFC/ml) de H. pylori B6 respecto del tiempo 0. No: Tiempo 0. N: Tiempo 0, 5, 19, 24 h. A) Control, B) H. pylori + Sobrenadante 12O3. C) H. pylori + Sobrenadante $20 \mathrm{O} 4$

Figura 4. Células H. pylori $\mathrm{B} 6$ a tiempo $0 \mathrm{~h}$ (izquierda) y $5 \mathrm{~h}$ (derecha) de contacto con el sobrenadante $12 \mathrm{O} 3$ 108

Figura 5. Células H. pylori B6 a tiempo 19 h (izquierda) y 24 h (derecha) con el sobrenadante $12 \mathrm{O} 3$. 108

Figura 6. Porcentaje de viables (SYTO9) y no viables (PI) en la muestra control con $H$. pylori $\mathrm{B} 6$. 109

Figura 7. Porcentaje de viables (SYTO9) y no viables (PI) en la muestra H. pylori B6+ Sobrenadante $12 \mathrm{O} 3$ 110

Figura 8. Porcentaje de viables (SYTO9) y no viables (PI) en la muestra H. pylori B6+ Sobrenadante 2004 110

\section{CAPITULO IV}

Figura 1. Perfiles generados con la técnica RAPD de las cepas BAL aisladas de leche de oveja Guirra y las pertenecientes a la CECT empleando el iniciador 1254. $L$. plantarum (3O9, CECT4645, 7O1, Q3), L. paracasei (4O4, 3O10), L. brevis (20O4, CECT4121), L. delbrueckii bulgaricus (CECT4005), L. delbrueckii delbrueckii (CECT286), L. casei (CECT475), L. acidophilus (9O3), Lactococcus lactis subsp lactis (1O3, 2O4, 1O8) (C-). M Marcador DNA 100 pb.

Figura 2. Dendrograma obtenido de los perfiles RAPD usando iniciador 1254 de las cepas ácido lácticas con actividad antimicrobiana frente a H. pylori y Salmonella spp. 
Figura 3. Perfiles generados con la técnica RAPD de las cepas BAL aisladas de leche de oveja Guirra y de la CECT empleando el iniciador 7254. L. plantarum (3O9, CECT4645, 7O1, Q3), L. paracasei (4O4, 3O10), L. brevis (20O4, CECT4121), L. delbrueckii bulgaricus (CECT4005), L. delbrueckii delbrueckii (CECT286), L. casei (CECT475), L. acidophilus (9O3), Lactococcus lactis subsp lactis (1O3, 2O4, 108) (C-). M Marcador DNA $100 \mathrm{pb}$ 126

Figura 4. Dendrograma obtenido de los perfiles RAPD usando iniciador 7254 de las cepas ácido lácticas con actividad antimicrobiana frente a H. pylori y Salmonella spp.

Figura 5. Antibiograma de la cepa láctica 13O5B aislada de leche de oveja Guirra. .131

Figura 6. Porcentaje de susceptibilidad cepas BAL aisladas de oveja Guirra y CECT.

Figura 7. Susceptibilidad de BAL frente a gentamicina $10 \mu \mathrm{g} / \mathrm{ml}$

Figura 8. Susceptibilidad de BAL frente a amoxicilina $30 \mu \mathrm{g} / \mathrm{ml}$ 134

Figura 9. Susceptibilidad de BAL frente a trimetoprim $25 \mu \mathrm{g} / \mathrm{ml}$ 134

Figura 10. Susceptibilidad de BAL frente a ciprofloxacino $5 \mu \mathrm{g} / \mathrm{ml}$ 135

Figura 11. Susceptibilidad de BAL frente a ceftriaxona $30 \mu \mathrm{g} / \mathrm{ml}$ 135

Figura 12. Susceptibilidad de BAL frente a cloranfenicol $30 \mu \mathrm{g} / \mathrm{ml}$ 135

Figura 13. Susceptibilidad de BAL frente a cefalotin $30 \mu \mathrm{g} / \mathrm{ml}$ 136

Figura 14. Susceptibilidad de BAL frente a tetraciclina $30 \mu \mathrm{g} / \mathrm{ml}$. 136

Figura 15. Susceptibilidad de BAL frente a amikacina $30 \mu \mathrm{g} / \mathrm{ml}$ .136 
Figura 16. Susceptibilidad de BAL frente a ampicilina $10 \mu \mathrm{g} / \mathrm{ml}$

Figura 17. Susceptibilidad de BAL frente a carbencilina $30 \mu \mathrm{g} / \mathrm{ml}$. 137

\section{CAPITULO V}

Figura 1. Interacción del CFDA con la célula Gram positiva. 145

Figura 2. Comparación tratamiento con mucina y sin mucina (poliestireno). 148

Figura 3. Porcentaje de adhesión de las BAL aisladas de leche de oveja Guirra y CECT. Con mucina y sin mucina. 151

\section{CAPITULO VI}

Figura 1. Supervivencia al tránsito gastrointestinal de la cepa $9 \mathrm{O} 3$ por recuento en placa y fluorocromo SYTO9. 164

Figura 2. Supervivencia al tránsito gastrointestinal de la cepa 207 por recuento en placa y fluorocromo SYTO9. 165

Figura 3. Supervivencia al tránsito gastrointestinal de la cepa Q2 por recuento en placa y fluorocromo SYTO9. 166

Figura 4. Supervivencia al tránsito gastrointestinal de la cepa Q3 por recuento en placa y fluorocromo SYTO9

Figura 5. Supervivencia al tránsito gastrointestinal de la cepa 1010 por recuento en placa y fluorocromo SYTO9.

Figura 6. Supervivencia al tránsito gastrointestinal de la cepa 103 por recuento en placa y fluorocromo SYTO9. 
Figura 7. Supervivencia al tránsito gastrointestinal de la cepa $12 \mathrm{O}$ por recuento en placa y fluorocromo SYTO9

Figura 8. Supervivencia al tránsito gastrointestinal de la cepa 2004 por recuento en placa y fluorocromo SYTO9.

Figura 9. Porcentajes de viabilidad celular al tránsito gastrointestinal frente a pepsina $\mathrm{pH} 2$

Figura 10. Porcentajes de viabilidad celular con SYTO al tránsito gastrointestinal frente a pancreatina $\mathrm{pH} 8$. 


\section{RESUMEN}

Los probióticos son microorganismos vivos que ejercen de una forma u otra una acción beneficiosa sobre el hospedador al administrarse en cantidades adecuadas. De acuerdo a los requisitos de la FAO, una cepa probiótica debe ser identificada a nivel de género, especie y cepa; en el estudio in vitro se ha de analizar la actividad antimicrobiana frente a patógenos, resistencia a las condiciones gastrointestinales y adherencia a la mucosa intestinal y células epiteliales. Además, para garantizar la seguridad se recomiendan pruebas de resistencia a antibióticos, estudios epidemiológicos y de actividades metabólicas perjudiciales para la salud de quien los ingiere. Dentro de los efectos saludables destacan la contribución nutricional, atenuación de la intolerancia a la lactosa, mejora de la digestibilidad, efecto positivo sobre el sistema inmunológico, mantenimiento de la microbiota intestinal normal, prevención de cáncer, reducción de infecciones respiratorias, reducción del colesterol sérico, mejora de la salud gástrica y coadyuvante en tratamientos con antibióticos. Diversos estudios señalan que varias especies pertenecientes a las Bacterias Acido Lácticas (BAL) poseen dichas propiedades y se encuentran comúnmente en los derivados lácteos. Actualmente, en la Comunidad Valenciana se comercializan quesos frescos y madurados elaborados a partir de la leche de oveja guirra, autóctona de esta comunidad e incluida dentro del catálogo de razas protegidas en España. Sin embargo, hasta el momento no se han realizado ensayos para determinar el potencial probiótico de cepas aisladas de esta leche.

En esta tesis, se han aislado 131 BAL de leche de oveja Guirra. Siguiendo los criterios antes mencionados, éstas cepas se han identificado inicialmente con métodos fenotípicos a nivel de género y especie. Posteriormente, se ha evaluado, en condiciones in vitro, la actividad antimicrobiana de las cepas lácticas frente a patógenos implicados en enfermedades del hombre como H. pylori y Salmonella spp. En detalle, se ha estudiado el efecto de las sustancias producidas por dos cepas BAL frente a la viabilidad de H. pylori. Las cepas BAL destacadas en la actividad antimicrobiana han sido identificadas y caracterizadas por medio de técnicas moleculares, perfiles de resistencia a antibióticos, habilidad de 
adhesión a la mucina de cerdo y finalmente, se ha evaluado la resistencia frente a las condiciones gastrointestinales. Los resultados muestran que las propiedades probióticas se pueden atribuir a una cepa y no es posible generalizarlo a una especie o género. Algunas de las cepas lácticas de oveja y de la CECT resultaron de especial interés porque en condiciones in vitro demostraron características probióticas que deberían ser confirmadas en posteriores estudios in vivo. Cabe resaltar que algunas de estas cepas se han aislado de productos que son actualmente comercializados y por tanto las propiedades probióticas de estas cepas representarían un valor añadido para los mismos. 


\begin{abstract}
Probiotics are live microorganisms that exert a beneficial effect on the host when administered in adequate amounts. According to the requirements of FAO, a probiotic isolate must be identified to genus, species and strain level and in vitro studies have to be carried out to analyze the antimicrobial activity against pathogens, resistance to gastrointestinal conditions and adherence to the mucosa intestinal epithelial cells. In addition, to ensure the safety, antibiotic resistance, epidemiological and metabolic activities tests are recommended. Within the beneficial effects on health, the nutritional contribution, attenuation of lactose intolerance, improved digestibility, positive effect on the immune system, maintenance of normal intestinal microbiota, prevention of cancer, reduction of respiratory infections, cholesterol attenuation, improving health and gastric adjuvant treatments with antibiotics have to be highlighted. Several investigations indicate that several species belonging to the lactic acid bacteria (LAB) have these properties and are commonly found in dairy products. Today in Valencia are sold fresh and ripened cheeses made from Guirra sheep milk. However, no studies have been conducted to determine the potential probiotic strains isolated from this milk to date
\end{abstract}

In this thesis, we have isolated 131 LAB strains from Guirra sheep milk. Following the above criteria, these strains were initially identified by phenotypic methods to genus and species level. Subsequently, we evaluated in vitro, the antimicrobial activity of lactic acid strains against pathogens involved in human diseases such as H. pylori and Salmonella spp. In particular, we have studied the effect of substances produced by two strains BAL compared to the viability of $H$. pylori. LAB prominent strains in the antimicrobial activity have been identified and characterized using molecular techniques, antibiotic resistance profiles, the ability of adherence to pig mucin and finally evaluated their resistance to gastrointestinal conditions. The results show that probiotic properties can be attributed to a strain in particular and can not be generalized to a species or genus level. Some of the lactic strains from sheep and CECT are of special interest because they demonstrated in vitro probiotic characteristics which should be confirmed in further in vivo studies. It must be 
noted that some of these strains have been isolated from dairy products that are currently marketed and therefore the probiotic properties of these strains represent an added value for them. 


\section{RESUM}

Els probiòtics són microorganismes vius que exerceixen una acció beneficiosa sobre l'hoste en administrar-se en quantitats adequades. D'acord amb els requisits de la FAO, una soca probiòtica ha de ser identificada a nivell de gènere, espècie i soca; en l'estudi in vitro s'ha d'analitzar l'activitat antimicrobiana davant de patògens, la resistència a les condicions gastrointestinals i l'adherència a la mucosa intestinal i les cèl·lules epitelials. A més, per a garantir la seguretat es recomanen proves de resistència a antibiòtics, estudis epidemiològics i d'activitats metabòliques perjudicials per a la salut de qui els ingereix. Entre els efectes saludables, destaquen els següents: contribució nutricional, atenuació de la intolerància a la lactosa, millora de la digestibilitat, efecte positiu sobre el sistema immunològic, manteniment de la microbiota intestinal normal, prevenció de càncer, reducció d'infeccions respiratòries, atenuació del colesterol, millora de la salut gàstrica i coadjuvant en tractaments amb antibiòtics. Diferents investigacions assenyalen que diverses espècies pertanyents als bacteris àcido-làctics (BAL) posseeixen les propietats esmentades i són comunament trobades en els derivats lactis. Actualment, a la Comunitat Valenciana es comercialitzen formatges frescos i madurats elaborats a partir de la llet d'ovella guirra. No obstant això, fins ara no s'han realitzat assajos per a determinar el potencial probiòtic de soques aïllades d'aquesta llet.

En aquesta tesi s'han aïllat 131 BAL de llet d'ovella guirra. Seguint els criteris abans esmentats, aquestes soques s'han identificat inicialment amb mètodes fenotípics a nivell de gènere i espècie. Posteriorment, s'ha avaluat, en condicions in vitro, l'activitat antimicrobiana de les soques làctiques davant de patògens implicats en malalties de l'home, com ara H. pylori i Salmonella spp. En detall, s'ha estudiat l'efecte de les substàncies produïdes per dues soques BAL davant de la viabilitat d'H. pylori. Les soques BAL destacades en l'activitat antimicrobiana han sigut identificades i caracteritzades per mitjà de tècniques moleculars, perfils de resistència a antibiòtics, habilitat d'adhesió a la mucina de porc i, finalment, se n'ha avaluat la resistència davant de les condicions gastrointestinals. Els 
resultats mostren que les propietats probiòtiques es poden atribuir a una soca i no és possible generalitzar-los a una espècie o gènere. Algunes de les soques làctiques d'ovella i de la CECT han resultar d'un interès especial perquè en condicions in vitro han demostrat característiques probiòtiques que haurien de ser confirmades en posteriors estudis in vivo. Cal ressaltar que algunes d'aquestes soques s'han aillat de productes que es comercialitzen actualment $i$, per tant, les propietats probiòtiques d'aquestes soques hi representarien un valor afegit. 
INTRODUCCIÓN 
A.C)(Walker 2008)

\section{Alimentos funcionales}

Los alimentos funcionales son definidos por la Organización de las Naciones Unidas para la Agricultura y la Alimentación (FAO) como aquellos que contienen componentes biológicos adicionales, con potencial de reducir el riesgo de enfermedad y favorecer la salud (FAO, 2007). Poseen efectos beneficiosos sobre una o más funciones en el organismo y se incluye alimentos que contienen minerales, vitaminas, ácidos grasos, fibra, alimentos con antioxidantes y probióticos (Sarmiento, 2008). Frutas y vegetales representan la forma más simple de un alimento funcional (Mulabagal et al., 2010; Aiba et al., 1998; Rokka et al., 2006).

El concepto de alimentos funcionales se introduce en Japón, a finales de la década de los años 80 y desde entonces se ha expandido mundialmente por las características antes mencionadas. Desde los años 90, las autoridades de países como Japón, Estados Unidos de América y de la Unión Europea han ido estableciendo políticas reguladoras para los alimentos funcionales, las cuales presentan algunas variaciones dependiendo del país. La nueva regulación Europea sobre nutrición y salud entra con fuerza en el año 2007 (Walker, 2008). El reglamento EC $\mathrm{N}^{\circ} 1924$ regula el uso de las declaraciones sobre propiedades nutricionales y saludables de los alimentos. Es importante que los alimentos funcionales tengan evidencia científica de su efecto beneficioso, que el componente funcional esté presente en el producto final en cantidad suficiente, en una forma asimilable por el organismo y en el momento del consumo ofrezca una cantidad significativa de la sustancia 
activa. Además, es fundamental que el consumidor comprenda los efectos beneficiosos que se expresan en la declaración (Sarmiento, 2008).

El interés por los alimentos funcionales ha aumentado en la última década debido a que los consumidores prestan especial atención a la dieta, la nutrición y el cuidado de la salud (Gamel et al., 2008; Walker 2008; Rosendale et al., 2008; Markosyan et al., 2009). El auge de estos productos representa un beneficio para el consumidor y una oportunidad para la industria de alimentos, al brindar mayor valor añadido a sus productos (Burdock et al., 2006). Para ello, esta debe controlar los procesos y asumir estándares de seguridad (Markosyan et al., 2009).

En la búsqueda de estos estándares, la FAO basándose en el Codex Alimentarius hace las siguientes recomendaciones:

- Adoptar una definición internacional de alimentos funcionales.

- Generar una base de datos de alimentos funcionales con información sobre su actividad, funciones estructurales y nutritivas con la respectiva validación y justificación científica.

- Estandarizar los métodos de análisis e inventariarlos.

En el mismo camino, algunos investigadores hacen énfasis en el estudio de componentes de los alimentos. Estos recomiendan en el desarrollo de dichos productos llevar un programa de control y análisis para evitar sinergias indeseables entre los ingredientes, certificar su seguridad, ausencia de toxicidad y profundizar en el conocimiento de la interacción entre los alimentos funcionales y la microbiota intestinal de cada individuo (Gamel et al., 2008; Laparra y Sanz, 2010). Actualmente los probióticos, componentes de los 
alimentos funcionales, son de especial interés por los beneficios potenciales en la salud y por ello, se ha incrementado la investigación en el desarrollo de estos productos.

\subsection{Probióticos}

Probiótico, derivado de bios, viene del griego y significa "por la vida". Son considerados un ingrediente funcional en el alimento (Jankovic et al., 2010). Según la FAO, son microorganismos vivos que ejercen una acción benéfica sobre la salud del huésped al ser administrado en cantidades adecuadas. A menudo el término se usa erróneamente para referirse a organismos comensales habituales sin sustentar sus beneficios en la salud ó falsamente se limita a bacterias de origen humano (Foligné et al., 2010). Los efectos beneficiosos deben demostrarse en animales y humanos (FAO y OMS, 2001; Azaïs-Braesco et al., 2010).

Predominan como probióticos las cepas pertenecientes a los géneros Lactobacillus y Bifidobacterium aunque se emplean otros géneros como Enterococcus, Streptococcus y Saccharomyces. Las cepas probióticas pueden ser autóctonas o alóctonas (Quigley, 2010), cada una tiene características particulares y con diferente potencial benéficioso para la salud (Warren et al., 2007). La respuesta a la dosis suministrada aún no está claramente definida (Salminen et al., 1999).

A nivel industrial existen gran variedad de productos probióticos enriquecidos con Bacterias Acido Lácticas (BAL) (Walker y Duffy, 1998) en yogures, quesos, helados, natillas, suplementos dietéticos, farmacéuticos, leches infantiles e incluso alimentos para animales. 


\subsubsection{Antecedentes de los probióticos}

Los efectos de las bacterias lácticas fueron descritos en 1857 por Pasteur. La base científica del concepto probiótico surgió cuando Elie Metchnikoff postuló la relación entre los fermentos de la leche y la longevidad analizando la dependencia entre los microbios intestinales y los alimentos ingeridos (Pot y Tsakalidou, 2009; Jankovic et al., 2010). Con esta premisa, fue posible adoptar medidas para modificar la microbiota del organismo humano y sustituir los microbios nocivos por microbios útiles (Metchnikoff, 1907). Los estudios desarrollados en Rusia, Bulgaria y otras partes de Europa sobre la microbiología de la leche y el yogurt, describieron organismos presentes y activos en el proceso de fermentación natural como la especie Bacillus bulgaricus, actualmente denominado Lactobacillus delbrueckii bulgaricus (Ljungh y Wadström, 2009). En 1911, Lorendon M. Douglass escribió sobre los Bacillus de larga vida. Más adelante, en 1920, Rettger y colaboradores encontraron que la especie Bacillus bulgaricus no sobrevivió a las condiciones del intestino pero encontraron la especie L. acidophilus capaz de asentarse en este hábitat y posteriormente en 1935 esta misma especie fue empleada en pruebas clínicas en pacientes con trastornos intestinales obteniendo resultados prometedores (Ljungh y Wadström, 2009).

Posteriormente, Freter en 1950 mostró un amplio espectro de antibióticos que destruían la microbiota intestinal de ratones haciéndolos vulnerables a patógenos como Salmonella y Shigella. Estudios en Japón entre 1940 y 1950 sobre la especie L. casei y algunas especies de Bifidobacterium demostraron que estas bacterias eran capaces de proteger a ratones jóvenes de infecciones intestinales y realizaron muchos estudios asociados a los efectos saludables de estas bacterias lácticas. A partir de 1960 se acuñó la palabra probiótico para designar las sustancias producidas por microorganismos que promovían el crecimiento de otros microorganismos (Lilly y Stillwell, 1965). Posteriormente, Fuller en 1989, lo definió como un suplemento alimentario microbiano vivo que afecta de forma beneficiosa al animal huésped a través de la mejora de su balance microbiano intestinal y, en 1999, Gibson realizó un cambio en el concepto, considerando que un probiótico es un 
microorganismo vivo que al ser ingerido en cantidades suficientes ejerce un efecto positivo en la salud más allá de los efectos nutricionales tradicionales (Fooks et al., 1999; Ljungh y Wadström, 2009). Esta última definición fue adoptada por la FAO en el 2001. Las características relevantes en una cepa probiótica se detallan a continuación.

\subsection{Propiedades de los probióticos}

La FAO proporciona una guía para evaluar las propiedades de los alimentos probióticos de forma sistemática. Entre las que se encuentran:

\section{Identificación de género, especie y cepa probiótica}

La caracterización de los productos probióticos a nivel de género, especie y cepa es fundamental para garantizar que se trata de un microorganismo inocuo y seguro denominado GRAS (Generally Regarded As Safe), en el estudio de sus efectos biológicos y clínicos (Azaïs-Braesco et al., 2010). Por otra parte, la inclusión de todas las especies de BAL y Lactobacillus en un grupo probiótico es incorrecta.

\section{Estudios in vitro para la selección de probióticos de uso en humanos}

Dentro de las pruebas in vitro para determinar las propiedades probióticas de cada cepa se encuentran:

1. Resistencia a la acidez gástrica y sales biliares, es una característica imprescindible en las bacterias probióticas cuando pasan por el tracto gastrointestinal. Las condiciones ácidas, sales biliares, variaciones de $\mathrm{pH}$ afectan en alguna medida la viabilidad de los microorganismos y es necesario que lleguen vivos al final del intestino para ejercer efectos inmunomoduladores (Ramasamy et al., 2010). 
2. $\quad$ Adherencia a la mucosa intestinal y células epiteliales es un pre-requisito para que el probiótico sea efectivo y desarrolle sus efectos inmunomoduladores, reduzca la adhesión de microbiota competitiva, desarrolle la actividad microbiana que favorece el desplazamiento de patógenos. La habilidad de adhesión a la superficie intestinal permite la colonización aunque sea transitoria y es una propiedad dependiente de la cepa (Kirjavainen et al., 1998). Hay pocos estudios sobre las interacciones de probióticos en relación con las propiedades de adhesión en el intestino; sin embargo, se mencionan que esta mediada por la unión de proteínas de la superficie bacteriana como lecitinas a oligosacáridos del tejido presentes en la superficie. Aunque, la adhesión puede ser no específica debida a interacciones hidrofóbicas con la superficie intestinal (Van den Abbeele et al., 2009). Otro mecanismo de adhesión para Lactobacillus es la vinculación a algunos glicoesfingolípidos específicos. Algunas cepas de Bifidobacterium poseen la enzima 1,2- $\alpha$-L-fucosidasa implicada en la adhesión en el tracto intestinal (Yamamoto y Katayama, 2004).

En condiciones in vitro no es posible simular el efecto de las bacterias probióticas sobre el sistema inmune (Quigley, 2010), por lo que es necesario realizar pruebas in vivo.

\section{Seguridad de los probióticos}

Durante décadas, varias especies y cepas probióticas se han ensayado en individuos saludables y enfermos. Aún hoy en día, no hay total certeza de la seguridad de las mismas. Sin embargo, los probióticos son tratados como un alimento y no como un producto farmacéutico aunque tengan la propiedad de atenuar una enfermedad.

En Estados Unidos de America la FDA (Food and Drug Administration) es la entidad encargada de regular los productos probióticos. La categorización de estos productos es determinada en parte por el uso como alimento o ingrediente de alimento, alimento medicinal, suplemento dietético y producto biológico (Degnan, 2008) y emplean el sistema GRAS para evaluar la seguridad de los microorganismos empleados en la producción de 
alimentos. En Europa, la European Food Safety Authority (EFSA) los clasifica dentro de los productos nutricionales para darle un rango más alto y emplea el sistema Qualified Presumption of Safety (QPS). Básicamente, solo los microorganismos identificados a nivel de cepa y cuyo uso histórico haya sido seguro pueden recibir la denominación de probiótico, de lo contrario se debe recurrir a estudios clínicos y de toxicidad (Havelaar et al., 2010; Quigley, 2010). Algunos autores sugieren adoptar las recomendaciones de la declaración "Consolidated Standards of Reporting Trials" (CONSORT), con el fin de facilitar la validación de los resultados (Moher et al., 2001; Kalliomäki, 2009).

Por tanto, la seguridad de un probiótico depende de la especie bacteriana de interés, la aplicación, el uso, la población objetivo, taxonomía, identificación y la caracterización fenotípica. Requiere especial cuidado las poblaciones vulnerables como recién nacidos, pacientes inmunocomprometidos o con enfermedades críticas (M. K. Salminen et al., 2004; Jankovic et al., 2010).

Para garantizar la seguridad de las cepas, se recomiendan las siguientes pruebas de caracterización (FAO y OMS, 2001).

1. Resistencia a antibióticos, verificando la ausencia de genes de resistencia transferibles (Danielsen y Wind, 2003; J. M. Rodríguez, 2006).

2. Actividades metabólicas perjudiciales.

3. Estudios epidemiológicos sobre posibles efectos adversos en los consumidores.

4. Determinación de la producción de toxinas y capacidad hemolítica, si la cepa pertenece a una especie potencialmente toxigénica.

5. Ausencia de infectividad en animales inmunodeprimidos. 
6. Determinar la dosis y la duración de la terapia (Warren et al., 2007).

7. Realización de pruebas aleatorias, ensayos en diferentes centros, doble ciego, controlado con placebo y con un apropiado diseño estadístico (Warren et al., 2007).

\section{Estudios in vivo utilizando animales y humanos}

Con el propósito de demostrar las propiedades atribuidas a los probióticos se han definido modelos animales donde entran en acción mayor número de variables como la matriz del alimento, el procesamiento de la cepa probiótica y la interacción con la microbiota intestinal del hospedador (Quigley, 2010). Resultados de varios estudios clínicos han demostrado que determinadas cepas probióticas tienen capacidad de acortar la duración o reducir el riesgo de ciertas infecciones bacterianas y virales. Se está trabajando en identificar los mecanismos de acción de los probióticos y como estos pueden llegar a afectar los diferentes alimentos en los que se introducen (Allgeyer et al., 2010; Jankovic et al., 2010).

\section{Viabilidad de las cepas declaradas en productos probióticos comerciales}

El mantenimiento de la viabilidad de los microorganismos en un producto probiótico durante toda la vida útil es imprescindible porque condiciona su actividad. El número de células viables en el alimento al final de su vida útil debe ser de al menos $10^{6}$ UFC/ml en productos con bifidobacterias (Collado 2004). Algunos autores, recomiendan un consumo de $10^{9}$ UFC/día para conservar los niveles suficientes (De Champs et al., 2003). Dicha cantidad de probiótico con L. acidophilus fue efectiva en la reducción de la inflamación del ciego y el colon en un estudio in vivo con ratones y con L. rhamnosus $G G$ fue suficiente para disminuir la diarrea en niños de 1 a 36 meses (Mattila-Sandholm et al., 1999; Marteau et al., 2002). En otros casos, algunas combinaciones de probióticos han sido más efectivas sobre la inhibición de adhesión de patógenos en comparación con los 
probióticos de una sola cepa microbiana (S. Salminen et al., 2010). La dosis efectiva depende del probiótico y la aplicación, hay pocos estudios de relación dosis-efecto.

\section{Etiquetado}

Se recomienda que un producto probiótico incorpore la siguiente información en su etiqueta:

1. Género, especie y nombre de la cepa para evitar confusiones sobre su funcionalidad.

2. Establecer el número mínimo de células viables.

3. Dosis recomendada en la que el probiótico es efectivo.

4. Condiciones adecuadas de almacenamiento.

5. Dirección de contacto con centros de información al consumidor.

6. Efectos beneficiosos claros sobre la salud del consumidor (Sarmiento, 2008).

\subsection{Efectos beneficiosos de los probióticos}

Debido a las implicaciones que tienen los probióticos sobre la salud, es necesario conocer su interacción con el organismo hospedador e identificar las diferencias genéticas que determinan que cepas filogenéticamente muy próximas muestren cualidades probióticas dispares. Los probióticos ejercen efectos beneficiosos en el sistema digestivo y tienen la capacidad de modular el sistema inmune contribuyendo al buen estado de la salud (MattilaSandholm et al., 1999; Marteau et al., 2002). Entre los beneficios estudiados se encuentran: 
Efectos nutricionales: Las bacterias probióticas son las responsables del proceso de fermentación y de esta forma se incrementa la biodisponibilidad de proteínas, aminoácidos y péptidos por su acción proteolítica (Fooks et al., 1999).

Atenuación de la intolerancia a la lactosa y mejora de la digestibilidad: Los pacientes intolerantes a la lactosa tienen riesgo de suprimir el consumo de calcio y vitamina D y están predispuestos a osteoporosis. Se estima que $65-75 \%$ de la población mundial tienen bajos niveles de lactasa (McCray, 2003). Las bacterias productoras de ácido acético y $\beta$-galactosidasa aumentan la actividad lactasa reduciendo posibles problemas de asimilación (Fooks et al., 1999; Vesa et al., 2000).

Personas con estreñimiento crónico al consumir productos prebióticos y probióticos de Lactobacillus y Bifidobacterium junto con ejercicio físico lograron reducir el estreñimiento. Una vez dejaron de consumir el suplemento dicho efecto se mantuvo durante 6 semanas (B. Jiménez 2008). Algunas combinaciones probióticas han estabilizado la microbiota funcional sin efectos adversos. Otras mezclas no han favorecido la microbiota y se ha ocasionado flatulencia a los pocos días de consumo (B. Jiménez 2008).

Efectos sobre el sistema inmunológico: El consumo de probióticos puede ayudar a disminuir y aliviar síntomas de alergias alimentarias por medio de la modulación del sistema inmune a través de la modificación de la microbiota intestinal. Es una alternativa, especialmente en niños que tienen su microbiota en pleno desarrollo. Las cepas no son las que inducen o modifican la respuesta inmune, pero si que están vinculadas a alteraciones transitorias que favorecen al consumidor (Mattila-Sandholm et al., 1999). Además, tienen efecto beneficioso sobre la evolución de enfermedades autoinmunes como la artritis reumatoide (Nagendra, 2001). La presencia de bacterias probióticas puede contrarrestar los efectos mutagénicos y genotóxicos en el colon (Salminen et al., 1999). Según algunos autores, estos efectos persisten mas allá de la duración de la colonización de la cepa probiótica debido a la capacidad de memoria del sistema inmune (Warren et al., 2007). Los 
probióticos actúan como adyuvantes de respuestas inmunes específicas por intervención de linfocitos T4, aumentan los mecanismos defensivos no específicos contra infecciones o tumores por fenómenos fagocitarios e incrementan los niveles de $\gamma$-interferón (Fooks et al., 1999).

Mantenimiento de la microbiota intestinal normal: La microbiota intestinal está influenciada por la edad, dieta, condición socio-económica, uso de antibióticos y estado de salud (Parkes et al., 2009). Los probióticos interactúan con la microbiota intestinal y con los receptores de la pared intestinal produciendo variedad de efectos en el hospedador (S. Salminen et al., 2010). Sin embargo, se desconoce el papel metabólico e inmunológico de la microbiota del tracto gastrointestinal y si estos cambios son primarios o secundarios (Parkes et al., 2009).

En estudios previos se ha demostrado que los probióticos previenen episodios de diarreas relacionadas con el consumo de antibióticos, aunque su uso en el tratamiento y prevención requiere comprobación cuando está asociada a Clostridium difficile (Warren et al., 2007). En la diarrea del viajero aún no existe una recomendación médica clara y se requieren más estudios (Marteau et al., 2002). Los probióticos tienen efecto preventivo sobre enteritis o colitis, incluso sobre infecciones de orina (L. Lee y Salminen, 1995; Nagendra, 2001; Arciero et al., 2010). Al mejorar la función de la barrera del intestino, protegen la muerte celular induciendo genes específicos del moco.

Prevención del cáncer: La flora endógena y el sistema inmune cumplen una función importante en la modulación de la carcinogénesis (Marteau et al., 2002). El consumo de probióticos redujo el riesgo de sufrir cáncer de colon (Nagendra, 2001) y en otro estudio, el uso de calostro fermentado inhibió el avance de tumores en ratones (Errecalde, 2004). Se considera que ocurre a través de varios mecanismos como alteración de las actividades metabólicas en la microbiota intestinal, alteración de las condiciones fisicoquímicas en el 
colón, vinculación y degradación del potencial carcinógeno, producción de compuestos antitumorales y mejora de la respuesta inmune del hospedador (Thirabunyanon et al., 2009).

Reducción infecciones respiratorias: Existe una tendencia a disminuir las infecciones respiratorias (Marteau et al., 2002). De acuerdo a los estudios de Pregliasco et al., (2008), la ingesta a largo plazo de simbióticos (probiótico y prebiótico) logró mejorar la salud mediante la reducción de la incidencia y gravedad de las enfermedades respiratorias durante la temporada de frío. De otro lado, la suplementación de probióticos en niños de 3 a 5 años en la dieta diaria durante 6 meses resultó una manera segura y efectiva de reducir la incidencia de fiebre y tos. Además, disminuyó la duración e incidencia de la prescripción de antibióticos (Leyer et al., 2009).

El estudio de Guillemard et al., (2010) concluyó que el consumo de productos lácteos con L. casei DN-114001 en personas mayores estuvo asociado con la disminución en la duración de infecciones de las vías respiratorias como la rinofaringitis. Además, estudios en ratones desnutridos a los que se les suministró una dieta balanceada con yogur probiótico incrementaron la función bactericida de los fagocitos bronco-alveolares. Los macrofagos alveolares constituyen la primera línea de defensa contra agentes infecciosos que tienen acceso a las vías respiratorias por el intercambio gaseoso (Villena et al., 2006). Otro estudio clínico demostró que la ingestión de Bifidobacterium longum aumentó el número de macrofagos en los pulmones (de Vrese y Schrezenmeir, 2002). Sigue siendo cuestión de debate el mecanismo por el cual el producto probiótico tiene un efecto contra las infecciones respiratorias. Una hipótesis es que el probiótico favorece los mecanismos inmunomoduladores implicados en la protección contra las infecciones respiratorias (Villena et al., 2006).

Reducción colesterol: Algunas hipótesis sugieren que ciertas cepas acido lácticas pueden asimilar la molécula del colesterol impidiendo su reabsorción, produciendo metabolitos que afectan los niveles de grasa en la sangre incidiendo favorablemente en las 
enfermedades coronarias. El efecto y los mecanismos de acción se desconocen (D. C. Lin, 2003). Según algunos autores, el consumo de $125 \mathrm{ml}$ de leche probiótica puede disminuir considerablemente los niveles de LDL- colesterol (Fooks et al., 1999).

Salud gástrica: Las bacterias intestinales producen gran variedad de sustancias como ácidos grasos, peróxidos, bacteriocinas que pueden inhibir el crecimiento de bacterias patógenas (Quigley, 2010).

Algunos probióticos estimulan la producción de mucina en el epitelio, compiten con las bacterias patógenas por adherirse y modifican las toxinas derivadas por estos patógenos (Warren et al., 2007). Las bacterias probióticas especialmente cepas de Lactobacillus tienen habilidad para influir en la colonización y actividad de Helicobacter pylori (Fenell y Michetti 2003; Hamilton-Miller, 2003), han inhibido la infección en animales y humanos a partir sus productos metabólicos (D. Sgouras et al., 2004; W. M. Wang et al., 2004).

Coadyuvante de antibióticos: El consumo indiscriminado de antibióticos en humanos y animales para tratar infecciones de origen microbiano afecta a patógenos y demás microorganismos naturales del huésped. Además, favorece la aparición de cepas resistentes y aumenta los riesgos a infecciones. El uso de antibióticos en los primeros años de vida puede estar asociado más tarde con síntomas de asma, rinoconjuntivitis alérgica y eccema (Kalliomäki, 2009). La resistencia a antibióticos por parte de los microorganismos probióticos es un problema porque a través de plásmidos pueden transferir la resistencia a bacterias patógenas presentes en el intestino del huésped, creando situaciones no deseables para la salud (Errecalde, 2004).

\section{Bacterias Acido lácticas}

El grupo de las BAL está formado por los siguiente géneros: Aerococcus, Alloiococcus, Carnobacterium, Dolosigranulum, Enterococcus, Globicatella, Lactobacillus, 
Lactococcus, Lactosphaera, Leuconostoc, Oenococcus, Pediococcus, Streptococcus, Tetragenococcus, Vagococcus y Weisella. Dicha clasificación corresponde a similitudes en las características morfológicas, metabólicas, fisiológicas, crecimiento a diferentes temperaturas, configuración del ácido láctico producido, capacidad de crecer a elevadas concentraciones de sales y en la tolerancia ácido-base (Axelson, 1998). Son Gram-positivas, no esporuladas, con forma cocoide o bacilar.

Las BAL mediante la fosforilación de los carbohidratos obtienen la energía metabólica formando como principal metabolito ácido láctico, de donde proviene el nombre de Bacterias Acido Lácticas. Su actividad proteolítica le permite obtener aminoácidos a partir de proteínas. La degradación de la proteína $\beta$-lactoglobulin tiene especial utilidad porque en ocasiones produce alergias (Pescuma et al., 2010). Se han empleado a lo largo de la historia en la fermentación de variados alimentos induciendo cambios en el sabor, la textura y tienen efecto conservante incrementando su vida útil, al mantener las propiedades sensoriales y reológicas de los mismos (Di Cagno et al., 2010; G. Liu et al., 2010).

Varias cepas lácticas producen exopolisacáridos que son secretados en el medio donde crecen o permanecen fuertemente adheridos a la superficie de la célula, son de especial interés en la elaboración de productos funcionales y muchos de ellos son heteropolisacáridos empleados como bioespesantes que mejoran la textura y la estabilidad de productos lácteos como leches fermentadas y quesos (Rodríguez-Carvajal et al., 2008). En contraste, los homopolisacáridos son poco evaluados y se emplean para fermentar productos no lácteos como por ejemplo productos de masas fermentadas (Garai-Ibabe et al., 2010).

\section{Importancia en la industria agroalimentaria}

Las BAL participan en variados procesos de fermentación y conservación de lácteos y carnes, entre otros. En la industria de alimentos fermentados es común la adición de cultivos iniciadores con las BAL con el propósito de mantener la calidad del producto 
evitando que la microbiota natural suspenda su proceso de fermentación y así cuidar la calidad del producto. El ideal de un cultivo iniciador es que produzca rápidamente gran cantidad de ácido láctico durante su crecimiento en la leche o en la matriz de alimento (Holler y Steele, 1995).

\section{Leche de oveja}

El tipo y número de microorganismos presentes en la leche están condicionados por el tipo de animal, la alimentación, el periodo de lactancia, el método de ordeño, el clima y el manejo de la leche después del ordeño (Madrid, 1994). Se han evidenciado recuentos más altos de las BAL cuando las ovejas consumen en la dieta un $25 \%$ de residuos cítricos (Jaramillo, 2007).

Una característica relevante de la región Mediterránea es la elaboración de productos de leche de cabra y oveja. Son una alternativa rentable e innovadora debido a su composición específica, gusto, textura, sabor y aspectos saludables. Además, son un vehículo adecuado para péptidos que reducen la actividad de enzimas implicadas en la presión arterial (Asteri et al., 2010).

La Comunidad Valenciana es productora de leche de oveja Guirra y su microbiota está caracterizada por su poder fermentativo sobre la lactosa para producir ácido láctico. Predominan los géneros Lactobacillus y Lactococcus, con recuentos de $10^{3}$ y $10^{6} \mathrm{UFC} / \mathrm{ml}$ respectivamente (Idoui et al., 2009). Los lactobacillus son más sensibles al proceso de pasterización que los lactococcus. En menor proporción se encuentran microorganismos pertenecientes a los géneros Propionibacterium y Leuconostoc. 


\subsection{Derivados lácteos}

La leche de oveja tiene una composición química y microbiológica de gran importancia en el rendimiento y en las características del producto final (Banks, 2000). En España $13.4 \%$ de los quesos producidos son de oveja (Jaramillo, 2007). Los quesos tradicionales de oveja Guirra frescos como "casoleta" y "servilleta" son elaborados en la Comunidad Valenciana y son reconocidos a nivel nacional en la categoría de quesos frescos artesanos (Compaire, 1976).

Algunas zonas de Europa transforman la leche en queso sin previo tratamiento térmico. La microbiota y las enzimas nativas presentes en la leche cruda son responsables de las características de sabor y aroma. La maduración de leche cruda con cultivos lácticos favorece el control de bacterias Gram negativas psicrofilas durante el almacenamiento en frío (Centeno et al., 2004). Sin embargo, en la etapa de maduración de quesos los niveles residuales de carbohidratos presentes limitan el crecimiento de las BAL (Hussain et al., 2009).

La pasterización asegura el control de microorganismos patógenos y uniformidad en el producto, aunque afecta las características sensoriales de quesos de leche de oveja. La industria quesera tiene especial interés en el uso de cultivos lácteos autóctonos, obtenidos a partir de microorganismos aislados de quesos artesanales que permitan que las características organolépticas de un queso elaborado con leche pasteurizada se acerquen a los quesos de las variedades artesanales. Por tanto, el empleo de estos cultivos iniciadores permitirán conservar las propiedades fundamentales del producto (L. González et al., 2010).

Las especies pertenecientes a Lactobacillus, Lactococcus y Leuconostoc son dominantes durante los primeros estados del proceso de maduración de quesos y son agentes lipolíticos débiles en comparación con otras especies. Sin embargo, su elevada presencia en los quesos y el incremento de su población durante la maduración propician la liberación de 16 
ácidos grasos libres. Los recuentos microbiológicos en quesos muestran que después de 60 días en maduración hay entre $10^{3}$ y $10^{6} \mathrm{UFC} / \mathrm{ml}$ de lactobacillus, $10^{7}-10^{8} \mathrm{UFC} / \mathrm{ml}$ de lactococcus y $10^{7} \mathrm{UFC} / \mathrm{ml}$ de Leuconostoc (Jaramillo, 2007; Casalta et al., 2009).

\subsection{Filogenia de las BAL}

La determinación de las relaciones filogenéticas es posible de forma optima a partir de comparaciones de la secuencia de ARNr. Se ha podido conocer en detalle las relaciones filogenéticas entre los género de las BAL y otros géneros con bajo contenido de $\mathrm{G}+\mathrm{C}$ por medio del uso de la transcriptasa y las técnicas de secuenciación por PCR. Todas las bacterias Gram-positivas se agrupan en uno de los 11 principales taxones, en donde su pared celular tiene una fuerte relevancia filogenética.

Entre cepas de la misma especie se encuentran variaciones de 3-5\% en el contenido de $\mathrm{G}+\mathrm{C}$ y del 10-12\% entre especies del mismo género. Por tanto, diferencias entre el 15$20 \%$ indican heterogeneidad filogenética. Sin embargo, aunque el porcentaje molar de $\mathrm{G}+\mathrm{C}$ es un parámetro característico del genoma, tiene un valor taxonómico limitado. Aunque diferencias en dicho porcentaje evidencian divergencia filogenética, la determinación de valores similares no asegura una relación de proximidad.

\subsection{Genero Lactobacillus}

Pertenece a la familia Lactobacillaceae. Existen actualmente 96 especies y 16 subespecies. Son bacilos largos y finos, algunos curvados o cortos y morfología cocobacilar corniforme, es habitual la formación de cadenas. La longitud de los bacilos y el grado de curvatura está en función de la edad del cultivo, composición y pH del medio. No es común la movilidad, aunque algunos presentan flagelos perítricos. 
Crecen en la superficie de medios sólidos en condiciones de anaerobiosis o con tensiones de oxigeno bajas y un $5-10 \%$ de $\mathrm{CO}_{2}$, en rangos de temperatura comprendidos entre $2-53^{\circ} \mathrm{C}, \mathrm{pH}$ óptimo entre 5.5-6.2, la velocidad de crecimiento a menudo se reduce en $\mathrm{pH}$ neutro y alcalino. Tienen metabolismo fermentativo, son sacarolíticos y su característica principal es fermentar azúcares con producción de ácido láctico. Son homofermentadores cuando originan ácido láctico y heterofermentadores al producir ácido láctico, ácido acético, dióxido de carbono $\left(\mathrm{CO}_{2}\right)$, etanol, ácido fórmico o succínico. El porcentaje molar $\mathrm{G}+\mathrm{C}$ tiene valores de 32-53 (P. De Vos et al., 2009; B. Pot y Tsakalidou, 2009).

Se encuentran en productos lácteos, cereales, carnes, pescados, agua de consumo, aguas residuales, cerveza, vino, frutas, zumos de frutas, encurtidos y chucrut. Forman parte de la flora de la boca, el tracto intestinal, el aparato reproductor femenino y de muchos animales (P. De Vos et al., 2009).

Los requerimientos nutricionales incluyen aminoácidos, péptidos derivados de ácidos nucleicos, vitaminas, sales, ácidos grasos y carbohidratos fermentables. El medio Man Rogosa Sharpe (MRS) es uno de los más empleados y es recomendado para la enumeración y el mantenimiento de los bacilos lácticos (Collado, 2004).

No son considerados patógenos aunque algunas especies son responsables de la placa dental y el inicio de caries dental. Infecciones causadas por este género son extrañas y representan $0.05-0.48 \%$ de todos los casos de endocarditis infectiva y bacteremias, aunque se han involucrado en infecciones locales y de la sangre. Este género contribuye positivamente en la tecnología de alimentos, producen compuestos volátiles que pueden otorgar un aroma placentero de alimento fermentado o deteriorarlos afectando las propiedades sensoriales como el sabor, textura, color, limo y formación de aminas biogénicas (P. De Vos et al., 2009). En la tabla 1, se detallan las diferentes especies de Lactobacillus aisladas en casos atípicos, otras empleadas en alimentos, presentes en humanos y las que producen heteropolisacáridos. Las características propias de Lactobacillus se muestran en la tabla 2. 
Tabla 1. Aislados y usos de especies de Lactobacillus

\begin{tabular}{|c|c|c|c|}
\hline $\begin{array}{l}\text { Aisladas casos } \\
\text { atípicos }\end{array}$ & $\begin{array}{l}\text { Empleadas en } \\
\text { alimentos }\end{array}$ & Presentes en humanos & $\begin{array}{l}\text { Producen pequeñas } \\
\text { cantidades } \\
\text { heteropolisacáridos }\end{array}$ \\
\hline $\begin{array}{l}\text { L. rhamnosus* } \text { rl }^{*} \\
\text { L. paracasei } *(1) \\
\text { L. plantarum *(1) } \\
\text { L. brevis* } \\
\text { L. delbrueckii* } \\
\text { L. johnsonii* } \\
\text { L. salivarius }+ \\
\text { L. acidophilus* } \\
\text { L. casei* } \\
\text { L. fermentum } * \\
\text { L. gasseri+ } \\
\text { L. jensenii }+\end{array}$ & $\begin{array}{l}\text { L. rhamnosus (2) } \\
\text { L. paracasei (2) } \\
\text { L. plantarum (2) } \\
\text { L. brevis (2) } \\
\text { L. delbrueckii } \\
\text { bulgaricus (2) } \\
\text { L. johnsonii** } \\
\text { L. salivarius ** } \\
\text { L. acidophilus (2) } \\
\text { L. casei (2) } \\
\text { L. fermentum (2) } \\
\text { L. helveticus (2) } \\
\text { L. reuteri (2) }\end{array}$ & $\begin{array}{l}\text { L. rhamnosus } \\
\text { L. paracasei } \\
\text { L. plantarum } \\
\text { L. brevis } \\
\text { L. delbrueckii } \\
\text { L. johnsonii } \\
\text { L. acidophilus } \\
\text { L. casei } \\
\text { L. fermentum } \\
\text { L. antri } \\
\text { L. curvatus } \\
\text { L. fructivorans } \\
\text { L. gastricus } \\
\text { L. kaliixensis } \\
\text { L. oris } \\
\text { L. paraplantarum } \\
\text { L. sakei } \\
\text { L. ultunensis } \\
\text { L. vaginalis }\end{array}$ & $\begin{array}{l}\text { L. rhamnosus } \\
\text { L. paracasei } \\
\text { L. delbrueckii bulgaricus } \\
\text { L. helveticus } \\
\text { L. sakei } \\
\text { L. kefiranofaciens }\end{array}$ \\
\hline
\end{tabular}

(1) Aislados con mayor frecuencia/*Relacionadas con intestino humano/+Asociadas a alimentos, cultivos iniciadores, probióticos

(2) Animales granja y alimentos/** Solo alimentos. (P. De Vos et al. 2009) 
Tabla 2. Características del género Lactobacillus.

\begin{tabular}{|c|c|c|c|}
\hline CARACTERÍSTICAS & $\begin{array}{l}\text { GRUPO I } \\
\text { Homofermentativos } \\
\text { Obligados }\end{array}$ & $\begin{array}{l}\text { GRUPO II } \\
\text { Heterofermentetivos } \\
\text { Facultativos }\end{array}$ & $\begin{array}{l}\text { GRUPO III } \\
\text { Heterofermentativos } \\
\text { Obligados }\end{array}$ \\
\hline Fermentación de pentosas & - & + & + \\
\hline $\mathrm{CO}_{2}$ a partir de glucosa & - & - & + \\
\hline $\mathrm{CO}_{2}$ a partir de gluconato & - & + & + \\
\hline Presencia de aldolasa & + & + & - \\
\hline \multirow[t]{6}{*}{ Presencia de fosfoquetolasa } & - & + & + \\
\hline & L. acidophilus & L. casei & L. brevis \\
\hline & L. delbrueckii & L. rhamnosus & L. buchneri \\
\hline & L. helveticus & L. plantarum & L. fermentum \\
\hline & L. salivarius & L. pentosus & L. reuteri \\
\hline & & L. paracasei & L. kefir \\
\hline
\end{tabular}

\subsection{Genero Pediococcus}

Pertenece a la familia Lactobacillaceae. Descrito por Claussen en 1903. Comprende 9 especies, incluyendo P. acidilactici, P. claussenii, P. cellicola, P. damnosus, $P$. dextrinicus, $P$. inopinatus, $P$. parvulus, $P$. pentosaceus subsp pentosaceus y $P$. pentosaceus subsp intermedius y $P$. stilesii. La especie tipo es $P$. damnosus. Las células representativas son inmóviles, esféricas, ocasionalmente ovoides, se dividen formando pares o en dos direcciones perpendiculares o forman tétradas pero nunca cadenas. Aparecen individualmente, especialmente en la mitad de la fase exponencial. Células individuales miden 0.5-1.0 $\mu \mathrm{m}$. Son Gram-positivas y oxidasa negativa (P. De Vos et al., 2009). Son 
anaerobias facultativas, quimioorganotróficas y con especies homo y heterofermentativas (B. Pot y Tsakalidou, 2009).

Comparten hábitat con especies de Lactobacillus, Leuconostoc y Weissella. Algunos estudios sugieren la presencia de especies de Pediococcus de humanos en la boca, tracto digestivo, heces y en animales (P. De Vos et al., 2009). Se encuentran en material vegetal, alimentos y deterioran bebidas alcohólicas como cerveza y vino.

\subsection{Género Lactococcus}

Son Gram-positivos. Células esféricas u ovoides. Aparecen individualmente, en pares o en cadenas, a menudo elongadas en la dirección de la cadena. Produce colonias pequeñas traslucidas o blanquecinas, forma circular, lisas, enteras con 1-2 días de incubación. Inmóviles, anaerobias facultativas, catalasa negativa, con metabolismo homofermentativo. El producto final de la glucosa es L(+) ácido láctico. Los requerimientos nutricionales son complejos y variables como carbohidratos, aminoácidos, vitaminas, derivados de ácidos nucleicos y ácidos grasos principalmente. Son mesófilas, crecen entre 10 y $40^{\circ} \mathrm{C}$. Produce cantidades significativas de exopolisacáridos. Contribuyen en el tratamiento tecnológico de quesos (P. De Vos et al., 2009).

Abundan en plantas y animales, son importantes en agricultura, veterinaria, medicina y procesos de industria de alimentos ( $\mathrm{Pu}$ et al., 2002). Lactococcus se separa claramente del género patógeno Streptococcus. Tiene 5 especies: Lactococcus garvieae, Lactococcus lactis, Lactococcus raffinolactis, Lactococcus piscium y Lactococcus plantarum. La especie tipo es Lactococcus lactis subsp lactis y es común en productos lácteos (Casalta y Montel 2008; P. De Vos et al., 2009). 
Lactococcus posee entre 1 a 12 plásmidos con un peso molecular de 2 a $100 \mathrm{~kb}$. Se les atribuye numerosas propiedades como el metabolismo de carbohidratos, resistencia a bacteriófagos, producción de proteinasa y bacteriocinas. En el hábitat natural los lactococos pueden transferir plásmidos entre su misma especie u otras especies bacteriales como Lactobacillus, Bacillus, Leuconostoc, Pediococcus, Listeria y Streptococcus por conjugación y movilización. La transferencia de ADN por transducción es también posible en sistemas experimentales.

Se han empleado solos y en cultivos mixtos para la producción de diferentes tipos de quesos y leches fermentadas. En los últimos años la fisiología, bioquímica, genética y biología molecular de Lactococcus está generando mucha atención debido a su gran importancia económica (P. De Vos et al., 2009).

\subsection{Género Leuconostoc}

Pertenece a la familia Leuconostocaceae. Gram-positiva, usualmente en pareja o cadenas, forma elipsoide a esférica, a menudo elongadas, morfológicamente se parecen a los Lactobacillus y Streptococcus. Anaerobias facultativas, catalasa negativa, no proteolítico. No reduce el nitrato, no hemolítico, no hidroliza la arginina, no forma indol, heterofermentativo. Comprende 10 especies. Normalmente no acidifican, ni cuajan la leche. La temperatura óptima de crecimiento es de 20 a $30^{\circ} \mathrm{C}$. Crece en medios ricos suplementados con aminoácidos. Las colonias se desarrollan después de 3-5 días, son lisas, color blanco a grisáceo con diámetros de menos de $1 \mathrm{~mm}$. La especie tipo es Leuconostoc mesenteroides. Son más ácido tolerantes que los lactobacillus (P. De Vos et al., 2009).

Leuconostoc puede encontrarse en tracto intestinal de humanos y animales en un rango de $10^{5}$ células/g. Las especies de Leuconostoc están asociadas a variedad de productos 
fermentados y cárnicos. Algunas especies son empleadas como iniciadores en mantequilla, crema de queso, leche cortada y producción de kefir (P. De Vos et al., 2009).

Fenotípicamente, Leuconostoc, Lactobacillus y Pediococcus comparten muchas características y a menudo son aislados del mismo hábitat. Filogenéticamente la rama de Leuconostoc está próxima a la de Lactobacillus. La identificación molecular con RAPD podría diferenciar aislados a nivel de cepa (P. De Vos et al., 2009).

\subsection{Especies presentes en leche de oveja Guirra}

\section{Lactobacillus casei}

Descubierto por Orla-Jensen en 1916 (Hansen y Lessel, 1971). Bacilos de $0.7-1.1$ x $2-4 \mu \mathrm{m}$. Se presentan en forma de cadenas. Especie de gran importancia económica, empleada en muchos alimentos, se ha aislado de quesos, leche, productos lácteos fermentados y tracto intestinal. Es capaz de mantener su actividad metabólica en medios con bajo contenido de carbohidratos (Hussain et al., 2009). Tiene un historial probado en la salud humana y animal.

La cepa L. casei Yakult ha sido efectiva en ratones destetados con infecciones intestinales (Ljungh y Wadström, 2009). Importante inhibidor de patógenos gastrointestinales como Helicobacter pylori y otros patógenos que causan diarrea, E. coli, Shigella dysenteriae, $V$. cholerae, Salmonella enteriditis, S. typhimurium, Yersinia enterocolitica (Cats et al., 2003; D. Sgouras et al., 2004; B. E. González et al., 2006; Goyal et al., 2008). L. casei GG ha detenido la fase de diarrea en niños con infección de rotavirus (Walker y Duffy, 1998). Se cree que sus componentes celulares como ácido lipoteicoico (LTA), proteínas de la superficie celular (CSPs) y ácidos nucleicos tienen propiedades antiinflamatorias. La cepa de L. casei subsp. rhamnosus ATCC 7469 ó CECT278 ha sido 
efectiva en el tratamiento de ratones infectados por el protozoo Babesia microti, debido en parte a la estimulación de la inmunidad innata (Ljungh y Wadström, 2009). Es útil contra parásitos como coccidiosis que suelen aparecer en pollos de engorde (Bautista et al., 2003).

\section{Lactobacillus rhamnosus}

Bacilos no móviles de 0.8-1.0 x 2.0-4.0 $\mu \mathrm{m}$, extremos cuadrados, aparecen individualmente o en cadenas. Aislado de productos lácteos, aguas residuales y muestras clínicas humanas (P. De Vos et al., 2009). Desde hace 20 años se emplea en productos farmacéuticos y alimenticios.

L. rhamnosus Gorbach - Goldin ( $L G G)$ se multiplica en la superficie del colon y reduce el número de bacterias patógenas en el tracto gastrointestinal (Salminen y Donohhue, 1996; Isolauri et al., 2002). El consumo de $L G G$ durante un tratamiento anti- Helicobacter pylori disminuye los efectos negativos de la terapia (Armuzzi et al., 2001). Produce una sustancia antimicrobiana que inhibe la multiplicación de enteropatógenos, incluyendo Clostridium difficile, Salmonella, E. coli, S. aureus, C. albicans, C. perfringens y S. mutans (Bennet, 1996; Salminen y Donohhue, 1996; Isolauri et al., 2002; Calderón et al., 2007; Warren et al., 2007).

La cepa $L$. rhamnosus GG fue administrada a una población de niños con alergia a alimentos y fue capaz de reducir el eczema atópico. Se evidenció resistencia a las infecciones respiratorias y diarreas, menos días de ausencia y menor uso de antibióticos (MattilaSandholm, et al., 1999; De Champs et al., 2003). 


\section{Lactobacillus delbrueckii}

Descrito por Leichmann en 1896. Necesita para su desarrollo ácido pantoténico y niacina (generalmente imprescindibles), riboflavina, ácido fólico y vitamina B12. Es la especie más antigua del género Lactobacillus y por tanto la especie tipo. Presenta homología de ADN con L. bulgaricus, L. lactis y L. Leichmanni (N. Weiss et al., 1983; Gatti et al., 2001). Existen cuatro subespecies: delbruekii, bulgaricus, lactis y indicus (P. De Vos et al., 2009). Las cuatro subespecies comparten al menos $78 \%$ de similitud de ADN. El contenido de $\mathrm{G}+\mathrm{C}$ es al menos $10 \%$ más alto que otras especies. Empleadas en productos lácteos fermentados, quesos y yogur.

L. delbrueckii bulgaricus produce polisacáridos extracelulares utilizados en la producción de productos lácteos como yogur (P. De Vos et al., 2009). Algunas cepas producen heteropolisacáridos cuando crecen en leche (Idoui et al., 2009). Produce ácido láctico durante el almacenamiento y se cree que puede afectar la viabilidad de otras bacterias probióticas (Pescuma et al., 2010). Esta especie es productora de Acido $\gamma$-Amino butírico (GABA), importante en funciones fisiológicas como la inducción de hipotensión, efectos diuréticos y tranquilizantes (B. J. Lee et al., 2010), regula funciones cardiovasculares como la presión arterial y la frecuencia cardiaca. Recientes estudios muestran que hace secretar insulina en el páncreas y así previene condiciones de diabetes (H. Li et al., 2010).

\section{Lactobacillus acidophilus}

Bacilo de $0.6-0.9 \times 1.5-6 \mu \mathrm{m}$. Aparece en parejas, individualmente y en cadenas cortas. Algunos fermentan almidón. Se encuentra de forma natural en el tracto gastrointestinal de humanos y animales, masas fermentadas y vino (P. De Vos et al., 2009). Empleado en la elaboración de leche acidificada, no hidrolizan lactosa, por tal motivo no es recomendado para personas con intolerancia a la lactosa (McCray, 2003). 
En el grupo L. acidophilus, la homología ADN-ADN ha llevado a la identificación de seis especies con diferencias claramente aceptables, pero que constituyen un mismo grupo genético y son L. acidophilus, L. crispatus, L. amylovorus, L. gallinarum, L. gasseri y $L$. johnsonnii (Holzapfel et al., 2006).

Son ácido resistentes y persisten en el estomago más tiempo que otras bacterias (Bernet et al., 1994; Hamilton-Miller, 2003). Utilizado clínicamente desde 1935 en pacientes con estreñimiento obteniéndose buenos resultados (Ljungh y Wadström, 2009). Es importante en el control de microbiota indeseable en el tracto intestinal de animales y humanos. Ha presentado efecto antagónico en diferentes cepas de $H$. pylori en presencia y ausencia de células (Bernet et al., 1994; Hamilton-Miller, 2003). En algunos tratamientos se logró erradicar H. pylori con tasas del $87 \%$ frente al $70 \%$ del grupo tratado sin probiótico (Canducci et al., 2000; Vilaichone et al., 2002; Ushiyama et al., 2003).

L. johnsonii LC1 disminuyó la densidad de H. pylori en pacientes infectados al administrarse durante cuatro meses en leche fermentada y sin emplear antibióticos (Pantoflickova et al., 2003). Otro producto comercial con L. johnsonii LA1 logró interferir en la colonización gástrica por H. pylori aunque no se logró erradicar (Obregón et al., 2003). $\mathrm{El}$ efecto bactericida del sobrenadante se ha probado en ensayos in vitro e in vivo (Michetti et al., 1999).

La acción inhibitoria de estas cepas se debe a la producción de ácidos orgánicos, incluido el ácido láctico y peróxido de hidrógeno (Bathia et al., 1989), entre otros. Las proteínas antimicrobianas o bacteriocinas son las que median el antagonismo por $L$. acidophilus (Barefoot y Klaenhammer, 1983; Vicent et al., 1959). La bacteriocina lactacin B ha inhibido especies cercanas filogenéticamente, sugiriendo que el agente antagónico es propio de L. acidophilus porque inhibe a cepas de su mismo género. 
En cultivo ha mostrado la capacidad de eliminar el colesterol de un medio preparado en laboratorio, al incorporarlo o adherirlo a la superficie celular durante su crecimiento. Los lípidos de las bacterias Gram-positivas predominan en la membrana celular y al eliminar colesterol del medio pueden alterar la composición de ácidos grasos en las células (Kimoto et al., 2002). En condiciones in vitro mostró capacidad de metabolizar proteínas como la $\beta$ lactoglobulina que produce alergias en adultos, niños (Pescuma et al., 2010). La cepa KFRI342 redujo el crecimiento de células de cáncer (Chang et al., 2010). Es una especie importante a nivel industrial debido a las propiedades probióticas de varias de sus cepas (B. Pot y Tsakalidou, 2009).

\section{Lactobacillus paracasei}

Bacilos de 0.8-1.0 x 2.0-4.0 $\mu \mathrm{m}$, con bordes cuadrados, aparecen individualmente o en cadenas. Tiene dos subespecies paracasei y tolerans. Aisladas de productos lácteos (P. De Vos et al., 2009).

A este grupo se atribuyen características anti-inflamatorias por las propiedades de sus componentes celulares como LTA, CSPs y ácidos nucleicos (Ljungh y Wadström, 2009). La cepa F19 fue empleada en pacientes con hipersensibilidad a la leche, clínicamente mostró buena tolerancia y sin efectos adversos. Esta cepa láctica adicionada en leche fermentada fue empleada durante 12 semanas con un grupo de ancianos infectados con $H$. pylori disminuyendo la actividad del patógeno (Mattila-Sandholm, et al., 1999). Además, mostró efecto inhibitorio frente a E. coli, S. aureus, C. albicans, C. perfringens y S. mutans (Verdenelli et al., 2009).

Los extractos libres de células de cepas aisladas de queso Genestoso mostraron un alto nivel aminopeptidasa (L. González et al., 2010), un tipo de antígeno propio del sistema inmune de mamíferos. En condiciones in vitro ha demostrado capacidad de descomponer 
proteínas como $\beta$-lactoglobulin que produce alergias y es productora de GABA ( H. Li et al., 2010; Pescuma et al., 2010).

\section{Lactobacillus plantarum}

Bacilos con extremos redondeados, tamaño 0.9-1.2 x 3-8 $\mu \mathrm{m}$. Aparecen individualmente, en pares o en cadenas cortas. Tiene dos subespecies $L$. plantarum y $L$. argentoratensis. L. plantarum contiene muchas características atípicas respecto a las demás especies de Lactobacillus como la movilidad, actividad pseudocatalasa o reducción de nitrato. Tiene variación entre sus especies, algunas se relacionan con L. pentosus. Predomina en queso de leche de oveja. Tiene importancia en el proceso de maduración por su alta actividad lipolítica y proteolítica (Pérez Elortondo et al., 1998).

Se ha aislado de aceitunas fermentadas. Produce las bacteriocinas plantaricina S y T activas frente a un gran número de competidores naturales entre ellos las bacterias que afectan la fermentación de olivas (Leal et al., 1998). Además, la cepa TN635 tiene un compuesto antimicrobiano de origen proteico, estable al calor, activo entre $\mathrm{pH} 3$ y 11, con una masa molecular aproximada de $4 \mathrm{KDa}$ y con efecto bactericida frente a Listeria ivanovii BUG 496 y fungistático contra Candida tropicalis R2 CIP203 (Smaoui et al., 2010). Produce GABA (H. Li et al., 2010).

El efecto antagónico frente a $H$. pylori ocasionado por L. plantarum aislado de chucrut se asoció principalmente con la pared celular y en menor medida con el sobrenadante (Rokka et al., 2006). En un estudio in vivo redujo severamente la enterocolitis (Walker y Duffy, 1998). L. plantarum mostró un fuerte efecto antagónico frente a la invasión de $S$. typhimurium sobre las células del epitelio intestinal, a través de la alta habilidad de inducir IgA (Ishikawa et al., 2010). 


\section{Lactobacillus brevis}

Productor de gas, bacilos largos con extremos redondeados (Boucher et al., 2003). Aparece individualmente y en cadenas cortas. Aislado de leche, queso, vegetales fermentados, chucrut, masa fermentada, ensilaje, estiércol de vaca, heces, boca y tracto intestinal de ratas y humanos (P. De Vos et al., 2009). Es considerado seguro (GRAS). La cepa ATCC 8287 mostró propiedades probióticas con potencial como vacuna oral (Hynönen et al., 2010).

Produce GABA (B. J. Lee et al., 2010; H. Li et al., 2010). Cepas de L. brevis aisladas de pollos tuvieron la capacidad de desconjugar ácido glicocólico (GCA) y en menor proporción Taurocolato de sodio (TCA). Además, presentaron la habilidad de metabolizar colesterol del medio de cultivo (Ramasamy et al., 2010). La cepa CLC23 aislada de leche de cerdo mostró actividad antimicrobiana frente a un amplio espectro de bacterias patógenas como Listeria monocytogenes ScottA, Salmonella cholerasuis y Salmonella enteritidis 4396 (R. Martín et al., 2009).

\section{Lactobacillus pentosus}

Bacilos no móviles, tamaño de 1-1.2 x 2-5 $\mu \mathrm{m}$, con bordes redondeados. Aparece individualmente, en pares o en cadenas cortas. Aislado de ensilaje de maíz, aceitunas fermentadas y aguas residuales (P. De Vos et al., 2009). Especie empleada en productos fermentados (J. Zhang et al., 2009). Producen exopolisacáridos y su concentración depende de las condiciones de cultivo (Rodríguez-Carvajal et al., 2008).

Inhibe el crecimiento de enterobacterias (Hurtado et al., 2010). La cepa 31-1 redujo significativamente las poblaciones de L. innocua y $S$. aureus durante la fase de maduración de productos cárnicos, lo cual puede atribuirse a la actividad proteolítica y lipolítica de esta 
especie (G. Liu et al., 2010). De otro lado, la cepa ST712BZ fue capaz de inhibir el crecimiento de L. casei, E. coli, Pseudomonas aeruginosa, Enterococcus faecalis, Klebsiella pneumoniae y Lactobacillus curvatus (Todorov y M. T. Dicks, 2005).

\section{Lactococcus lactis subsp lactis}

Las bacterias del género lactococcus se utilizan como cultivos iniciadores en la producción de leches, quesos y otros productos lácteos fermentados (Boucher et al., 2003). A veces se mezclan diferentes cepas para conferir un sabor y aroma deseado. Tienen la habilidad de crecer aunque no tenga los suficientes nutrientes disponibles (Hussain et al., 2009).

Tienen forma esférica $u$ ovoide, se encuentran principalmente en pares o cadenas cortas. Gram-positiva. No móviles, anaerobia facultativa y catalasa negativa. Se ha aislado del intestino de bovinos, leche de vacas saludables, vacas con mastitis, amígdalas de gatos, perros y cabras (P. De Vos et al., 2009). Cepas de Lactococcus han tenido la habilidad de reducir el colesterol presente en un medio de cultivo sin degradarlo y dicha habilidad es dependiente de la cepa (Kimoto et al., 2002).

La especie de Lactococcus lactis y sus subespecies son usadas en la industria láctea y reconocidas como seguras (GRAS) para el consumo humano (P. De Vos et al., 2009). Previno la alteración y el crecimiento de bacteria patógenas potenciales en leche de oveja (Casalta et al., 2009). La cepa IFPL 3593 produjo lacticinio 3147 y tuvo la capacidad de inhibir el crecimiento de Clostridium (Martínez-Cuesta et al., 2010). La nisina es una bacteriocina producida por Lactococcus lactis spp. permitida para su uso en 50 países (Bromberg et al., 2004).

Lactococcus lactis subsp lactis presenta sus propios antígenos que podrían ser usados en el futuro como vacunas. Una variedad de proteínas y péptidos pueden ser anclados 30 
o parcialmente presentados en la superficie de las células de Lactococcos (P. De Vos et al., 2009). Lactococcus lactis subsp lactis con actividad antimicrobiana y aislado de queso Genestoso del norte de España (Asturias) mostró un alto grado de acidificación, actividad proteolítica y los extractos libres de células con alta actividad caseinolítica y actividad dipeptidasa (L. González et al., 2010).

Aún es controvertido el estatus de probiótico de esta especie, aunque ha demostrado efectos inmunomoduladores y ha sobrevivido el paso por el tracto intestinal de ratones (Foligné et al., 2010). Además, es productor de GABA (H. Li et al., 2010).

\section{Lactococcus raffinolactis}

Células esféricas u ovoides, elongadas en la dirección de la cadena. Aparecen en pares o cadenas cortas. Gram-positiva, no móviles, anaerobia facultativa, catalasa negativa. Se encuentra en quesos, leche cruda, saliva, pieles de vacunos y sobre hierba, predomina en peces durante el invierno (Ouadghiri et al., 2005; Hagi y T. Hoshino, 2009). Se ha aislado de amígdalas de bovino e intestino de cabra (P. De Vos et al., 2009).

Fermenta $\alpha$-galactosidos como melobiosa y rafinosa. No es una especie empleada en la industria láctea porque carece de actividad caseinolítica (Boucher et al., 2003). Algunas cepas han producido niveles aceptables de acetaldehído y diacetilo, no crece a $40^{\circ} \mathrm{C}$. En algunos casos presenta un plásmido o ninguno, es posible que carezca de un factor transcripcional requerido para la expresión de la proteinasa. Es recomendada en el desarrollo de cultivos iniciadores lácteos (Holler y Steele, 1995). La cepa h47 presentó resistencia al ácido cólico, uno de los ácidos biliares más importantes en humanos. Además, mostró actividad antibacteriana frente a patógenos de pescado como Aeromonas Salmonicida JCM 7874, A. hydrophila JCM 1027 y A. caviae JCM 1060 (Hagi y T. Hoshino, 2009). 


\section{Leuconostoc mesenteroides mesenteroides}

Gram-positivas, catalasa negativa, no móviles, células esféricas o lenticulares especialmente cuando crecen en agar, se agrupan en pares o en cadenas. Las colonias son pequeñas, de al menos $1 \mathrm{~mm}$ de diámetro, lisas y de color blanco grisáceo. Crece entre $5 \mathrm{y}$ $30^{\circ} \mathrm{C}$. Ha sido aislada en leche y quesos de cabra y oveja (Colombo et al., 2010; Randazzo et al., 2010). Esta especie tiene una función importante en la maduración de quesos por la capacidad de fermentar el citrato presente en la leche de oveja, está involucrada en procesos proteolíticos y enzimáticos durante la maduración del queso (Casalta et al., 2009). Tiene baja capacidad de acidificación y de metabolizar lactosa (L. González et al., 2010). Predominante en jamón y otros productos cárnicos (Tu et al., 2010).

\section{Pediococcus pentosaceus}

La incubación anaeróbica no es necesaria, y las colonias son visibles sobre agar después de 24 horas a $30^{\circ} \mathrm{C}$. La cepa Pediococcus pentosaceus produce catalasa o pseudocatalasa, tienen alta capacidad de sobrevivir en el tracto gastrointestinal, reduce alergias y la invasión de Salmonella en ratones. Más del 50\% de esta cepa se ha aislado de leche de cabra, quesos feta y kasseri. Es homofermentativo, produce ácido láctico a partir de la glucosa pero no $\mathrm{CO}_{2}$. La especie Pediococcus pentosaceus está asociada a plantas y frutas (P. De Vos et al., 2009). Es empleada en procesos de fermentación (Harun-ur-Rashid et al., 2007). Tiene potencial como conservante en carnes (Bromberg et al., 2004).

Bacteriocinas pertenecientes al género Pediococcus se han aislado de cepas de productos cárnicos y bebidas fermentadas de cereales. Varias cepas de $P$. pentosaceus son conocidas por la producción de bacteriocinas como las pediocinas PA-1, A y ACCEL, N5p, SM-1 (P. De Vos et al., 2009). Se ha demostrado el efecto sinérgico entre la bacteriocina 
ST44AM y ciprofloxacino incrementando la acción antibacteriana frente a $L$. ivanovii subsp. ivanovii (Todorov y L. M. T. Dicks, 2009).

\subsection{Identificación de las BAL}

La identificación taxonómica abarca parámetros fenotípicos, genotípicos y filogenéticos. Pueden emplearse diferentes técnicas en la clasificación de bacterias. El uso adecuado de la información obtenida en dichas técnicas es primordial para hacer una adecuada agrupación de los organismos en un taxón determinado (Sarmiento, 2008). Las identificaciones polifásicas de caracterización proporcionan un sistema de identificación de alta fiabilidad.

\subsubsection{Características fenotípicas}

Son métodos clásicos de identificación basados en las relaciones filogenéticas en función de similitudes entre una serie de caracteres expresados por las cepas estudiadas. El estudio de estas propiedades tienen gran validez predictiva y representan una pequeña parte de la información genética en donde su expresión está condicionada por los factores ambientales. Este tipo de estudio comprende la caracterización cultural, morfológica, fisiológica y bioquímica.

Características bioquímicas: La identificación de cepas por la fermentación de azucares tiene una importancia especial (Sanz et al., 1998), diferencia entre especies de Lactobacillus (McLeod et al., 2008). Ofrece en ocasiones resultados ambiguos. Diferentes respuestas entre cepas pertenecientes a una misma especie repercute en la baja reproducibilidad entre distintos laboratorios (Andrighetto et al., 2001). En las BAL la ruta más estudiada es la de la lactosa y la capacidad de fermentación varía entre las diferentes especies lácticas (Hernández, 2005). 


\subsubsection{Características genotípicas}

El desarrollo de las diferentes técnicas moleculares ofrece información microbiológica complementaria en el estudio de las complejas comunidades microbiológicas. Las moléculas de ADN y ARN son elementos químicos empleados en taxonomía y su composición no varia por las condiciones de crecimiento (Sanz et al., 1998). Las técnicas basadas en ribotipado son herramientas exitosas para la identificación de bacterias a nivel de especie y subespecie.

\section{Hibridación ADN-ADN}

Es un parámetro indirecto que permite conocer la similitud entre genomas completos de dos microorganismos diferentes, importante en la agrupación de especies (Sarmiento, 2008). Se ha aplicado extensivamente en el estudio de la taxonomía de Lactobacillus. A menudo, la hibridación se ve limitada por el tipo de cepas de un pequeño grupo de especies cercanas. Los problemas aumentan cuando las cepas son fenotípicamente idénticas y los valores de asociación son iguales o menores al 70\% (B. Pot y Tsakalidou, 2009).

\section{Análisis genes 16S/23S ARNr}

El ribosoma bacteriano está compuesto por dos subunidades $30 \mathrm{~S}$ y $50 \mathrm{~S}$, la subunidad $30 \mathrm{~S}$ contiene la molécula de $16 \mathrm{~S}$ ARNr y la subunidad $50 \mathrm{~S}$ contiene rRNA $5 \mathrm{~S}$ y 23S. Los fragmentos $5 \mathrm{~S}, 16 \mathrm{~S}$ y $23 \mathrm{~S}$ se han empleado en estudios filogenéticos, siendo $16 \mathrm{~S}$ el más adecuado en el estudio de procariotas con cerca de 1550 pares de bases (Sarmiento, 2008). Los genes $16 \mathrm{~S}$ y $23 \mathrm{~S} \mathrm{ARNr}$ contienen secuencias conservadas, variables e hipervariables. 
Ribopatrones derivados de hibridación con pruebas de 16S rRNA específica de especie está siendo efectiva en la identificación de Lactobacillus (Sanz et al., 1998). Actualmente, la secuenciación por el gen $16 \mathrm{~S}$ es la herramienta más poderosa y fiable en los estudios de relaciones filogenéticas entre bacterias. Esta molécula tiene excelentes propiedades por su presencia universal. Puede ser secuenciado por PCR usando iniciadores universales de regiones conservadas a ambos lados del gen. El amplificado es secuenciado y luego se compara con las secuencias almacenadas en bases de datos. Esto favorece la caracterización de aislados desconocidos y ofrece información de la posición filogenética, lo cual fortalece el éxito de la técnica. Una vez se obtiene la secuencia, puede ser alineada y calculada su similitud (B. Pot y Tsakalidou, 2009).

Muchas especies de las BAL han sido descritas total o parcialmente a través de esta técnica. Los árboles filogenéticos de estas bacterias son heterogéneos, muestran la cercanía existente entre algunas especies de Lactobacillus y Pediococcus y confirma diferencias en el contenido de $\mathrm{G}+\mathrm{C}$ en el género.

Una de las desventajas de esta técnica es que la molécula tan bien conservada provee resolución a nivel de especie y subespecie. Por tanto, diferentes especies de las BAL comparten idénticas secuencias 16S. De hecho, algunos Lactobacillus han sido renombrados últimamente. Aunque para otras especies, hay suficientes diferencias fenotípicas y genotípicas que facilitan su identificación (B. Pot y Tsakalidou, 2009).

\section{Secuenciación de genes housekeeping}

Es una herramienta prometedora para estudios filogenéticos. Se ha ido recomendando el tipado de secuencias multilocus (multilocus sequence typing MLST), con la secuenciación de al menos 5 genes localizados en diversos lugares del cromosoma. En Lactobacillus se han empleado los genes recA, cpn60, tuf y slp. Lo más interesante de esta 
técnica es la obtención de árboles filogenéticos obtenidos de diferentes genes housekeeping (B. Pot y Tsakalidou, 2009).

Un fragmento del gen recA está presente en bacterias y se encuentra bien conservado. Las relaciones filogenéticas obtenidas corresponden bien con el análisis del gen completo del ARNr. Es una herramienta valiosa en el análisis comparativo de aislados humanos y de alimentos por su rapidez y facilidad (Collado, 2004).

\section{Téenicas basadas en la PCR}

- Análisis de Polimorfismos Amplificados (AFLPs): Este análisis está basado en la detección de polimorfismos mediante la PCR a partir de cualquier muestra de $\mathrm{ADN}$, independiente de su origen o complejidad. Los polimorfismos son detectados por la presencia o ausencia de fragmentos de restricción obtenidos con la digestión del ADN y posteriormente son amplificados por PCR. Analiza todo el genoma bacteriano, no se requiere el previo conocimiento de la secuencia genómica de las muestras. Es una técnica de fácil realización, discriminatoria y reproducible cuando las condiciones de digestión, ligado y amplificación de las muestras no cambian. Aunque es sensible a la calidad del ADN de la muestra (Collado, 2004). Es fiable y da información a nivel de especie (B. Pot y Tsakalidou, 2009). Proporciona información limitada acerca del genoma completo (McLeod et al., 2008).

\section{- Restricción del ADN amplificado mediante enzimas de restricción}

(RFLP): A partir de PCR se amplifica una secuencia conocida del ADN genómico utilizando dos cebadores homólogos a sus regiones extremas, seguido de una digestión con una endonucleasa de restricción y posterior comparación de los distintos patrones de bandas de restricción obtenidos. Es reproducible intra e inter laboratorio, la metodología de análisis resulta ser complicada y proporciona información restringida porque se analiza una parte del genoma (Collado, 2004). 


\section{Técnicas de fácil manejo}

Son técnicas de fácil manejo, no requieren demasiados equipos y tienen como desventaja la baja reproducibilidad.

\section{- Amplificación de ADN mediante iniciadores aleatorios, RAPD}

(Random Amplified Polymorphic DNA): Es un método simple de tipado basado en ácidos nucleicos. Consiste en la detección de diferencias en la secuencia del ADN genómico total de distintas cepas, amplifica regiones de ADN al azar encabezadas por secuencias a las que son capaces de unirse iniciadores de secuencia única aleatoria. La secuencia del iniciador no tiene homología conocida con el ADN diana, genera fragmentos de distintos tamaños que pueden apreciarse en gel de agarosa. No es necesario conocer previamente la secuencia de la muestra, se puede emplear con variedad de especies y es más rápido que otros métodos de tipado.

Presenta baja reproducibilidad interlaboratorios. El patrón de bandas obtenido en determinadas condiciones no siempre es constante. Es una técnica que diferencia a nivel de cepa y es útil en el monitoreo de cepas industriales dentro de grupos específicos (Collado, 2004). Es una herramienta que detecta variabilidad a lo largo de todo el genoma bacteriano, es fiable para la identificación, tipificación de las BAL de productos alimenticios y cepas del género Lactobacillus (Martín-Platero et al., 2009; Svec et al., 2010).

El poder discriminativo aumenta cuando es combinado con otras técnicas o se emplean diferentes iniciadores (Martín-Platero et al., 2009). Aunque es más exacta que otras técnicas de tipado, proporciona información limitada acerca del genoma completo (McLeod et al., 2008), es menos reproducible que REP-PCR permitiendo la construcción de bases de datos de referencia para un solo laboratorio (B. Pot y Tsakalidou, 2009). 
- REP (Repetitive Extragenic Palindromic), ERIC-PCR, GTG5-PCR,

Box-PCR, Al igual que la técnica de RAPD, estás técnicas tienen en común que son fáciles de realizar y no requieren demasiados equipos de laboratorio.

En la identificación de las BAL se encuentran en desarrollo metodologías de micromatrices (microarrays). La identificación usando matrices aumentará a medida que las secuencias del genoma estén disponibles. Estas matrices pueden involucrar la funcionalidad de los genes junto con marcadores taxonómicos. La combinación de múltiples marcadores proporcionará esquemas fiables de clasificación e identificación. La disponibilidad de plataformas de secuenciación de alto rendimiento que aceleren el proceso de recopilación del conocimiento de las BAL y la disponibilidad de un gran número de secuencias cromosómicas también pueden dar claridad por ejemplo, en la transferencia de genes (B. Pot y Tsakalidou, 2009).

\section{Bacterias patógenas}

\subsection{Helicobacter pylori}

El género Helicobacter pertenece a la familia Helicobacteriaceae, clase VI de ARNr, división Epsilon dentro de las bacterias Gram-negativas o Proteobacterias (Vandamme y De Ley, 1991). Crece en condiciones de microaerofilia $\left(5 \% \mathrm{O}_{2}, 7 \% \mathrm{CO}_{2}, 8 \%\right.$ $\mathrm{H}_{2}, 80 \% \mathrm{~N}_{2}$ ) en rangos de temperatura de $30-37^{\circ} \mathrm{C}$.

El género Helicobacter comprende 23 especies de bacterias microaerófilas, siendo Helicobacter pylori la más estudiada. Se ha detectado en heces, agua de bebida y residuales, leche, vegetales, y su aislamiento resulta complicado. Se considera que es resistente a las concentraciones de cloro y ozono utilizadas en la potabilización del agua de distribución. 
Algunos estudios manifiestan que en condiciones de estrés ambiental estos microorganismos pueden entrar en una fase viable pero no cultivable (VNC), conservando actividades metabólicas y expresando factores de virulencia. Las formas VNC pueden permanecer en sistemas acuáticos durante largos periodos de tiempo, mostrando cambios morfológicos al pasar de forma helicoidal a cocoide, un mecanismo de supervivencia en el ambiente que favorece su transmisión (Jimenez, 2005).

El nombre Helicobacter hace referencia a su morfología helicoidal. Son bacilos helicoidales, espirales, formas de $\mathrm{S}, \mathrm{V}$ y $\mathrm{U}$, curvados o rectos de 0.3-1.0 $\mu \mathrm{m}$ de largo. Presenta extremos redondeados y curvados con periodicidad espiral. Tiene 6 flagelos, envainados, unipolares, presentando bulbos terminales distintivos y pared celular lisa. Se considera que la vaina del flagelo es una adaptación para vivir, moverse a través de la mucosa y protegerse contra el ácido del estomago (Jimenez, 2005). No origina endosporas. $\mathrm{Su}$ contenido $\mathrm{G}+\mathrm{C}$ varía desde 35 a $44 \mathrm{~mol} \%$.

En agar infusión de corazón y cerebro suplementado con sangre o carbón, originan tras 2-5 días de incubación a $37^{\circ} \mathrm{C}$ colonias no pigmentadas, translúcidas de $1-2 \mathrm{~mm}$ de diámetro, convexas y con una ligera hemólisis a su alrededor. En los medios de cultivo líquido crecen muy lentamente, a menos que se incuben en constante agitación. En cultivos viejos adoptan forma cocoide, asociada a pérdida de cultivabilidad.

Presenta actividad ureasa y catalasa que puede perderse cuando las cepas son repetidamente subcultivadas en agar semisólido durante varios meses e incluso años (Goodwin et al., 1989).

H. pylori es la especie tipo del género y la más importante en patología humana por su estrecha relación con la colonización asintomática hasta la producción de gastritis crónica, ulcera péptica y en algunos casos cáncer gástrico, linfoma de MALT y ulcera de duodeno 
(Parsonnet, 1998). La actividad vacuolizante y citotóxica de H. pylori varía entre cepas (Cittelly D.M et al., 2001;Suerbaum y Michetti, 2002; García et al., 2009).

Interfiere en procesos fisiológicos protectores del estomago y duodeno. La OMS ha clasificado a esta bacteria como carcinógeno de clase uno. El cáncer gástrico tiene un índice de letalidad del 70\%, ocupa el segundo lugar después del cáncer de pulmón. En algunos países es la primera causa de muerte en varones y la tercera causa de fallecimiento en mujeres (Anselmi et al., 2007). Entre 25-50\% de la población de países desarrollados está infectada por $H$. pylori y el $80 \%$ en la población de los países en desarrollo (Cittelly et al., 2001; A. García et al., 2009).

De otro lado, también influyen la virulencia de la cepa patógena, los aspectos medioambientales, las condiciones del hospedador como los antecedentes genéticos, la respuesta inmune, reinfección, dieta, ingesta de alcohol y consumo de tabaco (Cittelly et al., 2001; Anselmi et al., 2007). Se contagia por vía digestiva de persona a persona (saliva) o por la ruta fecal-oral (De Cothi et al., 1989). H. pylori es una bacteria que se adquiere durante la infancia, cerca del 80 - 90\% de las personas están en contacto con esta bacteria a lo largo de su vida. Al estar presente en la mucosa gástrica genera una respuesta inmunológica celular y tumoral, la cual es incapaz de eliminar la bacteria. Para evitar la evolución de la gastritis, se recomienda la ingesta de vegetales ricos en antioxidantes naturales y embutidos con nitritos para mitigar los efectos nocivos que genera.

Inicialmente, en condiciones in vitro, $H$. pylori aislado de la mucosa gástrica de pacientes con ulceración y gastritis mostró sensibilidad a antibióticos (Jones et al., 1984) como ampicilina, rifampicina, gentamicina, amoxicilina, penicilina, eritromicina, metronidazol y tetraciclinas y resistencia a cimetidina, ranitidina, famotidina, sulfonamidas, trimetropim y resistencia variable al ácido nalidíxico y cefalotina. 
Agentes antimicrobiales como amoxicilina, claritromicina, sales de bismuto, metronidazol o tinidazol junto con un inhibidor de la bomba de protones (omeoprazol), o ranitidina se han usado en combinaciones triples o cuádruples (Ushiyama et al., 2003). Estos tratamientos curan entre el $80-90 \%$ de los casos, pero resultan costosos y existe el riesgo que no sea efectivo (Masaake et al., 2004).

Los tratamientos con metronidazol o tetraciclina son opciones en la erradicación de cepas resistentes a la claritromicina, su uso clínico se encuentra limitado debido a los efectos secundarios o también a la presencia de cepas resistentes a estos medicamentos. La claritromicina tiene un efecto fuerte sobre la infección de $H$. pylori respecto a otros antibióticos. Al menos, $5-10 \%$ de las cepas de H. pylori son resistentes a la claritromicina (Ushiyama et al., 2003). Este antibiótico también se utiliza para combatir otras infecciones bacterianas como la neumonía; lo cual puede contribuir en parte a la aparición de bacterias resistentes a este antibiótico. Se considera que la resistencia adquirida por H. pylori a la claritromicina se debe a la mutación del aminoácido (adenina-guanina) a 2143 ó 2144 en el dominio $\mathrm{V}$ del ácido ribonucleico en el gen 23S. El mecanismo de patogenicidad de esta bacteria no se ha explicado claramente (Masaake et al., 2004).

De ello deriva el interés en reducir el uso de antibióticos y buscar alternativas más favorecedoras (Hamilton-Miller, 2003). La terapia clínica de H. pylori con antibióticos a menudo está acompañada de efectos secundarios no deseados (W. H. Lin et al., 2009). Cepas probióticas pertenecientes al genero lactobacillus; Bifidobacterium y Enterococcus se han utilizado en la prevención de infecciones gastrointestinales ocasionadas por H. pylori por medio de sus ácidos orgánicos, bacteriocinas, capacidad de exclusión, inmunomodulación presentando una alternativa en el tratamiento de dicha infección (Ushiyama et al., 2003; A. García et al. 2009; W. H. Lin et al., 2009). 
Los daños agudos inducidos por este patógeno pueden evitarse con el pretratamiento con un probiótico. H. pylori en presencia de sustancias de las BAL cambia su morfología helicoidal a cocoide (W. H. Lin et al., 2009). Las cepas de Lactobacillus tienen la característica particular de establecerse en la mucosa gástrica cuando se encuentra lesionada y ejerce una función regenerativa en los procesos tisulares (A. García et al., 2009). Incluso se destacan por la capacidad de inhibir el crecimiento de cepas de $H$. pylori resistentes a claritromicina suprimiendo la producción de IL-8 sin dañar las células de $H$. pylori (Ushiyama et al., 2003). La interleucina IL-8 es una potente citocina que atrae neutrófilos y causa inflamación en el tejido y tiene un importante rol en la infección de H. pylori. Siendo dicho efecto dependiente de la cepa (Myllyluoma et al., 2008).

\subsection{Salmonella spp.}

Pertenece a la familia Enterobacteriaceae, Gram-negativa, anaerobios facultativos. Es una bacteria patógena, causa fiebres entéricas, gastroenteritis y septicemia en humanos y puede afectar a muchas especies animales. El porcentaje de $\mathrm{G}+\mathrm{C}$ es de $50-53 \%$. Todos los datos filogenéticos indican que la evolución del género Salmonella es continua. Recientes clasificaciones reconocen dos especies distintas de Salmonella, una de las cuales contiene seis subespecies. La especie tipo es Salmonella choleraesuis o Salmonella enterica (Krieg y Holt, 1984). El análisis del gen $16 \mathrm{~S}$ ARNr indica que Salmonella pertenece a Gammaproteobacteria. Además, se ha encontrado que $S$. enterica y $S$. bongori están estrechamente relacionadas con E. coli y Shigella.

Crecen bien en los medios ordinarios de cultivo sin requerir factores esenciales y pueden utilizar el citrato como fuente única de carbono, $\mathrm{pH}$ óptimo 6.5 a 7.5 , sensible a $\mathrm{NaCl}$, aunque se ha encontrado en salmuera con $3.2 \%$ de sal. El grado de crecimiento de Salmonella depende de la temperatura, $\mathrm{pH}$, salinidad, actividad de agua y el nivel de nutrientes. La temperatura óptima de crecimiento se encuentra entre 35 y $37^{\circ} \mathrm{C}$, puede 
multiplicarse desde 5 a $47^{\circ} \mathrm{C}$. Cuando los alimentos crudos y cocinados se almacenan a temperaturas inferiores de $10^{\circ} \mathrm{C}$ se previene su crecimiento. La congelación perjudica la supervivencia pero no garantiza su destrucción (Pascual, 2005).

Bacilos rectos, tamaño de $0.7-1.5 \times 2.0-5.0 \mu \mathrm{m}$. Generalmente móviles por flagelos perítricos, no esporulados ni capsulados, anaerobios facultativos. En los medios sólidos originan colonias de 2 a $4 \mathrm{~mm}$ de diámetro.

S. typhi es la única serovariedad que no produce gas en la fermentación de azúcares. Reducen los nitratos a nitritos. La diferenciación entre especies y subespecies se realiza tomando en cuenta diferentes propiedades bioquímicas. No fermentan la lactosa, excepto Salmonella entérica subsp. arizonae (Salmonella choleraesuis subsp. Arizonae) y Salmonella entérica subsp. diarizonae, fermentan glucosa con producción de gas, no producen indol, no degradan la urea, descarboxilan a los aminoácidos Lisina y Ornitina (Krieg y Holt, 1984; Aguilar y Escolástica, 2003).

Poseen antígenos somáticos, flagelares y algunos serovares presentan un antígeno capsular denominado antígeno Vi. El antígeno $\mathrm{O}$ es un lipopolisacárido termoestable, localizado en la pared celular, que está asociado con la endotoxina y permite la división de Salmonella en grupos. El antígeno flagelar $\mathrm{H}$ es termolábil, de naturaleza proteica y permite la división de las especies en monofásicas (siempre poseen el mismo antígeno flagelar) o difásicas (fase 1 y fase 2). El antígeno Vi solamente lo poseen algunos serovares (typhi, paratyphi-C y Dublin). Es un antígeno capsular, termolábil, responsable de la virulencia junto con el antígeno $\mathrm{O}$.

Al igual que otros géneros de enterobacterias Salmonella puede contener fagos y plásmidos que pueden codificar determinadas virulencias y resistencia a antibióticos. Cerca 
de 5\% de cepas de Salmonella produce bacteriocinas activas contra E. coli, Shigella y Salmonella (Krieg y Holt, 1984).

Salmonella spp. es un patógeno transmitido por alimentos y por ello se reconoce su importancia en seguridad alimentaria y salud pública. Los serovares de Salmonella pueden estar estrictamente adaptados a un hospedador en particular y encontrarse en un gran número de especies animales. Los serovares más adaptados a animales son Typha, Paratyphi A y Sendai que usualmente causan severas enfermedades como septicemia. El serovar Abortusovis es la mayor causa de aborto en ovejas y los serovar Typhisus y Gallinarum se presenta en cerdos y aves de corral respectivamente (Krieg y Holt, 1984).

La salmonelosis es trasmitida de persona a persona, a través de la contaminación fecal de agua y alimentos, dosis infectivas menores de $10^{3}$ son suficientes para causar síntomas clínicos, como tifoidea, septicemia, o una leve infección asintomática. Inicialmente invade la mucosa del intestino delgado, adhiriéndose rápidamente y entrando a las células $\mathrm{M}$ del folículo asociado al epitelio. La incidencia es alta en países con higiene precaria. La fiebre tifoidea, una infección sistémica causada por el serovar Typha es una preocupación pública. La OMS estima que hay más de 16.6 millones de casos de tifoidea por año causando 600.000 muertes anuales.

Salmonella enterica está dividida en seis subespecies. I. Enterica. II. Salamae.IIIa. Arizonae. IIIb. Diarizonae. IV. Houtenae. V. Bongori. VI. Indica. Cada subespecie está compuesta por diversos serotipos, en total se han identificado más de 2500 . La cepa tipo presenta una virulencia asociada al plásmido de $90 \mathrm{~kb}$. El porcentaje $\mathrm{G}+\mathrm{C}$ es de $50-53 \%$ (Krieg y Holt, 1984). Se ha demostrado que $S$. enteritidis ataca al íleon y en menor medida al colon (De Moreno de LeBlanc et al., 2010). 
Salmonella enterica subsp enterica, se ha aislado de humanos y animales de sangre caliente por consumo de huevos de pollo y productos avícolas contaminados (Smaoui et al., 2010). Se destacan los serovares enteritidis y typhimurium que frecuentemente ocasionan infecciones en humanos y animales. Ambas relacionadas en casos de gastroenteritis en el hombre (Krieg y Holt, 1984).

S. typhimurium causa fiebre tifoidea e infecciones sistémicas en seres vivos susceptibles, asociado con múltiples daños, muerte de órganos, enterocolitis en humanos (De Moreno de LeBlanc et al., 2010; Ishikawa et al., 2010). Se adhiere a las células epiteliales del intestino delgado, invadiéndolas y atravesando la mucosa. Una vez en la submucosa se multiplica provocando una reacción inflamatoria, lo que da lugar a un cuadro diarreico. En caso de no eliminarse por el peristaltismo intestinal, producen una endotoxina que es la responsable de la alteración de la mucosa intestinal (Ishikawa et al., 2010).

Las infecciones ocasionadas por cepas de Salmonella pueden tratarse con fluoroquinolonas como ciprofloxacino, cloranfenicol, cefalosporina ó trimetoprima/sulfametoxazol de amplio espectro (Murray et al., 2006).

Muchos estudios emplean bacterias probióticas viables como alternativa al tratamiento antibiótico. Algunas cepas de Lactobacillus han sido efectivas estimulando a las placas de peyer a producir altas cantidades de IgA, protegiendo de bacterias patógenas (Ishikawa et al., 2010) como Salmonella enteridis, S. enterica y S. typhimurium. Las especies, Lactobacillus acidophilus, L. rhamnosus y L. casei han sido eficaces en el manejo profiláctico de diarrea en niños producida por Salmonella y han incrementado la inmunidad (Goyal et al., 2008).

El principal mecanismo de acción es el bajo $\mathrm{pH}$ del medio debido a la producción de ácido láctico a concentraciones de 20-40 mM, que actúa como un permeabilizador de la 
membrana exterior de los patógenos Gram negativos aumentando así la susceptibilidad a las moléculas antimicrobianas permitiendo que penetren en las bacterias (Goyal et al., 2008). Además, la producción de ácidos orgánicos, bacteriocinas, moléculas diferentes al ácido láctico y el incremento de la secreción de IgA producido en la superficie de la mucosa contribuyen en la defensa del hospedador contra la adhesión de patógenos entéricos mejorando la inmunidad intestinal. Podemos decir que los mecanismos de la actividad antibacteriana de Lactobacillus probióticos parece ser multifactorial (Fayol-Messaoudi et al., 2005; Smaoui et al., 2010). 
OBJETIVOS

(2) 
Las bacterias ácido lácticas (BAL) se encuentran presentes en productos lácteos y contribuyen al desarrollo de algunas propiedades organolépticas de los mismos. Algunas cepas pertenecientes a los géneros Lactobacillus y Lactococcus han demostrado poseer propiedades probióticas y se han utilizado como alternativa al tratamiento antibiótico en infecciones causadas por ciertos patógenos humanos.

En los últimos años ha habido un incremento de investigaciones enfocadas en la búsqueda de nuevas cepas de estas BAL que presentan propiedades beneficiosas para la salud del hombre y que son empleadas en la elaboración de productos denominados probióticos. La oveja Guirra es típica de la Comunidad Valenciana, se encuentra en proceso de recuperación y esta incluida en el grupo de "Razas de protección especial" del Catálogo Oficial de Razas de Ganado de España. A partir de su leche se elaboran quesos frescos y maduros con propiedades organolépticas de gran calidad.

El presente trabajo se ha planteado evaluar las diferentes características que pueden mostrar el potencial probiótico de las BAL aisladas de esta leche de oveja y productos derivados de la misma mediante la consecución de los siguientes objetivos:

1. Identificar fenotípicamente las BAL aisladas de leche de oveja Guirra.

2. Evaluar la actividad antimicrobiana en presencia y ausencia de células de las BAL aisladas de leche de oveja frente a especies patógenas del hombre como H. pylori y Salmonella spp.

3. Estudiar in vitro el efecto sobre la viabilidad de H. pylori en contacto prolongado con cepas ácido lácticas con actividad antimicrobiana. 
4. Caracterizar las cepas acido lácticas con actividad antimicrobiana frente a H. pylori y Salmonella mediante la técnica de tipado molecular RAPD y perfiles de resistencia a antibióticos.

5. Evaluar in vitro la capacidad de adhesión a la mucina de las cepas acido lácticas que mostraron actividad antimicrobiana frente a los patógenos estudiados.

6. Evaluar in vitro la supervivencia de cepas acido lácticas frente a las condiciones de tránsito gastrointestinal. 
CAPITULO I

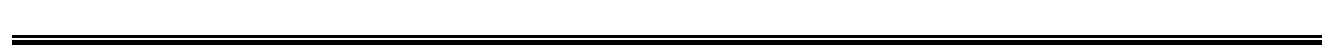

IDENTIFICACIÓN FENOTIPICA DE BACTERIAS ÁCIDO LÁCTICAS AISLADAS DE LECHE DE OVEJA GUIRRA 


\section{INTRODUCCIÓN}

Los métodos clásicos de identificación se basan en el establecimiento de relaciones fenotípicas definidas, en función de las similitudes existentes entre una serie de caracteres expresados por las cepas estudiadas (Logan, 1994). Las características fenotípicas permiten conocer propiedades con validez predictiva. Sin embargo, solo representan una pequeña parte de la información genética y su expresión puede estar influenciada por las condiciones ambientales (Stackenbrant et al., 1983). Los caracteres culturales y morfológicos tienen un valor taxonómico limitado y por esta razón, los métodos tradicionales de identificación se basan especialmente en el estudio de otros como los fisiológicos y los bioquímicos (Logan 1994).

El estudio de la capacidad de fermentar distintos carbohidratos tiene especial importancia en el proceso de identificación de Lactobacillus y otras BAL permitiendo obtener un perfil característico de cada especie (Jacobsen et al. 1999; Tamminen et al., 2004). Los sistemas comerciales que pueden ser usados con este fin son API20 STREP, API 50CHL, VITEK 2 COMPACT (bioMérieux, France), Diabts (Rosco, Denmark), BIOLOG GP MicroPlate (BIOLOG Inc US), los cuales ofrecen bases de datos para la identificación de microorganismos determinados (B. Pot y Tsakalidou, 2009). El sistema API basado en el concepto de la identificación numérica garantiza una identificación microbiana rápida y fiable mediante la combinación de un método sencillo, estandarizado, con bases de datos extensas, específicas y sumamente comprobadas para todos los microorganismos.

Desde 1970 ha sido un método de referencia en la identificación microbiológica, aunque dicha identificación presenta dificultades debido a que la taxonomía es compleja y evoluciona. El número de pruebas bioquímicas necesarias es muy alto ya que las bacterias son organismos vivos que cambian y por tanto, pueden generar perfiles atípicos. La interpretación de este tipo de pruebas puede complicarse y presentar poca reproducibilidad entre distintos laboratorios (Hammes et al., 1990). Incluso se ha detectado una gran 
variabilidad de respuesta entre las cepas pertenecientes a una misma especie (Dykes y Von Holy, 1994). Este hecho, motiva a continuar el proceso de caracterización con métodos moleculares, relevantes en la clasificación bacteriana y que contribuyen con mayor exactitud que los métodos fenotípicos (Ibourahema et al., 2008).

La inestabilidad de las características fenotípicas de las BAL puede estar relacionada con la presencia de plásmidos, fenómeno que obstaculiza estas pruebas en la taxonomía de las BAL (Pot y Tsakalidou, 2009). Algunas cepas presentan una identificación con porcentajes muy bajos o con perfiles dudosos tornándose verde. Lo cual lleva a grandes variaciones en la identificación del microorganismo. Se hace necesario completar estas pruebas con otras técnicas de identificación que trabajen con el ADN y ARN que son elementos químicos cuya composición no cambia en función de las condiciones de crecimiento.

A pesar de estos inconvenientes, es habitual la identificación de BAL aisladas de diferentes matrices mediante el sistema comercial API 50CHL (Ouoba et al., 2009; Todorov y Dicks, 2009; Avila et al., 2010).

Actualmente los productos elaborados con leche de oveja Guirra están presentes en el mercado español en especial la Comunidad Valenciana. La identificación bioquímica de BAL presentes en esta materia prima es básica para entender las propiedades beneficiosas de esta leche ya que dichas propiedades precisamente son atribuibles a la especie de las BAL que contenga. Del mismo modo ya que el objetivo principal de este trabajo es determinar el potencial probiótico de estas BAL, es esencial su identificación fenotípica. 


\section{MATERIAL Y METODOS}

\subsection{Cepas bacterianas}

Se identificaron un total de 139 cepas BAL, de las cuales 131 fueron aisladas de leche de oveja Guirra y 8 cepas provenían de la CECT (Colección Española de Cultivos Tipo). Todas las cepas se sembraron e incubaron en agar MRS (Anexo I) a $37^{\circ} \mathrm{C}$ durante 24 horas, en anaerobiosis (sistema ANAEROGEN, Oxoid).

\subsection{Identificación fenotípica}

Las cepas lácticas fueron identificadas fenotípicamente mediante tinción Gram. El estudio del metabolismo de los hidratos de carbono se realizó con el sistema comercial API50 CHL (BioMérieux). Un cultivo en placa de 24 horas de cada cepa láctica en agar MRS se inoculó en medio 50CH a una concentración de McFarland 2. Se llenaron cada uno de pocillos de la galería cubriéndose la cúpula con vaselina para crear condiciones de anaerobiosis y se incubaron a $37^{\circ} \mathrm{C}$ durante 48 horas. Las reacciones de fermentación ponen de manifiesto el catabolismo de los carbohidratos con formación de ácidos, de manera que al disminuir el pH se produce un viraje del indicador observándose un cambio de color (Figura 1). Finalmente, se obtuvieron diferentes perfiles en la fermentación de carbohidratos, registrándose los resultados correspondientes en la base de datos proporcionada por este sistema, obteniéndose una identificación a nivel de género y especie. 


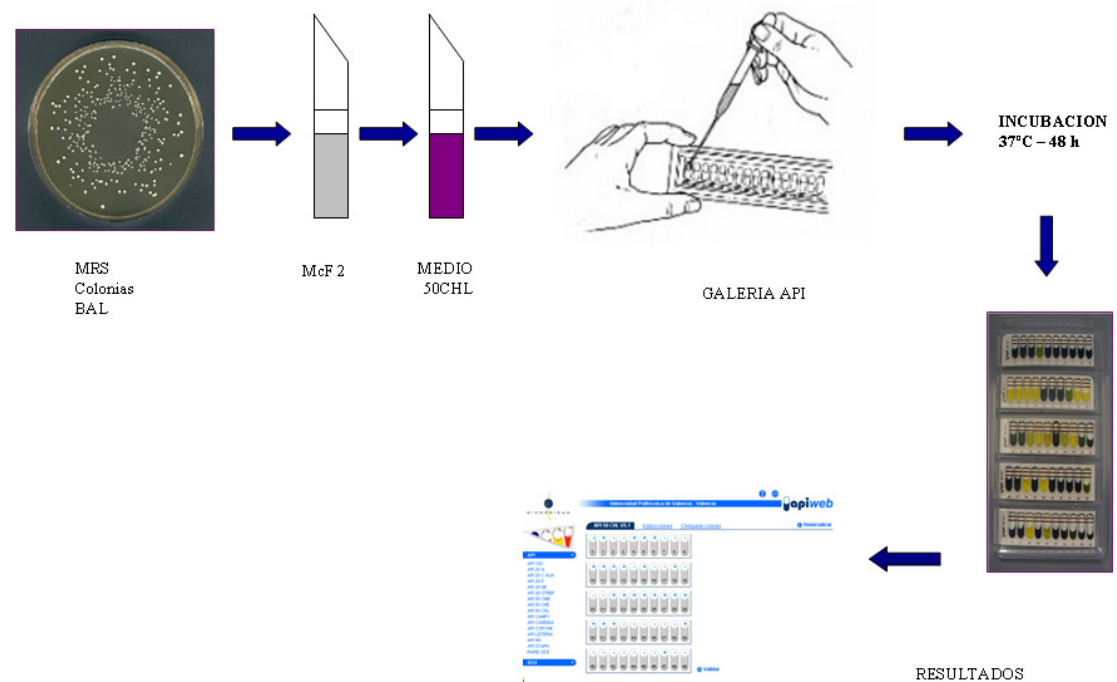

Figura 1. Identificación API 50 CHL

\subsection{Análisis estadístico}

Los resultados de las pruebas bioquímicas fueron analizados por medio del paquete estadístico SPSS versión 15.0. La capacidad de fermentación de las BAL estudiadas estuvo en función de 49 carbohidratos. Inicialemente, la fiabilidad y correlación de dichos datos se midió a partir del indicador estadístico Alpha de Cronbach. Luego, a partir del Análisis Factorial se busca agrupar los carbohidratos que mejor representan estas BAL y para ello, se otorgó un valor numérico de 0 para los resultados negativos, 50 para resultados dudosos y 100 para los positivos. En el análisis se descartaron las pruebas bioquímicas en las que no se presentó ninguna variación entre el conjunto de las BAL.

\section{RESULTADOS}

Las bacterias ácido lácticas aisladas de leche de oveja Guirra fueron identificadas como L. acidophilus, L. brevis, L. delbrueckii lactis, L. delbrueckii delbrueckii, L. paracasei paracasei, L. pentosus, L. plantarum, L. rhamnosus, Lactococcus lactis subsp lactis, 56 
Lactococcus raffinolactis, Leuconostoc mesenteroides mesenteroides y Pediococcus pentosaceus (Tabla 1). Mostrando la variedad de especies presentes en la leche de oveja.

Las especies predominantes fueron Lactococcus lactis subsp lactis, L. plantarum, $L$. paracasei paracasei con poblaciones de 30\%, 27\% y 25\% respectivamente (Figura 2).

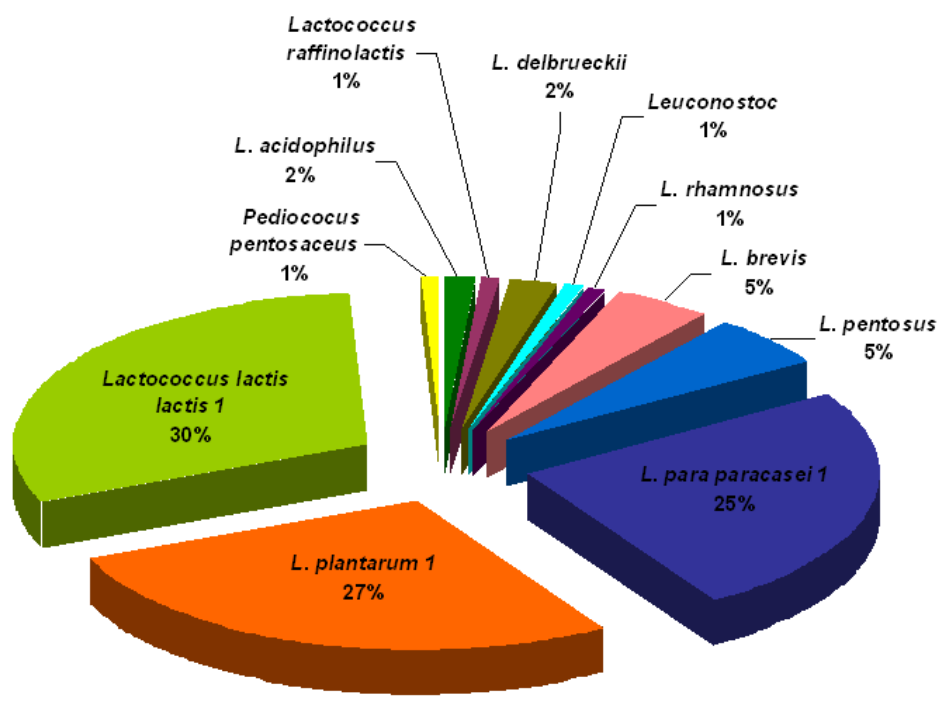

Figura 2. Distribución por especie de las cepas aisladas de leche de oveja Guirra.

Las BAL aisladas de leche de oveja y las pertenecientes a la CECT coinciden en fermentar D-Glucosa y no fermentan D-Arabinosa, L-Xilosa, Xilitol, D-Fucosa y L-Fucosa (Anexo 3). Los resultados obtenidos con API 50 CHL muestran que no hay ningún carbohidrato cuya fermentación permita diferenciar claramente entre Lactobacillus spp., Lactococcus y Leuconostoc. 
Tabla 1. Identificación de Bacterias Acido Lácticas de la CECT y aisladas de leche de oveja Guirra mediante el sistema comercial API-50CHL

\begin{tabular}{|c|c|c|}
\hline IDENTIFICACION API & CEPA & ORIGEN \\
\hline L. casei & CECT475 & QUESO \\
\hline L. delbrueckii bulgaricus & CECT4005T-CECT4006 & YOGUR \\
\hline L. delbrueckii delbrueckii & CECT286 & MEZCLA AGRIA \\
\hline L. paracasei paracasei & CECT4022 & PRODUCTOS LACTEOS \\
\hline L. pentosus & CECT4023 & ENSILADO DE MAIZ \\
\hline L. plantarum & CECT4645 & QUESO \\
\hline L. rhamnosus & CECT278 & PRODUCTOS LACTEOS \\
\hline L. acidophilus 1 & $13 \mathrm{O} 4$ & LECHE OVEJA \\
\hline L. acidophilus 3 & $9 \mathrm{O} 3$ & LECHE OVEJA \\
\hline L. brevis 1 & $509-1209-2004-2104$ & LECHE OVEJA \\
\hline L. brevis 3 & $808-909$ & LECHE OVEJA \\
\hline L. delbrueckii. lactis 1 & $305-1005$ & LECHE OVEJA \\
\hline L. delbrueckii.delbrueckii & $4 \mathrm{~T} 4$ & LECHE OVEJA \\
\hline L. paracasei paracasei 1 & $\begin{array}{c}\text { 1O7-2O11B-3O7-3O10-4O4-4O7- } \\
\text { 5O6-606-7O2-7O5-7O7-7O9-8O5- } \\
\text { 8O10-13O3-10O2-10O3-10O7-10O8- } \\
\text { 1O10-10O11-14O5-14O6-16O6- } \\
\text { 18O4-18O5-19O5-21O5-24O4-4A- } \\
2 \mathrm{~T} 4 \\
\end{array}$ & LECHE OVEJA \\
\hline L. paracasei paracasei 3 & 20O6-23O4 & LECHE OVEJA \\
\hline L. pentosus & 2O7-3O1-3O4-4O1-20O5-22O4-2T2 & LECHE OVEJA \\
\hline L. plantarum 1 & $\begin{array}{c}\text { 1O5-1O9-2O3-2O5-2O11A-3O9- } \\
\text { 3O11-4O8-4O10-5O4-5O7-5O10- } \\
\text { 7O1-8O7-9O7-9O8-10O9-11O11- } \\
\text { 12O5-13O9-15O3-15O5-15O6-16O5- } \\
\text { 17O5-3B-4B-5B-11T1-3T2-5T2 }\end{array}$ & LECHE OVEJA \\
\hline L. plantarum 1 & Q1-Q2-Q3 & QUESO OVEJA \\
\hline L. plantarum & $1105-306$ & LECHE OVEJA \\
\hline L. rhamnosus & $12 \mathrm{O} 3$ & LECHE OVEJA \\
\hline Lactococcus lactis subsp lactis & M3 & LECHE OVEJA \\
\hline Lactococcus lactis subsp lactis 1 & $\begin{array}{c}\text { 1O3-1O4-1O6-1O8-2O4-2O6-2O8- } \\
\text { 2O9-2O11-3O8-4O6-4O9-6O7-6O8- } \\
\text { 6O10-7O8-8O4-9O5-9O11-11O4- } \\
\text { 12O4-13O5A-13O5B-13O6-15O4- } \\
\text { 17O3-18O6-19O6-1A-3A-1B-2B-7B- } \\
\text { M1-M2-M4-1T1-2T1-1T4 }\end{array}$ & LECHE OVEJA \\
\hline Lactococcus raffinolactis & $2 \mathrm{~A}$ & LECHE OVEJA \\
\hline Leuconostoc.mesenteroides.mesenteroides & 13011 & LECHE OVEJA \\
\hline Pediococcus pentosaceus & D1 & LECHE OVEJA \\
\hline
\end{tabular}


En el análisis de fiabilidad, el Alfa de Cronbach obtenido es de 0.844. A partir del Análisis de Componentes Principales (ACP), la información se sintetiza en 5 factores (Tabla 2), las variables están suficientemente correlacionadas al mostrar KMO 0.671 y $\mathrm{p}<0.01$. Los factores 1 y 2 contienen los carbohidratos que fermentan la mayoría de cepas. El factor 3 presenta azúcares que son fermentados por la mitad de la colección de las BAL. El factor 4 muestra que D-rafinosa es fermentado por unas pocas cepas de bacterias y el factor 5, muestra que la colección de bacterias, coinciden en no fermentar 2-ceto gluconato potásico. Estos resultados indican que solo 12 de los 43 datos de pruebas bioquímicas logran acumular una variabilidad de $93 \%$ permitiendo desestimar aquellos datos que no aportan ninguna explicación a la variabilidad observada. El signo positivo muestra que la relación es directamente proporcional a la fermentación de dichos azúcares. El análisis de componentes principales permite establecer relaciones entre variables y agrupa los individuos de acuerdo a sus semejanzas.

La representación gráfica de las cepas analizadas y su separación en grupos de acuerdo a su relación con los factores F1-F2 se puede observar en la Figura 3. L. acidophilus, L. brevis, L. delbrueckii aparecen aislados, mientras que el resto de las cepas aparecen inmersas en un gran grupo que no permite una clara discriminación de las especies. El ideal en un ACP (Análisis de Componentes Principales) es que exista tal correlación entre las variables que con sólo los dos primeros factores se alcanzase una variabilidad mayor a la obtenida en este caso, y que los individuos pudiesen ser agrupados más eficientemente. Los resultados de los análisis estadísticos realizados nos indican que las pruebas fenotípicas no aportan la suficiente información para la clasificación de las cepas analizadas. El escaso valor discriminativo que tienen en taxonomía las pruebas fenotípicas para el complejo de $L$. acidophilus fue observado anteriormente por otros autores (Berger et al., 2007). 
Tabla 2. Matriz de componentes rotados.

\begin{tabular}{|c|c|c|c|c|c|}
\hline \multirow[b]{2}{*}{ CARBOHIDRATOS } & \multicolumn{5}{|c|}{ COMPONENTES - FACTORES } \\
\hline & $\begin{array}{c}1 \\
\text { Fermentación } \\
\text { total }\end{array}$ & $\begin{array}{c}2 \\
\text { Fermentación } \\
\text { máxima }\end{array}$ & $\begin{array}{c}3 \\
\text { Fermentación } \\
\text { media }\end{array}$ & $\begin{array}{c}4 \\
\text { Fermentación } \\
\text { baja }\end{array}$ & $\begin{array}{c}5 \\
\text { Sin } \\
\text { Fermentación }\end{array}$ \\
\hline Salicina & & 0.961 & & & \\
\hline D-celobiosa & & 0.961 & & & \\
\hline Esculina & & 0.946 & & & \\
\hline $\mathrm{N}$-acetil glucosamina & & 0.941 & & & \\
\hline Gentiobiosa & & 0.931 & & & \\
\hline Arbutina & & 0.835 & & & \\
\hline D-melezitosa & & & 0.953 & & \\
\hline D-tagatosa & & & 0.938 & & \\
\hline D-sorbitol & & & 0.682 & & \\
\hline D-rafinosa & & & & 0.947 & \\
\hline D-fructosa & 0.967 & & & & \\
\hline $\begin{array}{l}\text { 2-ceto Gluconato } \\
\text { potásico }\end{array}$ & & & & & 0.989 \\
\hline
\end{tabular}


Observaciones F1 y F2 63\%

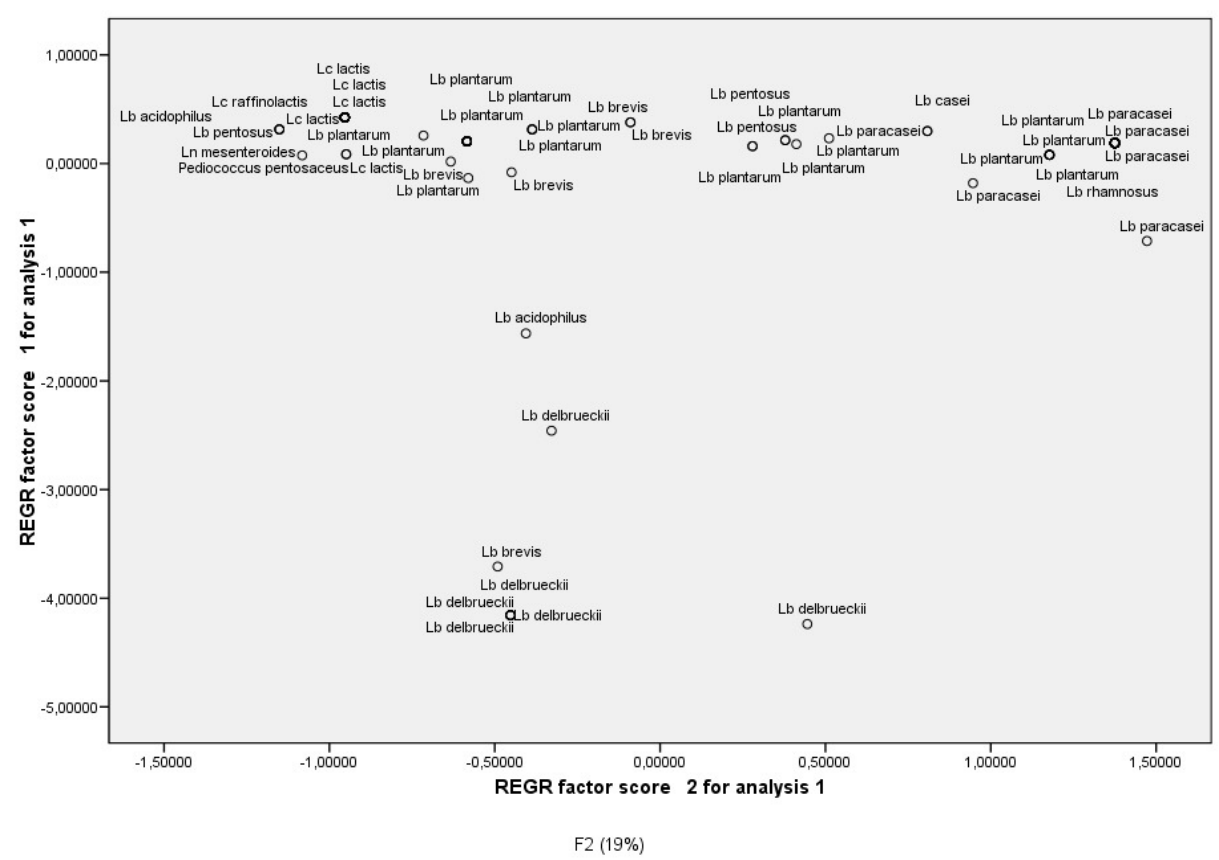

Figura 3. Agrupación de las cepas estudiadas de acuerdo al análisis de componentes principales.

\section{DISCUSIÓN}

Este sistema de identificación bioquímica es de metodología estandarizada, composición constante, cumple con las normas FDA, evita preparación, almacenado y manipulación de medios. La metodología es simple y estandarizada, maneja el mismo principio en todas las técnicas de identificación y resulta ser más rápido que otros métodos convencionales. Aunque, como algunos autores afirman (Pot y Tsakalidou, 2009), los patrones de fermentación de carbohidratos presentan algunas desventajas como las variaciones entre cepas de la misma especie y el largo tiempo de obtención de resultados respecto a las nuevas técnicas de identificación. 
Las especies de las BAL aisladas con más frecuencia en queso son Lactococcus lactis subsp lactis, Leuconostoc mesenteroides mesenteroides, L. paracasei paracasei, L. plantarum, Leuconostoc Pseudomesenteroides, Enterococcus faecalis, predominando Lactococcus lactis subsp lactis (L. González et al., 2010), al igual que en el presente estudio. La identificación bioquímica de la colección de las BAL estudiadas mostró la variedad de especies presentes en la leche de oveja Guirra. Según otros autores, cepas pertenecientes a $L$. acidophilus, L. brevis, L. casei, L. delbrueckii, L. plantarum, L. paracasei, L. reuteri, L. salivarius, Lactococcus lactis, Lactococcus raffinolactis y Pediococcus pentosaceus presentaron características probióticas (Ushiyama et al., 2003; Saggioro et al., 2005; Warren et al., 2007; Hagi y T. Hoshino 2009; Ljungh y Wadström, 2009; Verdenelli et al., 2009; Hynönen et al., 2010; Martínez-Cuesta et al., 2010; Smaoui et al., 2010). Por tanto, es de especial interés estudiar dichas propiedades en la colección de BAL del presente estudio que incluyen las especies citadas.

El conocimiento de la capacidad de fermentación de cada cepa frente a diversos azúcares, es muy útil en caso de que estas cepas vayan a ser empleadas en productos alimenticios, donde se busque mejorar, modificar o innovar características particulares. El conjunto de carbohidratos fermentados por las BAL han variado en cepas de la misma especie.

En conclusión, el sistema de identificación API 50 CHL proporciona información a nivel de género y especie. Sin embargo, no distingue entre especie y cepa. La identificación a nivel de cepa es importante porque los efectos beneficiosos que puedan tener estas bacterias sobre la salud humana no se pueden atribuir de forma generalizada a un género o especie, sino que depende de la cepa. 
EVALUACION DE LA ACTIVIDAD ANTIMICROBIANA DE BACTERIAS ÁCIDO LÁCTICAS AISLADAS DE LECHE DE OVEJA GUIRRA 


\section{INTRODUCCIÓN}

H. pylori esta implicado en la aparición de la úlcera péptica y está estrechamente relacionado con el desarrollo de cáncer gástrico (Vale y Vítor, 2010; Moreno et al., 2003). Salmonella es una especie patógena que causa enfermedades digestivas, puede ser trasmitida por alimentos, especialmente de origen animal, aves de corral, entre otros. Produce diarrea y puede causar severas enfermedades como inflamación en el íleon y el colón, incluso la muerte en humanos (Hütt et al., 2006; Goyal et al., 2008; Maragkoudakis et al., 2009). Las infecciones y enfermedades gastrointestinales inflamatorias producidas por $H$. pylori y Salmonella se vienen tratando con antibióticos, no siempre dan resultado y pueden ocasionar resistencias (Olivares et al., 2006). Algunas cepas pertenecientes a Salmonella, especialmente el serotipo typhimurium han incrementado la multi-resistencia a antibióticos (Fluit, 2005). La presencia de estas cepas en los alimentos representa un peligro para el consumidor, por ello, sería de gran interés encontrar otros métodos alternativos para tratar las infecciones producidas por estos patógenos. En los últimos años, con el fin de reducir la posibilidad de adquirir estas infecciones en las poblaciones de riesgo, se están estudiando con más énfasis bacterias probióticas ácido lácticas que podrían representar una alternativa al uso de antibióticos (Murry et al., 2004). Algunos estudios han comprobado la efectividad inhibitoria de las BAL probióticas frente a algunas cepas de H. pylori y Salmonella disminuyendo la inflamación en la mucosa gástrica, reduciendo el riesgo y la duración de diarrea en adultos y niños (Sigrid et al., 2006; Keohane et al., 2009; Thirabunyanon et al., 2009).

Las BAL son parte de la microbiota intestinal, tienen una serie de influencias fisiológicas sobre sus hospedadores como la interacción competitiva frente a patógenos, producción de productos antimicrobianos, interferencia microbiana, los efectos suplementarios en la nutrición, efectos antitumorales, reducción del colesterol, repercusión en el sistema inmunológico y señalización anti-inflamatoria (Ikeda et al., 2007; Keohane et 
al., 2009). Las especies de Lactobacillus y Lactococcus son empleados frecuentemente en alimentos por su potencial probiótico.

Para demostrar la funcionalidad y seguridad de las nuevas cepas antes de ser aplicadas en alimentos, es necesario realizar ensayos in vitro (Maragkoudakis et al., 2009). De este modo, se ha encontrado que la actividad antagónica es específica de la cepa y está relacionada con la presencia de células lácticas en algunos casos ó ácidos orgánicos y bacteriocinas (Mejía et al., 2007).

Uno de los objetivos de este trabajo es evaluar la actividad antimicrobiana de cepas BAL aisladas de la leche de oveja Guirra frente a cepas patógenas de las especies H. pylori, S. enterica, S. typhimurium y S. enteritidis y compararla con la de las cepas de referencia de la CECT incluidas en este trabajo.

\section{MATERIAL Y METODOS}

\subsection{Bacterias ácido lácticas}

En el presente estudio se incluyeron 131 cepas de las BAL aisladas de leche de oveja Guirra y 8 cepas de referencia de la CECT (Colección Española de Cultivos Tipo), mencionadas en el capitulo anterior.

\subsection{Bacterias patógenas}

Se utilizaron 6 cepas bacterianas patógenas de diversos orígenes. Las cepas de $H$. pylori (Tabla 1) y Salmonella procedían de muestras clínicas, alimentos y de referencia (Tabla 2). 
Tabla 1. Cepas de H. pylori

\begin{tabular}{|l|l|l|}
\hline BACTERIA & CEPA & ORIGEN \\
\hline \hline Helicobacter pylori & $\begin{array}{l}\text { NCTC* } \\
11637\end{array}$ & GASTRICO \\
& HUMANO \\
\hline \hline Helicobacter pylori & B6 & BIOPSIA \\
\hline
\end{tabular}

* National Collection of Type Cultures

Tabla 2. Cepas de Salmonella spp.

\begin{tabular}{|c|c|c|}
\hline BACTERIA & CEPA & ORIGEN \\
\hline $\begin{array}{l}\text { Salmonella enterica } \\
\text { subsp. enterica }\end{array}$ & CECT915 & INTESTINO \\
\hline Salmonella enteritidis & S58 & $\begin{array}{l}\text { LMU* } \\
\text { CLINICO }\end{array}$ \\
\hline Salmonella typhimurium & $\mathrm{S} 134$ & $\begin{array}{l}\text { LMU } \\
\text { ALIMENTARIO }\end{array}$ \\
\hline Salmonella enteritidis & $\mathrm{S} 135$ & $\begin{array}{l}\text { LMU } \\
\text { HECES }\end{array}$ \\
\hline
\end{tabular}

* Laboratorio de Microbiología de Alimentos UPV.

\subsection{Evaluación de actividad antimicrobiana de las BAL}

Se estudió el impacto de la presencia y ausencia de células BAL frente a los patógenos H. pylori y Salmonella spp.

\subsubsection{Método de discos}

Se empleó la técnica de discos según Yuan Kun (2006) con algunas modificaciones para evaluar la inhibición de los patógenos en presencia de células de las BAL. 


\subsubsection{Helicobacter pylori}

Las cepas de H. pylori se sembraron en placas de Agar Sangre de Caballo (ASC) suplementadas con un $10 \%$ con sangre desfibrinada de caballo y se incubaron a $37^{\circ} \mathrm{C}$ durante 48 horas en condiciones de microaerofilia (Bathia et al., 1989) (Anexo I y II).

Después de la incubación, cada cepa de H. pylori se resuspendió en caldo Brucella (Anexo I) y se midió su absorbancia en el espectrofotómetro (Spectronic 20 Genesys) a 550 $\mathrm{nm}$ hasta obtener una densidad óptica correspondiente a $1 \times 10^{9} \mathrm{UFC} / \mathrm{ml}$. Se tomó una alícuota de $100 \mu \mathrm{l}$ de la suspensión y se extendió sobre una placa de agar ASC con una torunda estéril.

De cada cepa ácido láctica se obtuvieron discos de $8 \mathrm{~mm}$ de diámetro cortandolos directamente con un sacabocados estéril de un cultivo en masa de 24 horas en agar MRS. Los discos se depositaron sobre la placa de agar ASC donde previamente se había extendido $H$. pylori. Las placas se incubaron a $37^{\circ} \mathrm{C}$ durante 48 horas en condiciones de microaerofilia. Se utilizó como control negativo un disco de agar MRS sin cultivo de bacteria láctica. Transcurrido el tiempo se procedió a medir los halos de inhibición en los casos que correspondía. Cada ensayo se realizó por triplicado (Figura 1). 


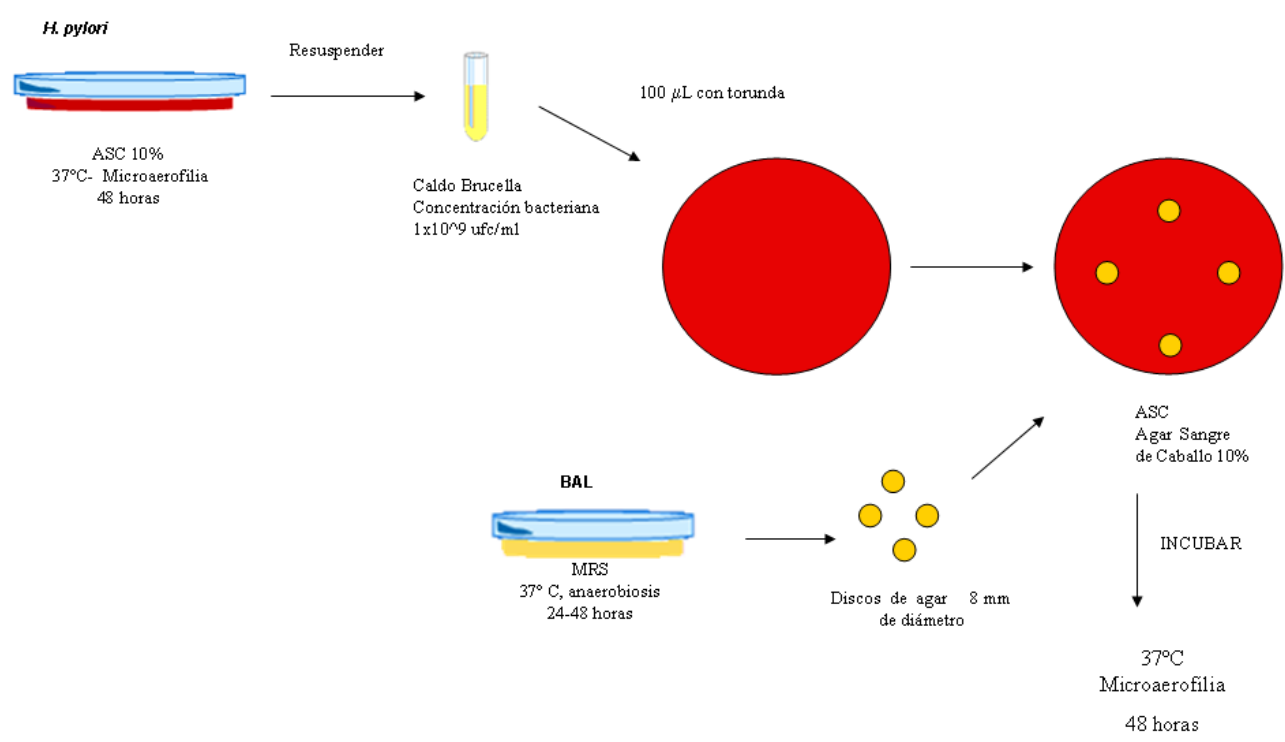

Figura 1. Diseño del ensayo de actividad antimicrobiana contra $H$. pylori en presencia de células viables de BAL.

\subsubsection{Salmonella spp.}

Las cepas de Salmonella se sembraron en agar para recuento en placa (Plate Count Agar) (Anexo I) y se incubaron a $37^{\circ} \mathrm{C}$ durante 24 horas.

Parte del cultivo de 24 horas se resuspendió en un tubo de $5 \mathrm{ml}$ de PBS $1 \mathrm{X}$ y se ajustó según escala de McFarland $2\left(6.0 \times 10^{8} \mathrm{UFC} / \mathrm{ml}\right)$. Se tomó $100 \mu \mathrm{l}$ de dicha suspensión y se trasfirió a tubos que contenían caldo nutritivo en estado semisólido ( $0.7 \%$ agar), se agitó en vortex y se vertió todo el contenido en placas de agar TSA (Anexo I). Se esperó hasta que solidificara el agar semisólido.

Del mismo modo que para el ensayo con H. pylori, los discos de $8 \mathrm{~mm}$ de cada cepa láctica se depositaron sobre la placa de agar TSA con la cepa de Salmonella una vez hubo solidificado. Se incubó a $37^{\circ} \mathrm{C}$ durante 24 horas en aerobiosis. El control negativo de nuevo 
fue un disco de agar MRS sin cultivo de bacteria láctica. Transcurrido el tiempo se procedió a medir los halos de inhibición en los casos correspondientes. Cada ensayo se realizó por triplicado (Figura 2).

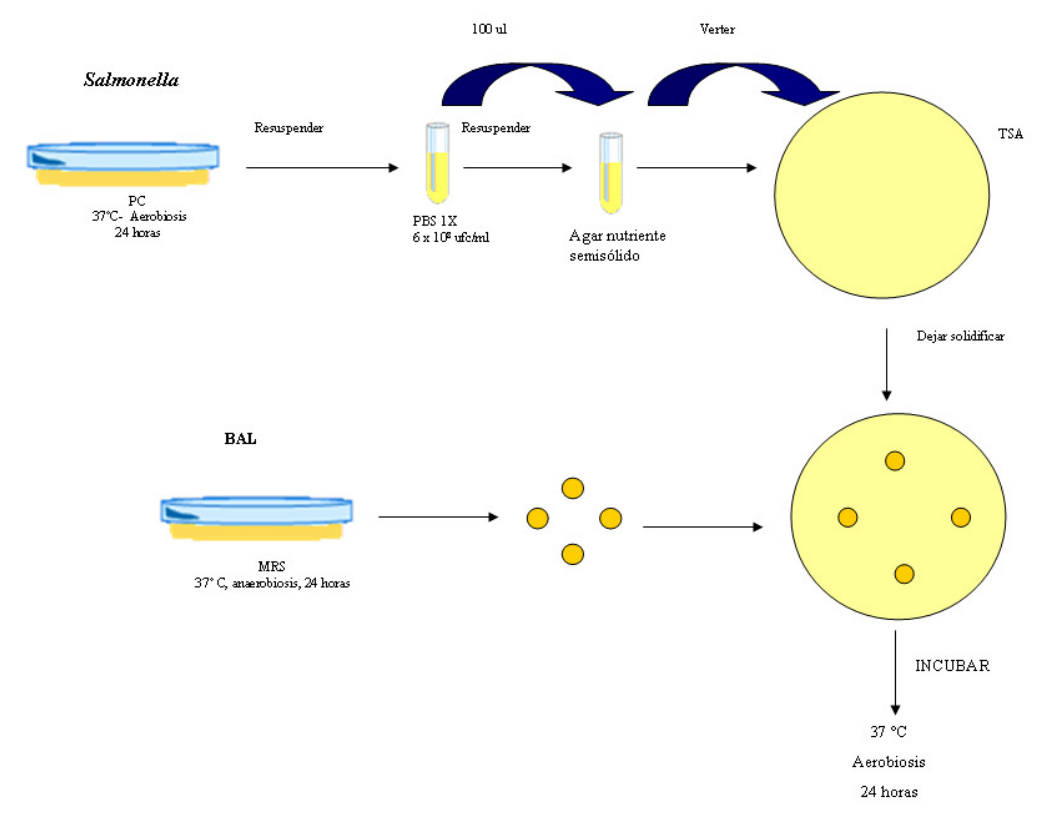

Figura 2. Diseño del ensayo de actividad antimicrobiana contra Salmonella en presencia de células viables de BAL.

\subsubsection{Método del sobrenadante en pocillos}

Este método se utilizó para evaluar la inhibición de los patógenos debido a los productos generados por las BAL y en ausencia de las células lácticas (Yuan Kun, 2006). A partir de un cultivo de 24 horas de cada cepa láctica en agar MRS, se inoculó una alícuota en tubos de $10 \mathrm{ml}$ de caldo MRS que se incubó a $37^{\circ} \mathrm{C}$ en condiciones de anaerobiosis. Después de 24 horas, se tomó una alícuota de $2 \mathrm{ml}$ del cultivo líquido, que se centrifugó a $10.000 \mathrm{rpm}$, durante 10 minutos a $4^{\circ} \mathrm{C}$. Con el propósito de eliminar las células, el sobrenadante obtenido se esterilizó mediante el uso de filtros con membrana de nitrocelulosa y $0.22 \mu \mathrm{m}$ de tamaño 
de poro (Milipore, Bedford, MA). A continuación, se evaporó en el equipo Concentrator 3501 (Eppendorf) hasta un 70\% del volumen para concentrar el sobrenadante y se almacenó a $-20^{\circ} \mathrm{C}$ hasta su posterior uso.

Los ensayos con sobrenadante se realizaron a $\mathrm{pH}$ a 4.5 y a $\mathrm{pH} 7$ ajustando con $\mathrm{NaOH} 1 \mathrm{~N}$.

\subsubsection{Helicobacter pylori}

Mediante un sacabocados estéril, se diseñaron pocillos de $8 \mathrm{~mm}$ de diámetro en placas de agar ASC con un cultivo de H. pylori de 48 horas. En cada pocillo se adicionó 50 $\mu l$ de cada sobrenadante obtenido como se ha descrito anteriormente (2.3.2). El control negativo consistió en caldo MRS sin cultivo.

Las placas se incubaron a $37^{\circ} \mathrm{C}$, durante 48 horas en condiciones de microaerofilia. Transcurrido dicho tiempo se procedió a medir halos de inhibición alrededor de los pocillos. Cada ensayo se realizó por triplicado (Figura 3). 


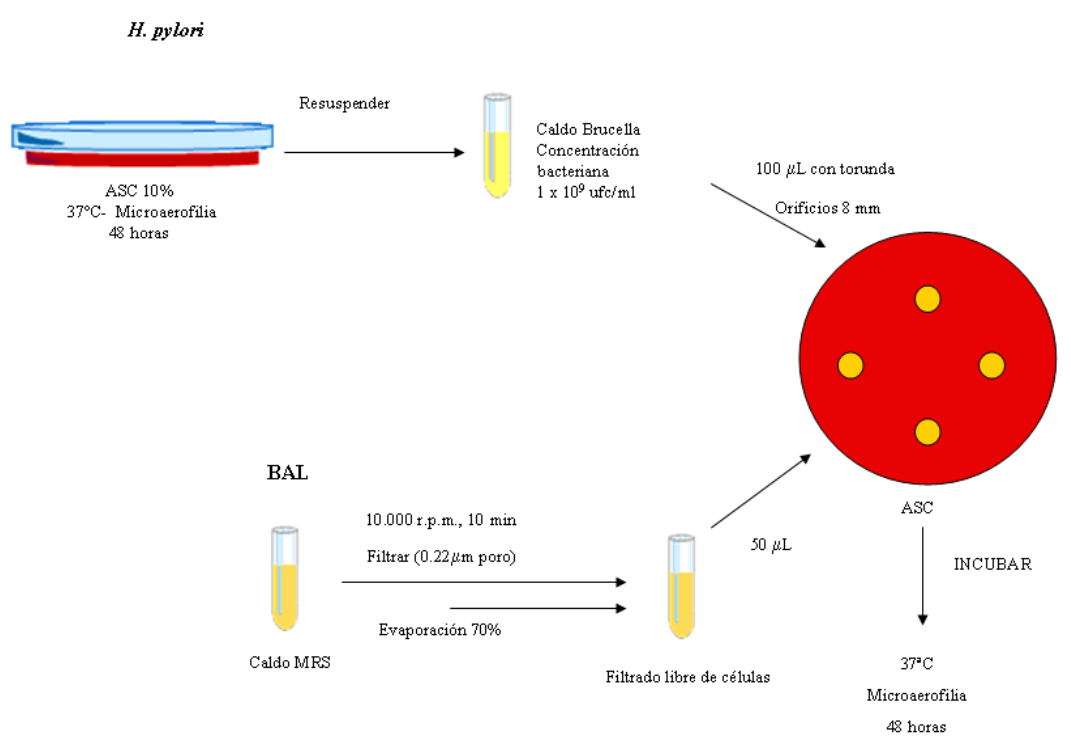

Figura 3. Diseño del ensayo de actividad antimicrobiana en ausencia de células. $H$. pylori frente a las sustancias producidas por BAL.

\subsubsection{Salmonella spp.}

Del mismo modo que para H. pylori, se hicieron pocillos en la placa de agar TSA donde previamente se había extendido el agar nutriente semisólido con la concentración correspondiente de Salmonella, como se explicó en el apartado 2.3.1.2. En cada pocillo se adicionó $50 \mu \mathrm{l}$ de cada sobrenadante. El control negativo fue el caldo MRS sin bacteria láctica.

Las placas se incubaron a $37^{\circ} \mathrm{C}$, durante 24 horas en condiciones de aerobiosis. Transcurrido dicho tiempo se procedió a medir los halos alrededor de los pocillos en los casos en los que se presentó la inhibición. De igual modo, cada ensayo se realizó por triplicado (Figura 4). 


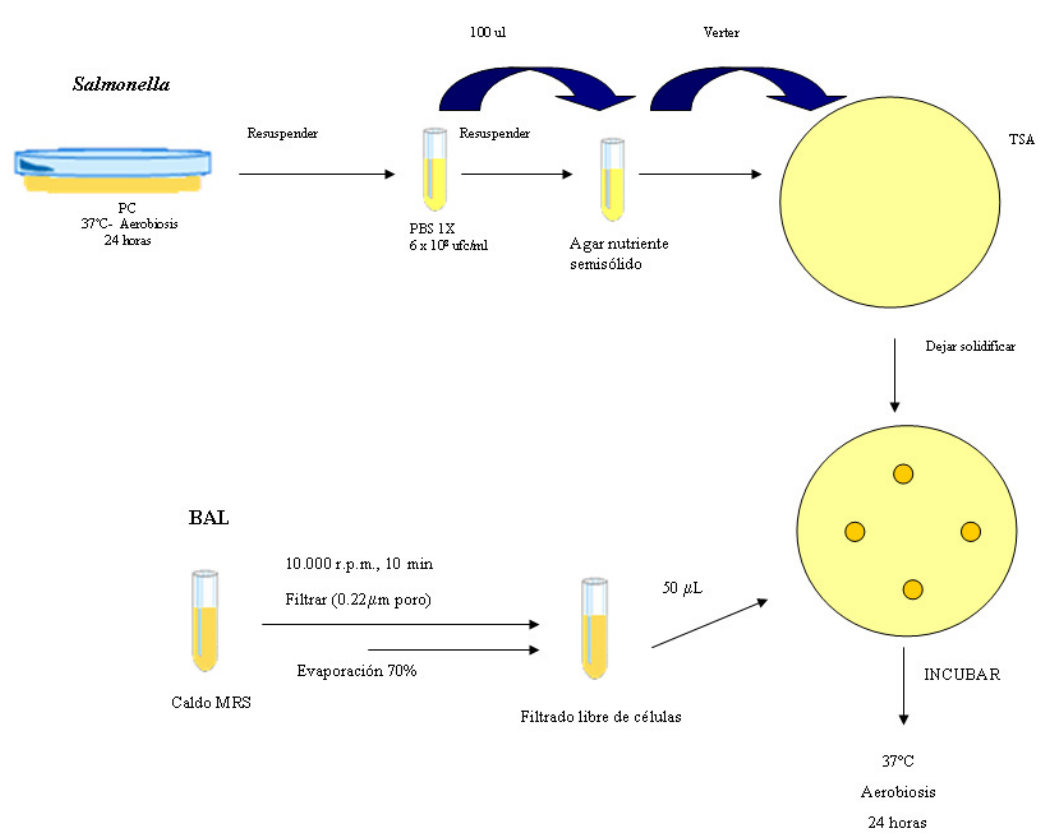

Figura 4. Diseño del ensayo de actividad antimicrobiana en ausencia de células. Salmonella frente a las sustancias producidas por BAL.

\subsection{Análisis Estadístico}

El análisis estadístico se hizo con el empleo del programa informático StatGraphics plus 5.1 y SPSS 15.0. Se realizó un análisis de varianza simple (ANOVA) para los datos de inhibición en cada uno de los tratamientos y entre tratamientos, el cual efectuó varios tests y gráficos para comparar los valores medios entre los diámetros de inhibición para los tres tratamientos. El F-test en la tabla ANOVA comprueba si existe alguna diferencia significativa entre medias. Si hay, los tests de Rangos múltiples indicarán las medias que son significativamente diferentes. En caso de presentarse valores atípicos se elige el test no paramétrico de Kruskal-Wallis que compara las medianas en lugar de las medias. Las diferencias entre medias o medianas fueron consideradas significativas cuando $\mathrm{p}<0.05$. 


\section{RESULTADOS}

Los métodos empleados fueron: el primero en presencia de las células BAL, el segundo en ausencia de células BAL a pH 4.5 y el tecero en ausencia de células BAL a pH 7.

Los resultados de inhibición de las diferentes BAL frente a los patógenos H. pylori y Salmonella spp. obtenidos de los diferentes ensayos se muestran en Anexo 4. En un total de 18 ensayos independientes se emplearon 2 cepas de H. pylori y 4 cepas de Salmonella utilizando los 3 métodos mencionados anteriormente. En las tablas y gráficos se reflejan solo 14 tratamientos porque los otros 4 no presentaron inhibiciones con el método de ausencia de células de las BAL a pH 7 contra todas las cepas de Salmonella spp.

\subsection{Actividad antimicrobiana frente a $\mathrm{H}$. pylori}

\section{Método discos}

Los resultados de inhibición antimicrobiana (Figura 5) muestran que 55 de 131 cepas aisladas de leche de oveja inhibieron la cepa B6 en presencia de células, predominando entre las especies L. paracasei paracasei (30\%), Lactococcus lactis subsp lactis (27\%) y L. plantarum (25\%) (Figura 6). La presencia de células de las cepas de referencia L. casei (CECT475), L. delbrueckii bulgaricus (CECT4006), L. delbrueckii delbrueckii (CECT286), L. pentosus (CECT4023), L. paracasei (CECT4022), L. plantarum (CECT4645), L. rhamnosus (CECT278) también tuvieron efecto inhibitorio frente a H. pylori $\mathrm{B} 6$. 


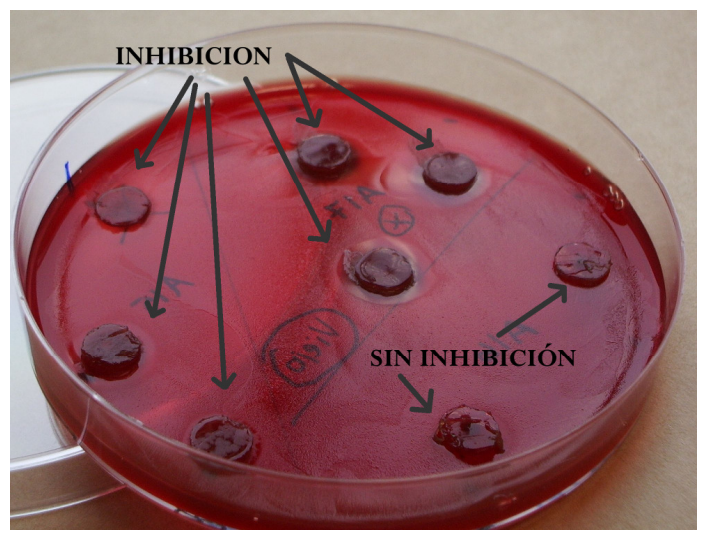

Figura 5. Ensayo de inhibición H. pylori B6 en presencia células de las BAL

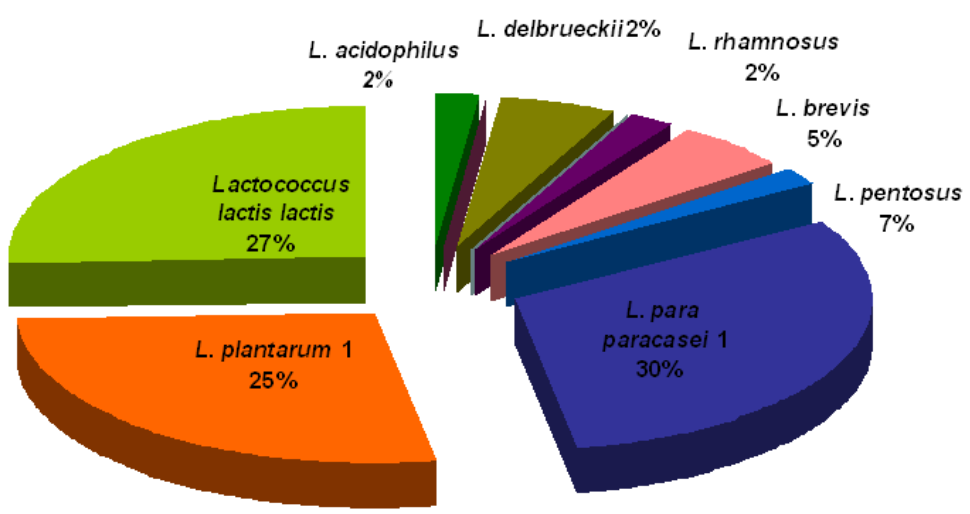

Figura 6. Inhibición de H. pylori B6 por presencia de células de las BAL aisladas de leche de oveja.

87 de las 131 cepas aisladas de leche de oveja (Figura 7) y las cepas de referencia $L$. casei (CECT475), L. delbrueckii bulgaricus (CECT4005), L. paracasei paracasei (CECT4022), L. pentosus (CECT4023), L. rhamnosus (CECT278) inhibieron el crecimiento de la cepa NCTC11637 en presencia de células. 


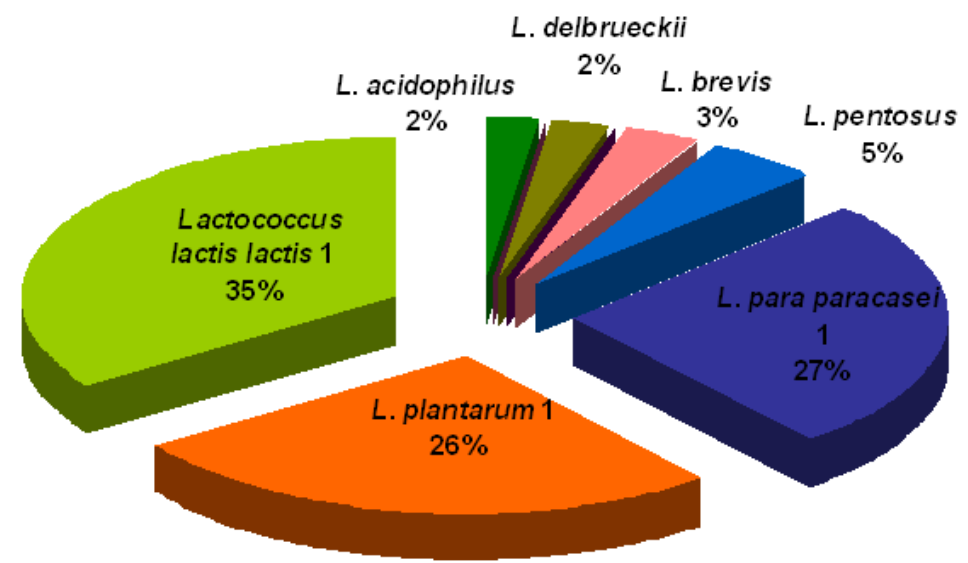

Figura 7. Inhibición de H. pylori NCTC11637 en presencia de células por las BAL aisladas de leche de oveja.

\section{Método del sobrenadante en pocillos}

En ausencia de células a pH 4.5 (Figura 8), un menor número de cepas BAL (11 de 131) mostraron efecto inhibitorio frente a $H$. pylori B6. Al igual que en el método anterior, destacaron las especies L. plantarum (28\%), Lactococcus lactis subsp lactis (27\%) y L. paracasei paracasei (18\%) (Figura 9). Las sustancias producidas por las cepas de referencia L. casei (CECT475), L. delbrueckii delbrueckii (CECT286), L. paracasei paracasei (CECT4022), L. plantarum (CECT4645), L. rhamnosus (CECT278) destacaron por su actividad antimicrobiana. A pH 7, solo 2 cepas de leche de oveja L. rhamnosus (12O3) y L. brevis (2004) mostraron la actividad antimicrobiana frente a H. pylori B6 (Figura 10). 


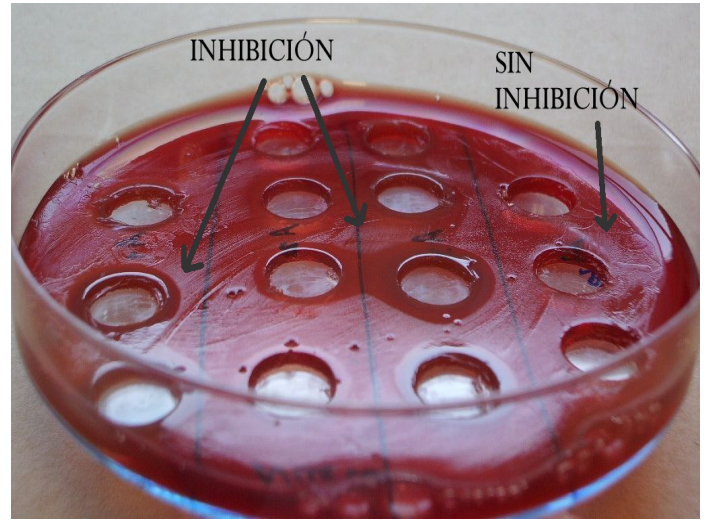

Figura 8. Ensayo de inhibición H. pylori B6 ausencia células de las BAL.

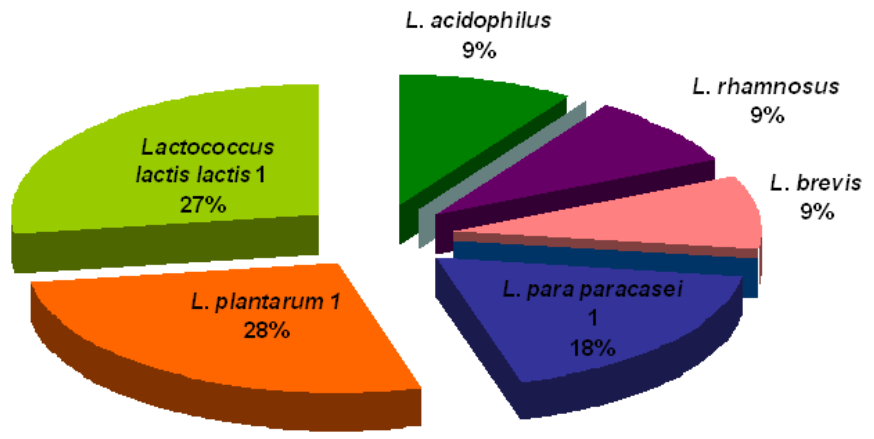

Figura 9. Inhibición de $H$. pylori B6 en ausencia de células de las BAL aisladas de leche de oveja. 


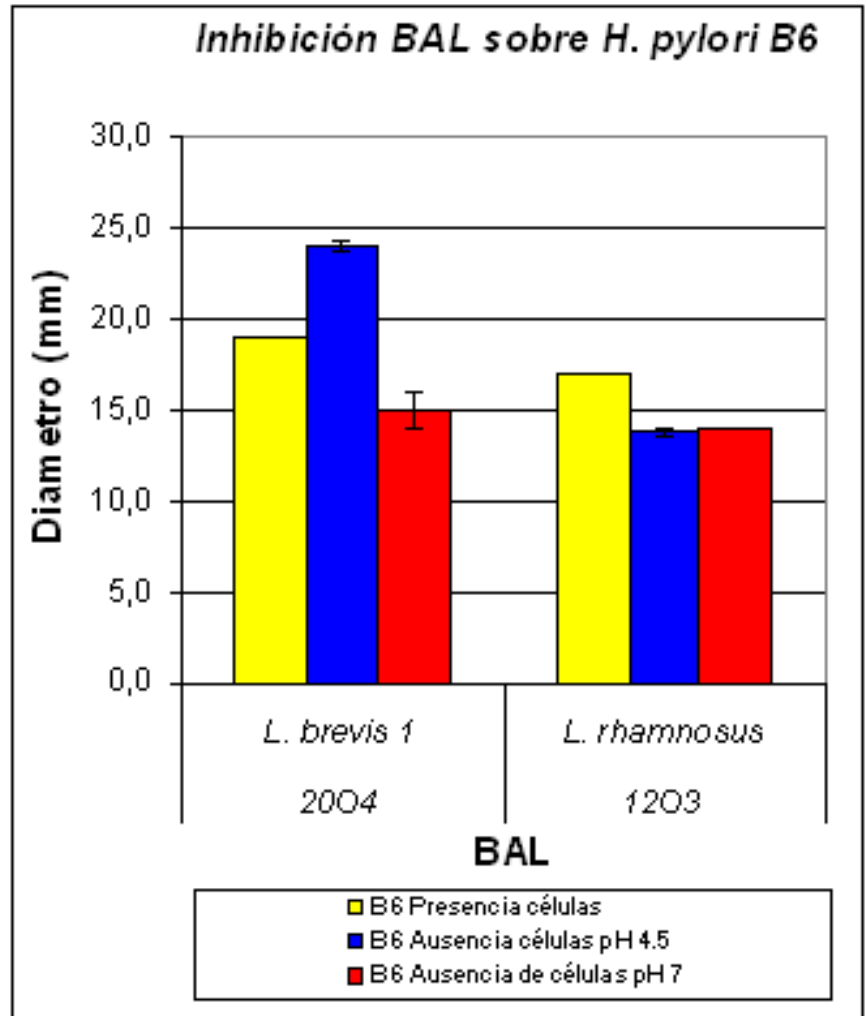

Figura 10. Actividad antimicrobiana de las BAL en presencia, ausencia de células sobre $H$. pylori B6 a pH 4.5 y 7.

Por tanto, el $42 \%$ de las cepas de oveja inhibieron $H$. pylori B6 en presencia de células mostrando diámetros entre 11 y $22 \mathrm{~mm}$ mientras que el $8 \%$ de las cepas inhibieron B6 en presencia y ausencia de células (diámetros de 13.8 a $24 \mathrm{~mm}$ ). Tan solo $1.5 \%$ de las cepas aisladas de leche de oveja mantuvieron la actividad antimicrobiana sobre $\mathrm{B} 6 \mathrm{a}$ pH 4.5 y 7 (diámetros de 14-15 mm).

La cepa de referencia NCTC11637 resultó sensible al 66\% de las BAL aisladas de leche de oveja en presencia de células (diámetros de 11.3 a $21.3 \mathrm{~mm}$ ), 56\% de las BAL 
fueron efectivos con el sobrenadante a pH 4.5 (diámetros de 12.3 a $24.5 \mathrm{~mm}$ ) y solo un $11 \%$ de las BAL presentaron acción inhibitoria a pH 4.5 y pH 7 (diámetros de 10-14 mm).

De acuerdo al análisis estadístico, el test de Kruskal-Wallis aplicado entre los métodos presencia, ausencia de células a pH 4.5 y 7 mostraron que hay diferencia significativa $(\mathrm{p}<0.05)$ entre los métodos utilizados (Figura 11). Los porcentajes y las frecuencias de inhibición de las BAL (aisladas de leche y CECT) estudiadas en cada tratamiento se muestran en la tabla 3.

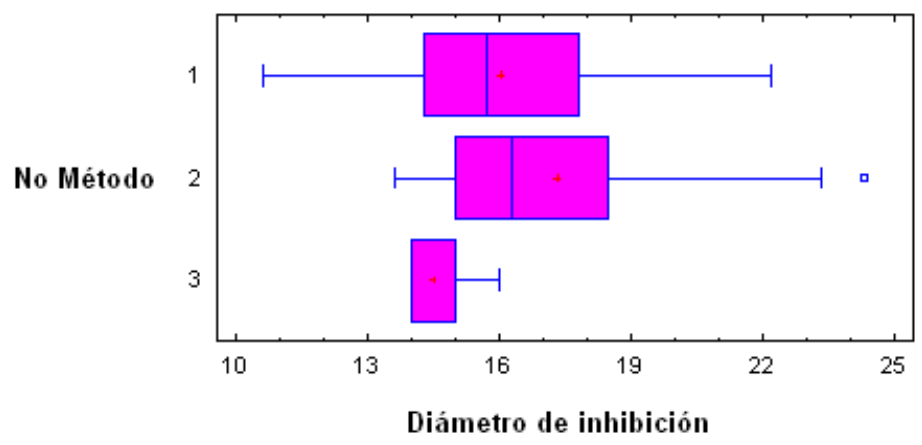

Figura 11. Comparación entre métodos aplicados a la inhibición de las BAL frente a $H$. pylori B6. No Método: 1: Presencia de células. 2: Ausencia de células pH 4.5. 3: Ausencia de células pH 7. 
Tabla 3. Porcentaje de inhibición de las BAL aisladas de leche de oveja y de cepas de la CECT frente a la cepa $\mathrm{B} 6$ de $\boldsymbol{H}$. pylori en cada método.

\begin{tabular}{|c|c|c|c|c|}
\hline & & & \multicolumn{2}{|c|}{ Inhibición frente B6 } \\
\hline & & & $\begin{array}{l}\text { No } \\
\text { inhibe }\end{array}$ & Inhibe \\
\hline \multirow{6}{*}{ Método } & \multirow[t]{2}{*}{ 1:DISCOS } & $\begin{array}{l}\text { Número cepas de las } \\
\text { BAL }\end{array}$ & 77 & 62 \\
\hline & & \% de Método & $55.4 \%$ & $44.6 \%$ \\
\hline & \multirow[t]{2}{*}{ 2: SOBRENADANTE pH 4.5} & Número cepas de las BAL & 123 & 16 \\
\hline & & \% de Método & $88.5 \%$ & $11.5 \%$ \\
\hline & \multirow[t]{2}{*}{ 3: SOBRENADANTE pH 7} & Número cepas de las BAL & 137 & 2 \\
\hline & & \% de Método & $98.6 \%$ & $1.4 \%$ \\
\hline
\end{tabular}

Chi-cuadrado de Pearson 274.329. $\mathrm{p}<0.05$ ( $\mathrm{El} \chi^{2}$ dice que hay diferencia entre los métodos)

Para determinar los porcentajes de eficacia de cada cepa láctica frente al patógeno en los tres métodos, se asignaron valores de 1 a los casos donde hubo inhibición y 0 en los casos de no inhibición. De este modo, se encontraron diferencias significativas entre cepas lácticas. En el caso de H. pylori B6, hay 77 cepas BAL que no inhiben, 47 presentaron inhibición en el 33\% de los ensayos realizados y 13 cepas, 1104, 1906, 204 de Lactococcus lactis subsp lactis, 1O10, CECT4022, 404 de L. paracasei, CECT4645, 4B, Q2, Q3 de L. plantarum, L. rhamnosus CECT278, CECT286 L. delbrueckii delbrueckii, CECT475 L. casei, y 903 L. acidophilus presentaron $67 \%$ de inhibición en los tratamientos probados. Destacaron las cepas $12 \mathrm{O} 3$ y $20 \mathrm{O} 4$ ya que inhibieron en todos los métodos probados frente a H. pylori B6.

Para H. pylori NCTC11637, hay 47 cepas de BAL que no inhiben, 15 presentaron inhibición en el 33\% de los ensayos realizados y 62 cepas mostraron el 67\% de inhibición en los métodos probados (Porcentajes de inhibición positivos de las cepas BAL frente al patógeno en todos los tratamientos y repeticiones). Quince cepas se destacaron ya que inhibieron en todos los métodos probados (Anexo 4). 
El sobrenadante de 73 de las 131 cepas aisladas de leche de oveja (Figura 12) y las cepas de referencia CECT475, CECT4005, CECT4022 y CECT278 inhibieron H. pylori NCTC11637. Tan solo, 14 de las 131 cepas de leche de oveja pertenecientes a las especies $L$. acidophilus (9O3), L. paracasei paracasei (18O4, 20O6, 2105, 2T4, 1008), L. pentosus (4O1), L. plantarum (4O8), Lactococcus lactis subsp lactis (2O4, 2O11, 6O8, 1104, 13O5B, 19O6) y la cepa $L$. paracasei paracasei CECT 4022 mantuvieron la actividad inhibitoria frente a H. pylori NCTC11637 a pH 7 (Figura 13).

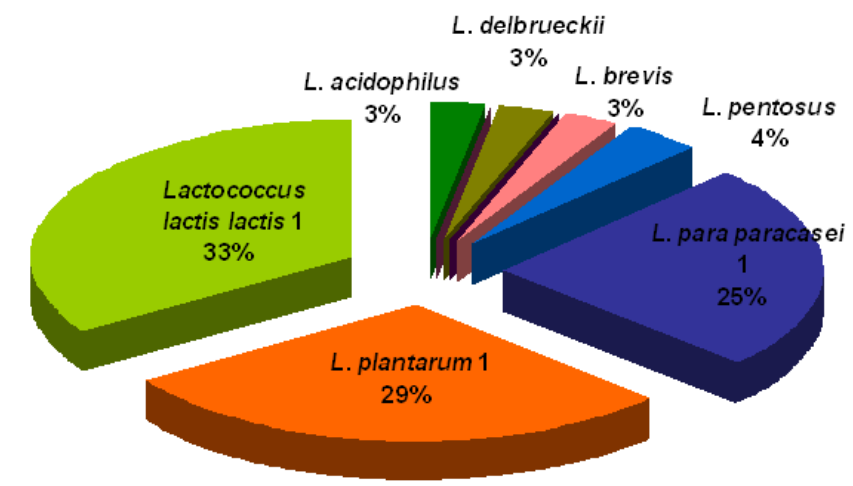

Figura 12. Inhibición de $H$. pylori NCTC11637 en ausencia de células de las BAL aisladas de leche de oveja. 


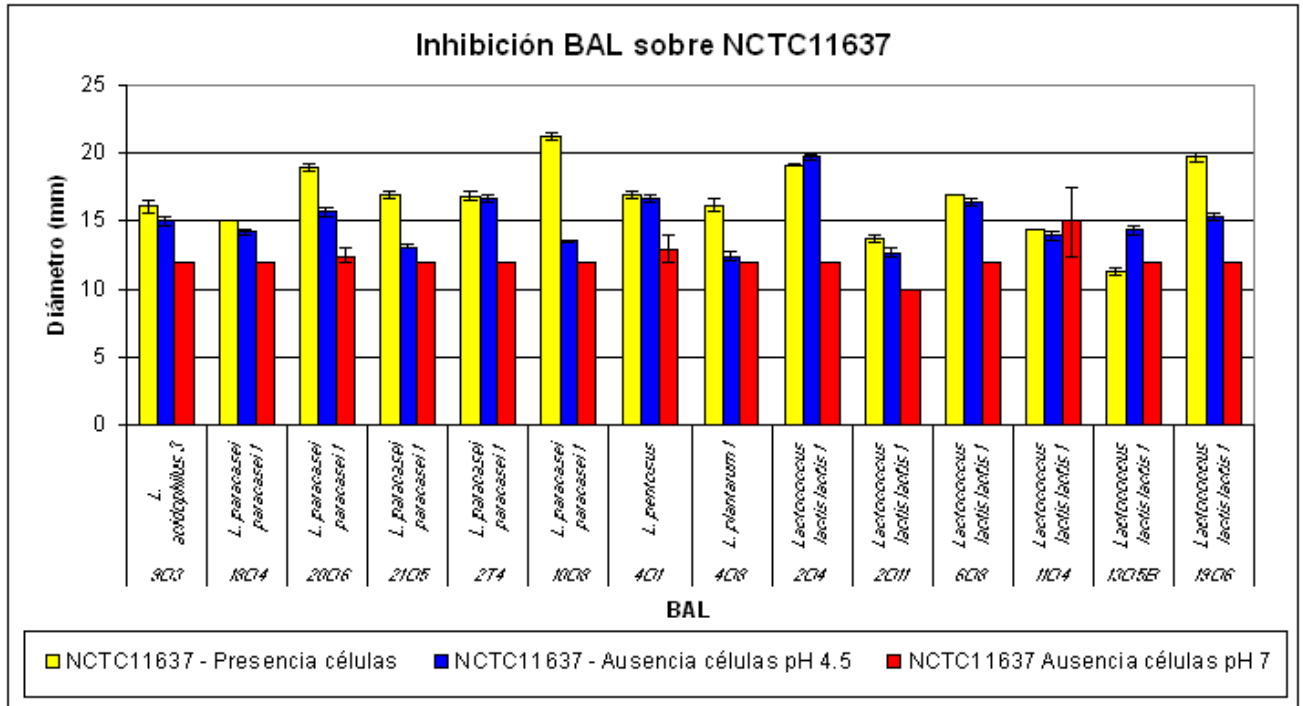

Figura 13. Actividad antimicrobiana de las BAL aisladas de leche de oveja en presencia y ausencia de células a pH 4.5 y 7 sobre $H$. pylori NCTC 11637 .

El test de Kruskal-Wallis muestra que hay diferencia estadísticamente significativa $(p<0.05)$ entre métodos y entre cepas lácticas, destacando las cepas mostradas en la Figura 13 junto con la cepa de referencia L. paracasei (CECT4022) que logran inhibir en todos los casos a H. pylori NCTC11637. La tabla 4 presenta los porcentajes de inhibición de las BAL aisladas de leche de oveja y la CECT frente a H. pylori NCTC11637. 
Tabla 4. Porcentaje de inhibición de las BAL aisladas de leche de oveja y la CECT frente a la cepa NCTC11637 de $H$. pylori en cada método.

\begin{tabular}{|c|c|c|c|c|}
\hline & & & \multicolumn{2}{|c|}{ Inhibición frente NCTC 11637} \\
\hline & & & No inhibe & Inhibe \\
\hline \multirow{6}{*}{ Método } & \multirow[t]{2}{*}{ 1: DISCOS } & Número cepas BAL & 47 & 92 \\
\hline & & \% de Método & $33.8 \%$ & $66.2 \%$ \\
\hline & \multirow[t]{2}{*}{ 2: SOBRENADANTE pH 4.5} & Número cepas BAL & 64 & 75 \\
\hline & & \% de Método & $46.0 \%$ & $54.0 \%$ \\
\hline & \multirow[t]{2}{*}{ 3: SOBRENADANTE pH 7} & Número cepas BAL & 124 & 15 \\
\hline & & $\%$ de Método & $89.2 \%$ & $10.8 \%$ \\
\hline
\end{tabular}

Chi-cuadrado de Pearson 287,171. $\mathrm{p}<0.05$

Las cepas aisladas de oveja L. paracasei paracasei 1 (4O4), L. plantarum 1 (Q3) y las cepas de CECT L. casei (CECT475), L. rhamnosus (CECT278), L. paracasei paracasei (CECT4022) inhibieron las dos cepas de H. pylori (Figura 14) en presencia y ausencia de células. Las cepas de oveja pertenecientes a las especies L. acidophilus (9O3), Lactococcus lactis subsp lactis 1 (2O4, 1104, 1906) inhibieron las dos cepas de H. pylori en presencia y ausencia de células. Además, mantuvieron el efecto antimicrobiano a pH 7 cuando se enfrentaron a H. pylori NCTC11637.
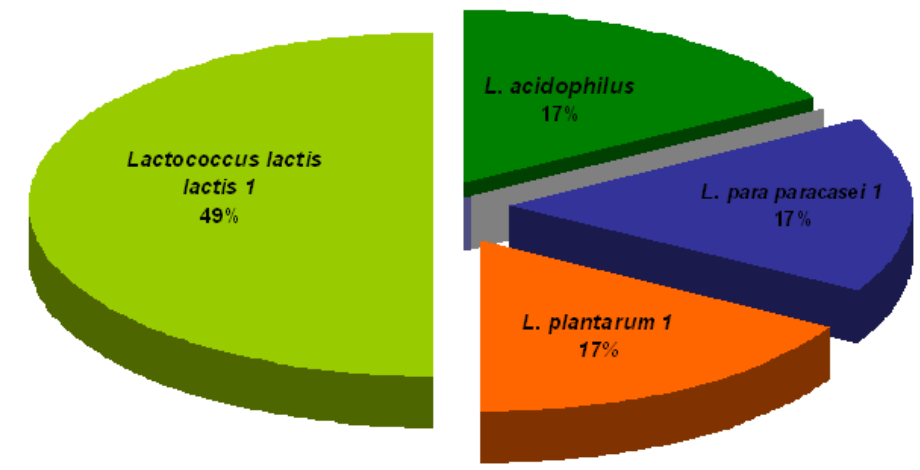

Figura 14. Inhibición H. pylori B6 y NCTC11637 por las BAL aisladas de leche de oveja. 
Al comparar entre las cepas de H. pylori B6 y NCTC11637 aplicando el test de Kruskal-Wallis se obtienen diferencias significativas estadísticamente $(\mathrm{p}<0.05)$ en la actividad antimicrobiana ejercida por las BAL frente a este patógeno. Mayor número de las BAL inhiben a $H$. pylori NCTC11637 y menos cepas lácticas tienen actividad inhibitoria frente a B6, siendo esta última resistente a la claritromicina (Tabla 5).

A nivel de cepa láctica, frente a los casos de inhibición de las dos cepas de $H$. pylori, se observa que las cepas de Lactococcus lactis subsp lactis (11O4, 19O6, 2O4), L. paracasei paracasei (CECT4022) y L. acidophilus (9O3) tienen una eficacia de inhibición de $83.3 \%$ (Porcentajes de inhibición positivos de las cepas BAL frente a las dos cepas de $H$. pylori en todos los tratamientos y repeticiones).

Tabla 5. Porcentaje de inhibición de las BAL frente a las cepas de H. pylori B6 y NCTC11637

\begin{tabular}{|l||l|l|l||l||}
\hline \multicolumn{2}{|l|}{} & & No inhibe & Inhibe \\
\hline \hline \multirow{2}{*}{$\begin{array}{l}\text { Helicobacter } \\
\text { pylori }\end{array}$} & B6 & \% de Inhibición & $80.8 \%$ & $\mathbf{1 9 . 2 \%}$ \\
\cline { 2 - 4 } & NCTC11637 & \% de Inhibición & $56.4 \%$ & $\mathbf{4 3 . 6 \%}$ \\
\hline
\end{tabular}

Chi-cuadrado 173,696. $\mathrm{p}<0.05$

\subsection{Actividad antimicrobiana frente a Salmonella spp.}

En condiciones in vitro, 24 de las 131 BAL aisladas de leche de oveja Guirra $L$. acidophilus (9O3), L. plantarum (3O9, 701, 908, 1705, Q2, Q3), L. paracasei paracasei (2O11B, 3O10, 7O7, 1010, 1405, 1008), L. pentosus (2O7), L. rhamnosus (12O3), Lactococcus lactis subsp lactis (103, 108, 13O5A, 13O5B, 1906, 1T4, 7B, 13O6), 
Lactococcus raffinolactis (2A) y 6 cepas de colección pertenecientes a las especies $L$. casei (CECT475), L. delbrueckii delbrueckii (CECT286), L. delbrueckii bulgaricus (CECT4006), L. paracasei paracasei (CECT4022), L. pentosus (CECT4023), L. rhamnosus (CECT278) presentaron actividad inhibitoria sobre las cepas de Salmonella estudiadas. Una muestra del ensayo de inhibición por el método del sobrenadante se observan en las Figura 15.

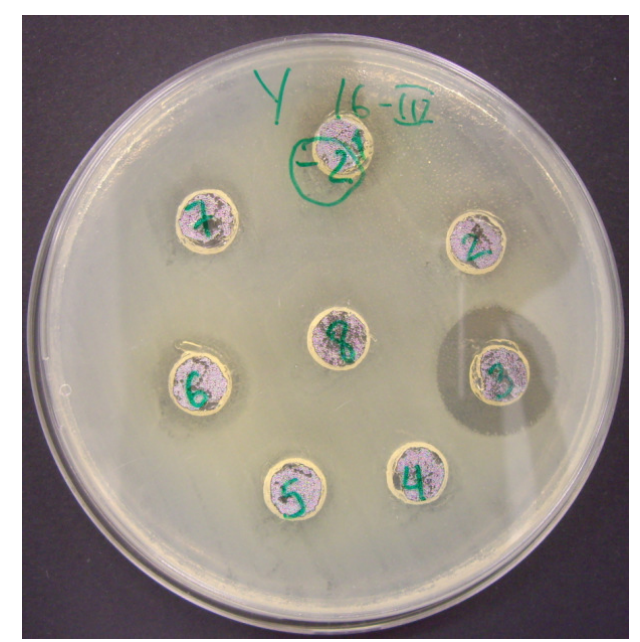

Figura 15. Ensayo de inhibición Salmonella spp. en ausencia células de las BAL.

Salmonella typhimurium (S134) fue inhibida por L. pentosus (2O7, CECT4023) y L. rhamnosus (CECT278) con ambos métodos (figura 17). Por otra parte, las cepas CECT475, 1008, 3O9, Q2 y 1906 presentaron efecto inhibitorio solo en presencia de células y las cepas 9O3, CECT286, CECT4022, 1 O10 y Q3 solo lo hicieron en ausencia de células a pH 4.5. El $3.8 \%$ (rango 10-15.3 mm) de las BAL de leche de oveja tuvieron efecto inhibitorio frente a S134 con ambos métodos. El 5.8\% de todas las BAL inhibieron en el método de discos y un $6.5 \%$ inhiben por las sustancias producidas (Tabla 6 ). El análisis estadístico muestra que hay diferencias estadísticamente significativas entre los métodos $(\mathrm{p}<0.05)$ al aplicar el test Kruskal-Wallis. Además, hay diferencias significativas entre cepas lácticas. 125 de las 139 BAL no inhibieron a S134 por ningún método, 11 inhiben en un 33\% de los métodos ensayados y las cepas CECT4023, 207 y CECT278 inhiben un 67\% de los métodos a S134. 
Tabla 6. Porcentaje de inhibición de las BAL frente a la cepa S134 en cada método.

\begin{tabular}{|c|c|c|c|c|}
\hline & & & \multicolumn{2}{|c|}{ Inhibición frente S134 } \\
\hline & & & No inhibe & Inhibe \\
\hline \multirow{6}{*}{ Método } & \multirow{2}{*}{ 1: DISCOS } & Número cepas BAL & 131 & 8 \\
\hline & & \% de Método & $94.2 \%$ & $5.8 \%$ \\
\hline & \multirow[t]{2}{*}{ 2: SOBRENADANTE pH 4.5} & Número cepas BAL & 130 & 9 \\
\hline & & \% de Método & $93.5 \%$ & $6.5 \%$ \\
\hline & \multirow[t]{2}{*}{ 3: SOBRENADANTE pH 7} & Número cepas BAL & 139 & 0 \\
\hline & & \% de Método & $100.0 \%$ & $0.0 \%$ \\
\hline
\end{tabular}

Tabla 7. Porcentaje de inhibición de las BAL frente a la cepa S58 en cada método.

\begin{tabular}{|c|c|c|c|c|}
\hline & & & \multicolumn{2}{|c|}{ Inhibición frente S58 } \\
\hline & & & No inhibe & Inhibe \\
\hline \multirow{6}{*}{ Método } & \multirow[t]{2}{*}{ 1: DISCOS } & Número cepas BAL & 129 & 10 \\
\hline & & \% de Método & $92.8 \%$ & $7.2 \%$ \\
\hline & \multirow[t]{2}{*}{ 2: SOBRENADANTE pH 4.5} & Número cepas BAL & 129 & 10 \\
\hline & & $\%$ de Método & $92.8 \%$ & $7.2 \%$ \\
\hline & \multirow[t]{2}{*}{ 3: SOBRENADANTE pH 7} & Número cepas BAL & 139 & 0 \\
\hline & & \% de Método & $100.0 \%$ & $0.0 \%$ \\
\hline
\end{tabular}

Tabla 8. Porcentaje de inhibición de las BAL frente a la cepa S135 en cada método.

\begin{tabular}{|c|c|c|c|c|}
\hline & & & \multicolumn{2}{|c|}{ Inhibición frente S135 } \\
\hline & & & No inhibe & Inhibe \\
\hline \multirow{6}{*}{ Método } & \multirow[t]{2}{*}{ 1: DISCOS } & Número cepas de BAL & 125 & 14 \\
\hline & & \% de Método & $89.9 \%$ & $10.1 \%$ \\
\hline & \multirow{2}{*}{ 2: SOBRENADANTE pH 4.5} & Número cepas de BAL & 132 & 7 \\
\hline & & $\%$ de Método & $95.0 \%$ & $5.0 \%$ \\
\hline & \multirow[t]{2}{*}{ 3: SOBRENADANTE pH 7} & Número cepas de BAL & 139 & 0 \\
\hline & & \% de Método & $100.0 \%$ & $0.0 \%$ \\
\hline
\end{tabular}


Tabla 9. Porcentaje de inhibición de las BAL frente a la cepa CECT915 en cada método.

\begin{tabular}{|c|c|c|c|c|}
\hline & & & \multicolumn{2}{|c|}{ Inhibición S915 } \\
\hline & & & No inhibe & Inhibe \\
\hline \multirow{6}{*}{ Método } & \multirow[t]{2}{*}{ 1: DISCOS } & Número cepas BAL & 129 & 10 \\
\hline & & \% de Método & $92.8 \%$ & $7.2 \%$ \\
\hline & \multirow{2}{*}{ 2: SOBRENADANTE pH 4.5} & Número cepas BAL & 130 & 9 \\
\hline & & $\%$ de Método & $93.5 \%$ & $6.5 \%$ \\
\hline & \multirow[t]{2}{*}{ 3: SOBRENADANTE pH 7} & Número cepas BAL & 139 & 0 \\
\hline & & \% de Método & $100.0 \%$ & $0.0 \%$ \\
\hline
\end{tabular}

Salmonella enteritidis (S58) fue inhibida por L. acidophilus (9O3), L. paracasei paracasei (1O10), L. pentosus (2O7, CECT4023) y L. plantarum (Q2) en ambos ensayos de inhibición. Las cepas CECT4006, 2011B, 7O7, 1T4, 7B inhibieron en presencia de células y un $6.1 \%$ (diámetro de 9.5-11 mm) de las BAL de leche de oveja. Las cepas lácticas CECT286, CECT4022, Q3, CECT278 y 103 inhibieron el crecimiento de la cepa S58 en ausencia de células a pH 4.5 y un $4.6 \%$ de las cepas de leche de oveja presentaron diámetros de inhibición entre 11.3-15 mm (Figura 16). La inhibición de la cepa por cada método del conjunto de las BAL se observa en la Tabla 7. El test de Kruskal-Wallis indica que hay diferencias estadísticamente significativas entre métodos y entre cepas lácticas $(p<0.05) .125$ cepas de las BAL no inhiben en ningún caso, 9 cepas inhiben en un 33.3\% de los casos y las cepas 1O10, 2O7, CECT4023, 903 y Q2 tienen una eficacia de 67\% en los métodos ensayados.

L. rhamnosus (12O3) solo fue capaz de inhibir a S. enteritidis (S135). Esta cepa patógena fue inhibida en ambos métodos por las cepas 9O3, CECT4022 y 7O1. Once cepas de 139 solo presentaron ese efecto en presencia de células, con un 9.2\% (rango 9-12 mm) de las cepas de leche de oveja. Cuatro de 139 cepas lo mostraron en ausencia de células, el 3.1\% correspondieron a cepas de leche de oveja y los diámetros de inhibición estuvieron entre 9.7$13 \mathrm{~mm}$ (Figura 16). La inhibición presentada por todas las BAL estudiadas en cada método se aprecia en la Tabla 8. Existen diferencias estadísticamente significativas $(p<0.05)$ entre los 
métodos al aplicar el test Kruskal-Wallis. Además, hay diferencias significativas $(\mathrm{p}<0.05)$ entre cepas lácticas. 121 de las 139 BAL no son eficaces al no inhibir en ningún método, 15 cepas lácticas tienen una eficacia de inhibición del $33 \%$ en los métodos ensayados y las cepas CECT4022, 207 y 903 inhiben en un $67 \%$ de los casos. 

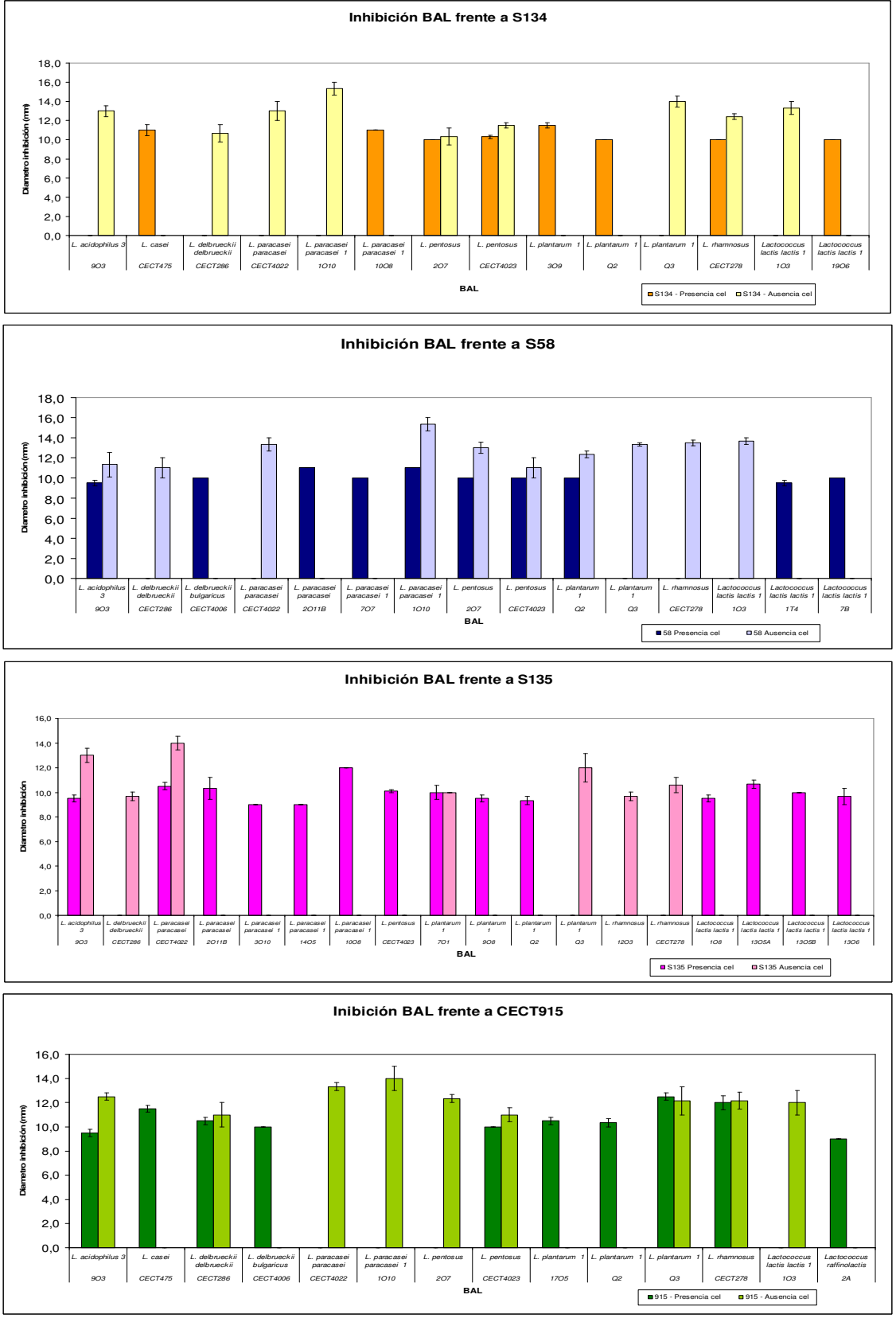

Figura 16. Inhibición de las BAL sobre Salmonella spp. Los resultados son la media de tres experimentos independientes. 
Salmonella enteritidis (CECT915) fue afectada por la presencia y ausencia de células de las cepas 9O3, CECT286, CECT4023, Q3 y CECT278. En presencia de células, fue inhibida por las cepas CECT475, CECT4006, 1705, Q2 y 2A y por las sustancias producidas por las cepas CECT4022, 1O10, $2 \mathrm{O} 7$ y 1O3. El 3.8\% (rango 9-14 mm) de las BAL de oveja inhibieron la cepa CECT915 en presencia y ausencia de células (Figura 16). Los porcentajes de inhibición de todas las BAL en cada método se registran en la Tabla 9. Se aprecian diferencias estadísticamente significativas $(\mathrm{p}<0.05)$ entre los métodos y las cepas lácticas. 125 cepas de BAL no inhiben en ningún caso, 9 lo hacen en un $33 \%$ de los métodos probados y 5 inhiben el $67 \%$ de los métodos ensayados.

Los sobrenadantes de las BAL estudiadas a $\mathrm{pH} 7$ no tuvieron ningún efecto antagónico frente a las cepas de Salmonella spp. estudiadas.

No se encontró diferencias significativas ( $\mathrm{p}>0.05)$ entre las cepas de Salmonella spp. al aplicar el test de Kruskal Wallis. Aunque, si hubo diferencias estadísticamente significativas $(\mathrm{p}<0.05)$ al aplicar el estadístico Chi-cuadrado de Pearson a los resultados de inhibición de las cepas lácticas frente a las cepas de Salmonella spp. en todos los métodos. Un total de 30 cepas lácticas presentaron actividad antimicrobiana, de las cuales 15 fueron eficaces en inhibir el crecimiento de Salmonella en un $8.3 \%$ de los métodos ensayados. Las cepas 10O8, 2O11B, 7O1, CECT475 y CECT4006 inhibieron a Salmonella en un 17\% de los casos. La cepa 103 inhibió a Salmonella en un $25 \%$ de los tratamientos probados. La cepa 1010 inhibió a Salmonella en un 33\% de los métodos. Las cepas 2O7, Q2, Q3, CECT286 y CECT4022 inhibieron a Salmonella en el $42 \%$ de los casos estudiados. La cepa CECT278 inhibió a Salmonella en un 50\% de los casos y las cepas $9 \mathrm{O} 3$ y CECT 4023 inhibieron en un $58 \%$ de los casos a Salmonella 110 de las BAL de 139 no mostraron actividad antimicrobiana. 
Tabla 10. Porcentaje inhibición de las BAL frente a las cepas S58, CECT915, S134, S135.

\begin{tabular}{|c|c|c|c|}
\hline & & \multicolumn{2}{|c|}{ \% Inhibición } \\
\hline & & No inhibe & Inhibc \\
\hline \multirow{4}{*}{ Salmonella } & S58 & $95.4 \%$ & $4.6 \%$ \\
\hline & $\begin{array}{l}\text { CECT } \\
915\end{array}$ & $95.4 \%$ & $4.6 \%$ \\
\hline & S134 & $95.9 \%$ & $4.1 \%$ \\
\hline & S135 & $95.0 \%$ & $5.0 \%$ \\
\hline
\end{tabular}

Chi-cuadrado de Pearson 1.323. $\mathrm{P}>0.05$

Dentro del conjunto de las BAL estudiadas, 28 de las 131 cepas de leche de oveja como L. brevis (8O8, 12O9), L. paracasei paracasei (3O7, 5O6, 8O10, 10O11, 24O4), L. pentosus (3O4, 20O5, 22O4), L. plantarum (2O11A, 3O6, 4O10, 10O9, 11011, 1205, 15O6, 5T2 ), Leuconostoc mesenteroides (13O11), Lactococcus lactis subsp lactis (2O6, 406, 6O7, 9O11, 17O3, 2T1, 1A, 2B), Pediococcus pentosaceus (D1) no presentaron ningún tipo de inhibición antimicrobiana frente a las cepas patógenas de H. pylori y Salmonella spp.

\section{DISCUSIÓN}

Las infecciones ocasionadas por bacterias enteropatógenas como H. pylori y Salmonella además de producir la sintomatología específica llegan a reducir la microbiota intestinal provocando desordenes y alteraciones en transito instetinal. Con el fin de reducir este riesgo, se pueden usar suplementos alimenticios con bacterias probióticas, que representan una alternativa terapéutica reciente no farmacológica para el manejo de los episodios de diarrea agudas en niños desnutridos y por consiguiente, ayudan a mejorar su estado nutricional (Mazo y Arias, 2006; Candela et al., 2008). Además, las bacterias ácido 
lácticas producen una variedad de sustancias con propiedades antibacterianas incluyendo ácidos orgánicos, peroxido de hidrógeno y bacteriocinas que afectan la viabilidad bacteriana, el metabolismo o la producción de toxinas (Wilson et al., 2005; Makras et al., 2006; Olivares et al., 2006). Además, algunas presentan actividad inmunomoduladora y así, tienen la capacidad de proteger los enterocitos de la acción de enteropatógenos (Candela et al., 2008).

Algunos autores, ya encontraron cepas ácido lácticas obtenidas de alimentos que inhibieron el crecimiento de H. pylori, S. typhimurium y S. enteritidis (Maragkoudakis et al., 2009; Thirabunyanon et al., 2009). En este estudio se encontró que la leche de oveja guirra contiene bacterias ácido lácticas que muestran actividad antimicrobiana contra estos mismos patógenos.

Las cepas de oveja L. acidophilus (9O3) y Lactococcus lactis subsp lactis 1 (2O4, 1104, 1906) destacaron dentro de la colección de las BAL porque tienen actividad antimicrobiana frente a las dos cepas de H. pylori B6 y NCTC11637 en presencia y ausencia de células. Además, mantienen el efecto sobre H. pylori NCTC11637 cuando el pH se ajusta a 7. Las cepas L. acidophilus (9O3), L. paracasei paracasei (18O4, 2006, 2105, 2T4, $10 \mathrm{O} 8$ y CECT4022), L. pentosus (4O1), L. plantarum (4O8) y Lactococcus lactis subsp lactis (2O4, 2O11, 6O8, 11O4, 1305B, 19O6) destacan por mostrar efecto inhibitorio frente a $H$. pylori NCTC11637 en los tres métodos probados. Las otras especies que sobresalen son $L$. paracasei paracasei 1 (4O4), L. plantarum 1 (Q3) y las cepas L. casei (CECT475), L. rhamnosus (CECT278), L. paracasei paracasei (CECT4022) al inhibir las dos cepas de $H$. pylori en presencia y ausencia de células (Figura 5). Por tanto, se considera que su actividad antagónica se debe a la presencia de las células, componentes celulares, a los ácidos orgánicos producidos como el ácido láctico y las cepas que mantuvieron la actividad antimicrobiana a $\mathrm{pH}$ neutro se debe a la producción de otras sustancias activas, como ya concluyeron Midolo et al., (1995) y Jacobsen et al., (1999) en estudios similares. 
La mayor parte de las BAL presentaron actividad inhibitoria frente a $H$. pylori en presencia y ausencia de células y solo 46 cepas lácticas inhibieron en presencia de células (Tabla 3 y 4). Este resultado coincide con otros estudios que concluyen la importancia de la presencia de células para adherirse y colonizar las células epiteliales del antro del estomago y de este modo competir con H. pylori, con el fin de mejorar la tasa de erradicación del patógeno (Aiba et al., 1998) .

En este trabajo, las cepas L. casei (CECT475) y L. acidophilus (9O3) inhibieron la cepa de referencia $H$. pylori NCTC11637 por medio del sobrenadante. Estudios previos mostraron que H. pylori NCTC11637 fue inhibida por otras cepas de las mismas especies asociando dicho efecto antimicrobiano a la acción del $\mathrm{pH}$ del sobrenadante y los ácidos orgánicos producidos por estas cepas lácticas (Cats et al., 2003). La cepa D1 de leche de oveja Guirra fue la única identificada como Pediococcus pentosaceus y no tuvo actividad inhibitoria frente a ningún patógeno, similar a los resultados publicados por Midolo et al., (1995).

En el caso de Salmonella, 28 de las 131 BAL inhiben alguna cepa de Salmonella spp. en presencia de células lácticas. Doce de los 131 sobrenadantes de las BAL mostraron actividad frente a las cepas de Salmonella a pH 4.5. Sin embargo, tal actividad desaparece cuando el pH de los sobrenadantes se ajustó a 7, lo que coincide con resultados de Hudault et al., (1997) donde el sobrenadante de la cepa L. rhamnosus GG fue efectivo a pH de 3 a 5 y al neutralizarse no logro evitar la invasión de $S$. typhimurium C5 a las células Caco-2, en un modelo celular in vitro. La investigación de Olivares et al., (2006) mostró que los sobrenadantes de L. coryniformis CECT5711, L. salivarius CECT5713 y L. gasseri CECT5714 inhibieron a $\mathrm{pH}$ entre 3.86 y 4.4 y perdieron dicha capacidad a $\mathrm{pH} 7$ al enfrentarse a S. choleraesuis, E. coli, S. aureus, Listeria y Clostridium. Los resultados en general, indicaron que la actividad inhibitoria frente a Salmonella de las BAL podría deberse a los componentes celulares, exclusión competitiva por nutrientes, a la presencia de ácido láctico y otras sustancias activas a pH bajo. Es decir, que solo la presencia de células y los 
ácidos orgánicos de algunas de las BAL estudiadas tienen efecto sobre las cepas de Salmonella ensayadas.

Otros autores también estudiaron productos probióticos comerciales que contenian L. acidophilus IBB801, L. amylovorus DCE 471, L. casei shirota, L. johnsonii La1, L. plantarum ACA-DC 287 y L. rhamnosus GG mostrando su capacidad de inhibir Salmonella enterica serovar typhimurium SL1344 bajo condiciones ácidas. También, L. casei GG ejerció actividad antimicrobiana in vitro contra S. typhimurium C5 y otras cepas de Lactobacillus presentaron dicho efecto hacia varios patógenos Gram negativos (Makras et al., 2006). Además, L. acidophilus BAR13, L. plantarum Bar10 fueron efectivos en el desplazamiento de S. typhimurium y E. coli (Hudault et al., 1997; Candela et al., 2008).

La actividad antimicrobiana de péptidos como nisina y bacteriocinas producidas por ciertas cepas de Lactococcus lactis subsp lactis y Carnobacterium piscicola JG126 respectivamente, están influenciados por el $\mathrm{pH}$ (Wilson et al., 2005). Los doce sobrenadantes de las BAL del presente estudio produjeron compuestos anti Salmonella a pH 4.5, similar a lo publicado por Wilson et al., (2005). Adicionalmente, en ambientes a bajo pH, el ácido láctico puede funcionar como permeabilizador de la membrana externa de bacterias Gram negativas y por tanto, facilitar los efectos de otras sustancias antimicrobianas (Makras et al., 2006). Sería de gran interés en estudios posteriores determinar si la actividad inhibitoria de las BAL de leche de oveja pudiera ser debida a la presencia de nisina u otra sustancia de las comentadas.

Otros estudios, indicaron que la preincubación de las cepas de Lactobacillus con cepas de Salmonella ocasionaron un importante decrecimiento en la adhesión del patógeno a la mucina (Olivares et al., 2006). También, Wilson et al., (2005) indicaron que Salmonella enteritidis resultó sensible a la actividad bactericida de acido láctico producido por cepas probióticas como L. acidophilus. En este estudio, L. acidophilus (9O3), L. paracasei paracasei (1O10), L. pentosus (2O7), L. plantarum (Q2, Q3) y Lactococcus lactis subsp 
lactis (1O3) mostraron buenos resultados de inhibición sobre las cepas de Salmonella. Particularmente, la cepa 903 demostró un potencial importante de actividad antibacteriana ya que inhibió todas las cepas de Salmonella spp. en presencia y ausencia de células BAL, excepto la cepa S134 que no fue inhibida en presencia de las células de la bacteria láctica. Estudios previos mostraron que L. acidophilus disminuyó la inflamación en el colon, sugiriendo que su administración regular moduló la respuesta inmunológica e inflamatoria en pacientes ancianos (de Roos y Katan, 2000) y evitó la diarrea asociada a antibióticos (Beausoleil et al., 2007). En general, los resultados del presente estudio evidenciaron el potencial de algunas de las BAL aisladas de leche de oveja Guirra y de la CECT en tratamientos coadyuvantes para alteraciones ocasionadas por Salmonella.

Al comparar los resultados de inhibición entre patógenos se destaca que un mayor número de las BAL tienen efecto inhibitorio frente a las cepas de $H$. pylori y un número más reducido lo tienen frente a las cepas de Salmonella spp. Es factible que las condiciones "in vitro" repercutan en el crecimiento del patógeno y en su respuesta frente a las BAL. Es importante resaltar que Salmonella crece más rápido, no es sensible a las condiciones ambientales y crece en aerobiosis a diferencia de $H$. pylori.

Los resultados de inhibicion son bastante heterogéneos. Los halos de inhibición mas destacables se han obtenido en el método de ausencia de células para las cepas B6 y NCTC11637 de H. pylori (Anexo 4). Estudios previos destacan la técnica de difusión en placa por el método de sobrenadante porque se observan halos de inhibición más claros y puede deberse a que es una técnica sencilla y es menos susceptible a contaminaciones (Hütt et al., 2005; Sigrid et al., 2006).

En las pruebas de actividad antimicrobiana frente a $H$. pylori se observa que las cepas que inhiben en ausencia de células también lo han hecho en presencia de células mientras que en los ensayos de inhibición de las BAL frente a Salmonella no ocurre lo mismo en todos los casos. Los resultados son dependientes de la cepa. El 16\% cepas lácticas 
tuvieron la capacidad de inhibir ambos patógenos. El análisis estadístico muestra que hay diferencia significativa $(p<0.05)$ entre las medianas de los métodos empleados mostrando que el método empleado influye en el resultado de la inhibición. Además, existen cepas lácticas que solo inhibieron a Salmonella spp. y otras que solo inhiben H. pylori sugiriendo que estas cepas lácticas podrían ser ensayadas frente a otros patógenos incluso aquellas que no presentaron actividad antagónica.

En la sociedad actual, se ha incrementado el consumo de productos naturales y se da importancia a los procesos de biopreservación como alternativa para la conservación de alimentos y como tratamiento alternativo de enfermedades gastrointestinales (Wilson et al., 2005; Maragkoudakis et al., 2009). En el presente estudio, una cepa de H. pylori y 2 cepas de Salmonella spp. resistentes a antibióticos fueron inhibidas por alguna cepa láctica aislada de leche de oveja lo cual indica que estas cepas pueden ser una alternativa frente a estas infecciones, incluyendo aquellas resistentes a claritromicina y ácido nalidíxico. Además, estas cepas lácticas podrían ser empleadas en la producción de productos lácteos fermentados seguros y saludables, ya que de hecho algunas de ellas se han aislado directamente del producto fermentado y comercializado. 


\section{INTRODUCCIÓN}

Son varias las publicaciones que demuestran la actividad antagónica de algunas cepas de Lactobacillus, incluyendo algunas ya comentadas en el capitulo anterior. Algunas cepas pertenecientes a $L$. rhamnosus se han empleado en el tratamiento frente a $H$. pylori (Armuzzi et al., 2001). Al igual que L. brevis, estas cepas producen sustancias antimicrobianas que inhiben la multiplicación de distintos enteropatógenos (Salminen y Donohhue, 1996; Isolauri et al., 2002; Warren et al., 2007; Calderón et al., 2007; B. Martín, et al., 2009).

Para evaluar el efecto de la inhibición de las BAL sobre $H$. pylori se pueden observar las posibles variaciones en la capacidad de crecimiento y cambios morfológicos que puedan producirse en este último tras incubación conjunta con las cepas de Lactobacillus.

Las técnicas tradicionales de cultivo suelen emplearse para determinar la viabilidad de las bacterias. Sin embargo, está técnica dificulta la detección de los estados intermedios, no contemplando las formas no cultivables y no estimando el número real de microorganismos presentes en una muestra debido a que las bacterias viables no cultivables no tienen la capacidad de crecer en un medio formando colonias. Además, su dilatado tiempo necesario para obtener resultados es una desventaja con respecto a otras técnicas.

En los últimos 20 años, los indicadores de viabilidad basados en la utilización de moléculas fluorescentes se ha convertido en una herramienta de gran alcance de la microbiología especialmente en procesos biotecnológicos, conservación de alimentos y procesos de desinfección química (Berney et al., 2007). El recuento de microorganismos por medio de tinción con fluorocromos es más rápido, permite observar directamente la morfología y determinar la viabilidad bacteriana haciendo posible de este modo un recuento exacto del número de microorganismos presentes en una muestra (Moreno et al., 2000; Collado, 2004). 
El objetivo de este estudio fue determinar la viabilidad de H. pylori evaluando la integridad de membrana y cambios morfológicos producidos al incubarse conjuntamente con el sobrenadante de las bacterias lácticas que previamente mostraron actividad antimicrobiana frente a este patógeno. Para este fin se empleó el kit de viabilidad LIVE/DEAD BacLight Bacterial Viability kit (Molecular probes-Invitrogen) y la técnica tradicional de recuento en placa.

\section{MATERIAL Y MÉTODOS}

\subsection{Cepas}

Se seleccionaron las cepas lácticas $12 \mathrm{O} 3$ y $20 \mathrm{O} 4$ que inhibieron $H$. pylori $\mathrm{B} 6$ en presencia, ausencia de células a $\mathrm{pH} 4.5$ y $\mathrm{pH} 7$, mostrando un importante potencial antimicrobiano contra el patógeno.

\subsection{Preparación del ensayo}

Se empleó un cultivo de $48 \mathrm{~h}$ de H. pylori B6 en agar ASC 10\% que se resuspendió en caldo Brucella hasta obtener una absorbancia de 0.045 a $550 \mathrm{~nm}$ (6 en la escala de McFarland $\left.1.8 \times 10^{9} \mathrm{UFC} / \mathrm{ml}\right)$. La suspensión se repartió en alícuotas de $12.5 \mathrm{ml}$.

Cada una de las cepas lácticas crecidas en agar MRS durante 24 horas, se resuspendieron en caldo MRS hasta alcanzar una concentración de 4 en la escala de McFarland ( $\left.1.2 \times 10^{8} \mathrm{UFC} / \mathrm{ml}\right)$. Los sobrenadantes de las BAL se obtuvieron como se describe en el capitulo II (apartado 2.3.2).

A cada tubo de suspensión de $H$. pylori se le añadieron $375 \mu$ de la suspensión de la cepa láctica. Los tubos se incubaron a $37^{\circ} \mathrm{C}$ en microaerofília y se tomaron muestras de $2 \mathrm{ml}$ 
tras $0,5,19$ y 24 horas. Se centrifugó a 7.000 rpm durante 5 minutos, se eliminó el caldo y se lavó con PBS 1X tres veces con el fin de eliminar los restos de caldo. Finalmente, se resuspendió en $2 \mathrm{ml}$ de PBS $1 \mathrm{X}$. El efecto de cada BAL sobre H. pylori se determinó mediante recuento en placa y la evaluación de la integridad de membrana mediante tinción con la técnica de fluorocromos.

Como control negativo se utilizó un cultivo que contenía únicamente la cepa de $H$. pylori $\mathrm{B} 6$.

\section{Recuento de viables mediante cultivo en placa}

A cada uno de los tiempos establecidos, se tomó muestra y se realizaron diluciones decimales seriadas en PBS 1X. Se inocularon $100 \mu \mathrm{l}$ en agar ASC 10\% de cada una de las diluciones por duplicado. Las placas fueron incubadas a $37{ }^{\circ} \mathrm{C}$ en microaerofilia durante 4 días.

\section{Recuento de viables mediante la técnica de tinción con fluorocromos}

Mediante el sistema comercial LIVE/DEAD BacLight Bacterial Viability kit (Molecular probes - Invitrogen), se logró conocer el total de células viables y no viables por microscopia de epifluorescencia. SYTO9 es un fluorocromo que penetra a través de las membranas de bacterias viables, no viables y presenta una fluorescencia verde con excitación y emisión máxima a 480 y $500 \mathrm{~nm}$. El fluorocromo ioduro de propidio (PI) penetra en aquellas bacterias que presentan las membranas celulares dañadas o con lesiones, desplazando así la molécula SYTO9 debido al tamaño de la molécula y proporcionando fluorescencia roja con excitación y emisión máxima a 490 y 635 nm. 
Se tomaron $250 \mu$ de la mezcla de H. pylori y BAL en PBS $1 \mathrm{X}$ mencionada al final del apartado 2.2 y se adicionó $0.8 \mu \mathrm{l}$ de la mezcla de fluorocromos SYTO9 y PI en proporción 1:1 tal como indica el fabricante. La mezcla se incubó en oscuridad a temperatura ambiente durante 10-15 minutos.

Transcurrido dicho tiempo, se tomó una alícuota de $5 \mu 1$ y se depositó en un portaobjetos cubierto con poli-L-lisina (SIGMA), se cubrió con un cubreobjetos y se selló con vaselina para evitar la evaporación de la muestra (Alonso et al., 2002).

La muestra se visualizó en un microscopio de epifluorescencia BX50 con filtros (UMWIB). Las bacterias viables marcadas con SYTO9 se observaron de color verde, mientras que las bacterias no viables, marcadas con PI se observaron de color rojo. Se realizó el recuento de las bacterias viables y no viables en 20 campos distintos para cada muestra analizada y por duplicado. Únicamente las células que presentaban fluorescencia verde se consideraron viables. Los resultados de recuento en placa se expresaron como la media y el error estándar de dos determinaciones.

\section{RESULTADOS}

\section{Recuento de viables mediante cultivo en placa}

El recuento de viables por cultivo para cada una de las muestras analizadas se muestra en la tabla 1 . El número total de UFC/ml de H. pylori estuvo entre $10^{6}$ y $10^{7}$ para la muestra control. En las muestras tratadas con el sobrenadante $12 \mathrm{O}$ la cultivabilidad de $H$. pylori se mantuvo hasta las 5 horas con un total de $10^{7} \mathrm{UFC} / \mathrm{ml}$ y no se apreció crecimiento del patógeno tras 19 y 24 horas de contacto. El recuento de H. pylori con el sobrenadante 2004 pasó de un total de $10^{7} \mathrm{UFC} / \mathrm{ml}$ en tiempo 0 a $10^{4} \mathrm{UFC} / \mathrm{ml}$ a las 19 horas. Tras 24 
Capitulo III

horas de contacto no se obtuvo crecimiento. La figura 1 muestra la variación de la cultivabilidad para cada muestra a través del tiempo respecto del tiempo inicial. 
Tabla 1. Viabilidad de H. pylori B6 en contacto con sobrenadantes de BAL aisladas de leche de oveja guirra mediante técnicas de cultivo en placa y recuento de epifluorescencia empleando el kit de viabilidad LIVE/DEAD. Media \pm (SEM) Error estándar de la media.

\begin{tabular}{|c|c|c|c|c|c|c|c|c|}
\hline \multirow{4}{*}{ MUESTRA } & \multicolumn{8}{|c|}{ Horas } \\
\hline & \multicolumn{2}{|r|}{0} & \multicolumn{2}{|c|}{5} & \multicolumn{2}{|c|}{19} & \multicolumn{2}{|c|}{24} \\
\hline & $\begin{array}{c}\text { Recuento } \\
\text { placa }\end{array}$ & Células viables & $\begin{array}{c}\text { Recuento } \\
\text { placa }\end{array}$ & $\begin{array}{l}\text { Células } \\
\text { viables }\end{array}$ & $\begin{array}{c}\text { Recuento } \\
\text { placa }\end{array}$ & $\begin{array}{l}\text { Células } \\
\text { viables }\end{array}$ & $\begin{array}{c}\text { Recuento } \\
\text { placa }\end{array}$ & $\begin{array}{l}\text { Células } \\
\text { viables }\end{array}$ \\
\hline & $\begin{array}{c}\mathrm{Log} \\
\mathrm{UFC} / \mathrm{ml}\end{array}$ & $\begin{array}{c}\text { SYTO9 } \\
\text { Log cel/ml }\end{array}$ & $\begin{array}{c}\log \\
\mathrm{UFC} / \mathrm{ml}\end{array}$ & $\begin{array}{l}\text { SYTO9 } \\
\text { Log } \\
\text { cel/ml }\end{array}$ & $\begin{array}{c}\log \\
\mathrm{UFC} / \mathrm{ml}\end{array}$ & $\begin{array}{l}\text { SYTO9 } \\
\text { Log } \\
\text { cel/ml }\end{array}$ & $\begin{array}{c}\log \\
\mathrm{UFC} / \mathrm{ml}\end{array}$ & $\begin{array}{c}\text { SYTO9 } \\
\text { Log } \\
\text { cel } / \mathrm{ml}\end{array}$ \\
\hline $\begin{array}{l}\text { H. pylori } \\
\text { Control }\end{array}$ & $6.4(0.1)$ & $7.4(3.7)$ & $6.4(0.6)$ & $7.4(2.2)$ & $5.5(0.5)$ & $7.5(1.5)$ & $6.0(0.3)$ & $7.4(3.9)$ \\
\hline $\begin{array}{l}\text { H. pylori }+ \\
\text { Sobrenadante } \\
12 \mathrm{O} 3 \\
\end{array}$ & $6.8(0.1)$ & $7.3(1.6)$ & $6.1(0.8)$ & $7.4(2.3)$ & - & $7.3(1.3)$ & - & 7.5(1.9) \\
\hline $\begin{array}{l}\text { H. pylori }+ \\
\text { Sobrenadante } \\
20 \mathrm{O} 4\end{array}$ & $6.8(0.4)$ & $7.5(2.4)$ & $6.5(0.0)$ & $7.5(4.9)$ & $4.2(0.1)$ & $7.5(3.4)$ & - & $7.2(2.9)$ \\
\hline
\end{tabular}




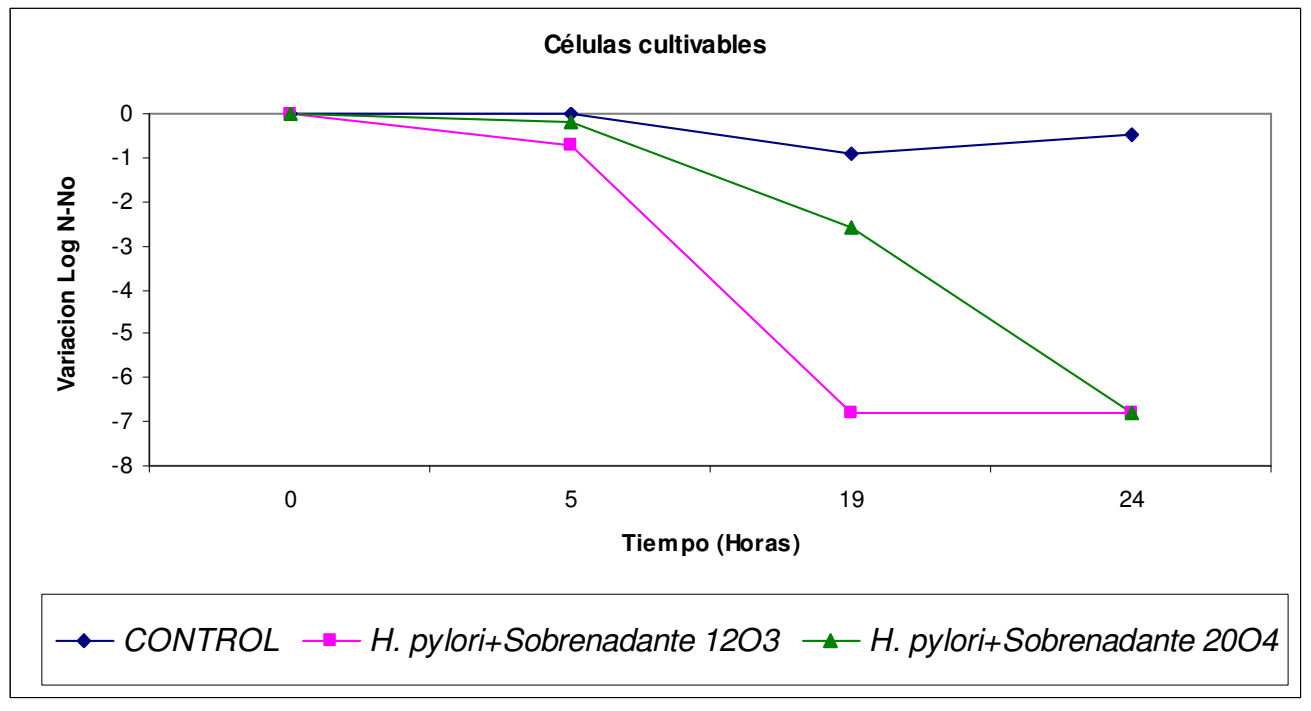

Figura 1. Variación de la cultivabilidad para cada muestra respecto del tiempo 0. No: Tiempo 0. N: Tiempo 0, 5, 19, 24 horas.

\section{Recuento de viables mediante epifluorescencia (integridad de membrana)}

Los resultados mostraron que el recuento en placa resultó de 0.5 a 3 órdenes menor que los recuentos obtenidos mediante la técnica de tinción con fluorocromos (Tabla 1). Por tanto, no todas las células viables de la muestra fueron capaces de crecer en medio de cultivo (Figura 3).

Los recuento totales de $H$. pylori estimados con el sistema comercial LIVE/DEAD fueron del orden de $10^{7}$ a $10^{8}$ células $/ \mathrm{ml}$ en la muestra control durante las 24 horas (Tabla 1). La viabilidad del patógeno disminuyó levemente con los sobrenadantes $12 \mathrm{O} 3$ y $20 \mathrm{O} 4$ después de 19 y 24 horas de contacto, respectivamente. Parece que el ácido producido por la cepa $12 \mathrm{O} 3$ afecta a $H$. pylori entre las 5 y 19 horas y después el patógeno logra recuperarse bien a dichas condiciones. Mientras que H. pylori B6 en contacto con el sobrenandante 2004 se ve más afectado entre las 19 y 24 horas, posiblemente la reducción del patógeno se deba a 
otra sustancia diferente a los ácidos orgánicos (Figura 2). Estas muestras tuvieron valores muy similares a la muestra control en la prueba de viabilidad con SYTO9 (Tabla 1). Sin embargo, H. pylori perdió capacidad de cultivabilidad en el medio de cultivo en presencia de los sobrenadantes de las BAL (Figura 3). La cultivabilidad de H. pylori se empieza a perder en las primeras 5 horas. Similares resultados fueron publicados cuando $H$. pylori fue tratado con diferentes concentraciones de cloro y la cultivabilidad disminuyó a partir de 10 minutos de exposición (Moreno et al., 2007; Gião et al., 2010).

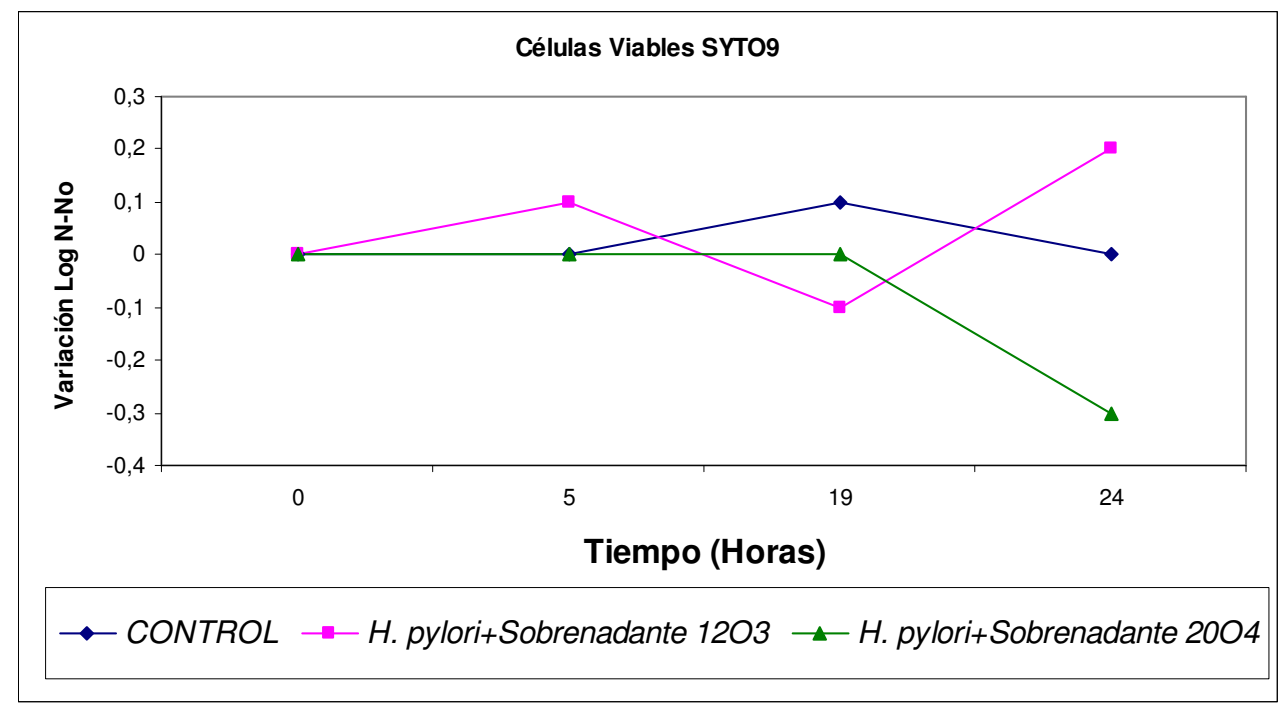

Figura 2. Variación del número de células viables para cada muestra respecto del tiempo 0. No: Tiempo 0. N: Tiempo 0, 5, 19, 24 h. 

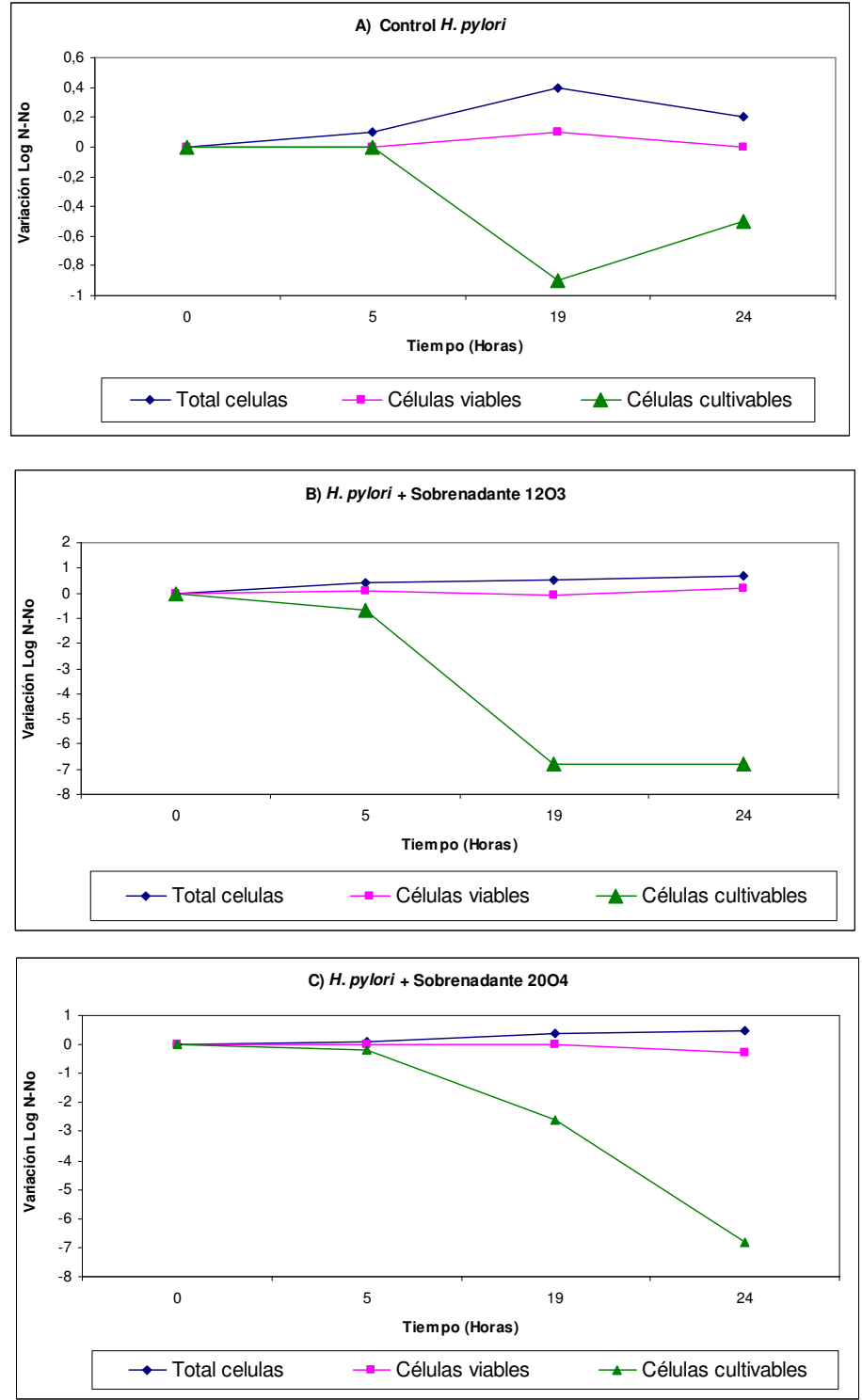

Figura 3. Variación del número de células viables, no viables (cel/ml) y cultivables (UFC/ml) de H. pylori B6 respecto del tiempo 0. No: Tiempo 0. N: Tiempo 0, 5, 19, 24 h. A) Control, B) $H$. pylori + Sobrenadante 12O3. C) H. pylori + Sobrenadante 2004. 
Después de 24 horas de contacto entre las células de $H$. pylori y las sustancias inhibidoras fue más difícil observar el crecimiento en placa debido a la aparición de células degradadas. Aunque, seguían coexistiendo formas espirales, cocos y formas de transición viables en las muestras observadas en el microscopio de epifluorescencia (Figura 4 y 5). Al enfrentar a $H$. pylori con los sobrenadantes de BAL, la transición a formas de resistencia se acelera respecto al control. Es por tanto evidente, como otros autores observaron, que las células de H. pylori estuvieron expuestas a condiciones ambientales hostiles (Cava y Cobas, 2003).
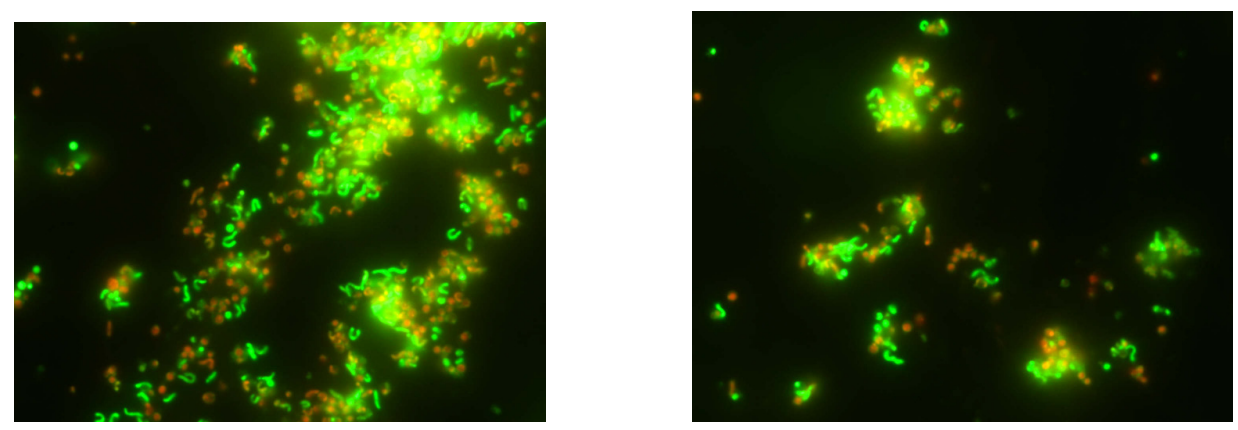

Figura 4. Células H. pylori B6 a tiempo 0 h (izquierda) y 5 h (derecha) de contacto con el sobrenadante 1203.
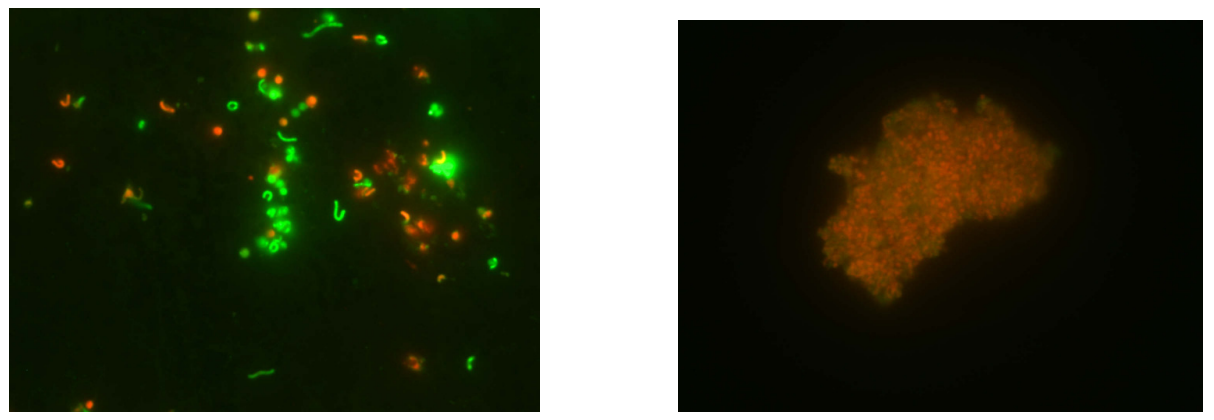

Figura 5. Células H. pylori B6 a tiempo 19 h (izquierda) y 24 h (derecha) con el sobrenadante 1203. 
La concentración inicial de células espirales varió entre el control y los cultivos mixtos con H. pylori. El porcentaje de células viables disminuyó en todas las muestras después de 24 horas. El 12\% en el control (Figura 6), 16\% en el cultivo mixto de H. pylori y el sobrenadante $12 \mathrm{O} 3$ (Figura 7) y $28 \%$ con el sobrenadante $20 \mathrm{O} 4$ (Figura 8). Estos porcentajes fueron poco representativos respecto de la densidad de H. pylori. Es posible, que la viabilidad de $H$. pylori disminuya en mayor proporción cuando se empleen mayores tiempos de exposición y concentración de las sustancias antimicrobianas de BAL.

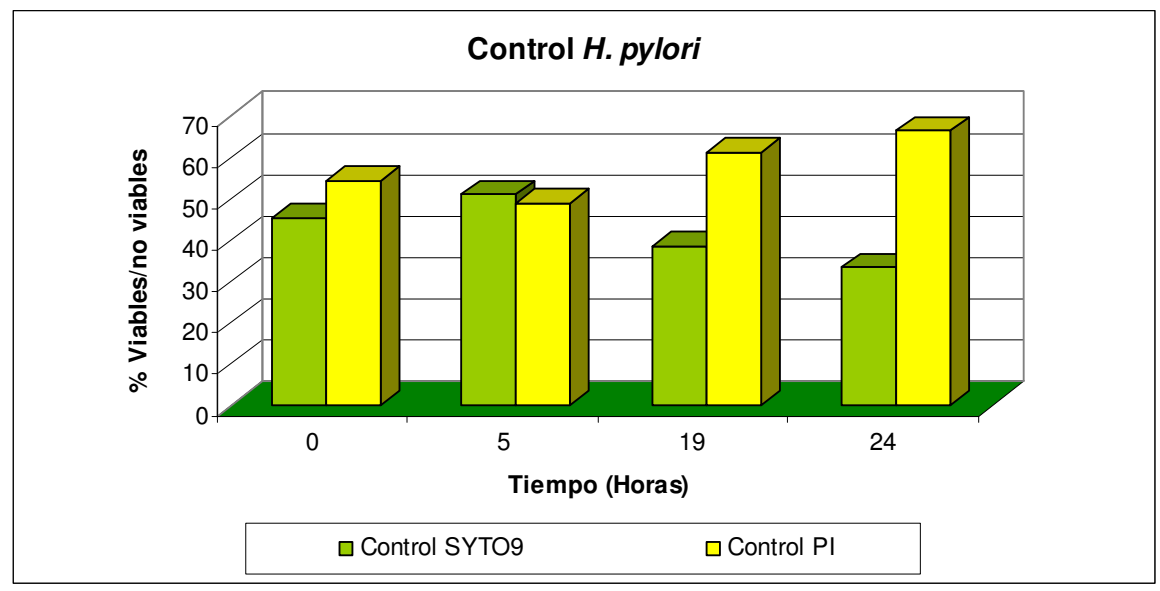

Figura 6. Porcentaje de viables (SYTO9) y no viables (PI) en la muestra control con H. pylori B6. 


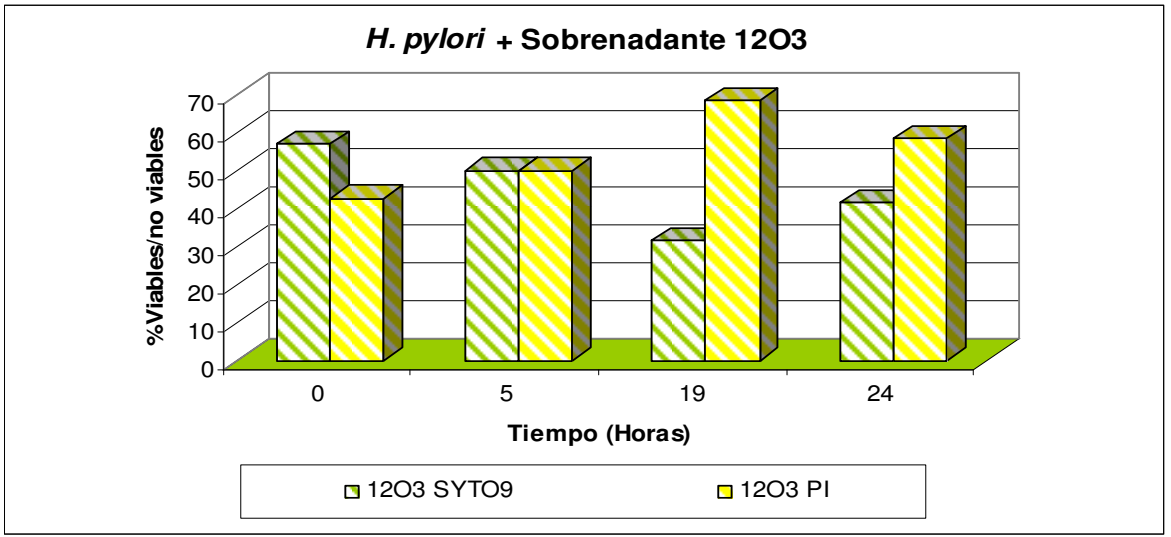

Figura 7. Porcentaje de viables (SYTO9) y no viables (PI) en la muestra $\mathrm{H}$. pylori B6+ Sobrenadante 1203

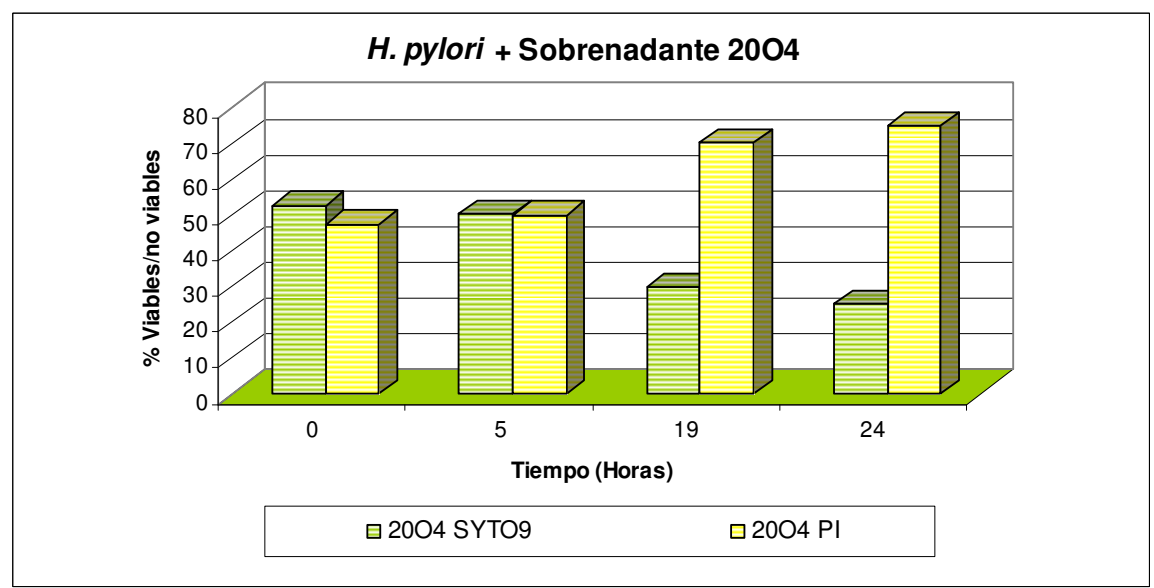

Figura 8. Porcentaje de viables (SYTO9) y no viables (PI) en la muestra H. pylori B6+ Sobrenadante 2004.

Los resultados mostraron que L. rhamnosus $12 \mathrm{O} 3$ y L. brevis $20 \mathrm{O} 4$ produjeron algún tipo de sustancia antimicrobiana que afectó la capacidad de cultivabilidad de H. pylori B6 en condiciones in vitro. Entre estos productos se podrían incluir componentes de la célula 
láctica, ácidos orgánicos (Wilson et al., 2005; Makras et al., 2006; Olivares et al., 2006) y bacteriocinas (Todorov y M. T. Dicks, 2005; Estrada et al., 2005; Ljungh y Wadström, 2009; Sarika et al., 2010).

\section{DISCUSIÓN}

Los resultados de algunos estudios con probióticos en animales y humanos sugirieron que estos pueden contribuir al tratamiento de la infección con H. pylori (Sgouras et al., 2005). La actividad inhibitoria de BAL sobre este patógeno fue evaluada por medio del test de difusión en condiciones in vitro (Midolo et al., 1995; Michetti et al., 1999; Lorca et al., 2001; Francavilla et al., 2008; Thirabunyanon et al., 2009). Pruebas en animales infectados mostraron que L. acidophilus no suprimió a $H$. pylori quizá por la baja producción de ácido láctico (Aiba et al., 1998); al aplicarse en personas tuvo un efecto parcial de supresión sobre H. pylori a largo plazo y no redujo significativamente la inflamación de la mucosa gástrica (Bazzoli et al., 1992; Michetti et al., 1999). El pre-tratamiento con yogurt disminuyó la densidad del patógeno y mejoró la eficacia de la terapia cuádruple de amoxicilina, metronidazol, omeoprazol y subnitrato de bismuto (Sheu et al., 2006). Otras BAL ocasionaron el decrecimiento en la densidad de H. pylori en adultos y niños, aunque, no se logró erradicar el patógeno (Francavilla et al., 2008). En el capitulo II de esta tesis $H$. pylori $\mathrm{B} 6$ fue inhibido en presencia y ausencia de células a $\mathrm{pH} 4.5$ y 7 de las cepas ácido lácticas $12 \mathrm{O} 3$ y 2004 mediante el test de difusión de discos.

Ciertas investigaciones prestaron especial interés en el cambio morfológico de $H$. pylori cuando fue incubado con bacterias lácticas o sus sobrenadantes. Por medio de tinción Gram se observaron los cambios de formas espirales a cocoides y la forma de $\mathrm{U}$ se considera un estado previo al estado cocoide (Lorca et al., 2001; Sgouras et al., 2005; Gotteland et al., 2006). En este estudio, H. pylori presentó morfología espiral, U y cocoide en forma viable y no viable. Por lo cual, se puede considerar que algunas formas cocoides o de resistencia mantienen integras las membranas, considerándolos formas viables que podrían ser 
potencialmente infectivas como ya sugieren otros autores (Adams et al., 2003; Azevedo et al., 2007; Gião et al., 2010).

Mediante el uso de fluorocromos, el porcentaje de células viables pasó del $45.5 \%$ en tiempo 0 al $33.4 \%$ a las 24 horas en la muestra control, con una disminución del 12\% en la viabilidad (Figura 6). En la muestra tratada con la cepa $12 \mathrm{O} 3$ la viabilidad inicial fue de $57.2 \%$ y pasó a $41.7 \%$ transcurridas las 24 horas (Figura 7) decreciendo un 16\%. La muestra con el sobrenadante 2004 inicialmente fue de $53 \%$ y disminuyó al $25 \%$ a las 24 horas de contacto (Figura 8) disminuyendo un 28\%. No obstante, no se aprecian diferencias de la viabilidad entre las muestras tratadas con BAL y el control debido a que estos porcentajes son bajos respecto a la densidad de H. pylori (Tabla 1).

Los resultados previos (Figuras 2 a la 8), evidencian que las muestras incubadas con el sobrenadante $12 \mathrm{O} 3$ y $20 \mathrm{O} 4$ afectan a la viabilidad de H. pylori B6 mostrando el potencial inhibidor de las cepas lácticas estudiadas pero no logra erradicarlo porque sobrevive en un estado viable y no cultivable (Gião et al., 2010). Investigaciones previas indicaron que la cepa $L$. rhamnosus $G G$ no tuvo efecto inhibidor sobre $H$. pylori.

El presente estudio de viabilidad mostró que H. pylori perdió la capacidad de cultivabilidad al estar en contacto con las sustancias producidas por BAL pero mantuvo la viabilidad y por ello su posible capacidad infectiva (Figura 3), pasando por transformaciones morfológicas (Figura 4 y 5); quizá como mecanismo de defensa a condiciones adversas en el medio (Gião et al., 2008). De hecho, otros autores constataron que este patógeno logró reponerse a la presencia de cloro (Gião et al., 2010).

El kit de viabilidad LIVE/DEAD fue una herramienta potente para evaluar la viabilidad de $H$. pylori al ser tratado con sustancias producidas por cepas lácticas. Un método más rápido que el recuento en placa siendo suficientes unas horas para obtener los resultados. Este método fue fiable porque permitió estimar todas las bacterias viables y no viables de las 
muestras y así obtener recuentos más precisos de todas las bacterias viables aunque no sean cultivables. Los métodos de cultivo estándar proporcionaron información de la capacidad de cultivabilidad y el sistema LIVE/DEAD permitió evaluar la viabilidad de H. pylori. Este ultimo, resultó mas fiable en el momento de evaluar el efecto de las cepas probióticas en la viabilidad de este patógeno (Gião et al., 2008) .

Es recomendable profundizar en los mecanismos de acción y en las pautas de administración de las BAL y sus metabolitos frente a $H$. pylori porque afecta su estado morfológico pero no logra eliminarlo. Se deben identificar las sustancias que ejercen el efecto antimicrobiano y realizar estudios in vivo para confirmar las propiedades antagónicas de las cepas lácticas aisladas de leche de oveja Guirra. 
CARACTERIZACION DE LAS CEPAS ACIDOLACTICAS CON POTENCIAL INHIBIDOR FRENTE A BACTERIAS PATÓGENAS 


\section{INTRODUCCIÓN}

La caracterización molecular nos permite obtener información de cepas no tipables por métodos bioquímicos de manera rápida y confiable (Tynkkynen et al., 1999; Pot y Tsakalidou, 2009).

La técnica RAPD (Random Amplified Polymorphic DNA) tiene como ventajas la rapidez, fiabilidad y simplicidad en su desarrollo, no es necesario conocer previamente la secuencia y requiere pequeñas cantidades de ADN genómico (Zapparoli et al., 2000; Huang y Lee, 2009). Además, permite distinguir entre cepas de una misma especie y especies relacionadas (Berthier y Ehrlich, 1999). Estudios previos trabajaron en la discriminación entre cepas de diferentes especies de Pediococcus aislados de sidra, Enterococcus, Lactococcus y Lactobacillus presentes en productos lácteos y cárnicos empleando RAPD obteniendose buenos resultados (Andrighetto et al., 2001; Martín-Platero et al., 2009; Colombo et al., 2010).

Por otra parte, el análisis de los perfiles de resistencia a antibióticos es una información valiosa en el caso de bacterias con potencial probiótico. La mayoría de estas bacterias son de origen animal o humano, por tanto, el uso indiscriminado de antibióticos ha generado un incremento de estos genes de resistencia en las mismas. Es necesario por ello, desarrollar ensayos normalizados para establecer perfiles de resistencia en bacterias acido lácticas e investigar sobre la posibilidad de transmisión de estos elementos genéticos a otros microorganismos intestinales y/o de origen alimentario (FAO y OMS, 2001).

Por ello, se planteó en este capitulo caracterizar las BAL con actividad antimicrobiana mediante la técnica molecular RAPD y perfiles de resistencia a antibióticos y así lograr establecer relaciones entre los aislados. 


\section{MATERIALES Y METODOS}

\subsection{Caracterización molecular por RAPD}

\subsubsection{Cepas bacterianas}

Se caracterizaron un total de 33 cepas BAL aisladas de leche de oveja que presentaron efecto inhibitorio frente a H. pylori y Salmonella spp. y 14 cepas de la CECT.

\subsubsection{Aislamiento del ADN genómico}

A partir de un cultivo puro de las cepas lácticas citadas, se realizó la extracción del ADN genómico por medio del sistema comercial REALPURE (Extracción DNA genómico) (Durviz, SA). Se siguió el protocolo descrito por el fabricante.

La concentración del ADN se determinó por espectrofotometría y el ADN obtenido fue visualizado mediante electroforesis en un gel de agarosa en tampón TAE a $100 \mathrm{mV}$ durante 1 hora. Posteriormente el gel fue teñido con bromuro de etidio $(0,5 \mu \mathrm{g} / \mathrm{ml})$ y fotografiado bajo luz UV (260 nm). 
Tabla 1. BAL con actividad antimicrobiana frente a $\boldsymbol{H}$. pylori y Salmonella spp.

\begin{tabular}{|c|c|c|}
\hline BACTERIA & CEPA & ORIGEN \\
\hline L. casei & CECT475 & QUESO \\
\hline L. delbrueckii bulgaricus & CECT4005T-CECT4006 & YOGUR \\
\hline L. delbrueckii delbrueckii & CECT286 & MEZCLA AGRIA \\
\hline L. paracasei paracasei & CECT4022 & PRODUCTOS LACTEOS \\
\hline L. pentosus & CECT4023 & ENSILADO DE MAIZ \\
\hline L. plantarum & CECT4645 & QUESO \\
\hline L. rhamnosus & CECT278 & PRODUCTOS LACTEOS \\
\hline L. acidophilus & CECT903T* & HUMANO \\
\hline L. brevis & CECT4121* & HECES HUMANO \\
\hline L. reuteri & CECT925* & INTESTINO ADULTO \\
\hline L. salivarius & CECT4063* & SALIVA \\
\hline Leuconosctoc mesenteroides mesenteroides & CECT394* & OLIVAS FERMENTADAS \\
\hline Lactococcus lactis subsp lactis & CECT185 & LECHE \\
\hline L. acidophilus 3 & $9 \mathrm{O} 3$ & LECHE OVEJA \\
\hline L. brevis 1 & $20 \mathrm{O} 4$ & LECHE OVEJA \\
\hline L. paracasei paracasei 1 & $\begin{array}{c}\text { 2O11B-3O10-4O4-10O8- } \\
\text { 1O10-14O5-18O4-21O5- } \\
2 \mathrm{~T} 4\end{array}$ & LECHE OVEJA \\
\hline L. paracasei paracasei 3 & 2006 & LECHE OVEJA \\
\hline L. pentosus & $207-401$ & LECHE OVEJA \\
\hline L. plantarum 1 & $3^{\circ} 9-408-701-908-1705$ & LECHE OVEJA \\
\hline L. plantarum 1 & Q2-Q3 & QUESO OVEJA \\
\hline L. rhamnosus & $12 \mathrm{O} 3$ & LECHE OVEJA \\
\hline Lactococcus lactis subsp lactis 1 & $\begin{array}{c}\text { 1O3-1O8-2O4-2O11- } \\
\text { 6O8-11O4-13O5A- } \\
\text { 13O5B-13O6-19O6-1T4 }\end{array}$ & LECHE OVEJA \\
\hline
\end{tabular}

*Cepas CECT utilizadas solamente para RAPD

\subsubsection{RAPD (Amplificación del DNA mediante iniciadores aleatorios)}

Los dos iniciadores que se utilizaron para amplificar el ADN de las cepas a estudiar se detallan en la tabla 2 . 
Tabla 2. Iniciadores

\begin{tabular}{|l|l|l|}
\hline Nombre & Secuencia & Referencia \\
\hline 1254 & ${ }^{5}$ CCGCAGCCAA $^{3^{\prime}}$ & Torriani et al., 1999 \\
\hline 7254 & ${ }^{5}$ AGTCAGCCAC $^{3^{\prime}}$ & Collado et al., 2006 \\
\hline
\end{tabular}

La reacción de amplificación con el primer 1254 se llevó a cabo en un volumen total de $20 \mu$ que contenía $2.5 \mathrm{U}$ Taq ADN polimerasa, $2 \mu$ lampón, $1 \mu \mathrm{l}$ mezcla dNTP $(10 \mathrm{mM})$, $1.5 \mu \mathrm{Cl}_{2} \mathrm{Mg}(50 \mathrm{mM}), 1.5 \mu \mathrm{l}$ iniciador $1254(20 \mu \mathrm{M})$ y $2.5 \mu \mathrm{l}$ muestra de ADN.

Las condiciones de la PCR fueron (Tabla 3):

Tabla 3. Condiciones PCR. Iniciador 1254

\begin{tabular}{|c||c||c|l|}
\hline No ciclos & Temperatura $\left({ }^{\circ} \mathrm{C}\right)$ & Tiempo (minutos) & Etapa \\
\hline \hline 1 & 94 & 5 & Desnaturalización \\
\hline \multirow{2}{*}{34} & 94 & 1 & \multirow{2}{*}{ Acoplamiento } \\
\cline { 2 - 3 } & 36 & 1 & \\
\hline \hline 1 & 72 & 2 & Polimerización \\
\hline
\end{tabular}

Respecto al iniciador 7254, la reacción de amplificación se efectuó en un volumen de $25 \mu$ l que contenía 2.5 U Taq ADN polimerasa, $2.5 \mu$ l tampón, $1 \mu \mathrm{ldNTP}(10 \mathrm{mM}), 1.5 \mu 1$ $\mathrm{Cl}_{2} \mathrm{Mg}(50 \mathrm{mM}), 1.5 \mu \mathrm{l}$ iniciador $7254(33 \mu \mathrm{M})$ y $2.5 \mu 1$ muestra de ADN. 
Las condiciones de PCR fueron (Tabla 4):

Tabla 4. Condiciones PCR - iniciador 7254

\begin{tabular}{|c|c|c|c|}
\hline $\mathrm{N}^{\mathrm{o}}$ ciclos & Temperatura $\left({ }^{\circ} \mathrm{C}\right)$ & Tiempo (minutos) & Etapa \\
\hline 1 & 94 & 5 & Desnaturalización \\
\hline \multirow{3}{*}{35} & 94 & 1 & \multirow{3}{*}{ Acoplamiento } \\
\hline & 32 & 2 & \\
\hline & 72 & 2 & \\
\hline 1 & 72 & 2 & Polimerización \\
\hline
\end{tabular}

La PCR se realizó en el temociclador (PTC-100. Peltier Thermal Cycler. M J Research). La amplificación fue comprobada por medio de electroforesis en gel de agarosa al 2\% (Roche) a 100 voltios durante 90 minutos. El gel teñido con bromuro de etidio, se visualizó y fue fotografiado bajo luz UV.

\subsubsection{Análisis de los datos}

Los perfiles obtenidos con la técnica RAPD visualizados bajo luz ultravioleta fueron registrados en un soporte informático. Las bandas se analizaron en el programa informático Lane Manager (TDI - España), se utilizó el coeficiente de Dice $\left(\mathrm{S}_{\mathrm{D}}\right)$ para comparar los perfiles de las cepas analizadas y se construyó el dendrograma para obtener una visión gráfica de los datos y establecer como se agrupan las cepas estudiadas. 
$\mathrm{S}_{\mathrm{D}}=2 \mathrm{a} / 2 \mathrm{a}+\mathrm{b}+\mathrm{c}$

Donde:

a : Número de bandas comunes

b y c : Número de bandas no comunes en ambas cepas

\subsection{Antibiogramas}

\subsubsection{Cepas bacterianas}

Además de la caracterización molecular, se analizaron los perfiles de susceptibilidad a antibióticos de las cepas seleccionadas (Tabla 1) por el método de difusión en disco (Bauer

et al., 1966). Una alícuota de $100 \mu \mathrm{l}$ de un cultivo de 24 horas de cada cepa láctica, se inoculó en $10 \mathrm{ml}$ de MRS semisólido ( $0.7 \%$ agar), atemperado a $50{ }^{\circ} \mathrm{C}$ y se vertió en una placa que contenía agar MRS (Collado 2004) (Anexo I). Una vez solidificada la última capa, en la superficie se colocaron los discos de antibióticos, las placas se incubaron a $37^{\circ} \mathrm{C}$ en anaerobiosis durante 24-48 horas. A continuación, se midieron los diámetros de inhibición. Los ensayos se realizaron por duplicado. 
Se emplearon en total 12 antibióticos clasificados de la siguiente forma (Tabla 5):

Tabla 5. Antibióticos

\begin{tabular}{|c|c|}
\hline Modo Acción & Antibióticos \\
\hline \hline \begin{tabular}{c|c|}
\hline Inhibidores de la síntesis de la pared celular \\
B-lactamicos
\end{tabular} & $\begin{array}{c}\text { Amoxicilina }(30 \mu \mathrm{g}), \text { Ceftriaxona }(30 \mu \mathrm{g}), \text { Cefalotina } \\
(30 \mu \mathrm{g}), \text { Ampicilina }(10 \mu \mathrm{g}), \text { Carbencilina }(100 \mu \mathrm{g})\end{array}$ \\
\hline $\begin{array}{c}\text { Inhibidores de la síntesis proteica } \\
\text { Aminoglucósidos }\end{array}$ & $\begin{array}{c}\text { Gentamicina }(10 \mu \mathrm{g}), \text { Cloranfenicol }(30 \mu \mathrm{g}), \\
\text { Tetraciclina }(30 \mu \mathrm{g}), \text { Amikacina }(10 \mu \mathrm{g})\end{array}$ \\
\hline \hline $\begin{array}{c}\text { Inhibidores de la síntesis de ácidos nucleicos } \\
\text { Trimetoprim }(25 \mu \mathrm{g}), \text { Ciprofloxacino }(5 \mu \mathrm{g}), \mathrm{Acido} \\
\text { Nalidíxico }(30 \mu \mathrm{g})\end{array}$ \\
\hline
\end{tabular}

\section{RESULTADOS}

\subsection{Caracterización molecular por RAPD}

La cepa de la CECT185 identificada como Lactococcus lactis subsp lactis no pudo ser tipada con ninguno de los dos iniciadores empleados a las condiciones descritas en las tablas 5 y 6. Lo mismo, sucedió con las cepas 608 de Lactococcus lactis subsp lactis y CECT4063 de L. salivarius al amplificarlas con el iniciador 1254.

\section{Iniciador 1254}

Algunos de los perfiles obtenidos mediante la técnica RAPD con el iniciador descrito por Torriani et al. (1999) se muestran en la figura 1. El número de bandas estuvo entre 1 y 8 con pesos moleculares entre 1856 y 130 pares de bases (pb).

La similitud del conjunto de todas las BAL aisladas de leche de oveja y la CECT basada en los perfiles obtenidos mediante RAPD con el iniciador 1254 fue evaluada generando un dendrograma mostrado en la Figura 2. Se aprecian 2 grupos con un nivel de 
similitud de $10.2 \%$. Las cepas estudiadas no se asocian de acuerdo a los perfiles de inhibición frente a H. pylori y Salmonella spp. El grupo I se dividió en dos grupos A y B, con un nivel de homología de $18 \%$. En el subgrupo A, las cepas comparten la banda $400 \mathrm{pb}$ con una similitud de $30 \%$. El subgrupo B está subdividido en un subgrupo $b .1$ y $b .2$ con una similitud de 30\%. En el subgrupo b.1 las cepas tienen en común la banda 490 pb. El subgrupo b.2 está subdividido en b.2.1 y b.2.2. En b.2.1 predomina la banda $570 \mathrm{pb}$ y en b.2.2 las bandas 990 y 320 pb. En el grupo II las cepas comparten la banda 770 pb.

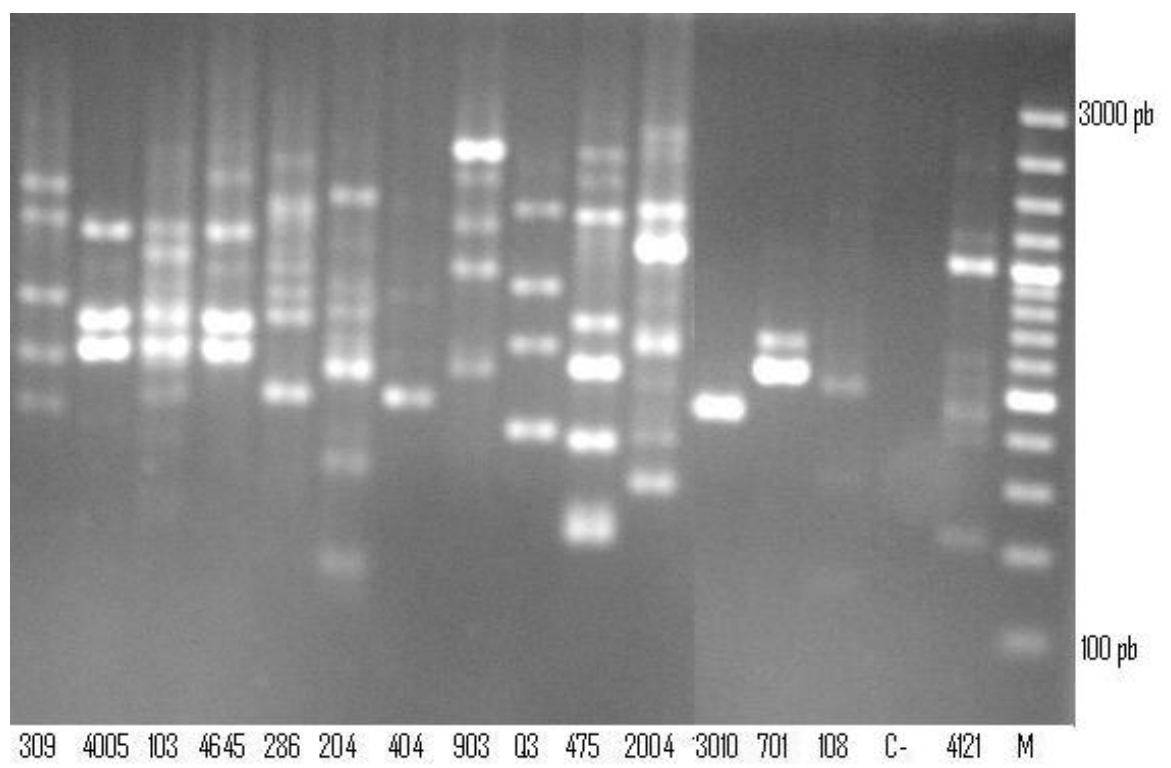

Figura 1. Perfiles generados con la técnica RAPD de las cepas BAL aisladas de leche de oveja Guirra y las pertenecientes a la CECT empleando el iniciador 1254. L. plantarum (309, CECT4645, 701, Q3), L. paracasei (4O4, 3010), L. brevis (2004, CECT4121), L. delbrueckii bulgaricus (CECT4005), L. delbrueckii delbrueckii (CECT286), L. casei (CECT475), L. acidophilus (903), Lactococcus lactis subsp lactis (103, 204, 108) (C-).

M Marcador DNA 100 pb. 


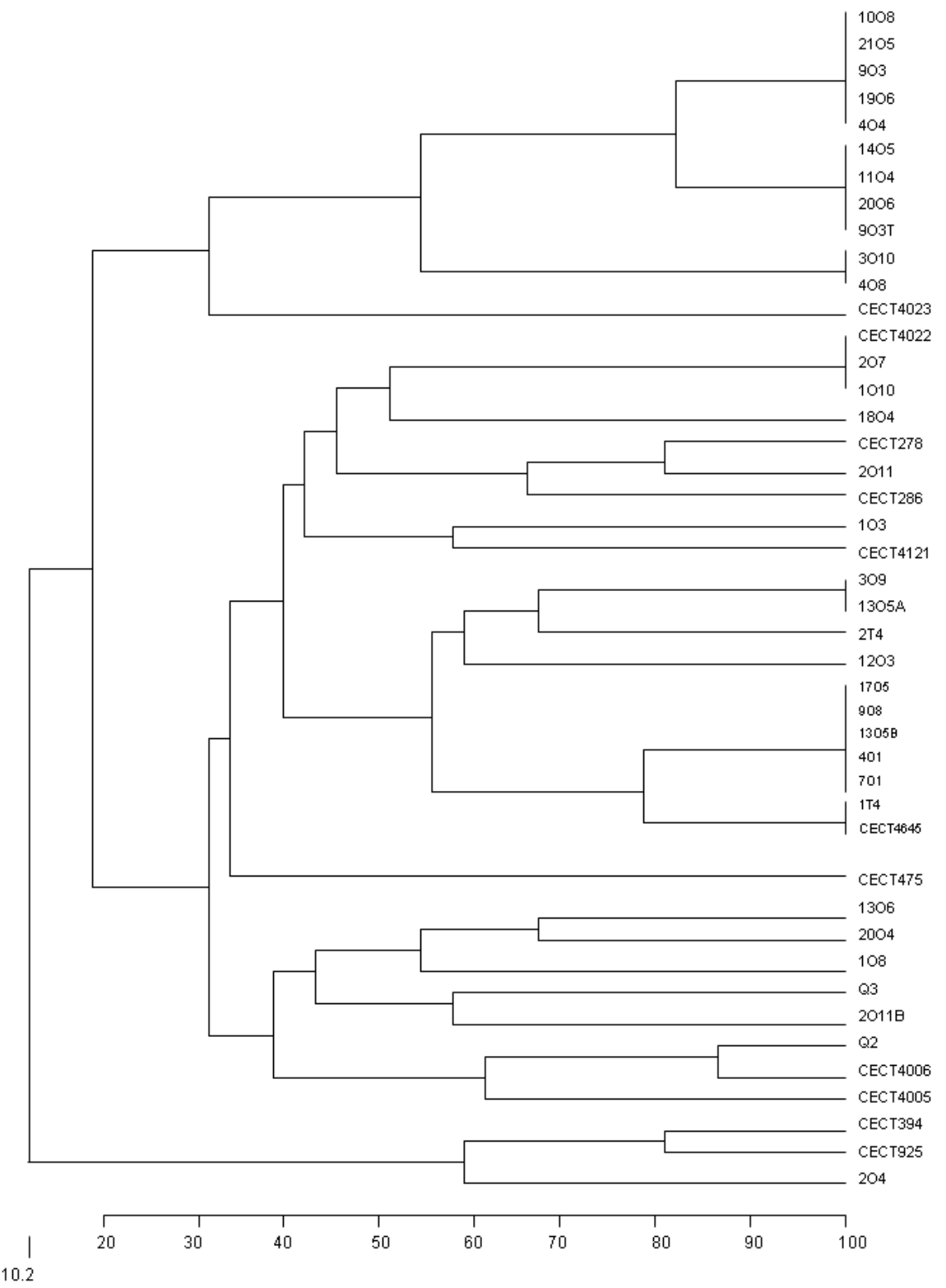

Figura 2. Dendrograma obtenido de los perfiles RAPD usando iniciador 1254 de las cepas ácido lácticas con actividad antimicrobiana frente a $\mathrm{H}$. pylori y Salmonella spp. 


\section{$\underline{\text { Iniciador } 7254}$}

Con el iniciador descrito por Collado et al., (2006) se obtienen los perfiles mostrados en la figura 3. El número de bandas estuvo entre 1 y 7 con pesos moleculares que variaron entre 2600 y $200 \mathrm{pb}$.

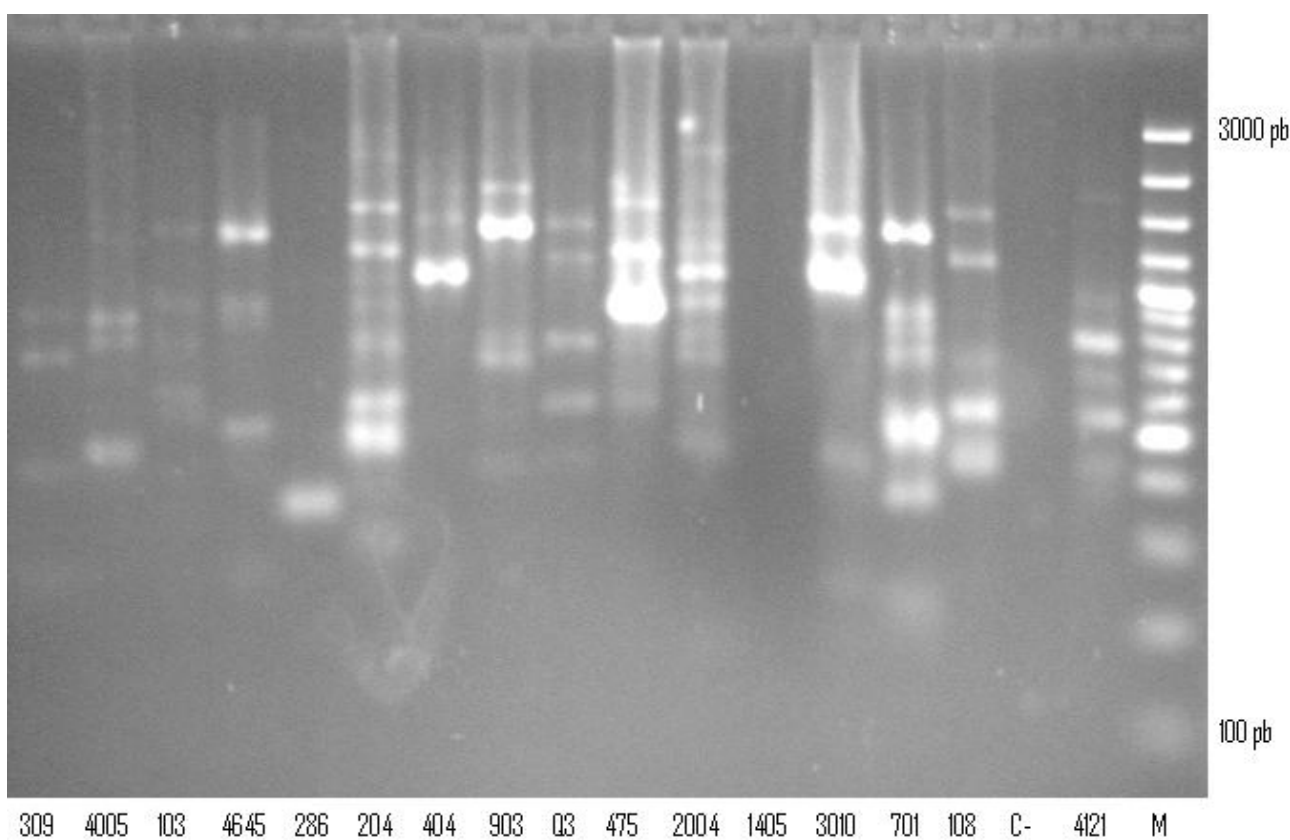

Figura 3. Perfiles generados con la técnica RAPD de las cepas BAL aisladas de leche de oveja Guirra y de la CECT empleando el iniciador 7254. L. plantarum (309, CECT4645, 701, Q3), $L$. paracasei (404, 3010), L. brevis (2004, CECT4121), L. delbrueckii bulgaricus (CECT4005), L. delbrueckii delbrueckii (CECT286), L. casei (CECT475), L. acidophilus (9O3), Lactococcus lactis subsp lactis (103, 204, 108) (C-). M Marcador DNA 100 pb.

La similitud entre las cepas lácticas aisladas de leche de oveja y de la CECT basada en los perfiles obtenidos mediante la técnica RAPD con el iniciador 7254 se examinó mediante un dendrograma mostrado en la Figura 4. El conjunto de BAL estudiadas fueron agrupadas con un nivel de similitud de 16.7 \%. Similar a lo presentado con el iniciador 1254 , 
las cepas lácticas no se asocian a perfiles de inhibición antimicrobiana frente a patógenos. Se observan tres grupos diferenciados.

El grupo I se subdivide en A y B con una similitud de $25 \%$. El grupo A se compone de $a .1$ y a.2. El subgrupo a.1 se subdivide en a.1.1 y a.1.2, las cepas comparten las bandas $870 \mathrm{pb}$ y $410 \mathrm{pb}$, respectivamente. En el subgrupo a.2 la banda común es de 400 pb. En el grupo B, la banda compartida es de $1190 \mathrm{pb}$.

En el grupo II con una homología de 33\%, las cepas comparten la banda $650 \mathrm{pb}$.

El grupo III, con una homología de $18 \%$, esta formada por los grupos A y B. El primer grupo tiene en común la banda $580 \mathrm{pb}$ y el segundo una banda de $1410 \mathrm{pb}$. 


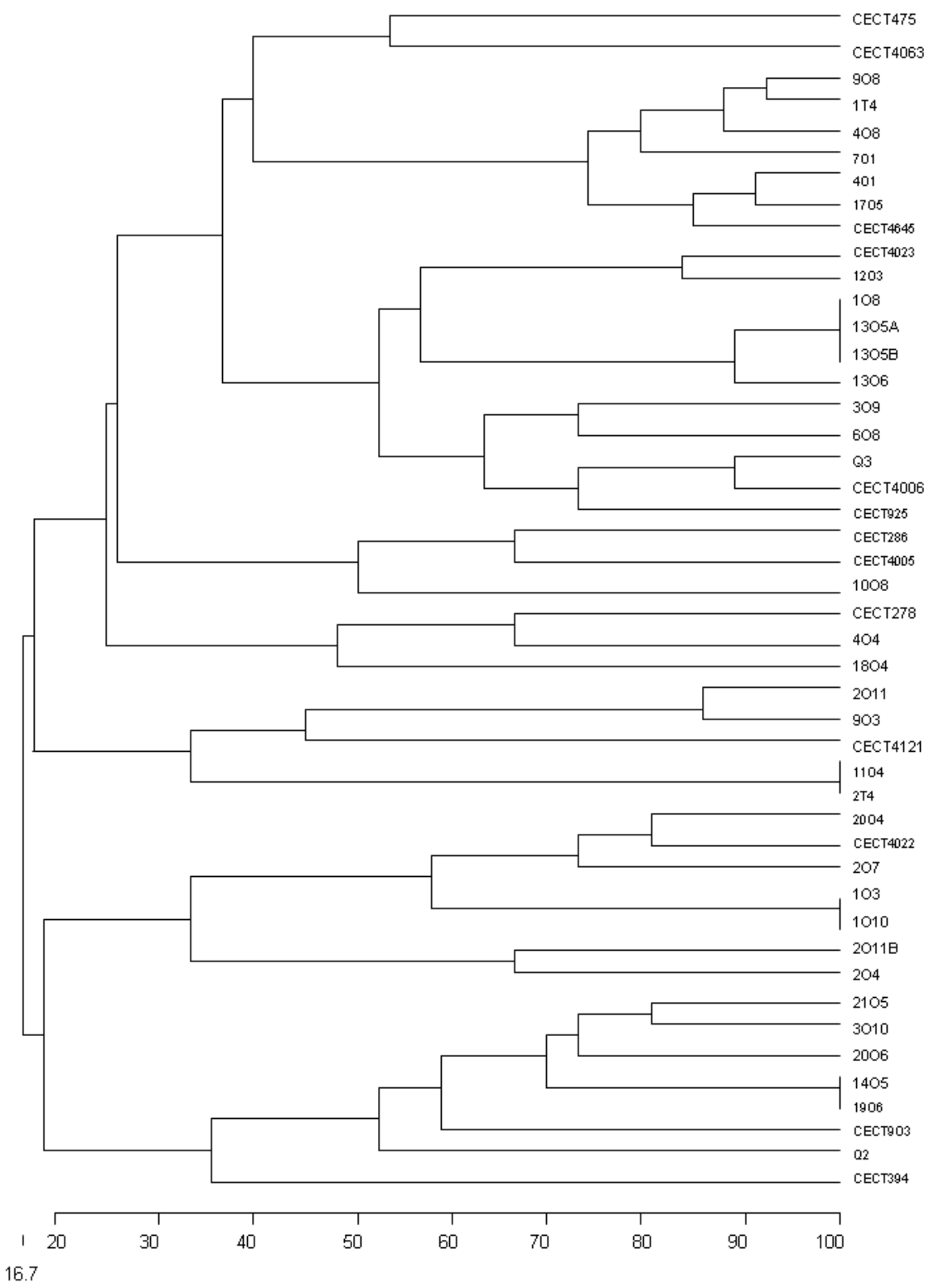

Figura 4. Dendrograma obtenido de los perfiles RAPD usando iniciador 7254 de las cepas ácido lácticas con actividad antimicrobiana frente a $\mathrm{H}$. pylori y Salmonella spp. 


\subsection{Antibiogramas}

\subsubsection{Cepas bacterianas}

La susceptibilidad de las BAL estudiadas respecto a los antibióticos se ilustra en la Tabla 6 y figura 5. La selección de nuevas cepas probióticas requiere de este criterio para asegurar su uso y las posibles aplicaciones como adyuvante en los tratamientos de infecciones gastrointestinales.

Todas las BAL estudiadas fueron resistentes a ácido nalidíxico, un 90\% de las cepas fueron resistentes a trimetoprim, $80 \%$ a amikacina, $72 \%$ a gentamicina, $38 \%$ a ciprofloxacino y $3 \%$ a ceftriaxona y tetraciclina (Figura 6). Según Fukao et al., (2009), se encontraron genes de resistencia a tetraciclina en Lactobacillus. Todas las cepas pertenecientes a las especies $L$.

acidophilus y L. delbrueckii lactis fueron resistentes a trimetoprim (Figura 9) y ciprofloxacino (Figura 10); L. brevis y L. casei a trimetoprim; L. delbrueckii delbrueckii, L. pentosus y L. paracasei paracasei a gentamicina (Figura 7), trimetoprim y amikacina (Figura 15); L. plantarum a gentamicina y amikacina y L. rhamnosus a trimetoprim y amikacina. Las cepas de L. paracasei y L. rhamnosus aisladas de heces fueron resistentes a vancomicina, gentamicina, kanamicina, sulfato de colistina y ácido oxolínico (Verdenelli et al., 2009).

Las BAL estudiadas fueron sensibles a $\beta$-lactamicos como amoxicilina (Figura 8), ampicilina (Figura 16), carbencilina (Figura 17), cefalotin (Figura 13) y aminoglucósidos como cloranfenicol (Figura 6, 12). Estos resultados coinciden con las recomendaciones de la EFSA y las publicaciones de R. Martín et al., (2009) y P. Rodriguez et al., (2009).

35 de las 39 cepas fueron resistentes a $25 \mu \mathrm{g} / \mathrm{ml}$ trimetoprim. Estos resultados son similares a lo publicado por Mejía et al., (2007), quien trabajó con cepas BAL. 
Las BAL estudiadas por Mejía et al., (2007), fueron sensibles a $0.5 \mu \mathrm{g}$ de ampicilina con halos de inhibición entre 12 y $30 \mathrm{~mm}$. En este estudio, todas las BAL fueron susceptibles a $10 \mu \mathrm{g} / \mathrm{ml}$ de ampicilina con halos de inhibición entre 17 y $38.5 \mathrm{~mm}$ (Figura 16).

El conjunto de las cepas de las especies $L$. paracasei, L. plantarum y L. rhamnosus presentaron resistencia a gentamicina y amikacina. Se sugiere que Lactobacillus tiene resistencia a aminoglucósidos debido a la impermeabilidad de la membrana (P. Rodriguez et al., 2009). De otro lado Mannua et al., (2003), consideraron que puede existir una resistencia sinérgica entre los agentes de la pared celular y los aminoglucósidos. Este es un problema grave porque se reduce el número de posibles tratamientos para infecciones por enterococos.

Los Lactococcus fueron más resistentes a aminoglucósidos, especialmente a gentamicina (P. Rodriguez et al., 2009). Los resultados del presente este estudio mostraron cepas sensibles y resistentes a gentamicina y amikacina.

24 cepas de las BAL fueron sensibles a la fluoroquinolona ciprofloxacino. En contraste, otros estudios indicaron que el ciprofloxacino desplegó poca actividad sobre BAL. Se considera, que la resistencia a fluoroquinolona en bacterias Gram positivas esta asociada a mutaciones en el QRDR de gyrA y parC (Fukao et al., 2009).

L. acidophilus fue resistente a tres antibióticos, L. brevis y L. casei a dos. Mientras, L. delbrueckii, L. paracasei, L. pentosus, L. plantarum, L. rhamnosus y Lactococcus lactis presentaron resistencias a dos y cinco antibióticos respectivamente. Algunas cepas han presentado multi-resistencia. Es importante realizar otras pruebas que comprueben dicha multi-resistencia y verificar si es codificada en el cromosoma o en los plásmidos, con el fin de evitar transmitir dicha resistencia a otras bacterias próximas. 


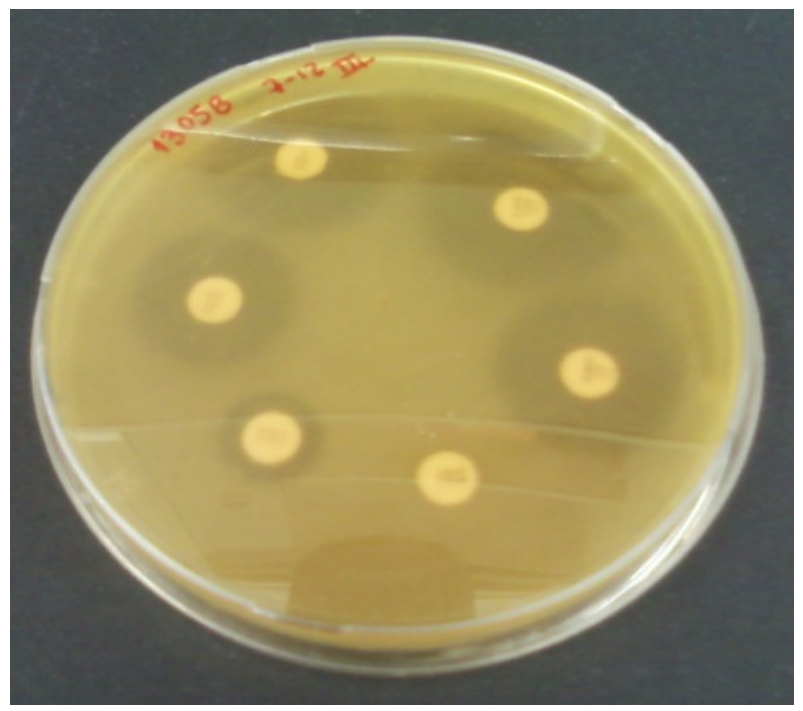

Figura 5. Antibiograma de la cepa láctica 1305B aislada de leche de oveja Guirra.

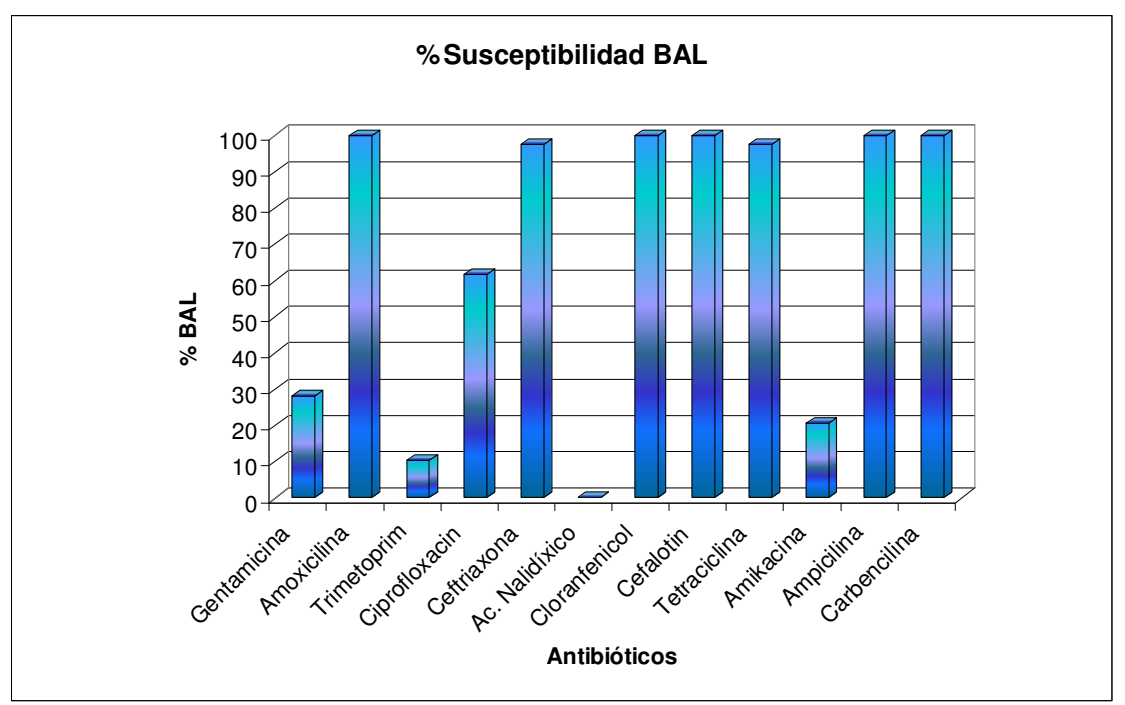

Figura 6. Porcentaje de susceptibilidad cepas BAL aisladas de oveja Guirra y CECT. 
Tabla 6. Antibiograma de las cepas aisladas de leche de oveja Guirra y CECT con actividad antimicrobiana frente a $\mathrm{H}$. pylori y Salmonella. Media en mm y (SEM) error estándar de la media de dos análisis.

\begin{tabular}{|c|c|c|c|c|c|c|c|c|c|c|c|c|c|}
\hline \multirow{3}{*}{$\begin{array}{c}\text { CEPA } \\
\text { BALA }\end{array}$} & \multirow[t]{3}{*}{ ID API } & \multicolumn{12}{|c|}{ Antibioticos tus } \\
\hline & & 10 & 30 & 25 & 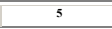 & 30 & & 30 & ${ }^{30}$ & 30 & 30 & 10 & 100 \\
\hline & & G en tam icina & A moxicilina & Trimetop rim & Ciprofloxacin & Ceffriaxona & Ac. Nalididico & Clora nefenicol & Cefalot tin & Tetraciclina & Am ika cina & Ampicilina & Carbencilin \\
\hline 903 & L. acidoph ilus 3 & $9.0 \pm 0.0$ & $35.5 \pm 2.1$ & & & $28.0 \pm 0.0$ & & $27.0 \pm 1.4$ & $34.0 \pm 0.0$ & $31.0 \pm 0.0$ & $7.9 \div 1.4$ & $31.5 \pm 0.7$ & $37.5 \pm 2.1$ \\
\hline 2004 & L.brevis I & $11.5 \pm 0.7$ & $36.5 \neq 2.1$ & & $9.5 \pm 0.7$ & $28.5 \neq 2.1$ & & $34.0 \pm 0.0$ & $36.5 \neq 2.1$ & $20.5 \pm 0.7$ & $9.0 \pm 0.0$ & $33.0 \pm 1.4$ & $37.0 \pm 1.4$ \\
\hline CEC T475 & L. cassei & $8.9+1.4$ & $27.9 \pm 2.8$ & & $11.4 \pm 2.1$ & $17.9 \pm 2.8$ & & $25.0 \pm 0.0$ & $30.4 \pm 3.5$ & $30.0 \pm 0.0$ & $8.9 \div 1.4$ & $27.0 \pm 1.4$ & $32.5 \pm 0.7$ \\
\hline CEC T4006 & L. delbrue ckii bulgaricus & $21.0 \pm 0.0$ & $38.4 \pm 3.5$ & & & $32.5 \pm 0.7$ & & $30.0 \pm 0.0$ & $33.9+2.8$ & $33.5 \pm 0.7$ & $29.0 \pm 1.4$ & $36.0 \pm 0.0$ & $37.0 \pm 0.0$ \\
\hline CEC T286 & L. delbruec kii delbru eckii & & $35.5 \pm 2.1$ & & & $33.5 \pm 2.1$ & & $29.5 \pm 0.7$ & $38.5 \pm 0.7$ & $29.9 \pm 2.8$ & & $32.5 \pm 2.1$ & $37.9 \pm 2.8$ \\
\hline CEC T4022 & L.paracasei paracasei & & $29.9 \pm 2.8$ & & $10.0 \pm 0.0$ & $22.0 \pm 0.0$ & & $25.0 \pm 0.0$ & $26.5 \pm 0.7$ & $28.5 \pm 2.1$ & & $30.0 \pm 0.0$ & $35.5 \pm 0.7$ \\
\hline 1008 & L.paracasei paracasei I & & $34.5 \pm 2.1$ & & $13.5 \pm 0.7$ & $32.0 \pm 1.4$ & & $30.5 \pm 0.7$ & $28.0 \pm 0.0$ & $10.5 \pm 0.7$ & & $35.0 \pm 0.0$ & $32.5 \pm 0.7$ \\
\hline 1010 & L.paracaseiparace & & $35.5 \pm 0.7$ & & $12.0 \pm 1.4$ & $26.0 \pm 0.0$ & & $29.0 \pm 1.4$ & $26.5 \pm 0.7$ & $30.0 \pm 0.0$ & & $33.5 \pm 0.7$ & $41.5 \pm 0.7$ \\
\hline 1405 & L. paracasei paracasei 1 & & $31.0 \pm 0.0$ & $12.0 \pm 0.0$ & & $24.0 \pm 0.0$ & & $22.0 \pm 0.0$ & $19.5 \pm 0.7$ & $18.0 \pm 0.0$ & & $29.0 \pm 1.4$ & $26.5 \pm 0.7$ \\
\hline 2006 & L.paracasei paracase 3 & & 38.5 & & 16.5 & 34.5 & & 31.5 & $27.0 \pm 1.4$ & 14. & & $38.5 \pm 2.1$ & $37.0 \pm 1.4$ \\
\hline $2011 \mathrm{~B}$ & L.par. & & $30.5 \pm 0.7$ & & $10.5 \pm 0.7$ & 23.9 & & $28.5 \pm 0.7$ & $31.5 \pm 0.7$ & $13.0 \pm 1.4$ & & $30.5 \pm 0.7$ & $29.0 \pm 0.0$ \\
\hline 2105 & 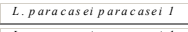 & & $35.0 \pm 1.4$ & & & 25.5 & & $30.0 \pm 0.0$ & $27.0 \pm 0.0$ & $13.0 \pm 1.4$ & & $33.0 \pm 1.4$ & $33.5 \pm 0.7$ \\
\hline 3010 & L.paracasei paracasese i & & $39.0 \pm 1.4$ & & & $34.5 \neq 0.7$ & & $31.9 \pm 2.8$ & $27.0 \pm 0.0$ & $14.5 \neq 0.7$ & & $36.0 \pm 1.4$ & $39.4 \pm 3.5$ \\
\hline 404 & L. paracasei paracasei I & & $33.9 \pm 2.8$ & & $12.0 \pm 0.0$ & $33.9 \pm 2.8$ & & $30.4 \pm 3.5$ & $29.9 \pm 2.8$ & $17.9 \pm 2.8$ & & $38.5 \pm 0.7$ & $33.0 \pm 1.4$ \\
\hline$\frac{2 \mathrm{~T} 4}{1804} \mathrm{r} \mathrm{l} \mathrm{C}$ & 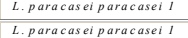 & & $\begin{array}{l}37.5 \pm 0.7 \\
22.5 \pm 0.7 \\
\end{array}$ & & $13.0 \pm 0.0$ & \begin{tabular}{|l|l|}
$31.0 \pm 0.0$ \\
$15.5 \pm 0.0$ \\
\end{tabular} & & $\begin{array}{l}31.5 \pm 0.7 \\
21.5 \pm 0.7\end{array}$ & $\begin{array}{l}27.9 \pm 2.8 \\
20.5 \pm 0.7\end{array}$ & $\begin{array}{l}18.0 \pm 0.0 \\
9.0 \pm 0.0\end{array}$ & & \begin{tabular}{|l|l|l}
$37.0 \pm 1.4$ \\
$19.0 \pm 0.0$
\end{tabular} & $\begin{array}{l}39.0 \pm 1.4 \\
24.0 \pm 0.0\end{array}$ \\
\hline CECT & L. pentosus & $12.0 \pm 0.0$ & 31.5 & & & $33.5 \pm 0.7$ & & $30.0 \pm 1.4$ & $24.0 \pm 0.0$ & $27.0 \pm 0.0$ & $10.5 \pm 0.7$ & $29.5 \div 0.7$ & $30.5 \pm 2.1$ \\
\hline 207 & L.pentosus & & 29. & & & $18.0=$ & & $22.0 \pm 0.0$ & $21.0 \pm 0.0$ & $30.0 \pm 1.4$ & & $6.5 \neq 2.1$ & $34.0 \pm 0.0$ \\
\hline 401 & L.pentosus & & $33.0 \pm 1.4$ & & $9.0 \pm 0.0$ & $18.0 \pm 0.0$ & & $25.5 \pm 0.7$ & $25.0 \pm 0.0$ & $125 \pm 0.7$ & & $30.5 \div 0.7$ & $33.0+1.4$ \\
\hline
\end{tabular}


Capitulo IV

\begin{tabular}{|c|c|c|c|c|c|c|c|c|c|c|c|c|c|}
\hline \multirow{3}{*}{$\begin{array}{c}\text { CEXA } \\
\text { BAA }\end{array}$} & \multirow[t]{3}{*}{ D API } & \multicolumn{12}{|c|}{ 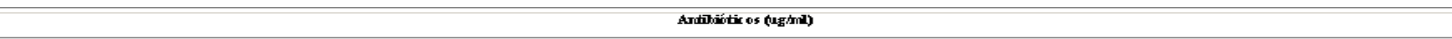 } \\
\hline & & 10 & 30 & 25 & 5 & 30 & 30 & 30 & 30 & 30 & 30 & 10 & 100 \\
\hline & & Gertaminina & Amoxialina & Thinetoprim & Gyrefloxacion & Ceffinixena & Ac. Nalifaice & Cacrantenic ol & Cefstotin & Tetraciktha & Anditacina & Ampiatina & Cartenatina \\
\hline 1705 & 2. panterven 1 & $\cdot$ & $31.5 \pm 0.7$ & $\cdot$ & $9.0 \pm 0.0$ & $20.4 \pm 2.1$ & & $27.0 \pm 0.0$ & $24.0 \pm 0.0$ & $12.5 \pm 0.7$ & - & $29.0 \pm 0.0$ & $28.0 \pm 0.0$ \\
\hline 309 & 2. phanterymen 1 & - & $28.5 \pm 2.1$ & - & & $13.0 \pm 0.0$ & & $25.0 \pm 1.4$ & $19.9 \pm 2.8$ & $11.5 \pm 0.7$ & - & $28.0 \pm 1.4$ & $26.9 \pm 2.8$ \\
\hline 408 & 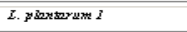 & $\cdot$ & $30.0 \pm 1.4$ & - & $10.0 \pm 0.0$ & $18.4 \pm 2.1$ & - & $25.5 \pm 0.7$ & $24.5 \pm 0.7$ & $22.0 \pm 0.0$ & - & $25.5 \pm 0.7$ & $26.5 \pm 0.7$ \\
\hline 701 & 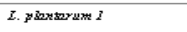 & - & $33.5+2.1$ & - & - & $19.0 \pm 0.0$ & - & $29.0 \pm 1.4$ & $26.0 \pm 0.0$ & $15.0 \pm 0.0$ & $\cdot$ & $31.0 \pm 0.0$ & $31.5 \pm 0.7$ \\
\hline $\mathrm{Q}^{2}$ & 2. pinstarym 1 & $\cdot$ & $36.5 \pm 2.1$ & $16.4 \pm 2.1$ & - & $35.5 \pm 0.7$ & $\theta$ & $26.0 \pm 1.4$ & $24.0 \pm 1.4$ & $2,4 \pm 2.1$ & - & $37.0 \pm 1.4$ & $30.5 \pm 0.2$ \\
\hline$Q^{3}$ & 2. pientervem & - & $36.5 \pm 0.7$ & $14.9 \pm 2.8$ & & $34.0 \pm 0.0$ & - & $23.5 \pm 2.1$ & $22.0 \pm 1.4$ & $21.0 \pm 0.0$ & - & $34.0 \pm 0.0$ & $31.5 \pm 2.1$ \\
\hline 908 & 2. phenterym & . & $30.0 \pm 0.0$ & . & $9.0 \pm 0.0$ & $17.5 \pm 0.7$ & . & $20.0 \pm 0.0$ & $24.0 \pm 0.0$ & $13.0 \pm 0.0$ & - & $30.0 \pm 0.0$ & $30.0 \pm 0.0$ \\
\hline CECT278 & 2. rhamnosus & $7.5 \pm 0.7$ & $25.5 \pm 0.7$ & - & $9.5 \pm 0.7$ & $14.0 \pm 1.4$ & - & $20.5 \pm 0.7$ & $18.5 \pm 0.7$ & $23.0 \pm 1.4$ & - & $23.0 \pm 1.4$ & $26.0 \pm 0.0$ \\
\hline 1203 & 2. hemenosus & 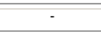 & $40.5 \pm 0.7$ & 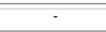 & & $33.0 \pm 1.4$ & - & $30.0 \pm 1.4$ & $30.0 \pm 0.0$ & $13.5 \pm 0.7$ & - & $35.5 \pm 0.7$ & $34.0 \pm 1.4$ \\
\hline 103 & 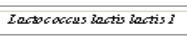 & - & $29.5 \pm 0.7$ & - & $11.0 \pm 0.0$ & $19.0 \pm 1.4$ & - & $24.5 \pm 2.1$ & $24.0 \pm 1.4$ & $20.5 \pm 0.7$ & - & $27.0 \pm 1.4$ & $33.4 \pm 3.5$ \\
\hline 108 & Zactococous lactis lactis I & $14.3 \pm 0.6$ & $31.0 \pm 0.0$ & - & $11.7 \pm 0.6$ & $30.0 \pm 0.0$ & & $27.0 \pm 1.0$ & $28.0 \pm 1.0$ & $93 \pm 0.6$ & $12.0 \pm 1.0$ & $26.0 \pm 0.0$ & $32.0 \pm 0.0$. \\
\hline 1104 & 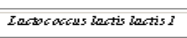 & & $36.5 \pm 0.7$ & - & & $31.5 \pm 0.7$ & & $20.0 \pm 0.0$ & $23.5 \pm 2.1$ & $13.0 \pm 1.4$ & & $35.0 \pm 1.4$ & $33.5 \pm 0$. \\
\hline 130SB & Zarbococcus lactis leatis I & $8.0 \pm 0.0$ & $26.3+0.6$ & - & $11.7 \pm 0.6$ & $16.0 \pm 0.0$ & - & $25.0 \pm 0.0$ & $19.7 \pm 0.6$ & $11.0 \pm 0.0$ & $73 \pm 0.6$ & $21.7 \pm 0.6$ & $24.7 \pm 0.3$ \\
\hline 1006 & 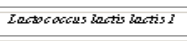 & $9.5 \pm 0.7$ & $32.0 \pm 0.0$ & . & $9.9 \pm 1.4$ & $26.5 \pm 2.1$ & 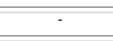 & $2.0 \pm 0.0$ & $29.0 \pm 0.0$ & $30.0 \pm 0.0$ & . & $31.0 \pm 1.4$ & $33.5 \pm 2.1$. \\
\hline 2011 & 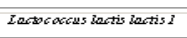 & $9.5 \pm 0.7$ & $36.0 \pm 0.0$ & $12.0 \pm 0.0$ & $15.5 \pm 0.7$ & $29.5 \pm 0.7$ & & $27.5 \pm 2.1$ & $33.0 \pm 0.0$ & $90 \pm 0.0$ & & $34.0 \pm 1.4$ & $36.5 \pm 2.7$ \\
\hline 204 & 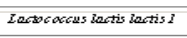 & $13.0 \pm 1.4$ & $24.0 \pm 0.0$ & 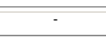 & & $18.0 \pm 0.0$ & - & $18.0 \pm 0,0$ & $20.0 \pm 0.0$ & & $12.0 \pm 0.0$ & $19,0 \pm 0,0$ & $22.0 \pm 0.0$. \\
\hline 608 & Zactococus lactis lactis I & . & $20.0 \pm 0.0$ & & $14.0 \pm 0.0$ & $11.0 \pm 0.0$ & & $15.0 \pm 0,0$ & $15,0 \pm 0,0$ & $9,0 \pm 0,0$ & ${ }^{\prime}$ & $17,0 \pm 0,0$ & $17.0 \pm 0.0,0$ \\
\hline 1T4 & Zarbococcus bactis beatis $P$ & $=$ & $22.0 \pm 0.0$ & - & $10.5 \pm 0.7$ & $10.0 \pm 0.0$ & & $22.0 \pm 0.0$ & $15.5 \pm 0.7$ & $9.5 \pm 0.7$ & $=$ & $20.0 \pm 0.0$ & $22.5 \pm 0.3$ \\
\hline 1305A & Zarbococcus bertis lactis I & - & $23.0 \pm 0.0$ & - & $9.0 \pm 0.0$ & & - & $21.0 \pm 0.0$ & $14.0 \pm 0.0$ & $10,0 \pm 0,0$ & - & $18.0 \pm 0.0$ & $20.0 \pm 0.0$. \\
\hline 1306 & Zarstococcus bectis lactis I & & $22.4 \pm 0.7$ & & $11.5 \pm 0.7$ & $10.5 \pm 0.7$ & & $20.0 \pm 0.7$ & $16.0 \pm 0.0$ & $10.0 \pm 0.0$ & $\cdot$ & $18.5 \pm 0.7$ & $20.0 \pm 0.0$ \\
\hline
\end{tabular}

(-) No se detecta inhibición. 


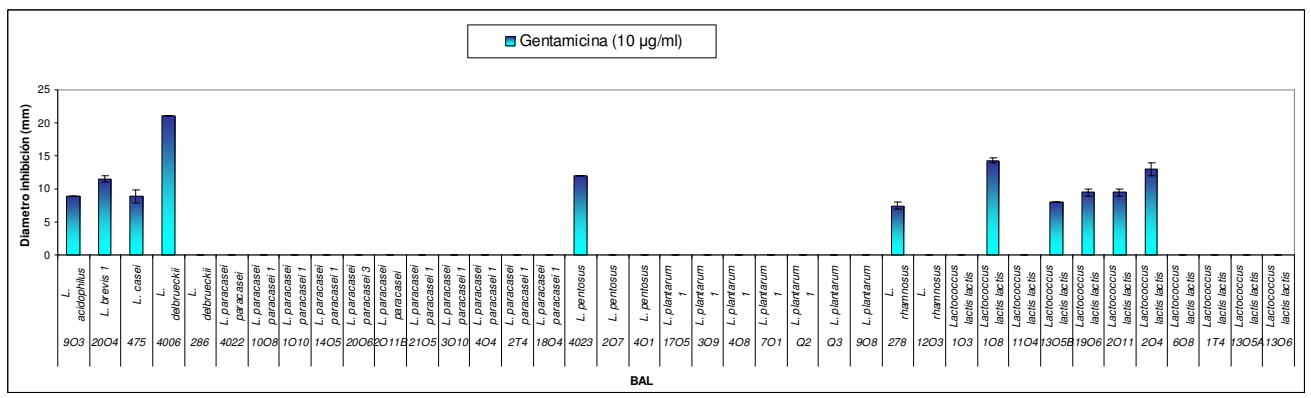

Figura 7. Susceptibilidad de BAL frente a gentamicina $10 \mu \mathrm{g} / \mathrm{ml}$

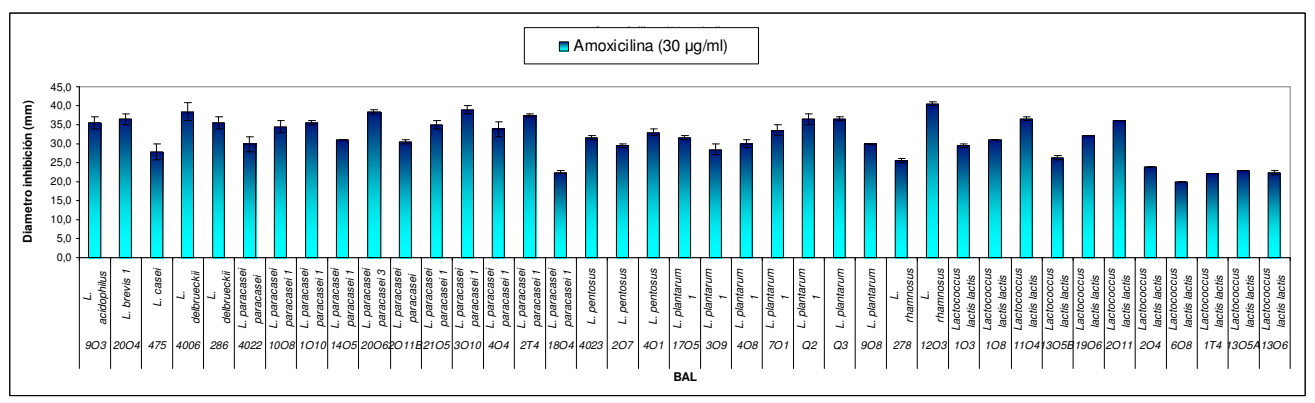

Figura 8. Susceptibilidad de BAL frente a amoxicilina $30 \mu \mathrm{g} / \mathrm{ml}$

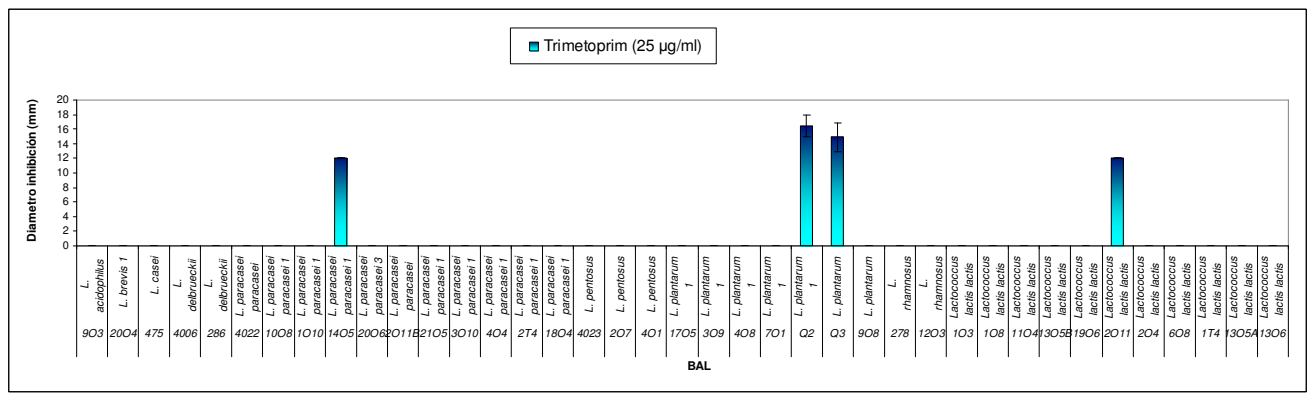

Figura 9. Susceptibilidad de BAL frente a trimetoprim $25 \mu \mathrm{g} / \mathrm{ml}$ 


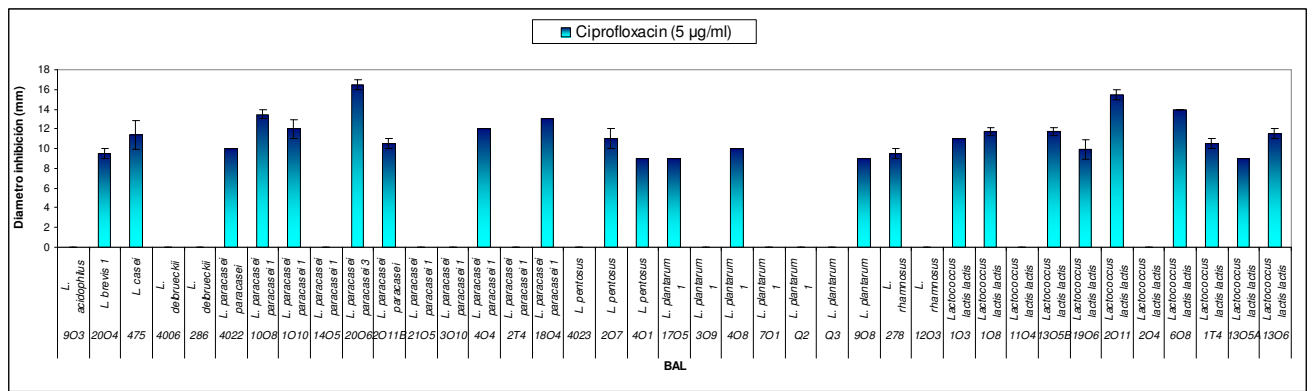

Figura 10. Susceptibilidad de BAL frente a ciprofloxacino $5 \mu \mathrm{g} / \mathrm{ml}$

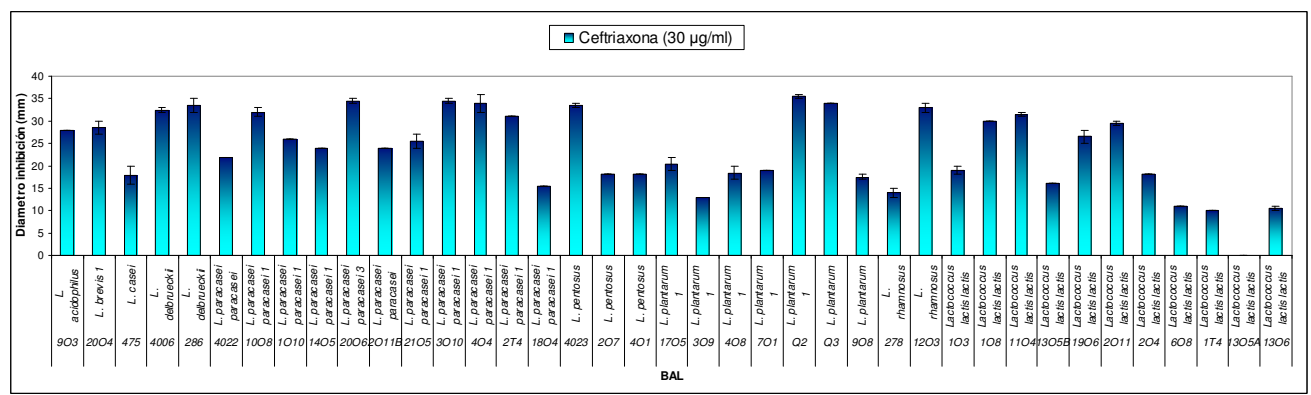

Figura 11. Susceptibilidad de BAL frente a ceftriaxona $30 \mu \mathrm{g} / \mathrm{ml}$

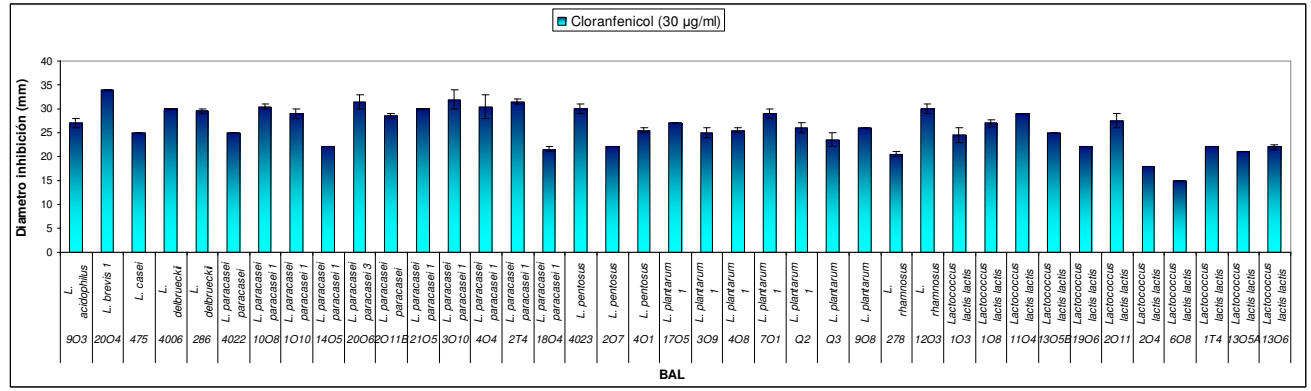

Figura 12. Susceptibilidad de BAL frente a cloranfenicol $30 \mu \mathrm{g} / \mathrm{ml}$ 


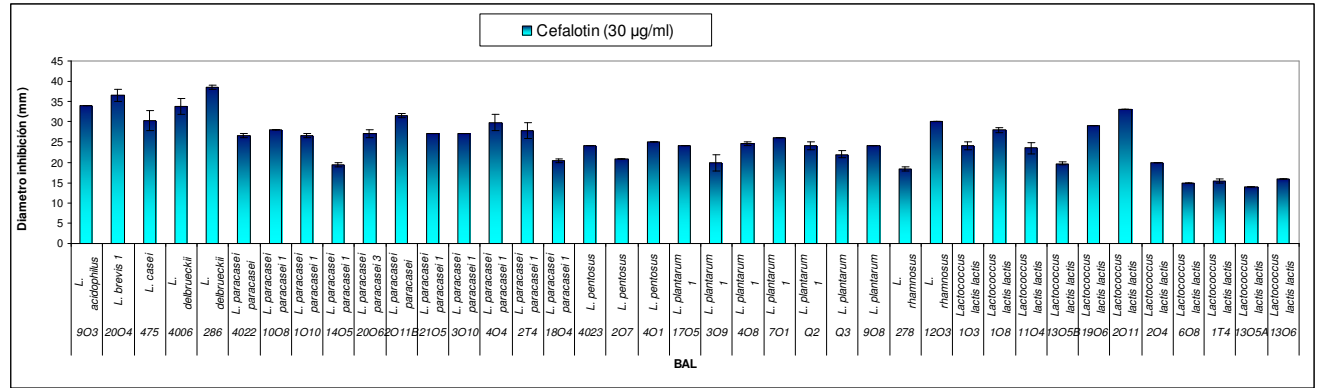

Figura 13. Susceptibilidad de BAL frente a cefalotin $30 \mu \mathrm{g} / \mathrm{ml}$

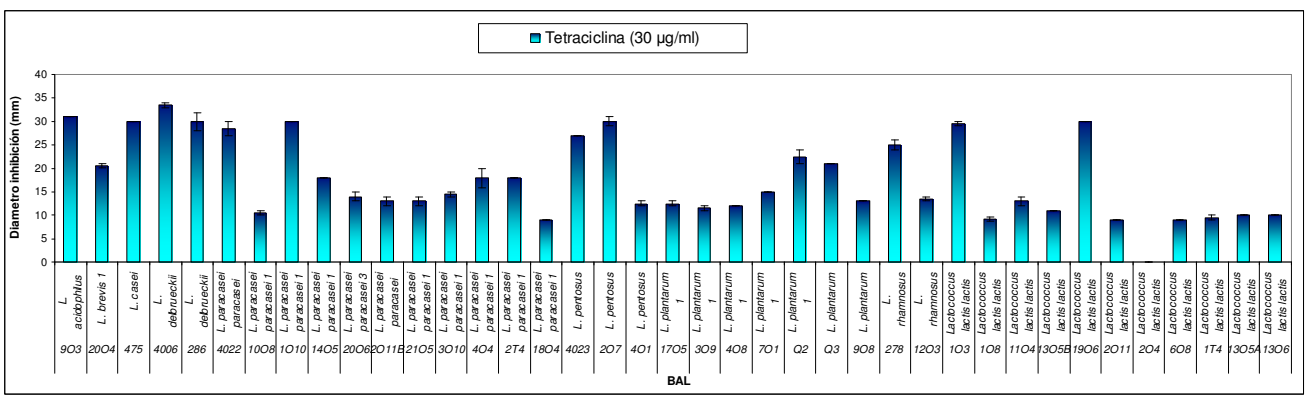

Figura 14. Susceptibilidad de BAL frente a tetraciclina $30 \mu \mathrm{g} / \mathrm{ml}$

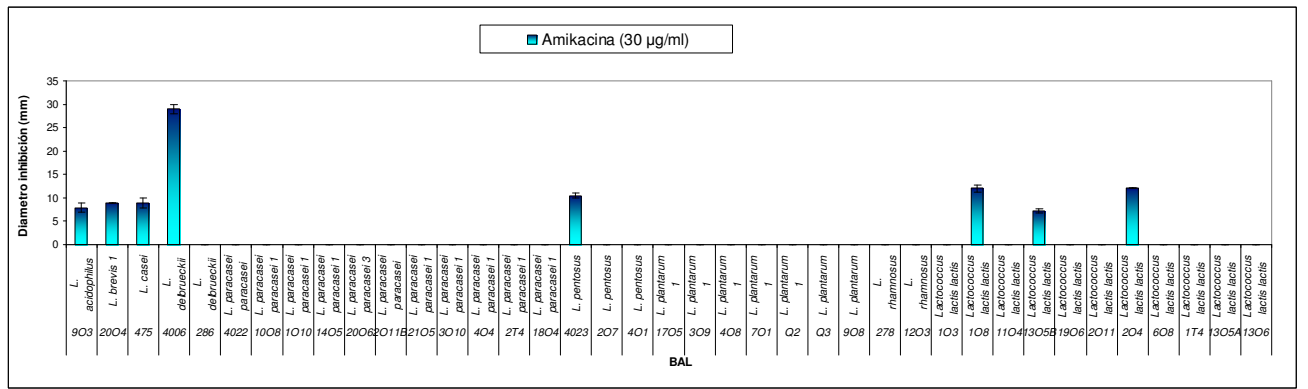

Figura 15. Susceptibilidad de BAL frente a amikacina $30 \mu \mathrm{g} / \mathrm{ml}$ 


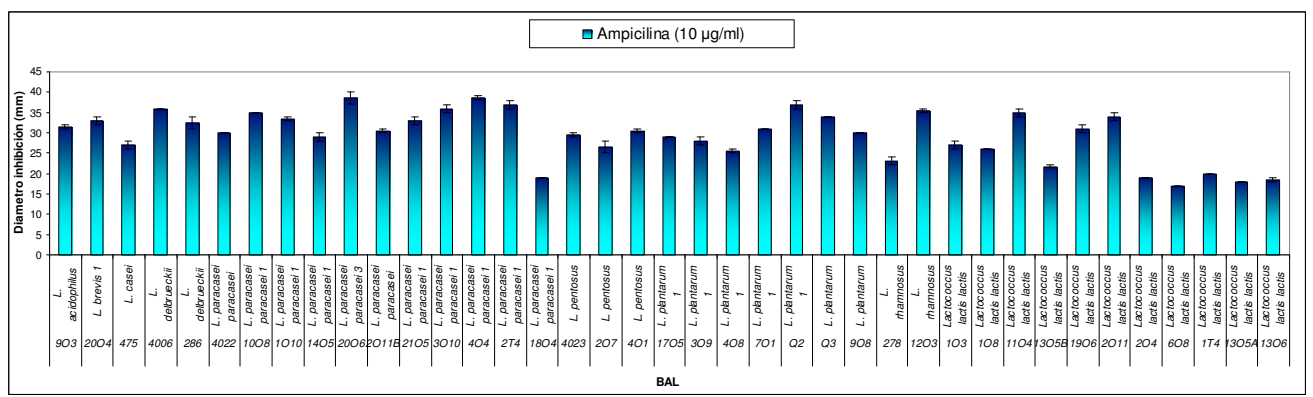

Figura 16. Susceptibilidad de BAL frente a ampicilina $10 \mu \mathrm{g} / \mathrm{ml}$

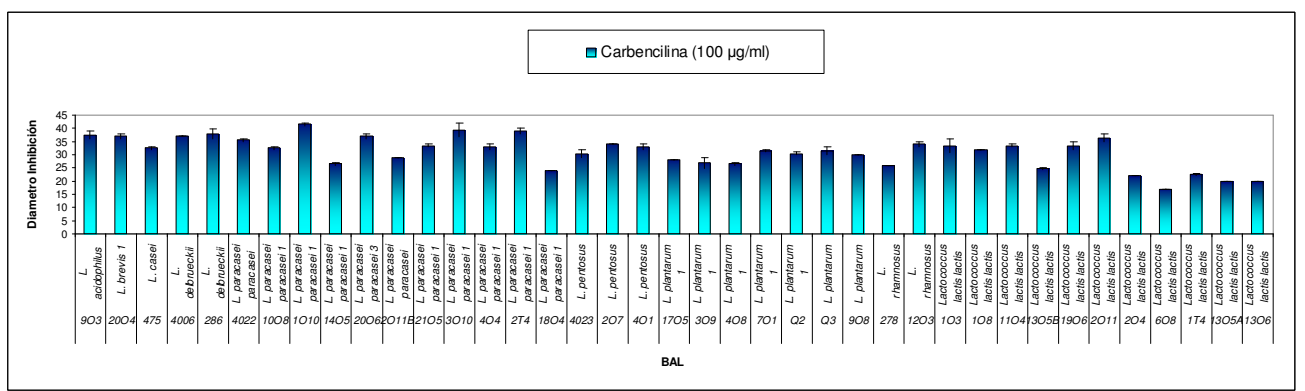

Figura 17. Susceptibilidad de BAL frente a carbencilina $30 \mu \mathrm{g} / \mathrm{ml}$

\section{DISCUSION}

Las cepas de oveja y algunas pertenecientes a la CECT poseen características probióticas (ver capitulo II). Según la FAO (2007), las cepas con potencial probiótico deben ser identificadas a nivel de género, especie y cepa ya que no se puede atribuir un efecto saludable a un género o especie porque esta propiedad es dependiente de la cepa (Collado y Hernández, 2007). Mediante la técnica RAPD y perfiles de resistencia a antibióticos se ha discriminado entre cepas de diferentes especies.

Estudios previos de identificación que combinaron pruebas fenotípicas y genotípicas obtuvieron resultados satisfactorios en la identificación de especies (Berthier y Ehrlich, 
1999; Wang et al., 2009). Aunque, en otras investigaciones se encontraron discrepancias (Jacobsen et al., 1999; Pu et al., 2002; McLeod et al., 2008).

En este estudio se emplearon dos iniciadores por separado en la técnica RAPD, con el fin de evaluar la diversidad intra específica de las BAL ensayadas. No se observó asociación de acuerdo a los resultados de inhibición antimicrobiana frente a los patógenos estudiados, ni perfiles a especies, similar a lo publicado por Gardiner et al., (2002). Varias especies compartieron perfil con un iniciador y con el segundo presentaron perfiles distintos (Zapparoli et al., 2000; Garai-Ibabe et al., 2010). El poder discriminativo aumenta cuando es combinado con otras técnicas o se emplean diferentes iniciadores, lo cual se observó en los resultados obtenidos en este capitulo al emplear los dos iniciadores. No obstante, la información obtenida fue limitada en relación al genoma completo de cada cepa. La técnica RAPD discriminó a nivel intra-específico para las BAL investigadas y la asociación está en función del tamaño de la banda compartida. De acuerdo a R. Martín, et al., (2009), la diversidad intra-específica depende de las especies analizadas y su origen. Las BAL aisladas de leche de oveja Guirra provienen de diferentes granjas, se han obtenido en diferentes periodos de tiempo y han recibido tratamientos diferentes; lo cual puede explicar la variabilidad presentada (Martín-Platero et al., 2009).

La caracterización incluyó la susceptibilidad de las cepas lácticas frente a antibióticos. Lactobacillus asociados a alimentos pueden asociarse al intestino, adquirir e intercambiar genes de resistencia. Por esta razón, es preferible no usar Lactobacillus con genes de resistencia a antibióticos en cultivos iniciadores, con el fin de no afectar a los microorganismos de interés que habitan el intestino (Mejía et al., 2007; P. De Vos et al., 2009).

En el presente estudio los aislados de leche de oveja tienen resistencia a gentamicina, trimetoprim, ciprofloxacino, ceftriaxona, ácido nalidíxico, tetraciclina, amikacina. Otras cepas fueron sensibles a amoxicilina, ceftriaxona, cloranfenicol, cefalotin, 
tetraciclina, ampicilina y carbenicilina (Figura 6). Los mecanismos de resistencia bacteriana están distribuidos en una amplia variedad de bacterias y otros parecen ser mas específicos en ciertas especies y géneros de bacterias (P. Rodriguez et al., 2009). En nuestro caso de estudio, el conjunto de bacterias lácticas mostraron resistencia a acido nalidíxico. A nivel de especie, se encontró que las especies L. acidophilus y L. delbrueckii lactis fueron resistentes a trimetoprim y ciprofloxacino; L. brevis y L. casei a trimetoprim; L. delbrueckii delbrueckii, L. pentosus y L. paracasei paracasei a gentamicina, trimetoprim y amikacina; L. plantarum a gentamicina y amikacina y L. rhamnosus a trimetoprim y amikacina.

Las anteriores variaciones de resistencia a antibióticos indican los cambios en el uso de estos en medicina veterinaria durante los últimos años y muestra como la modernización en la ganadería ha influido en la composición microbiológica de la leche cruda. Este estudio evaluó la susceptibilidad de las BAL frente a antibióticos, de todas maneras es importante determinar la mínima concentración inhibitoria (MIC) y la mínima concentración bactericida (MBC) (P. De Vos et al., 2009) de los aislados, entender los mecanismos genéticos de resistencia y su relación con los atributos tecnológicos en productos lácteos (P. Rodriguez et al., 2009). The European Scientific Committee on Animal (SCAN) y EFSA -FEEDAP proveen detalles explícitos en el estudio de cepas ausentes de genes de resistencia transferibles (Fukao et al., 2009). Preferiblemente las cepas probióticas deben ser sensibles a los antibióticos y en caso contrario, comprobar que los genes de resistencia no sean transferibles (FAO y OMS, 2001; QPS, 2004; Verdenelli et al., 2009).

El presente estudio tiene múltiples implicaciones. Las características fenotípicas de cada cepa son un criterio previo de diferenciación. Los grupos obtenidos por RAPD revelan diferentes perfiles moleculares con los iniciadores 1254 y 7254 . Existe cierta correlación entre la distribución de cepas y la sensibilidad o resistencia a antibióticos. Los resultados de las pruebas fenotípicas y RAPD son una clave de identificación propuesta y permiten asociar un efecto específico a una cepa concreta para posteriores investigaciones a nivel tecnológico, clínico y epidemiológico (Collado, 2004; Berney et al., 2007). Los resultados obtenidos han 
permitido conocer que el conjunto de las cepas BAL aisladas de leche de oveja Guirra y algunas de la CECT además de poseer actividad antimicrobiana frente a patógenos, presentan sensibilidad a algunos antibióticos y a otros no. Esta información es de gran utilidad en el momento que se desee utilizar dichas cepas como probióticos y cuando se pretenda diseñar cultivos iniciadores específicos de las BAL aisladas de leche de oveja Guirra (Tu et al., 2010). 
CAPITULO V

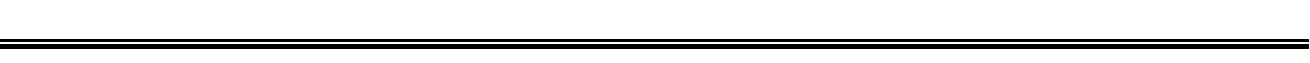

ESTUDIO DE ADHESION A LA MUCINA 


\section{INTRODUCCIÓN}

La adhesión a la mucosa intestinal es un mecanismo complejo, un pre-requisito para la colonización bacteriana en el intestino, necesaria para lograr persistir en el tracto gastrointestinal (Bianchi et al., 2004) y un factor esencial para ejercer una función probiótica (He et al., 2001; Iñiguez-Palomares y Acevedo, 2006; Mejía et al., 2007; Kinoshita et al., 2008).

Las bacterias que constituyen la microbiota intestinal son metabolitamente activas e interaccionan con el ambiente que les rodea influyendo en la fisiología del hospedador (LaraVilloslada et al., 2007). Los patógenos antes de generar la infección, necesitan adherirse al mucus, integrarse a la mucosa y alcanzar el epitelio (Schultsz et al., 1999; Van den Abbeele et al., 2009). Las bacterias probióticas por su capacidad de adhesión pueden proteger al epitelio intestinal generando diferentes respuestas a lo largo del intestino compitiendo por los sitios intestinales, los nutrientes, modulando y estimulando el sistema inmune (Del Re et al., 2000; Deplancke y Gaskins, 2001; Koninkx et al., 2010). Inicialmente estas bacterias probióticas actúan directamente con la capa del mucus y luego con la superficie de los enterocitos (Bianchi et al., 2004). Algunas cepas de L. casei subs. rhamnosus, L. acidophilus, L. coryniformis y L. gasseri inhiben la colonización intestinal por patógenos, reducen la invasión celular por cepas enterovirulentas a través de su habilidad de incrementar la producción de mucinas intestinales e interactuar con la mucosa (Lara-Villoslada et al., 2007; Kinoshita et al., 2008).

En cuanto a los mecanismos de adhesión, Lactobacillus se une a algunos glucolípidos específicos como $\mathrm{G}_{\mathrm{A}} 1$ y tri-hexoxil-ceramida en el tracto intestinal. En el caso de Bifidobacterium, la adherencia al tracto intestinal ocurre por la intervención de la enzima 1,2- $\alpha$-L-fucosidasa (Yamamoto y Katayama, 2004). La habilidad de degradar la mucina es considerada un factor de potencial patogenicidad y toxicidad local. La producción de enzimas que degraden la mucina es un determinante de virulencia de enteropatógenos. Por 
tanto se recomienda un test de degradación de mucina como un marcador importante en la evaluación de seguridad de cepas con potencial probiótico. De hecho, anomalías en la capa del mucus esta asociada con variedad de desordenes, incluyendo cáncer colorrectal, pólipos benignos, enfermedades inflamatorias intestinales, fibrosis quística, procesos de infección y la protección y reconstrucción de la capa del mucus es considerada una estrategia importante en el tratamiento de estos desórdenes (Zhou et al., 2001).

El modelo in vitro más común para evaluar la adhesión de las BAL al mucus intestinal esta basado en la inmovilización de mucina comercial en una placa multipocillos y posterior adhesión de las BAL (Laparra y Sanz, 2009). Las bacterias a ensayar son marcadas con carboxifluoresceina diacetato (CFDA), un compuesto que una vez entra en la célula, es hidrolizado por esterasas no específicas produciendo fluorescencia (Figura 1). El CFDA solo es retenido por células con la membrana intacta y activas metabólicamente (Bunthof y Abee, 2002; Hoefel et al., 2003). El CFDA es hidrofóbico y puede difundirse en la célula a través de la bicapa de fosfolípidos, permeable a moléculas hidrofóbicas y la carboxifluoresceina (CF) al ser hidrófila impide la difusión fuera de la célula (Morono et al., 2004). Por tanto, la capacidad de adhesión se mide mediante la cuantificación de la fluorescencia.

Los modelos in vitro son necesarios para pre-seleccionar las cepas que podrían ensayarse a continuación en pruebas clínicas. Algunos estudios han coincidido en relacionar los resultados de ambos estudios (Collado, 2004). Pero, los estudios in vivo son la herramienta definitiva para establecer la funcionalidad probiótica (P. Fernández et al., 2008).

El principal objetivo de este estudio fue cuantificar la propiedad de adhesión de las BAL con efecto antimicrobiano (Capitulo II), a la mucina de cerdo mediante la medición de la fluorescencia en un sistema multipocillos para poder seguir caracterizando estas cepas lácticas potencialmente probióticas. 


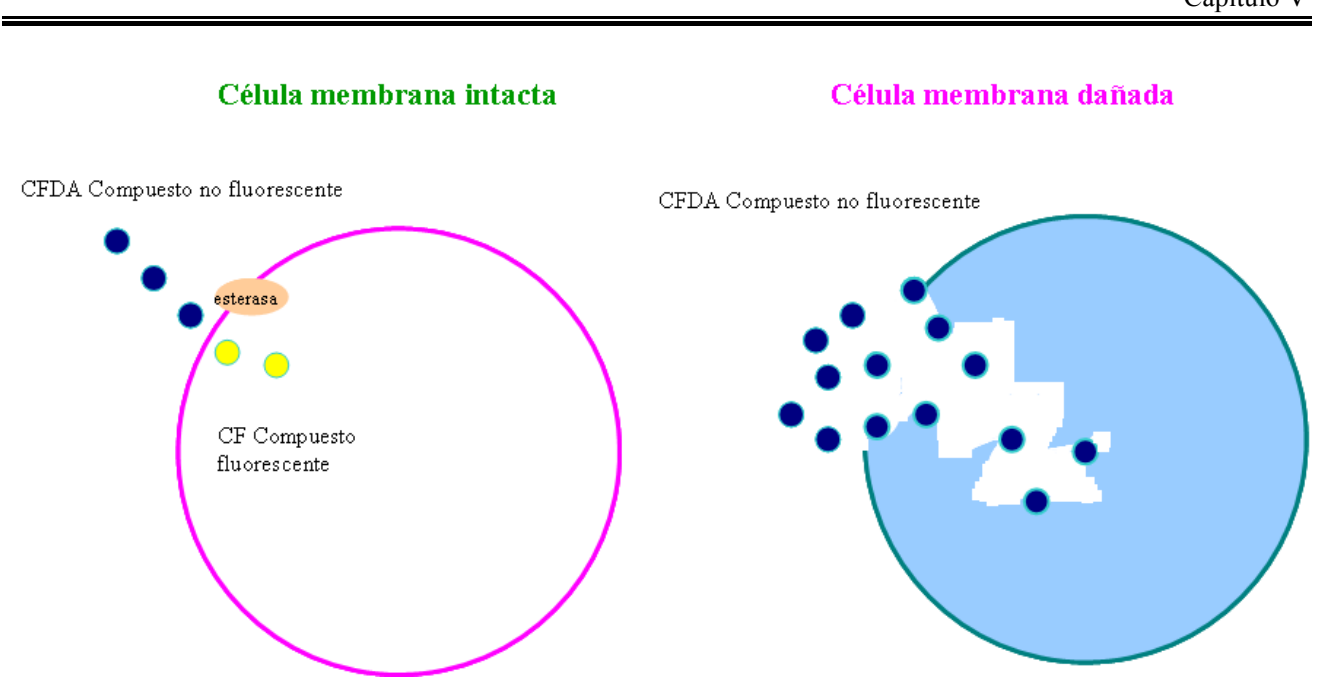

Figura 1. Interacción del CFDA con la célula Gram positiva.

\section{MATERIAL Y METODOS}

\subsection{Cepas bacterianas y condiciones de crecimiento}

Las cepas ácido lácticas empleadas fueron de nuevo aquellas que demostraron actividad antimicrobiana frente a H. pylori y Salmonella spp. (en uno o ambos casos) (Ver capitulo IV Tabla 1). Cada una de las cepas BAL se inocularon en caldo MRS y se incubaron a $37^{\circ} \mathrm{C}$ en condiciones de anaerobiosis durante 24 horas.

\subsection{Tratamiento de la mucina}

La mucina de cerdo (Sigma) fue diluida en PBS 1X $(0.5 \mathrm{mg} / \mathrm{ml})$. Una alícuota de $100 \mu \mathrm{l}$ de esta solución se inoculó en cada uno de los pocillos de una placa de 96 pocillos de poliestireno estériles y de color negro específica para fluorescencia (NUNC) y se incubó a $4^{\circ} \mathrm{C}$ toda la noche según el protocolo de Kirjavainen et al., (1998). Transcurrido este periodo, la mucina no adherida se eliminó lavando los pocillos dos veces con $200 \mu 1$ de PBS 1X (130 $\mathrm{mM}$ sodium chloride, $10 \mathrm{mM}$ sodium phosphate, $(\mathrm{pH} 7.2)$ ). 


\subsection{Ensayo de adhesión}

Un cultivo de 24 horas de cada cepa se centrifugó a $6000 \mathrm{xg}$, a $4^{\circ} \mathrm{C}$ durante 10 minutos. Las células se lavaron dos veces con PBS $1 \mathrm{X}$ y se resuspendieron finalmente en el mismo tampón. Cada suspensión bacteriana fue ajustada a una densidad óptica de $0.5 \pm 0.1$ $\left(\mathrm{A}_{600}\right)$. A su vez, se realizó un recuento en placa de agar MRS por duplicado a partir de diluciones seriadas en PBS 1X para determinar las unidades formadoras de colonia de cada muestra. Las suspensiones de las diferentes cepas estudiadas se incubaron con $100 \mu \mathrm{M}$ de carboxifluoresceina diacetato a $37^{\circ} \mathrm{C}$ durante 30 minutos para teñir o marcar las células bacterianas. Las células se lavaron dos veces para eliminar el resto de CFDA y se resuspendieron en $1 \mathrm{ml}$ de PBS $1 \mathrm{X}$.

Después, se tomaron $100 \mu 1$ de la suspensión bacteriana marcada y se depositaron en los respectivos pocillos de la placa de poliestireno donde previamente se había adherido la mucina de cerdo. La placa se incubó a $37^{\circ} \mathrm{C}$ durante 1 hora. Se midió la fluorescencia inicial empleando el instrumento TECAN M200 (Grupo Taper), lector multifuncional de microplacas con inyector. Las longitudes de onda empleadas fueron $485 \mathrm{~nm}$ de excitación y $538 \mathrm{~nm}$ de emisión. Los pocillos se lavaron dos veces con $200 \mu \mathrm{l}$ de PBS $1 \mathrm{X}$ con el fin de eliminar las bacterias no adheridas. Las bacterias adheridas se lisaron incubando la placa a $37^{\circ} \mathrm{C}$ durante 1 hora con $1 \%(\mathrm{w} / \mathrm{v})$ SDS en $0.1 \mathrm{M} \mathrm{NaOH}$. La fluorescencia final se midió a las mismas longitudes de onda. La capacidad de adhesión fue expresada como el porcentaje de fluorescencia recuperada después de la adhesión a la mucina en relación a la fluorescencia de la suspensión bacteriana añadida a los pocillos (Laparra y Sanz, 2009). Cada cepa láctica fue evaluada por triplicado.

Con el propósito de evaluar la potencial adsorción no específica de la CFDA en los pocillos, se evaluó la adhesión sin emplear mucina en los pocillos. El control negativo sin bacterias se tuvo en cuenta en el experimento. 


\subsection{Análisis Estadístico}

El análisis estadístico se realizó con el empleo del programa StatGraphics plus 5.1 y SPSS 15.0. Se efectuó un análisis de varianza simple (ANOVA) para los datos de adhesión entre tratamientos, el cual realizó varios tests y gráficos para comprobar los valores medios entre los porcentajes de adhesión a la mucina, al tratamiento sin mucina y entre tratamientos. El F-test en la tabla ANOVA comprueba si existe alguna diferencia significativa entre medias. Si hay, los test de Rangos múltiples indicarán las medias que son significativamente diferentes. En caso de presentarse valores atípicos se elige la prueba W de Mann-Whitney para determinar las diferencias estadísticamente significativas $(p<0.05)$ entre medianas.

\section{RESULTADOS}

El número de bacterias cultivables de la suspensión marcada con CFDA que se adicionó a la placa multipocillos, se determinó por medio de la técnica de recuento en placa, estableciéndose en un número entre $10^{6}$ y $10^{8} \mathrm{UFC} / \mathrm{ml}$ (Tabla 1). Los porcentajes de adhesión a la mucina de cerdo, medidos como fluorescencia se recogen en la Tabla 1 y Figura 3. Como control se empleo una muestra sin bacterias a la que se le agregó CFDA, dichos resultados se tuvieron en cuenta para determinar la fluorescencia generada por la unión inespecífica de la CFDA a la placa (ruido de fondo).

29 de 39 cepas pertenecientes a las especies L. acidophilus, L. brevis, L. casei, L. paracasei paracasei, L. pentosus, L. plantarum y Lactococcus lactis presentaron adhesión a la mucina de cerdo con valores entre $0.25 \%$ y $78.37 \%$ y 36 cepas lácticas mostraron adhesión en el tratamiento sin mucina con valores entre $1.72 \%$ y $84.75 \%$ (Tabla 1 ). Las cepas sin capacidad de adhesión a la mucina fueron L. delbrueckii bulgaricus (CECT4006), L. delbrueckii delbrueckii (CECT286), L. paracasei paracasei (14O5, 2006, 2O11B, 3O10), L. plantarum (7O1) y Lactococcus lactis subsp lactis (1104, 2011 y 6O8). De acuerdo a la 
prueba de W de Mann-Whitney existe diferencia significativa entre los tratamientos con y sin mucina $(\mathrm{p}<0.05)$ (Figura 2).

A partir de los datos de Log UFC/ml y los porcentajes de adhesión a la mucina, podemos obtener un valor estimado de la cantidad de bacterias que se adhirieron (Tabla 1). Las cepas CECT475, 10O8. 1O10, 2105, 4O4, 2T4, 4O1, 17O5, 3O9, Q2, 13O5B, 19O6, 2011 y 1T4 destacaron por su adhesión ya que tienen valores superiores a $6 \mathrm{Log} \mathrm{UFC} / \mathrm{ml}$.

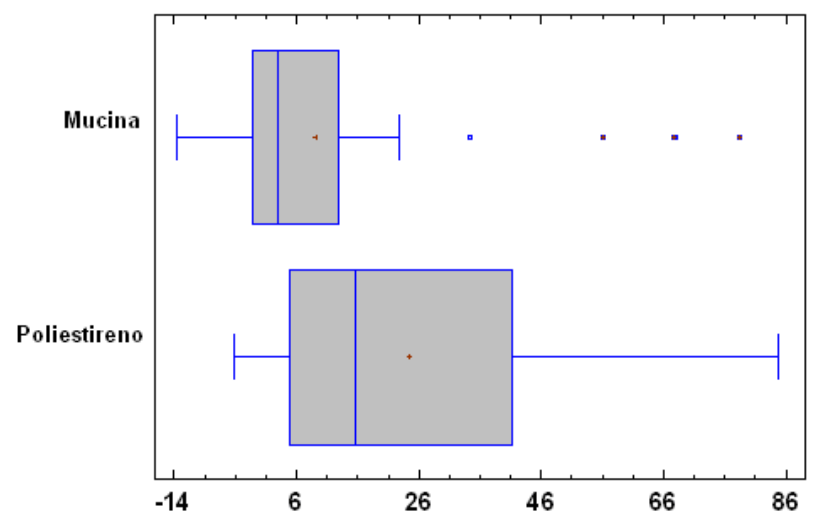

Figura 2. Comparación tratamiento con mucina y sin mucina (poliestireno). 
Tabla 1. Adhesión de las BAL a mucina y tratamiento sin mucina. Densidad bacteriana inicial de cada muestra en placa Log UFC/ml. (-) valor no observado. Media de tres observaciones y error estándar (SD).

\begin{tabular}{|c|c|c|c|c|c|}
\hline CEPA & ID API & $\begin{array}{l}\text { Adhesion } \\
\text { mucina (\%) }\end{array}$ & $\begin{array}{c}\text { Adhesion } \\
\text { policarbonato } \\
(\%)\end{array}$ & $\begin{array}{l}\log \\
\mathrm{UFC} / \\
\mathrm{ml}\end{array}$ & $\begin{array}{c}\text { Log } \\
\text { UFC/ml } \\
\text { Adherido } \\
\text { mucina }\end{array}$ \\
\hline 903 & L acidophilus 3 & $0.25 \pm 1.08$ & $16.88 \pm 1,83$ & 6.00 & 3.40 \\
\hline 2004 & L. brevis 7 & $3.35 \pm 0.85$ & $2.06 \pm 0.79$ & 6.00 & 4.53 \\
\hline CECT475 & L. casei & $15.39 \pm 1.36$ & $35.74 \pm 1.96$ & 7.64 & 6.83 \\
\hline CECT4006 & L. delbruechi bulgaricus & (-) $5,22 \pm 1,28$ & $2.82 \pm 0.70$ & 6.00 & - \\
\hline CECT286 & L. delbrueckii delbrueckii & (-) $3.66 \pm 2.06$ & $1.72 \pm 2.44$ & 6.00 & - \\
\hline CECT4022 & L. paracasei paracasei & $3.09 \pm 0.86$ & $11.43 \pm 2.10$ & 6.00 & 4.49 \\
\hline 1008 & L. paracasei parcasei 7 & $16.84 \pm 1.10$ & $52.89 \pm 1.03$ & 7.40 & 6.62 \\
\hline 1010 & L. paracasei paracasei 7 & $59.70 \pm 7.03$ & $74.32 \pm 3.55$ & 7.30 & 7.08 \\
\hline 1405 & L. paracasei parcacasei 7 & (-) $11.93 \pm 0.56$ & (-) $2.54 \pm 0.09$ & 7.18 & - \\
\hline 2006 & L. paracasei paracasei 3 & $(-) 3.97 \pm 0.57$ & $9.35 \pm 1.40$ & 6.60 & - \\
\hline 2011B & L. paracasei paracasei & (-) $12.98 \pm 0.12$ & $(-) 4.18 \pm 0.44$ & 7.18 & - \\
\hline 2105 & L. paracasei paracasei 7 & $24.70 \pm 3.06$ & $76.11 \pm 10.50$ & 7.68 & 7.07 \\
\hline 3010 & L. paracasei paracasei 7 & (-) $1.24 \pm 0.08$ & $5.25 \pm 0.13$ & 8.23 & - \\
\hline 404 & L. paracasei paracasei 7 & $8.65 \pm 1.75$ & $14.39 \pm 2.99$ & 7.85 & 6.78 \\
\hline $2 \mathrm{~T} 4$ & L. paracasei paracasei 7 & $7.45 \pm 0.17$ & $41.18 \pm 1.97$ & 7.32 & 6.19 \\
\hline 1804 & L. paracasei paracasei 7 & $6.92 \pm 0.28$ & $18.86 \pm 1.16$ & 7.00 & 5.84 \\
\hline CECT4023 & L. pentosus & $8.88 \pm 1.70$ & $20.10 \pm 3.73$ & 6.00 & 4.95 \\
\hline 207 & L. pentosus & $41.50 \pm 2.71$ & $41.23 \pm 4.06$ & 6.00 & 5.62 \\
\hline 401 & L. pentosus & $2.78 \pm 0.65$ & $7.57 \pm 0.50$ & 8.04 & 6.49 \\
\hline
\end{tabular}




\begin{tabular}{|c|c|c|c|c|c|}
\hline CEPA & ID API & $\begin{array}{l}\text { Adhesion mucina } \\
\qquad(\%)\end{array}$ & $\begin{array}{c}\text { Adhesion } \\
\text { policarbonato } \\
(\%)\end{array}$ & $\mathrm{UFC}_{\mathrm{L} / \mathrm{ml}}^{\log }$ & $\begin{array}{c}\text { Log } \\
\text { UFC/ml } \\
\text { Adherido } \\
\text { mucina }\end{array}$ \\
\hline 1705 & L. plantarum 7 & $2.75 \pm 0.15$ & $3.64 \pm 0.07$ & 7.93 & 6.37 \\
\hline 309 & L. plantarum 7 & $78.37 \pm 1.07$ & $55.44 \pm 2.47$ & 6.30 & 6.20 \\
\hline 408 & L. plantarum 1 & $2.37 \pm 0.13$ & $4.70 \pm 0.27$ & 7.57 & 5.94 \\
\hline 701 & L. plontarum 7 & $0.0 \pm 0.0$ & $3.69 \pm 0.04$ & 8.08 & - \\
\hline Q2 & L. plantarum 7 & $34.36 \pm 0.43$ & $79.83 \pm 3.07$ & 7.51 & 7.04 \\
\hline Q3 & L. plantorum 7 & $12.66 \pm 1.98$ & $25.22 \pm 2.31$ & 6.00 & 5.10 \\
\hline 908 & L. plontarum 7 & $0.56 \pm 0.20$ & $5.01 \pm 0.40$ & 8.08 & 5.83 \\
\hline CECT278 & L. rhamnosus & $15.38 \pm 1.28$ & $35.76 \pm 0.47$ & 6.00 & 5.19 \\
\hline 1203 & L. rhamnosus & $12.60 \pm 0.87$ & $15.57 \pm 2.34$ & 6.00 & 5.10 \\
\hline 103 & Lactococcus lactis lactis I & $67.68 \pm 3.24$ & $84.75 \pm 5.86$ & 6.00 & 5.83 \\
\hline 108 & Lactococcus lactis lactis I & $10.90 \pm 0.20$ & $18.79 \pm 1.66$ & 6.00 & 5.04 \\
\hline 1104 & Lactococcus lactis lactis I & (-) $13.38 \pm 0.28$ & (-) $3.49 \pm 0.03$ & 7.53 & - \\
\hline $1305 \mathrm{~B}$ & Lactococcus lactis lactis I & $21.59 \pm 1.32$ & $36.68 \pm 1.99$ & 7.23 & 6.56 \\
\hline 1906 & Lactococcus lactis lactis 1 & $22.78 \pm 1.82$ & $73.54 \pm 6.70$ & 7.45 & 6.80 \\
\hline 2011 & Lactococcus lactis lactis I & $(-) 7.32 \pm 0.39$ & $8.95 \pm 1.46$ & 7.64 & 6.51 \\
\hline 204 & Lactococcus lactis lactis I & $9.95 \pm 0.63$ & $18.16 \pm 0.03$ & 6.00 & 5.00 \\
\hline 608 & Lactococcus lactis lactis I & (-) $5.58 \pm 0.43$ & $10.78 \pm 0.71$ & 7.40 & - \\
\hline $1 \mathrm{~T} 4$ & Lactococcus lactis lactis I & $1.48 \pm 0.29$ & $5.11 \pm 0.46$ & 8.08 & 6.25 \\
\hline $1305 \mathrm{~A}$ & Lactococcus lactis lactis I & $12.82 \pm 1.11$ & $22.54 \pm 0.78$ & 6.85 & 5.95 \\
\hline 1306 & Lactococcus lactis lactis $I$ & $1.23 \pm 0.02$ & $4.98 \pm 0.08$ & 7.89 & 5.98 \\
\hline
\end{tabular}


Capitulo V

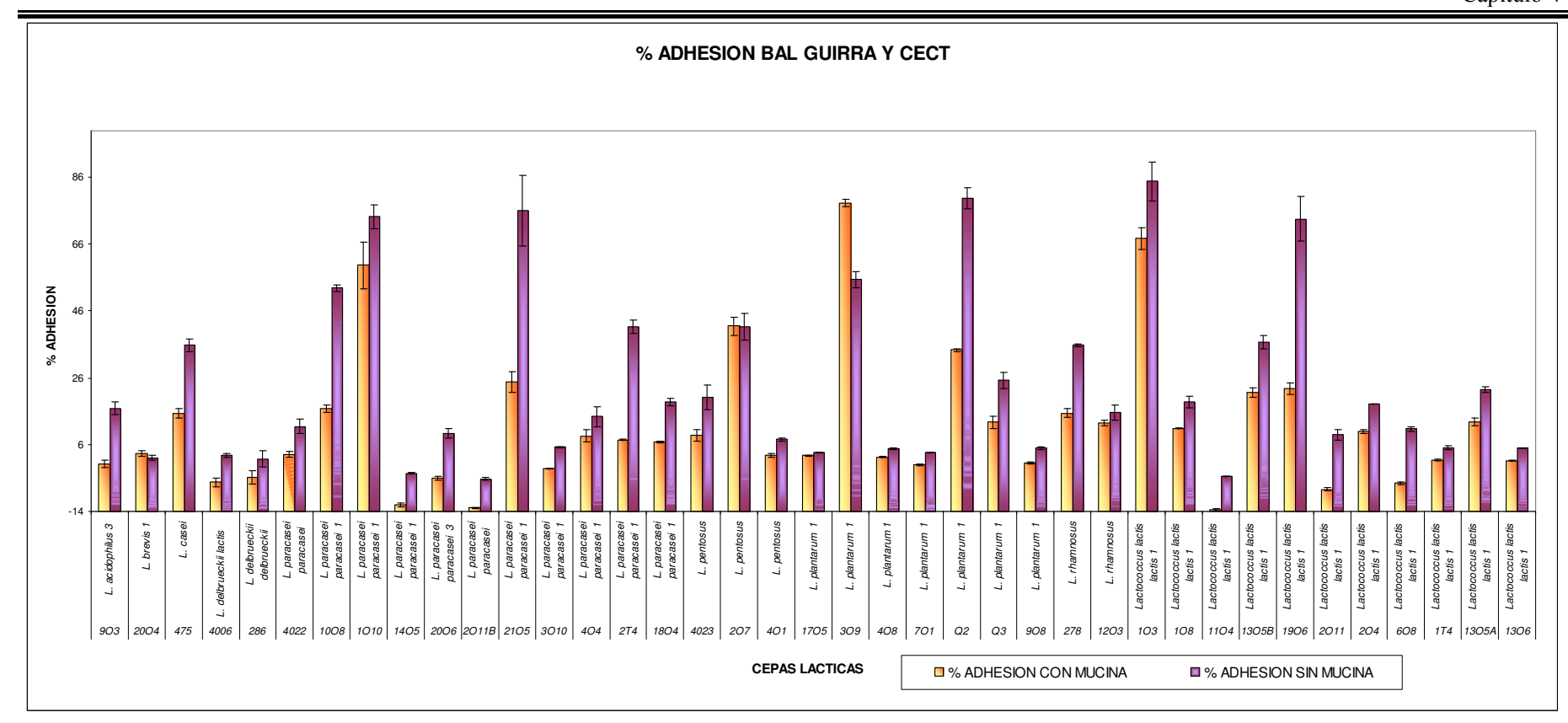

Figura 3. Porcentaje de adhesión de las BAL aisladas de leche de oveja Guirra y CECT. Con mucina y sin mucina. 


\section{DISCUSION}

Varios estudios indican que desordenes fisiológicos y enfermedades infecciosas están asociadas a alteraciones en la microbiota intestinal humana, con bajos números de Lactobacillus y Bifidobacterium (He et al., 2001). La adhesión de las BAL es pre-requisito para generar sus efectos saludables y su capacidad de inhibir patógenos puede estar asociada a la habilidad de adhesión a la mucina y su efecto antimicrobiano (Bianchi et al., 2004; Izquierdo et al., 2008). La adherencia de las BAL a la mucina es necesaria para proteger el epitelio de daños mecánicos y de bacterias patógenas ya que cualquier daño o alteración en la mucina puede comprometer la función de defensa del huésped (Tuomola et al., 1999; Zhou et al., 2001). La adhesión se ve afectada por muchos factores como la microbiota residente en el tracto gastrointestinal, $\mathrm{pH}$, fase de crecimiento y densidad bacteriana (P. Fernández et al., 2008). Las BAL estudiadas en este capitulo demostraron poseer actividad antimicrobiana frente a patógenos, pero no todas presentaron la capacidad de adhesión.

La cepa 2004 aislada de leche de oveja Guirra perteneciente a $L$. brevis presentó poca adhesión (3.35\%) respecto al conjunto de las BAL estudiadas. En estudios previos las cepas CLC23 y 6042 de $L$. brevis presentaron valores bajos de adhesión a mucina de cerdo (0.03\%) y células HT-29 (3.75\%), respectivamente (B. Wang et al., 2008; R. Martín et al., 2009). Las cepas 1O3, 1O8, 13O5B, 19O6, 2O4, 1T4, 13O5A, $13 \mathrm{O}$ de Lactococcus lactis subsp lactis mostraron habilidad de adhesión a la mucina. Según el estudio realizado por Vesterlund et al., (2006), en el que también se utilizó Lactococcus lactis subsp lactis, este logró adherirse al mucus intestinal humano reduciendo la adhesión de Staphylococcus aureus por medio de la producción de ácidos orgánicos y peroxido de hidrógeno.

En el presente estudio, las cepas de las especies L. casei CECT 475, L. rhamnosus (12O3, CECT278) y L. plantarum $(17 \mathrm{O} 5,3 \mathrm{O} 9,4 \mathrm{O} 8$, Q2, Q3 y 9O8) presentaron capacidad de adherirse a la mucina, a excepción de la cepa 701 de L. plantarum (Figura 2). En trabajos previos, $L$. casei, L. plantarum, L. rhamnosus mostraron alta adhesión a células Caco 2 y $L$. 
rhamnosus GG se adhirió a mucus de diferentes orígenes, al igual que L. plantarum 299v (Deplancke y Gaskins, 2001; Bianchi et al., 2004; Sánchez et al., 2010).

Otras cepas como, L. delbrueckii bulgaricus CECT4006, L. delbrueckii delbrueckii CECT286 y L. paracasei $(14 \mathrm{O} 5,20 \mathrm{O} 6,2 \mathrm{O} 11 \mathrm{~B}$ y $3 \mathrm{O} 10)$ no se adhirieron a la mucina de cerdo. Estas especies ya mostraron dificultad de adhesión presentando niveles de adherencia del 7\% y 2\% (Fernández et al., 2008).

Veintinueve de treinta y nueve cepas lácticas estudiadas en este capitulo fueron capaces de adherirse a la mucina de cerdo al mostrar porcentajes positivos. Entre especies no se aprecian diferencias significativas $(\mathrm{p}>0.05)$ en la capacidad de adhesión. Los resultados del presente estudio mostraron que la propiedad de adhesión es dependiente de la cepa y que no todas las cepas lácticas con actividad antimicrobiana frente a H. pylori y Salmonella spp. poseen dicha capacidad de adhesión. Similares resultados se obtuvieron en otros estudios de adherencia de Lactobacillus a células Caco-2 (Servin y Coconnier, 2003; Laparra y Sanz, 2009). La adherencia de Lactobacillus a las células epiteliales en la superficie de la mucosa depende de proteínas y vinculaciones específicas de las adhesinas microbianas a receptores de la célula epitelial (Kinoshita et al., 2008; Van den Abbeele et al., 2009), por tanto esto podría explicar la capacidad intraespecífica de adhesión.

En la presente investigación, los resultados de adhesión a la mucina de las cepas lácticas están entre un 0.25 y un $78.37 \%$. Según Tuomola et al., (1999), cepas de lactobacillus presentaron porcentajes de adhesión a glicoproteínas del íleon entre $0.36 \mathrm{y}$ $31.6 \%$. Consideramos que los aislados de leche de oveja y CECT con porcentajes de adhesión más altos pueden ser más efectivos como probióticos. De acuerdo a los porcentajes obtenidos de adhesión con mucina y el valor obtenido en log UFC/ml podemos tener una estimación de la cantidad de bacterias que podrían adherirse (Tabla 1). Teniendo en cuenta que es recomendable encontrar en el epitelio intestinal una cantidad a partir de 6 Log $\mathrm{UFC} / \mathrm{ml}$, para que las bacterias acido lácticas logren colonizar y ejercer los efectos 
beneficiosos, en la presente investigación dicha condición la cumplen 14 cepas de las especies L. casei (CECT475), L. paracasei paracasei (10O8, 1O10, 21O5, 4O4 y 2T4), L. pentosus (2O7), L. plantarum (1705, $3 \mathrm{O} 9$ y Q2) y Lactococcus lactis subsp lactis (13O5B, 19O6, 2011 y 1T4). Según esta hipótesis, los porcentajes de adhesión a la mucina iguales o superiores a $7.45 \%$ podrían garantizar estas condiciones recomendadas.

En los resultados obtenidos la mayoría de las cepas que presentaron adherencia al policarbonato también la tuvieron a la mucina, con algunas excepciones. De hecho, las cepas de las especies L. acidophilus (9O3), L. casei (CECT475), L. paracasei (CECT4022, 1008, 1O10, 2105,4O4, $2 \mathrm{~T} 4$ y 18O4), L. pentosus (4O1), L. plantarum (17O5, 4O8, Q2, Q3 y 9O8), L. rhamnosus (CECT278, 12O3) y Lactococcus lactis (1O3, 108, 13O5B, 19O6, 2O4, 1T4, 1305A y 13O6) mostraron capacidades de adhesión mas altas al policarbonato que en el tratamiento con mucina de cerdo existiendo diferencias significativas $(\mathrm{p}<0.05)$ entre los tratamientos (Figura 2). Resultados similares se publicaron previamente para las cepas $B$. bifidum IATA-ES2 y L. monocytogenes CECT 935 (Laparra y Sanz, 2009), afirmando que el ensayo de adhesión con y sin mucina permite determinar el tipo de interacciones implicadas en la adhesión.

La habilidad de adhesión de las bacterias es difícil de medir porque el proceso de adhesión celular está determinado por interacción con la estructura de la superficie y por las condiciones ambientales. En Lactobacillus se ha observado una relación entre hidrofobicidad y la habilidad de adhesión (Del Re et al., 1998). Los porcentajes de adhesión a los pocillos tratados sin mucina sugieren que existen interacciones hidrofóbicas que son importantes en la habilidad de adhesión de las bacterias a la mucina (Laparra y Sanz, 2009; Van den Abbeele et al., 2009). Del Re (2000) demostró que la habilidad de hidrofobicidad puede ser predictiva de la adherencia de bifidobacterias. La hidrofobicidad puede determinarse por la adhesión microbiana a hidrocarburos. Otros autores demostraron la relación existente entre la hidrofobicidad celular y la adhesión al poliestireno (Tuomola et al., 1999). La adhesión al tratamiento sin mucina no puede emplearse para demostrar las propiedades adhesivas de 
algunas cepas testadas de L. delbrueckii bulgaricus (CECT4006), L. delbrueckii delbrueckii (CECT 286), L. paracasei paracasei (2006 y 3010) y Lactococcus lactis subsp lactis (2O11 y 608), ya que no fueron capaces de adherirse a la mucina a pesar de su aparente hidrofobicidad, coincidiendo con lo obtenido en estudios previos con la cepa de L. plantarum ATCC 8014 (Tuomola et al., 1999). Esto indica que la prueba con mucina es efectiva en el estudio de la habilidad de adhesión y que el tratamiento sin mucina no es válido para evaluar la adhesión bacteriana (Tuomola et al., 1999). Posiblemente, las interacciones hidrofóbicas de estas cepas lácticas no son suficientes en la habilidad de adhesión y requieran de la acción de otros componentes de naturaleza proteica, acción de carbohidratos, ácidos lipoteicoicos, fuerzas pasivas, interacciones electrostáticas y estructuras específicas (Van den Abbeele et al., 2009).

Varios estudios en roedores afirmaron que la hidrofobicidad aumenta del duodeno al colon (Van den Abbeele et al., 2009). Por tanto, aquellas cepas acido lácticas en las que hay interacciones hidrofóbicas resultan de especial interés en los sitios del intestino mas hidrófobos.

Algunas bacterias ácido lácticas al estar expuestas a condiciones de estrés, entre ellas las condiciones gastrointestinales, perdieron cultivabilidad y la capacidad de adherirse al mucus humano (Morono et al., 2004; Fernández et al., 2008). Según Tuomola et al., (1999) resultados de adhesión in vitro no necesariamente tienen correlación con estudios in vivo. En otros casos, se encontraron relaciones entre estudios (Collado, 2004). Sin embargo, el uso de diferentes modelos de adhesión in vitro con diferentes fuentes de mucus, que comprenda condiciones de estrés y la presencia de la microbiota intestinal pueden proveer información mas completa sobre las diferentes habilidades de adhesión de las bacterias, ayudando a elucidar el tipo de interacciones y moléculas que median la interacción microorganismo-hospedador y posteriormente, ensayar las cepas destacadas en ensayos in vivo (Servin y Coconnier, 2003; Van den Abbeele et al., 2009). 
Las bacterias probióticas compiten con las bacterias patógenas por los mismos sitios de adhesión. Sin embargo, diferentes cepas de bacterias probióticas no son igualmente efectivas en el bloqueo de la adhesión a sitios por patógenos. Los oligosacáridos que aparecen sobre la superficie del epitelio intestinal varían entre individuos como entre células. También, la dieta influye en los oligosacáridos presentes en el borde de la membrana de las células intestinales así como la composición de la microbiota intestinal (Koninkx et al., 2010).

Realizar otras pruebas de adhesión de las BAL con diferentes matrices permitirá apreciar las estrategias empleadas para su crecimiento y colonización de un nicho (Lorenzo, 2008). Además, proporcionaría información de los componentes involucrados (Fernández et al., 2008). Las cepas que no presentaron capacidad de adhesión a la mucina deberían descartarse para posteriores pruebas in vivo.

El presente estudio mostró que la leche de oveja Guirra cuenta con una microbiota láctica variada y con propiedades antimicrobianas contra H. pylori y Salmonella spp. Además, poseen capacidad de adhesión a la mucina y por tanto podemos pensar que in vivo podrían poseer esta propiedad probiótica. Esta capacidad de adhesión depende de la cepa y no de la especie, aunque coincidiendo con la bibliografía si se observa que ciertas especies como L. acidophilus, L. casei, L. brevis, L. paracasei, L. plantarum y Lactococcus lactis subsp lactis destacaron en dicha habilidad (Fernández et al., 2008; Martín et al., 2009; Sánchez et al., 2010). 
ESTUDIO DE VIABILIDAD CELULAR DE LAS BAL FRENTE A CONDICIONES GASTROINTESTINALES 


\section{INTRODUCCIÓN}

Estudios ecológicos indican que las especies de Lactobacillus encontradas en el tracto gastrointestinal son originarias de los alimentos (P. De Vos et al., 2009). En los productos probióticos se recomienda un contenido de al menos $10^{6}-10^{7} \mathrm{UFC} / \mathrm{ml}$ de microorganismos viables en el momento de su consumo para que se consideren bajo dicha denominación (Angelov et al., 2006). El tamaño del inoculo de partida es importante debido a que la viabilidad disminuye a largo del tránsito gastrointestinal a causa de variaciones de $\mathrm{pH}$, la acción de enzimas como la pepsina, pancreatina, movimientos peristálticos y el tiempo de exposición del alimento a dichas condiciones (Marteau et al., 1997; Goderska y Czarnecki, 2007). La supervivencia de las BAL en el intestino es fundamental para que puedan ejercer su función probiótica entre ellas, la prevención de desordenes gastrointestinales y enfermedades inflamatorias en el intestino (Mattila-Sandholm et al., 2002; Lorca y de Valdez, 2009). Es necesario que lleguen en cantidades de $10^{6} \mathrm{UFC} / \mathrm{g}$ al intestino para que ejerzan sus efectos en el tracto intestinal (Lee et al., 2009). Las BAL aisladas de leche de oveja Guirra demostraron previamente su potencial antimicrobiano frente a patógenos y adhesión a la mucina, lo cual las hace de especial interés como se mostró en los capítulos II y V. Sin embargo, la tolerancia a las condiciones gastrointestinales es otra prueba fundamental en la selección de probióticos (FAO y OMS, 2001; Mejía et al., 2007).

Otros autores realizaron estudios in vitro en los que se evaluó la capacidad de resistencia de cepas probióticas exponiéndolas a condiciones gastrointestinales, en donde la viabilidad de las cepas fue determinada por tinción de células con fluorescencia y recuento en placa (Fernández et al., 2008). El objetivo del presente capitulo fue evaluar en condiciones in vitro algunas cepas lácticas exponiéndolas a variaciones de $\mathrm{pH}$ y la acción de pepsina y pancreatina. La viabilidad celular fue analizada a diferentes tiempos mediante de métodos convencionales como el recuento en placa en medios selectivos y el sistema de viabilidad LIVE/DEAD Baclight Bacterial Viability kit (Molecular-Invitrogen). 


\section{MATERIAL Y METODOS}

\subsection{Estudio in vitro de la supervivencia frente a los jugos gástricos}

\subsubsection{Cepas}

Se analizaron 8 cepas acido lácticas aisladas de leche de oveja Guirra que mostraron elevado potencial como inhibidoras. Las cepas 2O7, 1O10, 9O3, 1O3, Q2, Q3 que inhibieron cepas patógenas de H. pylori, S. typhimurium, S. enteritidis y las cepas $12 \mathrm{O} 3$ y $20 \mathrm{O} 4$ que inhibieron a $H$. pylori B6 en presencia, ausencia de células y a pH 7.

Cada una de las cepas lácticas se inoculó en caldo MRS e incubó a $37^{\circ} \mathrm{C}$ durante 24 horas. Se tomó $1 \mathrm{ml}$ del cultivo y se centrifugó a $7.000 \mathrm{rpm}$ durante 5 minutos, se eliminó el sobrenadante y se lavó con PBS $1 \mathrm{X}$ tres veces con el fin de eliminar los restos de caldo MRS. Finalmente, las células se resuspendieron en $500 \mu$ de PBS 1X, ajustando el contenido celular a la escala 2 de McFarland $\left(10^{8} \mathrm{UFC} / \mathrm{ml}\right)$. Se realizó el recuento de viables en agar MRS de la suspensión celular antes del ensayo de supervivencia a los jugos gástricos, considerando este recuento como el control.

\subsubsection{Preparación de los jugos gástricos y pancreáticos}

Tanto la pepsina como la pancreatina utilizada para simular los jugos, procedían de cerdo (Sigma). Cada uno de los enzimas se diluyó en suero salino $0.5 \% \mathrm{w} / \mathrm{vol}$ en una relación de $3 \mathrm{~g} / \mathrm{L}$ la pepsina y $1 \mathrm{~g} / \mathrm{L}$ la pancreatina. El pH de la solución se ajustó a 2 para pepsina y 8 para pancreatina usando HCL $0.5 \mathrm{~N}$ y NaOH $1 \mathrm{~N}$ respectivamente (Charteris et al., 1998). 


\subsubsection{Determinación de la supervivencia "in vitro" al tránsito gastrointestinal}

Se tomó $0.2 \mathrm{ml}$ de la suspensión de células de BAL en PBS $1 \mathrm{X}$ y se mezcló con 1 $\mathrm{ml}$ de pepsina ( $\mathrm{pH}$ 2) o pancreatina ( $\mathrm{pH}$ 8). La mezcla se agitó en vortex y posteriormente se incubó a $37^{\circ} \mathrm{C}$ en los tiempos establecidos para cada estudio.

Se tomaron alícuotas de $0.1 \mathrm{ml}$ a tiempos de 0, 5, 40 y 180 minutos para el tratamiento con pepsina y para pancreatina a 0, 240 y 360 minutos. Luego, cada una de las muestras se centrifugó, se retiró el sobrenadante para eliminar los jugos y se resuspendió en PBS 1X. Se tomó como referencia el proceso de digestión humana, en donde el transito en el estomago tiene una duración de 3 horas y de 6 horas en el transito intestinal.

La viabilidad de las BAL se determinó mediante recuento en placa y medida de la integridad de membrana mediante el sistema comercial LIVE/DEAD ya explicado en el capitulo III apartado 2.2 (Recuento de viables mediante la técnica de tinción con fluorocromos).

\section{RESULTADOS}

En la mayoría de los casos el recuento de bacterias viables resultó mayor al emplear el sistema de viabilidad LIVE/DEAD respecto al recuento en placa debido a la presencia de bacterias viables y no cultivables. Al comparar ambos métodos se encontraron diferencias significativas $(\mathrm{p}<0,05)$.

\subsection{Determinación de la tolerancia gastrointestinal}

La viabilidad de las bacterias frente a las condiciones gastrointestinales se comprobó antes y después de los tratamientos mediante el recuento con las dos técnicas antes 
mencionadas (Figuras 1 a 8). En las tablas 1 y 2 se puede observar la tinción con fluorocromos SYTO9 y PI antes y después del tratamiento con pepsina y pancreatina para cada cepa.

El número total de bacterias al inicio del ensayo fue $10^{8}$ bacterias $/ \mathrm{ml}$, buscando que después de la exposición a los jugos gastrointestinales llegaran en cantidades de entre $10^{6} \mathrm{y}$ $10^{7}$ bacterias $/ \mathrm{ml}$ como lo recomienda Moreno et al., (2000) pero solo de un $34 \%$ a un $97 \%$ de estas resultaron ser viables (Figura 9), con un número de $10^{5}$ a $10^{6} \mathrm{cel} / \mathrm{ml}$ para las cepas más resistentes (Figuras 1 a 8 ).

Después de 3 horas de exposición a la pepsina, las cepas L. acidophilus (9O3), L. pentosus (2O7), L. paracasei paracasei (1010) y L. rhamnosus (12O3) presentaron valores de viabilidad de $1.89 \%, 0.23 \%, 1.21 \%$ y $0.43 \%$ (Figura 3), respectivamente. Aplicando el procedimiento de diferencia mínima significativa (LSD) de Fisher que discrimina entre medias, existen diferencias significativas $(\mathrm{p}<0.05)$ entre la muestra control y la muestra tomada a $180 \mathrm{~min}$ de la cepa $9 \mathrm{O} 3$. Esta cepa aunque logró sobrevivir durante dicho tiempo fue afectada significativamente por la pepsina y el pH ácido. La cepa de Lactococcus lactis subsp lactis 103 se mantuvo viable hasta los 40 minutos con un $11 \%$ de viabilidad. $L$. plantarum (Q2, Q3) y L. brevis (2004) resistieron solo 5 minutos con un $6 \%, 16 \%$ y $4 \%$ de viabilidad, respectivamente. Hay diferencias significativas entre la muestra inicial y final de estas cepas $(\mathrm{p}<0.05)$. En general, todas las cepas mostraron una perdida de viabilidad después de 180 minutos cuando fueron sometidas a la acción de la pepsina (figura 9). El recuento en placa fue de 0-1 Log UFC/ml y con el fluorocromo SYTO9 de 5.11-5.89 Log cel/ml para las cepas 9O3, 2O7, 1010 y $12 \mathrm{O} 3$ (Figuras 1, 2, 5 y 7).

Tras el tratamiento con pancreatina todas las cepas pasaron de $10^{8}$ a valores entre $10^{6}$ y $10^{7} \mathrm{cel} / \mathrm{ml}$ después de 360 minutos (Figuras 1 a 8 ) y los porcentajes de viabilidad de células/ml estuvieron en el rango de 16\% - 94\% (Figura 10). El recuento en placa mostró valores entre 5.80 - 8.15 Log UFC/ml y con SYTO9 6.65 - 7.41 Log cel/ml (Figuras 1 a 8). 
Todas las cepas lácticas ensayadas frente a las condiciones intestinales disminuyeron su viabilidad levemente respecto de la muestra control y en algunos casos presentaron incrementos no significativos. Según la LSD de Fisher hubo diferencia significativa $(p<0.05)$ entre la muestra inicial y final de la cepa 1010 tratada con pancreatina. Aunque esta cepa fue la mas afectada por esta enzima, logró sobrevivir el transito intestinal con un número de viables de Log cel/ml de 7.41 apropiado para ejercer su efecto probiótico.

Los porcentajes de viabilidad se obtuvieron a partir de la relación entre el número de células viables y el recuento total (células viables y no viables) a distintos tiempos de exposición frente a los jugos gastrointestinales. La supervivencia de cada cepa ácido láctica frente a las condiciones gastrointestinales presentaron diferencias entre especies. En términos generales, las cepas estudiadas fueron más sensibles a la pepsina que a la pancreatina. 

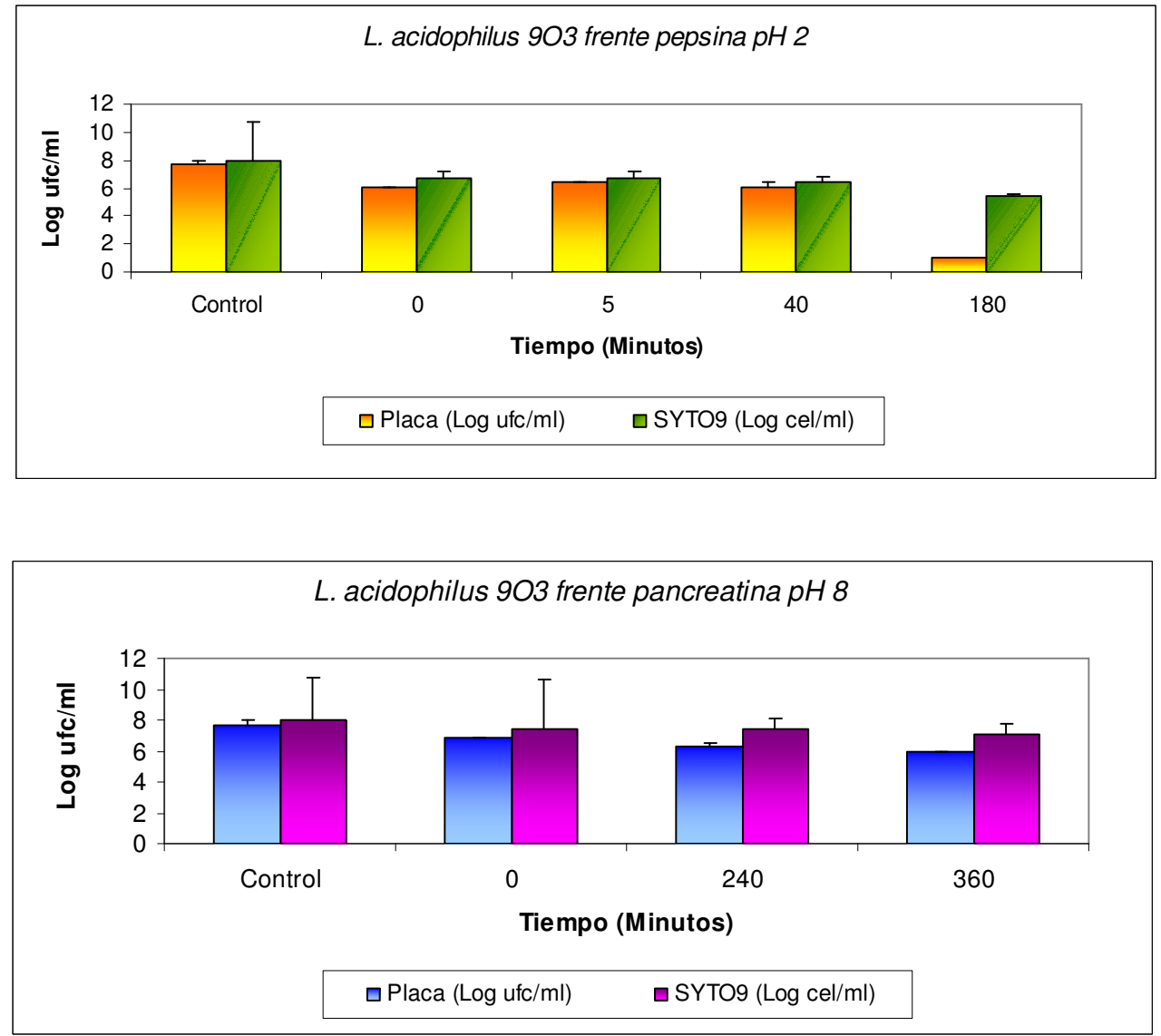

Figura 1. Supervivencia al tránsito gastrointestinal de la cepa 903 por recuento en placa y fluorocromo SYTO9. 

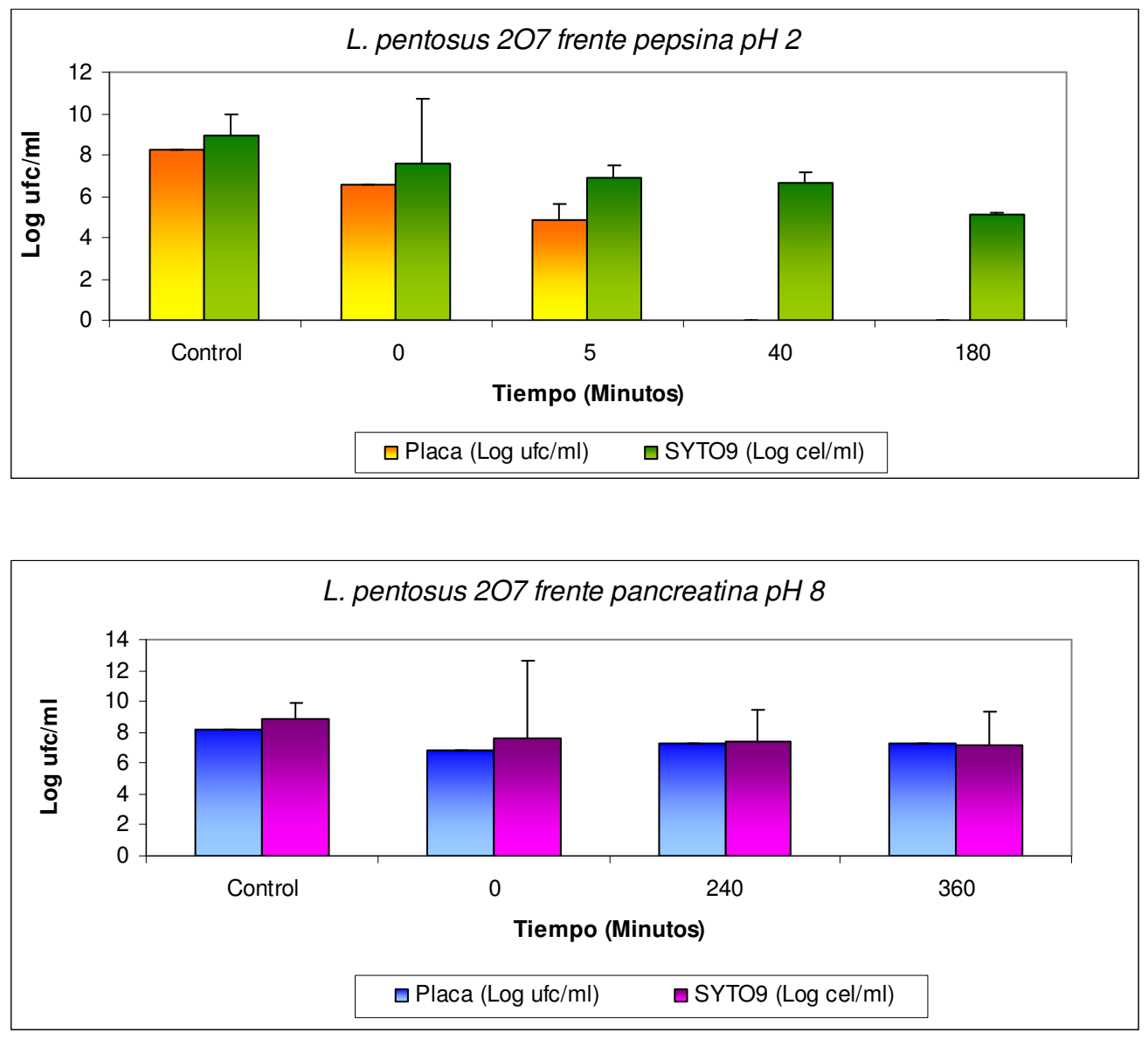

Figura 2. Supervivencia al tránsito gastrointestinal de la cepa 207 por recuento en placa y fluorocromo SYTO9. 

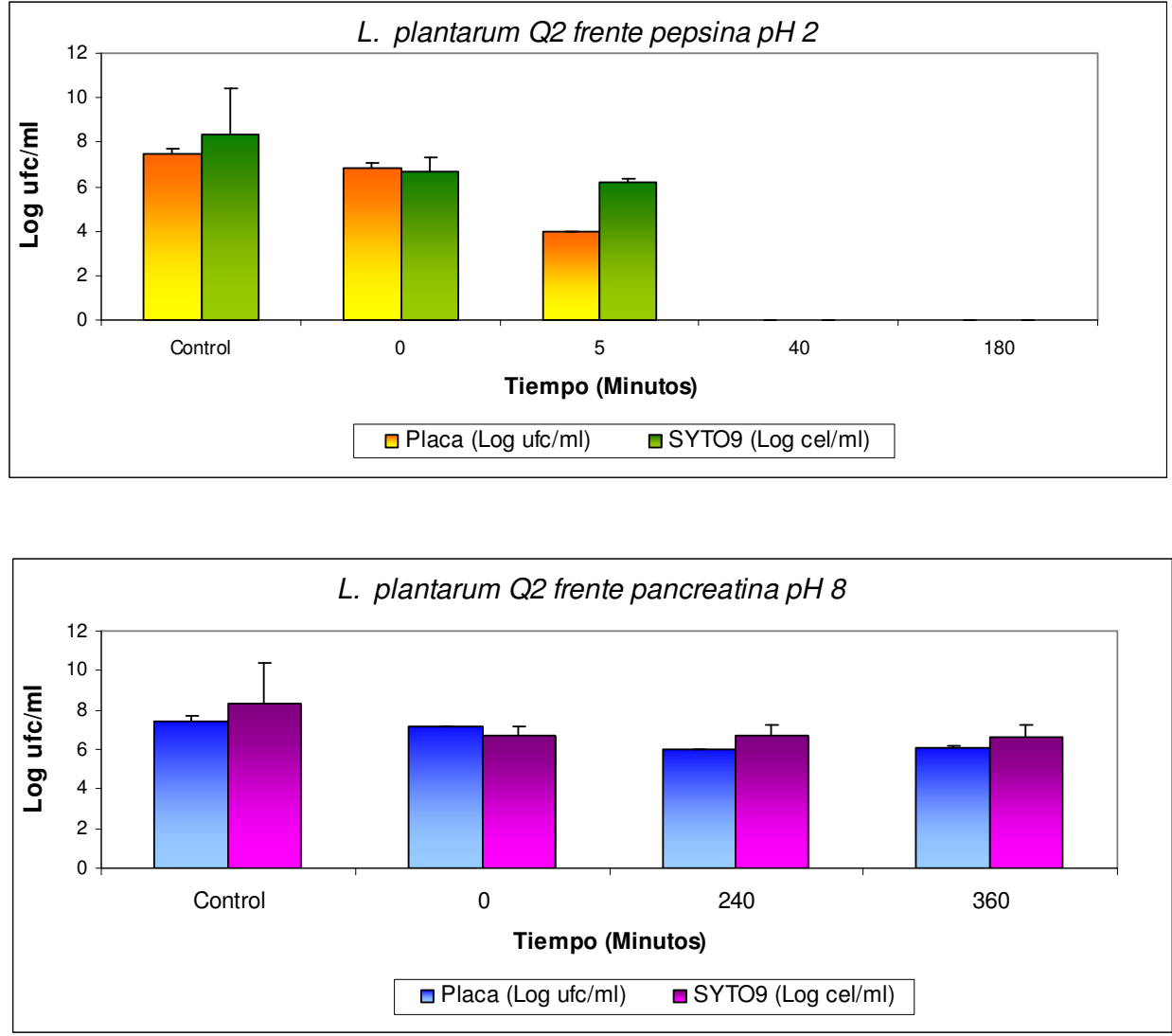

Figura 3. Supervivencia al tránsito gastrointestinal de la cepa Q2 por recuento en placa y fluorocromo SYTO9. 

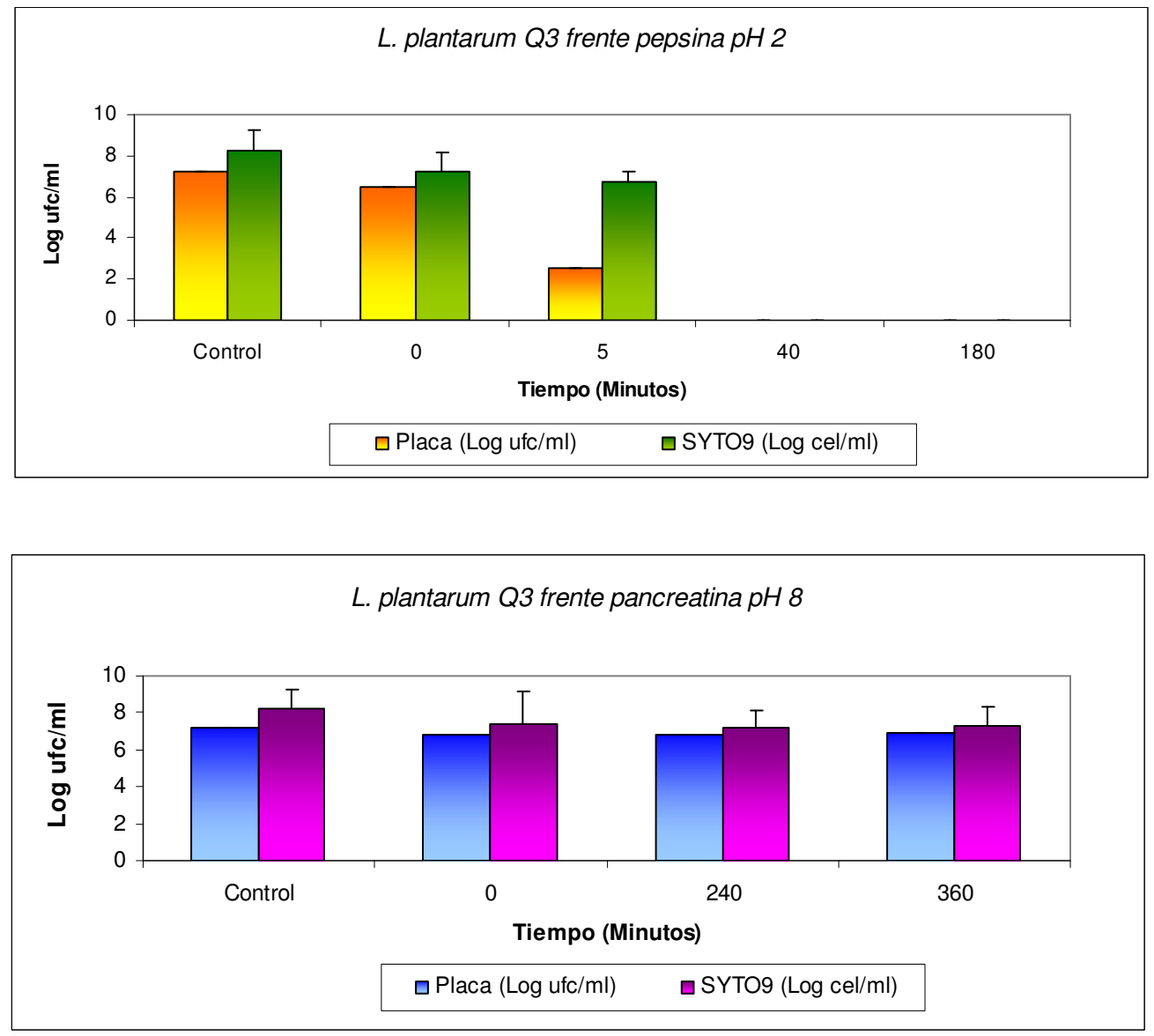

Figura 4. Supervivencia al tránsito gastrointestinal de la cepa $Q 3$ por recuento en placa y fluorocromo SYTO9. 

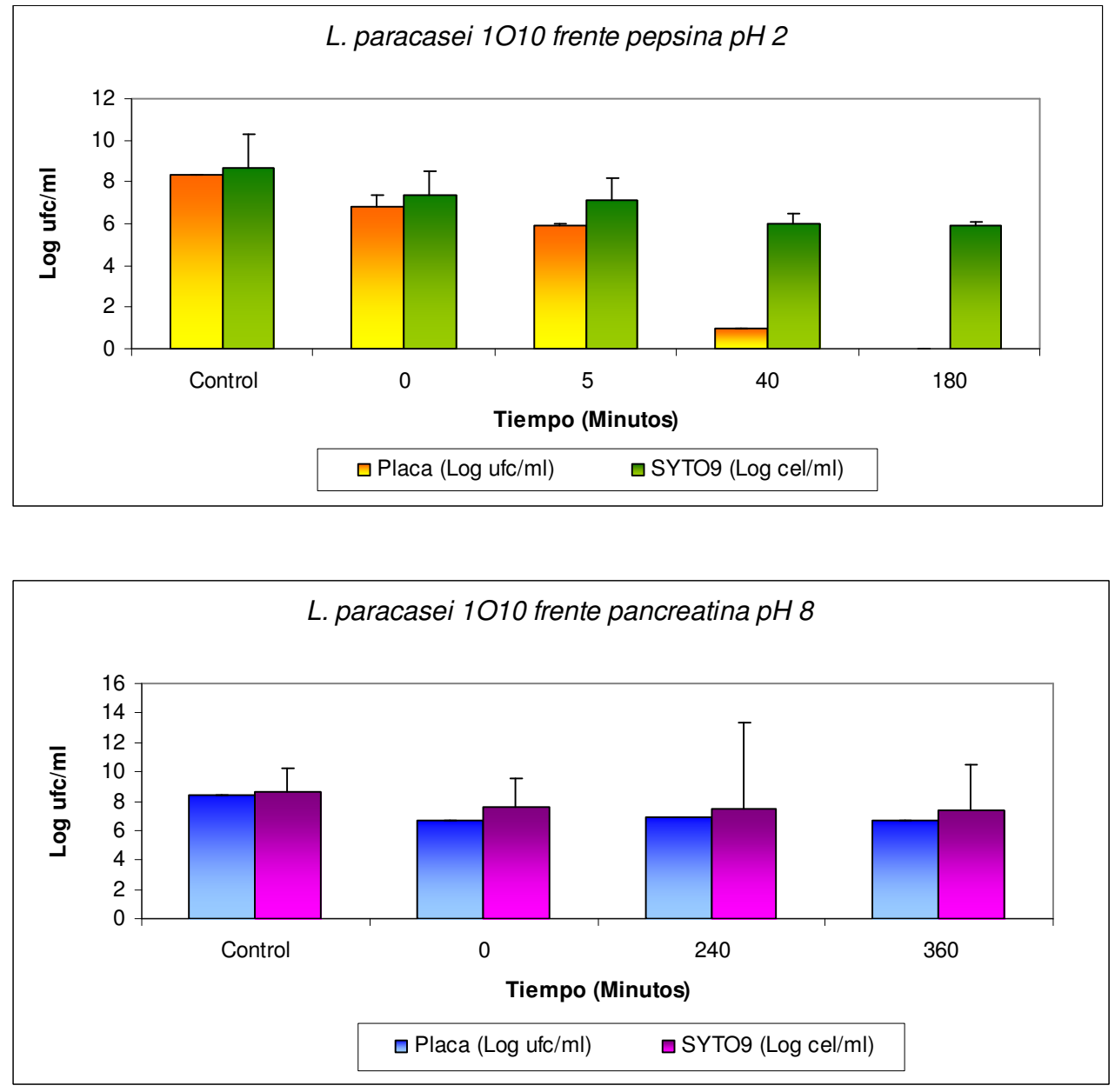

Figura 5. Supervivencia al tránsito gastrointestinal de la cepa 1010 por recuento en placa y fluorocromo SYTO9. 

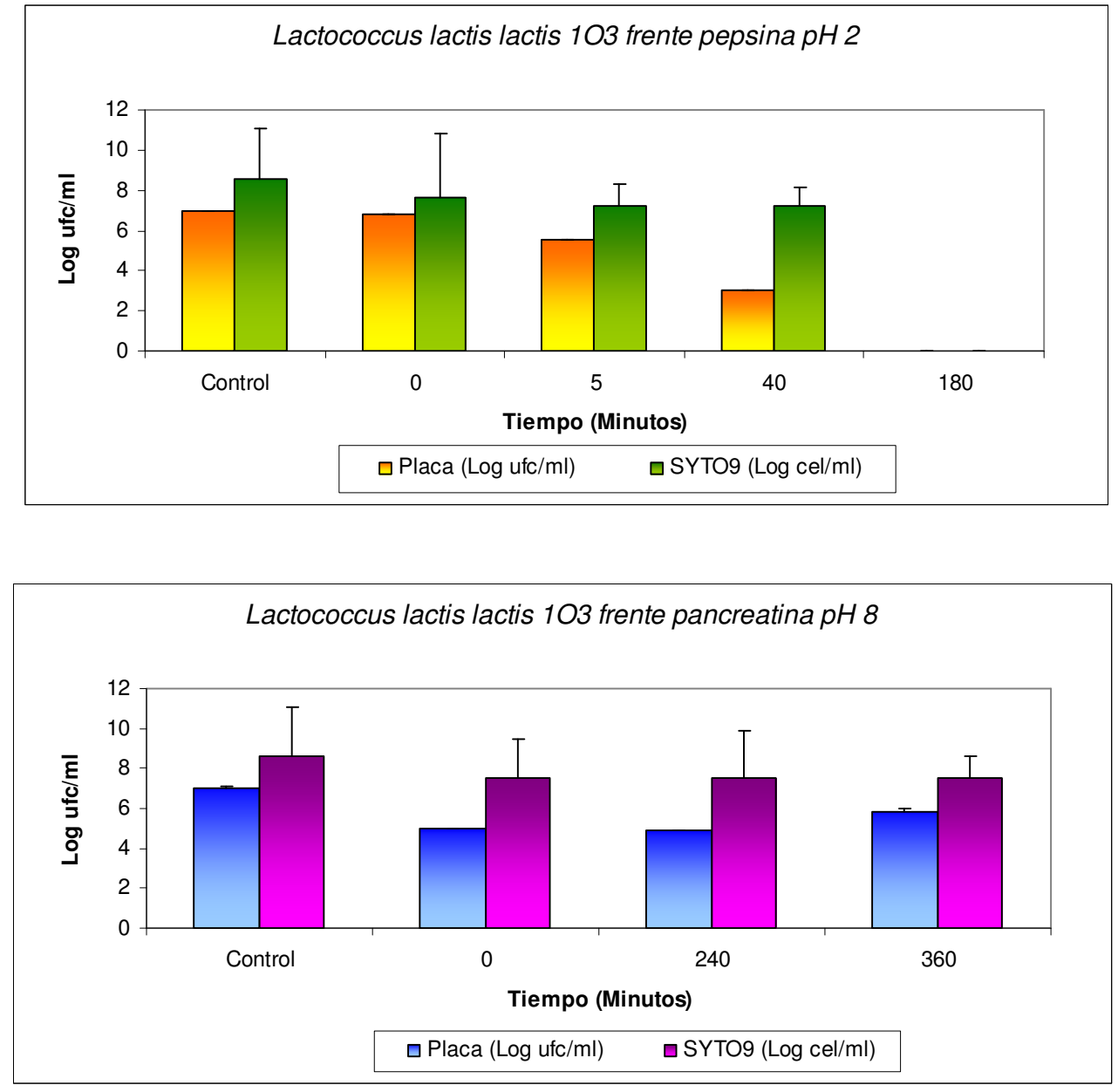

Figura 6. Supervivencia al tránsito gastrointestinal de la cepa 103 por recuento en placa y fluorocromo SYTO9. 

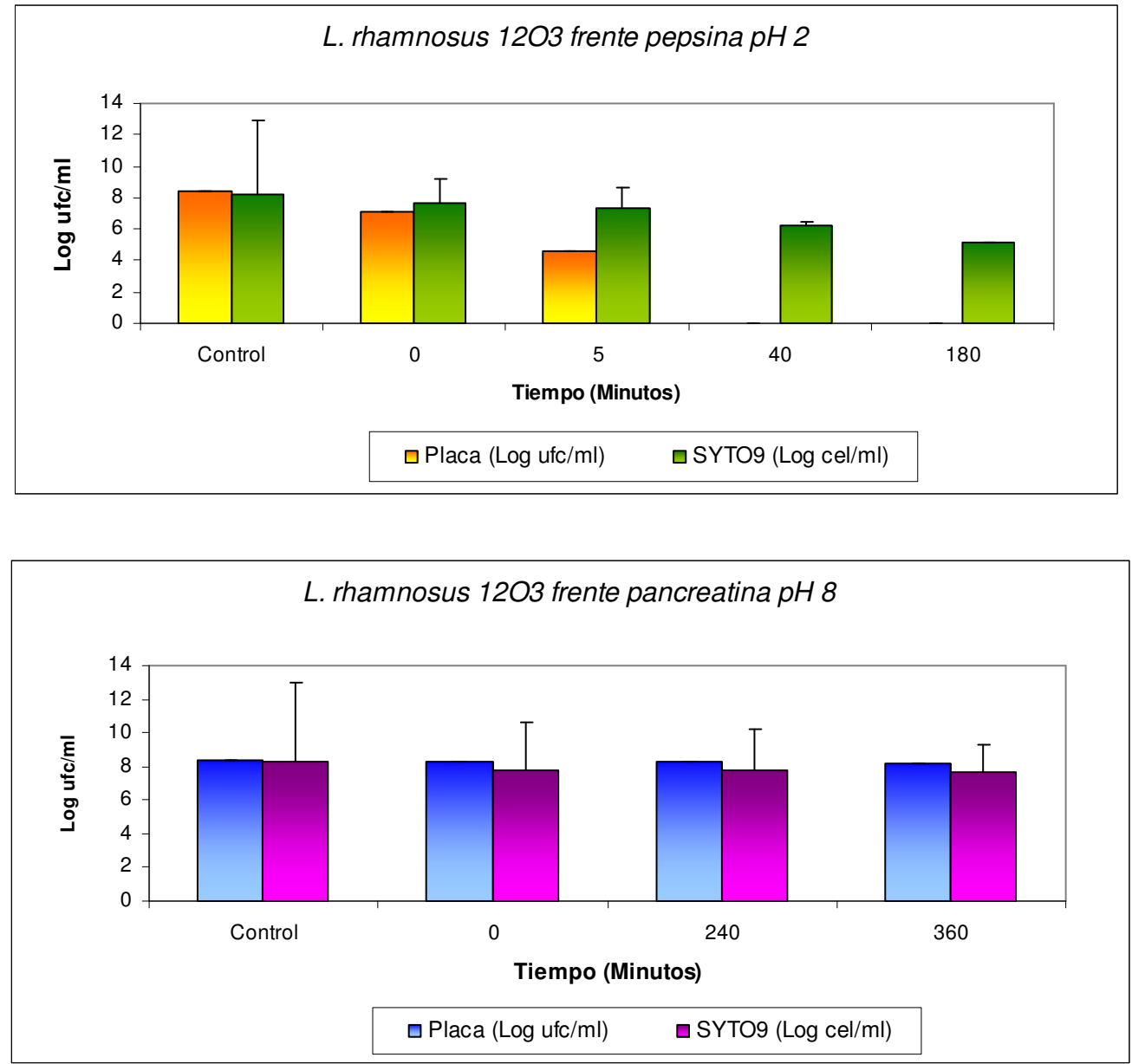

Figura 7. Supervivencia al tránsito gastrointestinal de la cepa 1203 por recuento en placa y fluorocromo SYTO9. 

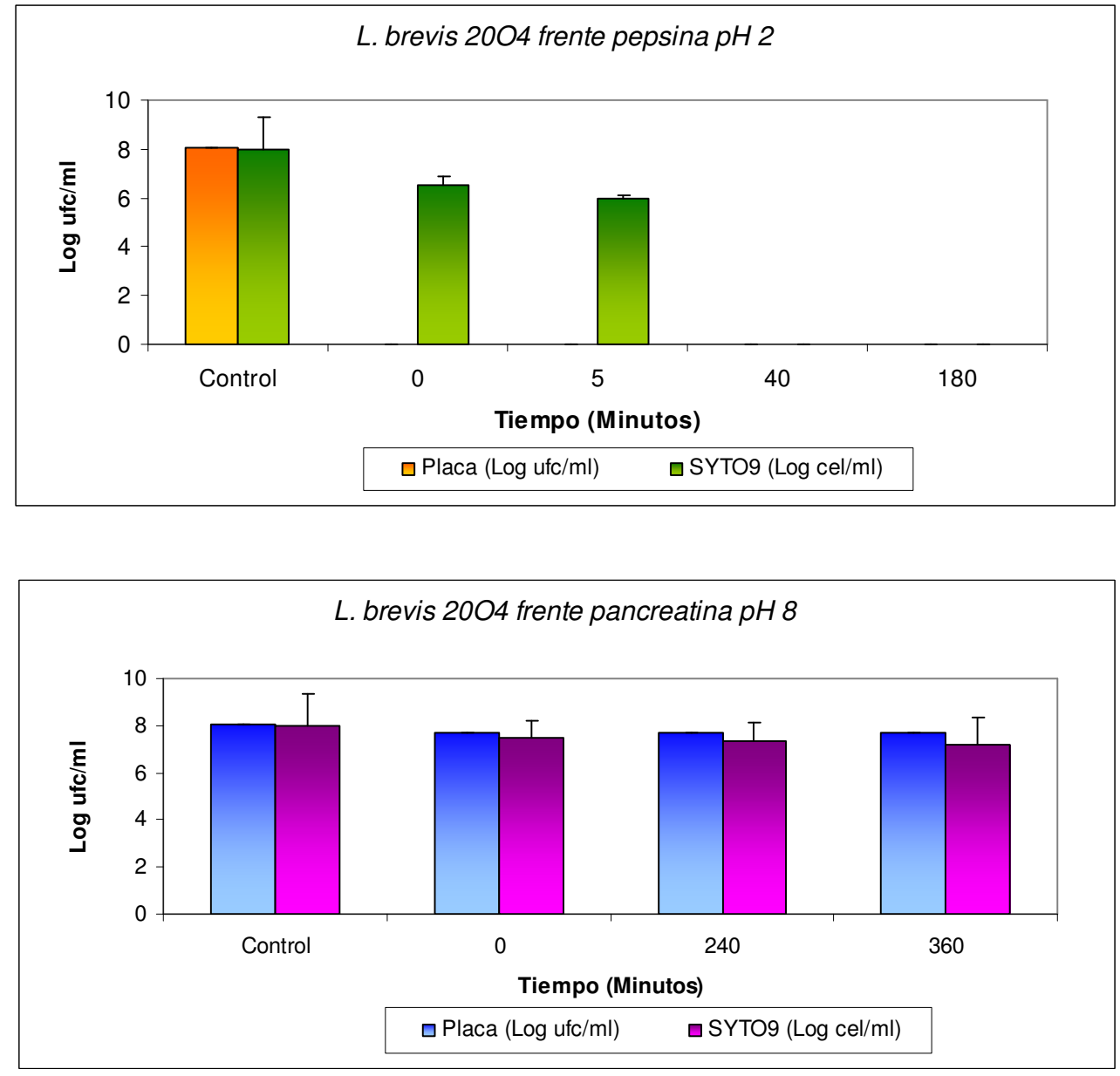

Figura 8. Supervivencia al tránsito gastrointestinal de la cepa 2004 por recuento en placa y fluorocromo SYTO9. 


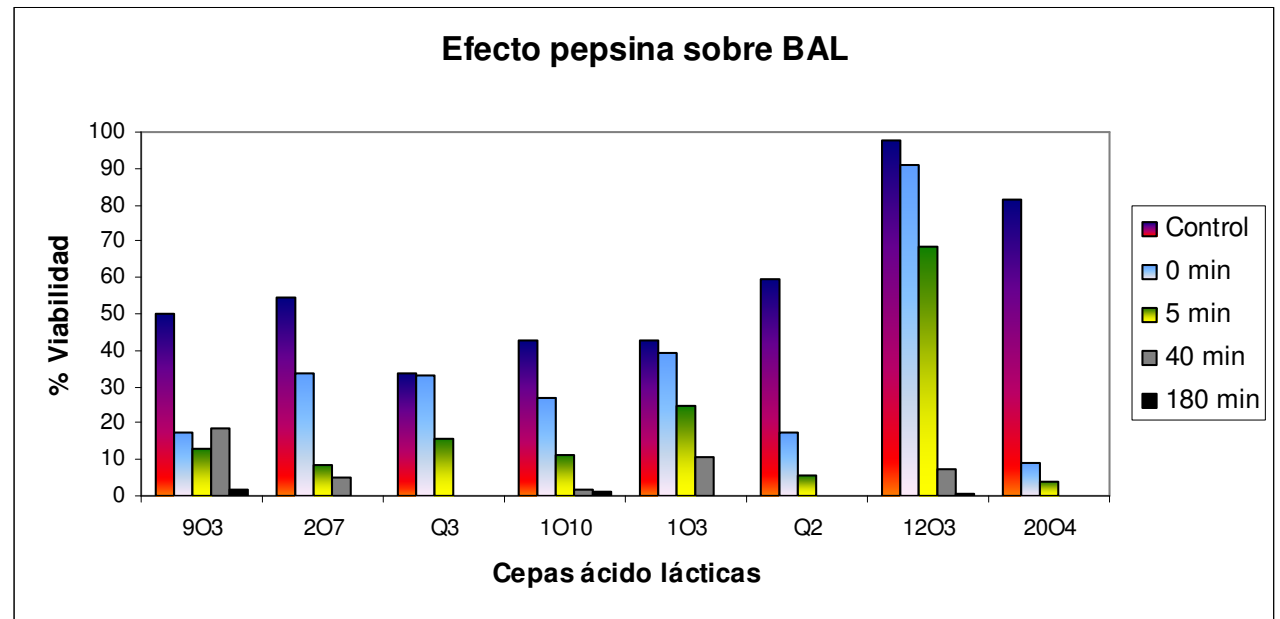

Figura 9. Porcentajes de viabilidad celular al tránsito gastrointestinal frente a pepsina pH 2

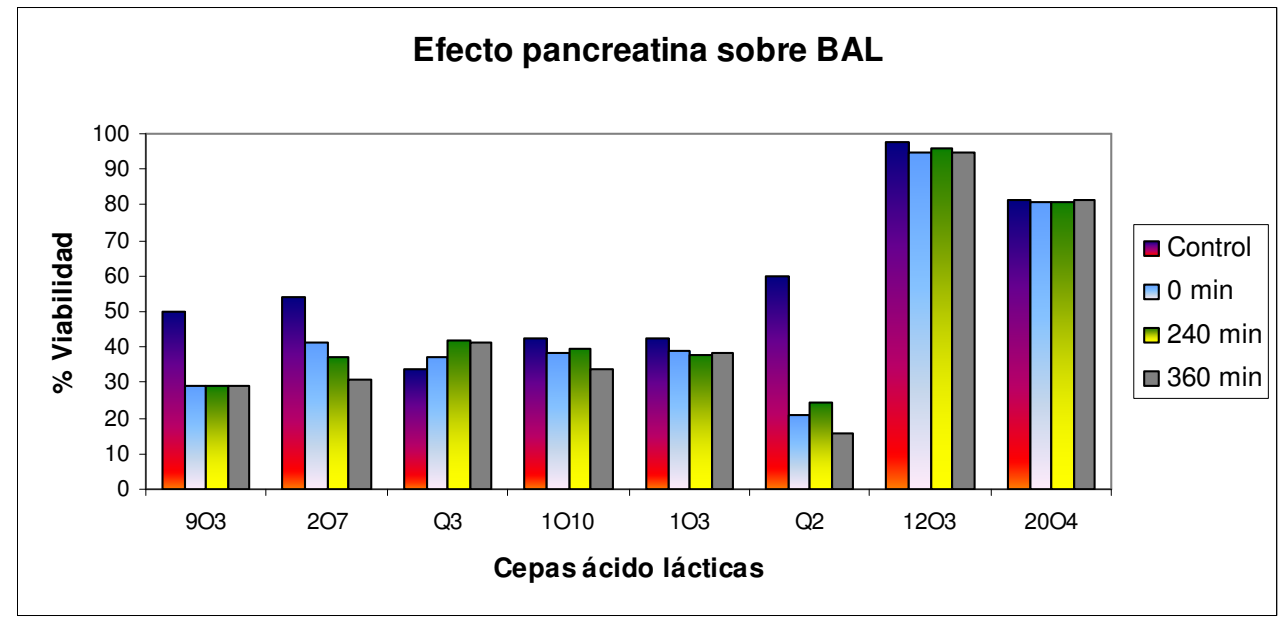

Figura 10. Porcentajes de viabilidad celular con SYTO al tránsito gastrointestinal frente a pancreatina $\mathrm{pH} 8$. 
Tabla 1. Tinción con los fluorocromos SYTO9 y PI de BAL antes y después del tratamiento con pepsina $\mathbf{p H} 2$.

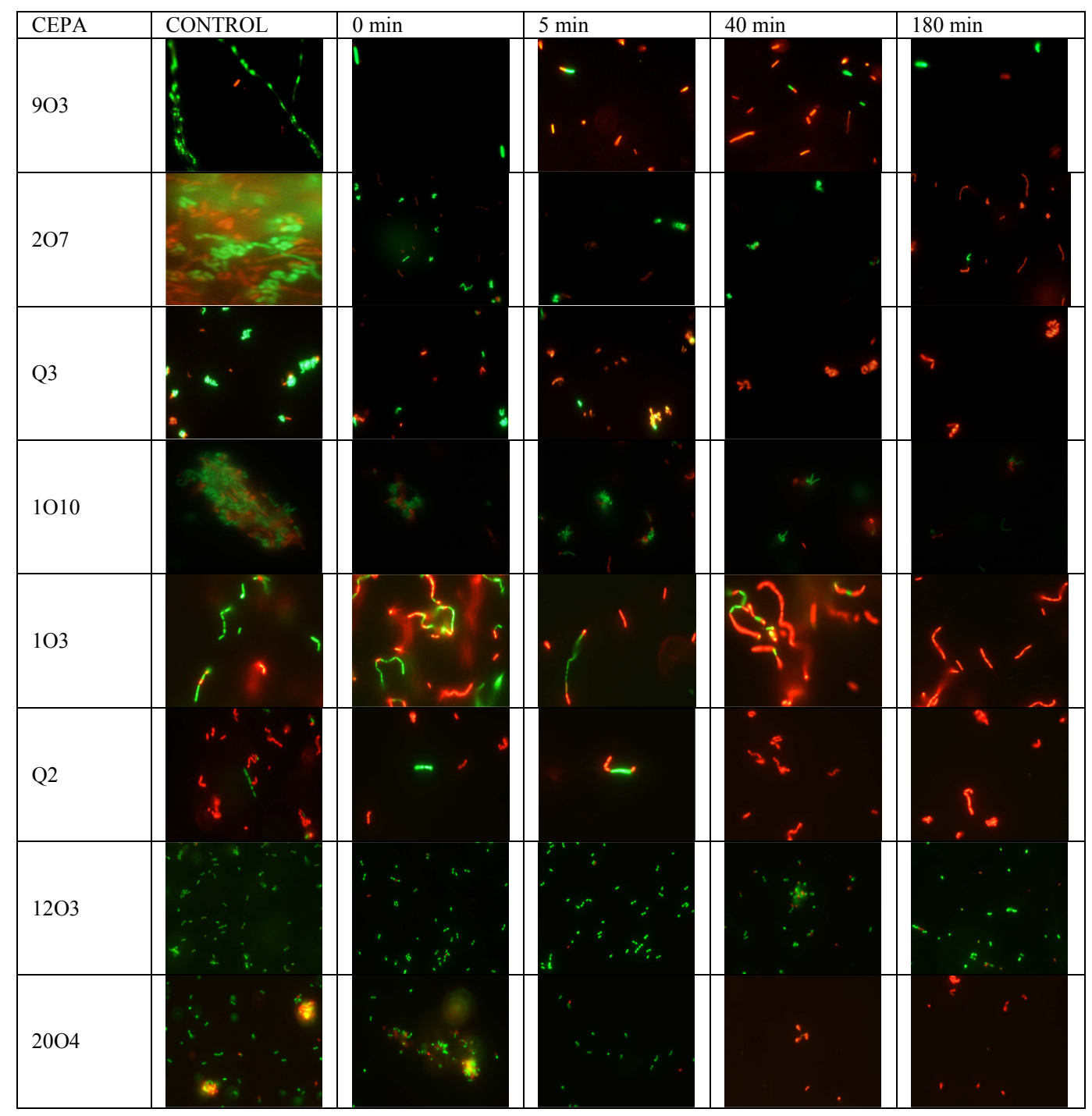


Tabla 2. Tinción con los fluorocromos SYTO9 y PI de BAL antes y después del tratamiento con pancreatina pH 8.

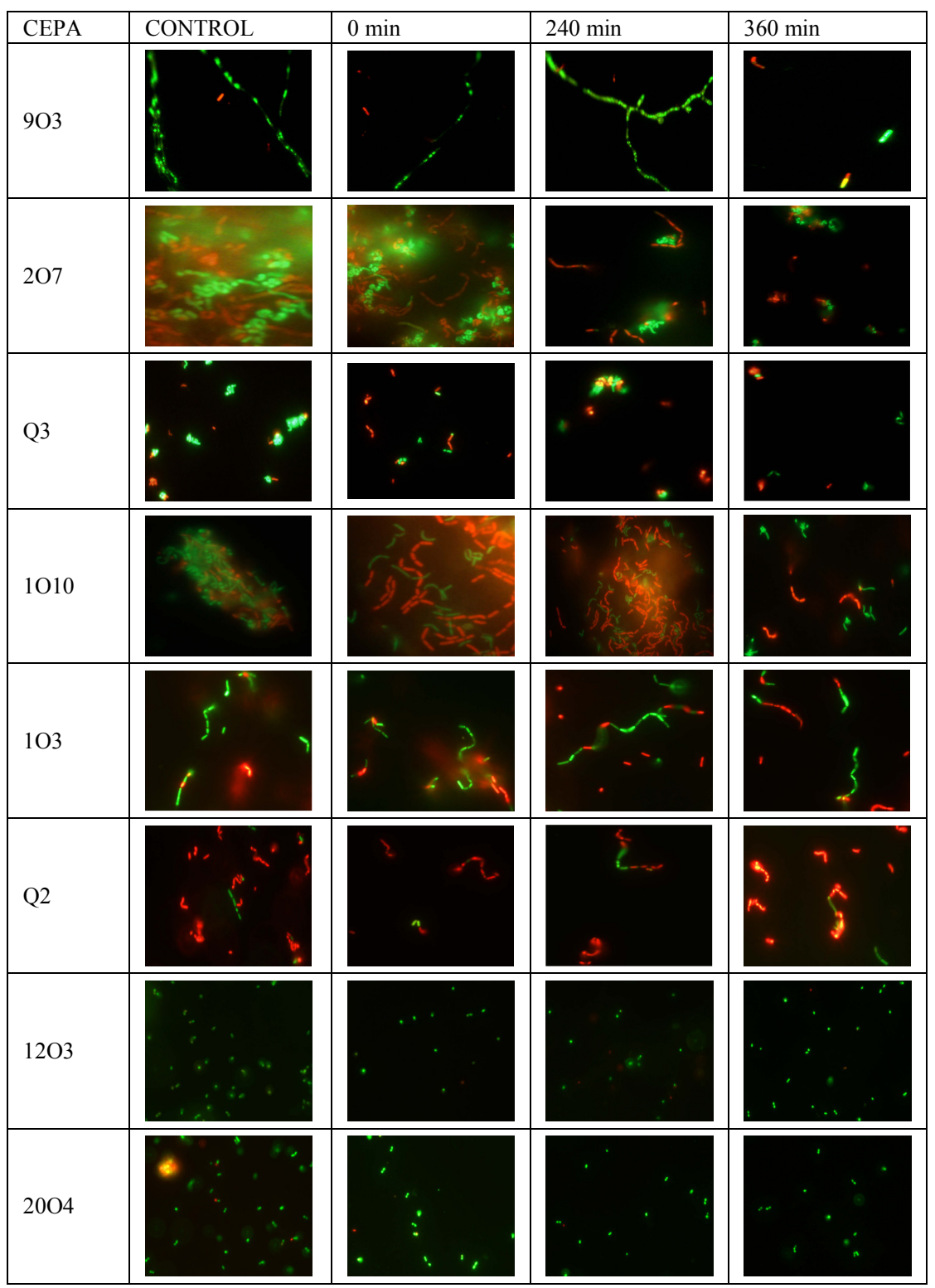




\section{DISCUSION}

El presente estudio evaluó el efecto de los jugos gastrointestinales sobre la viabilidad de 8 cepas BAL aisladas de leche de oveja Guirra frente a las condiciones gástricas e intestinales durante 180 y 360 minutos, respectivamente. Todas las BAL de oveja fueron mas sensibles a los jugos gástricos que a los intestinales. Los tiempos de exposición a dichas condiciones se seleccionaron teniendo en cuenta que normalmente, el alimento en el estomago tarda entre 2 a 4 horas y cuando se trata de la ingesta de líquidos con el estomago vacío puede durar 20 minutos. Las sales biliares y la pancreatina están presentes en el intestino y las bacterias probióticas deben sobrevivir en este tramo durante 1 a 4 horas, incluso 6 horas (Huang y M. C. Adams, 2004; Collado, 2004).

Las muestras de cada cepa láctica en el presente estudio, antes de aplicar los respectivos tratamientos, estuvieron del orden de $10^{8}$ células $/ \mathrm{ml}$. Las cepas L. acidophilus (9O3), L. pentosus (2O7), L. paracasei paracasei (1O10) y L. rhamnosus (12O3) resistieron las condiciones ácidas después de 180 minutos de exposición con aproximadamente $10^{5}$ células $/ \mathrm{ml}$, destacándose la cepa 1010 con $10^{6}$ células $/ \mathrm{ml}$. Las bacterias probióticas interactúan con los jugos gástricos e intestinales y para que las células epiteliales obtengan sus efectos inmunomoduladores es necesario que lleguen en cantidades de al menos $10^{6}$ $\mathrm{cel} / \mathrm{ml}$ al intestino para actuar eficazmente, apreciar sus efectos, adherirse y multiplicarse en el tracto intestinal (Moreno et al., 2000; Myllyluoma et al., 2008). De acuerdo a los resultados de Fernández et al., (2008) y Mejía et al., (2007), L. paracasei fue resistente a las condiciones ácidas, al igual que L. acidophilus que se caracterizó por ser activo en el intestino humano.

De otro lado, la cepa de leche de oveja de Lactococcus lactis subsp lactis (1O3) que previamente mostró actividad antimicrobiana frente a H. pylori y Salmonella (Capitulo II) sobrevivió 40 minutos a las condiciones gástricas (pepsina $\mathrm{pH}$ 2). Estos resultados coinciden con estudios previos con cepas de Lactococcus presentes en productos lácteos que inhibieron 
a bacterias entéricas y toleraron las condiciones del tracto gastrointestinal como el bajo $\mathrm{pH}$ (Kimoto et al., 2002). Las cepas de leche de oveja de L. plantarum (Q2, Q3) resistieron las condiciones gástricas durante 5 minutos, en contraste a los resultados de Grangette et al., (2004) que mostraron que la cepa de L. plantarum fue mas resistente que la cepa Lactococcus lactis a las condiciones severas del estomago y la parte superior del intestino en el tracto gastrointestinal de roedores y humanos.

En esta investigación, las cepas de L. plantarum (Q2, Q3) y L. brevis (2004) tuvieron una viabilidad entre 4 y $16 \%$ bajo condiciones gástricas durante 5 minutos y de 15 a $81 \%$ a las condiciones intestinales durante 360 minutos. Estas cepas de oveja fueron sensibles a las condiciones gástricas y por tanto no alcanzaron a llegar en cantidades apropiadas al intestino. Los anteriores resultados son contrarios a lo publicado por R. Martín et al., (2009) en donde las cepas de L. plantarum y L. brevis presentaron porcentajes de viabilidad más altos entre $38-40 \%$ al exponerse a las condiciones gastrointestinales.

La resistencia a las condiciones de tránsito intestinal es vital para que puedan colonizar el intestino. Todas las cepas estudiadas toleraron las condiciones intestinales mostrando bajas pérdidas de viabilidad, similares resultados se aprecian en Collado, (2004). Aunque, en algunos casos, se aprecian leves incrementos no significativos $(p>0.05)$ en el porcentaje de viabilidad. Sin embargo, al tener en cuenta el porcentaje de supervivencia total de pepsina y pancreatina se obtuvo un estimado más cercano a las condiciones reales. La cepa $L$. acidophilus (9O3) llegaría al intestino en una cantidad de $9.9 \times 10^{5}$ células $/ \mathrm{ml}, L$. pentosus (2O7) con $5.8 \times 10^{5}$ células $/ \mathrm{ml}$, L. paracasei (1O10) con $1.8 \times 10^{6}$ células $/ \mathrm{ml}$ y $L$. rhamnosus (12O3) con $7.3 \times 10^{5}$ células $/ \mathrm{ml}$. Lo cual confirma los resultados obtenidos por Chang et al., (2010) que mostraron que las bacterias probióticas al pasar por el estómago fueron afectadas por las condiciones adversas y esto repercutió en el número de bacterias que posteriormente llegaron al colon a ejercer sus funciones beneficiosas. Por eso, aunque las cepas 9O3, 207, 1010 y 1203 presentaron porcentajes positivos de viabilidad con el recuento de SYTO en las condiciones gástricas e intestinales, solo la cepa 1010 alcanzó a 
resistir las condiciones gastrointestinales in vitro con una densidad bacteriana recomendada para ejercer los efectos saludables en el intestino.

Todos los datos de viabilidad anteriormente expuestos se obtuvieron con el sistema LIVE/DEAD que permite apreciar las formas viables no cultivables, metabolitamente activas y que pueden tener una función beneficiosa, mostrando recuentos mas altos que el obtenido por el recuento en placa. El uso del recuento en placa no resultó ser el adecuado para detectar las formas viables microbianas, debido a la ausencia de un vinculo entre viabilidad y cultivabilidad (Gatti et al., 2006). Además, el sistema LIVE/DEAD proporcionó resultados en menor tiempo que el recuento convencional.

En la elaboración de productos probióticos es aconsejable seleccionar cepas resistentes a las condiciones ácidas. Las cepas que resistieron durante poco tiempo dichas condiciones podrían tratarse como ingredientes alimenticios o liofilizados en capsulas que protegen los microorganismos probióticos incrementando de esta forma su viabilidad (Collado, 2004). Otra alternativa, es partir de un inoculo con una concentración inicial mas alta de la recomendada teniendo en cuenta que hay cepas lácticas más sensibles a las condiciones gastrointestinales. Además, podría ingerirse el probiótico en forma líquida con el estomago vacío donde el tiempo de exposición a dichas condiciones disminuye.

Los mecanismos por los cuales la cepa 1010 logró sobresalir de las demás cepas estudiadas, no son conocidos en detalle. Previas investigaciones mencionan que existe un mecanismo que protege a las células de la muerte por ácido ATR (Acid tolerante Response) y fue estudiado en especies como L. acidophilus, L. helveticus, L. bulgaricus, L. delbruekii bulgaricus y L. plantarum (Lorca y de Valdez, 2009). Otros mecanismos implicados en la adaptación de los Lactobacillus incluyen la bomba de protones y enzimas involucradas en la producción de compuestos alcalinos (Lorca y de Valdez, 2009). 
Inicialmente en este estudio se destacaron las características con potencial probiótico de 8 cepas lácticas, de las cuales solo una resiste las condiciones gastrointestinales recomendadas. Por eso, la tolerancia a las condiciones gastrointestinales y el tiempo de supervivencia son indispensables en la declaración y selección de una cepa probiótica (Goderska y Czarnecki, 2007). L. paracasei (1O10) podría ser una opción en la elaboración de productos lácteos probióticos porque en condiciones in vitro demostró dichas propiedades como actividad antimicrobiana frente a patógenos, capacidad de adhesión a la mucina y tolerancia a las condiciones gastrointestinales a diferentes tiempos. Por tanto, podrían proporcionar beneficios a la salud del hospedador al administrarse en cantidades adecuadas, con buenos efectos nutricionales y reforzando los mecanismos naturales de defensa (FAO y OMS, 2001; Keohane et al., 2009).

La persistencia de los probióticos en el tracto intestinal desaparecen después de dos semanas en que se ha interrumpido el consumo (Mattila-Sandholm et al., 2002). Por tanto, estas cepas deberían probarse en posteriores estudios in vivo, realizar ensayos de alimentación teniendo en cuenta las dosis y el tiempo de administración. Los productos elaborados con leche de oveja guirra constituyen una buena fuente para la obtención de cepas BAL probióticas, de interés para la industria alimentaria y el consumidor. 
DISCUSION GLOBAL 
La identificación fenotípica por medio del sistema comercial API 50CHL de las cepas BAL aisladas de leche de oveja Guirra proporcionó información a nivel de género y especie. La microbiota láctica presente en esta materia prima fue variada y se encontraron las especies L. acidophilus, L. brevis, L. delbrueckii lactis, L. delbrueckii delbrueckii, L. paracasei paracasei, L. pentosus, L. plantarum, L. rhamnosus, Lactococcus lactis subsp lactis, Lactococcus raffinolactis, Leuconostoc mesenteroides mesenteroides y Pediococcus pentosaceus. Sin embargo, no distinguió entre cepas. Los resultados obtenidos fueron analizados por el método estadístico de análisis de componentes principales (ACP), que establece relaciones entre las variables y agrupa a los individuos de acuerdo a sus semejanzas mostrando que no se logró una adecuada diferenciación de especies debido a que las cepas BAL estudiadas presentan diferentes perfiles de fermentación, coincidiendo con las observaciones de Sarmiento (2008) y Pot y Tsakalidou (2009). Cabe destacar que esta identificación proporcionó información de la capacidad de fermentación de cada cepa frente a 50 azúcares y es útil en el momento de seleccionar cepas que deseen introducirse en un alimento específico. Sin embargo la presente caracterización fenotípica se debería complementar con la aplicación de técnicas moleculares a nivel de especie como la técnica de secuenciación de marcadores taxonómicos como el gen del 16S rRNA para la obtención de una identificación más exacta.

Actualmente, las infecciones ocasionadas por H. pylori y Salmonella spp. son tratadas con antibióticos y un porcentaje muy bajo de dichos tratamientos son fallidos por la presencia de cepas patógenas resistentes. Los probióticos son propuestos como una alternativa al uso de antibióticos y algunos pertenecen a las cepas BAL. El presente estudio evaluó la actividad antimicrobiana de las BAL aisladas de leche de oveja Guirra junto con algunas cepas pertenecientes a la CECT frente a H. pylori y Salmonella spp. Según Servin y Coconnier (2003) algunas BAL produjeron sustancias antimicrobianas que fueron activas contra bacterias Gram-negativas. La presente investigación confirma que la actividad antimicrobiana de algunas cepas lácticas de leche de oveja Guirra frente a estas especies patógenas está influenciada por la presencia de las células, las sustancias producidas y el $\mathrm{pH}$. H. pylori fue afectado por las células BAL y las sustancias producidas como ácidos 
orgánicos y sustancias activas a $\mathrm{pH}$ neutro. Mientras, las cepas de Salmonella spp. solo fueron inhibidas por la presencia de las células de las BAL y los ácidos orgánicos. Los resultados de inhibición fueron dependientes de la cepa ácido láctica y patógena. Algunas de las BAL destacaron por su actividad antimicrobiana y resultan de interés en el tratamiento de alteraciones ocasionadas por estos patógenos.

De las pruebas de actividad antimicrobiana destacaron las cepas lácticas $12 \mathrm{O} 3$ y $20 \mathrm{O} 4$ porque tuvieron la capacidad de inhibir en presencia y ausencia de células a pH 4.5 y 7 a H. pylori $\mathrm{B} 6$ resistente a la claritromicina. El ensayo de viabilidad in vitro de $H$. pylori al estar en contacto con las sustancias de las BAL se realizó con el sistema LIVE/DEAD y recuento en placa. Los resultados demuestran que las sustancias de las BAL afectaron la integridad de la membrana de algunas células de $H$. pylori. El porcentaje de células viables disminuyó en la muestra control en menor proporción que las muestras de cultivo mixto de H. pylori y los sobrenadante de las cepas BAL $12 \mathrm{O} 3$ y $20 \mathrm{O} 4$ después de 24 horas. Estos porcentajes fueron poco representativos respecto al número total de células de $\mathrm{H}$. pylori presentes en la muestra. Las cepas 1203 y 2004 tuvieron la habilidad de inhibir el crecimiento de $H$. pylori pero no lograron erradicarlo. Tal vez, mayores tiempo de exposición con las sustancias de estas cepas favorezcan el control de H. pylori. El cual, al estar en contacto con las sustancias producidas por las BAL presentó cambios morfológicos pasando de formas espirales a U, V y cocos a través del tiempo. Dichos cambios posiblemente fueron originados porque el patógeno estuvo expuesto a condiciones adversas y por ello buscó una forma de resistencia. Requiere especial cuidado, aquellas formas cocoides con la membrana intacta porque se encuentran en un estado viable y son potencialmente infectivas. Además, estas formas viables en la mayoría de los casos no son cultivables. Por otro lado, el método LIVE/DEAD resultó mas seguro en el momento de evaluar el efecto de cepas probióticas en la viabilidad del patógeno H. pylori.

Según la FAO, las cepas con características probióticas deben ser identificadas a nivel de género, especie y cepa para atribuir dichas características a una cepa concreta. Por 
ello, se seleccionaron 33 cepas BAL de oveja y 6 de la CECT que mostraron mayores casos de inhibición frente a los patógenos H. pylori y Salmonella spp. para caracterizarlas por medio de la técnica RAPD y perfiles de resistencia a antibióticos. Los perfiles encontrados fueron heterogéneos, varias especies compartieron perfil con un iniciador y con el segundo mostraron perfiles distintos. La técnica RAPD proporcionó una identificación a nivel intraespecífico y la asociación de las cepas estuvo en función del tamaño de la banda compartida. La variabilidad presentada pudo ser debido a que las muestras de leche se tomaron de diferentes granjas, épocas del año, recibieron diferente manejo, algunas muestras se obtuvieron directamente de la leche cruda, otras fueron almacenadas en tanques y otras fueron aisladas de quesos. Las BAL estudiadas fueron resistentes al ácido nalidíxico y presentaron sensibilidad a algunos antibióticos dependiendo de la cepa. Por tanto, cada cepa expresó unas características propias y se confirmó que no se pueden generalizar las propiedades probióticas a un género o especie. La información obtenida es útil en el momento que se deseen emplear estas cepas en alimentos probióticos porque permiten monitorizar determinadas bacterias.

Además, una cepa probiótica para lograr colonizar el intestino requiere poseer propiedades de adhesión a la mucosa intestinal (He et al., 2001). Por ello, las 39 BAL mencionadas anteriormente se evaluaron in vitro por su capacidad de adhesión a la mucina. Los resultados mostraron que las BAL estudiadas poseen actividad antimicrobiana frente a patógenos, pero solo 29 de 39 cepas lácticas presentaron capacidad de adhesión y entre las especies no se apreciaron diferencias significativas. Por tanto, esta propiedad de adhesión fue dependiente de la cepa. Similares resultados publicaron Servin y Coconnier (2003) y Laparra y Sanz, (2009). En la presente investigación 14 cepas pertenecientes a las especies $L$. casei (CECT475), L. paracasei paracasei (10O8, 1010, 2105, $4 \mathrm{O} 4$ y 2T4), L. pentosus (2O7), L. plantarum (17O5, 3 O9 y Q2) y Lactococcus lactis subsp lactis (13O5B, 19O6, 2011 y 1T4) presentaron porcentajes de adhesión suficientes para que las bacterias acido lácticas logren colonizar y ejercer los efectos beneficiosos en el intestino (Collado, 2004). 
El ensayo de adhesión con mucina y policarbonato mostraron el tipo de interacciones implicadas en la adhesión de las BAL. Los porcentajes de adhesión al policarbonato sugirieron que existen interacciones hidrofóbicas importantes en la habilidad de adhesión de las bacterias a la mucina (Laparra y Sanz, 2009; Van den Abbeele et al., 2009). Del Re (2000) demostró que la habilidad de hidrofobicidad puede ser predictiva de la adherencia de bifidobacteria. Sin embargo, los resultados de este tratamiento no fueron predictivos de la capacidad de adhesión de algunas BAL de Lactobacillus y Lactococcus, ya que no lograron adherirse a la mucina a pesar de sus propiedades de hidrofobicidad. Posiblemente, las interacciones hidrofóbicas de estas cepas lácticas no son suficientes en la habilidad de adhesión y se requiera estudiar la acción de otros componentes de naturaleza proteica, acción de carbohidratos, ácidos lipoteicoicos, fuerzas pasivas, interacciones electrostáticas y estructuras específicas que de acuerdo a Van den Abbeele et al., (2009) estuvieron vinculadas con la adhesión.

La tolerancia a las condiciones gastrointestinales es otra prueba fundamental en la selección de probióticos (FAO y OMS, 2001). Las pruebas de supervivencia a las condiciones gastrointestinales in vitro de $8 \mathrm{BAL}$ aisladas de leche de oveja Guirra se realizó con el sistema LIVE/DEAD y recuentos en placa. Estas cepas lácticas presentaron actividad antimicrobiana frente a H. pylori y Salmonella spp., capacidad de adhesión a la mucina, con resistencia al ácido nalidíxico, sensibilidad a amoxicilina, ceftriaxona, cloranfenicol, cefalotin, tetraciclina, ampicilina y carbenicilina. De acuerdo a los resultados obtenidos en este ensayo las BAL aisladas de leche de oveja Guirra fueron más sensibles a las condiciones ácidas en presencia de pepsina que a la pancreatina en condiciones básicas. Las pérdidas de viabilidad variaron dependiendo de la cepa, el tipo de enzima, $\mathrm{pH}$ y el tiempo. Destacan las cepas L. pentosus (2O7), L. paracasei (1O10), L. acidophilus (9O3) y L. rhamnosus (12O3) porque lograron resistir las condiciones de los jugos gástricos durante 3 horas con valores entre 5.1 a $5.9 \mathrm{Log}$ cel $/ \mathrm{ml}$. La técnica de tinción con fluorocromos (LIVE/DEAD BacLight) proporcionó resultados en menor tiempo respecto a la técnica de recuento en placa permitiendo la detección de las células microbianas en su ambiente y fue posible detectar las formas viables no cultivables y metabolitamente activas (Gatti et al., 2006). 
A partir de los resultados obtenidos a lo largo de este trabajo, cabe destacar la cepa láctica $L$. paracasei 1010 aislada de leche de oveja ya que demostró en condiciones in vitro actividad antimicrobiana frente a patógenos, capacidad de adhesión a la mucina y tolerancia a las condiciones gastrointestinales a diferentes tiempos. Por tanto, resulta de especial interés en estudios posteriores que confirmen su potencial probiótico en condiciones in vivo.

Los probióticos son utilizados para reforzar la capacidad de defensa natural de la microflora comensal del intestino. El presente estudio demostró que algunas cepas de leche de oveja Guirra tuvieron características probióticas. Los resultados de actividad antimicrobiana, la habilidad de adhesión y resistencia a las condiciones gastrointestinales in vitro señalaron la actividad probiótica de estas cepas pero no es posible extender estos atributos y correlacionarlos con una actividad probiótica efectiva, similar a lo publicado por Izquierdo et al., (2008). Estas cepas lácticas son de interés para la industria de lácteos de la Comunidad Valenciana y específicamente para los productores de leche de oveja Guirra que están en proceso de distinguir los productos que elaboran con esta materia prima. Aún falta profundizar en los mecanismos de acción de las cepas lácticas y para garantizar su seguridad se recomienda otras pruebas de caracterización ya mencionadas. Además, es necesario realizar ensayos in vivo para confirmar las características probióticas. 


\section{CONCLUSIONES}


* La identificación bioquímica con el sistema comercial API 50 CHL permite identificar las bacterias a nivel de género y especie. Sin embargo, no logra diferenciar a nivel de cepa.

* A partir de la identificación bioquímica fue posible identificar en la leche de oveja guirra las especies L. acidophilus, L. brevis, L. delbrueckii lactis, L. delbrueckii delbrueckii, L. paracasei paracasei, L. pentosus, L. plantarum, L. rhamnosus, Lactococcus lactis subsp lactis, Lactococcus raffinolactis, Leuconostoc mesenteroides mesenteroides y Pediococcus pentosaceus.

* El 66\% (87/131) de las BAL aisladas de leche de oveja y $63 \%(6 / 8)$ pertenecientes a la CECT inhibieron por medio de la presencia de las células lácticas el crecimiento de $H$. pylori NCTC11637. Mientras, $H$. pylori B6 solo fue afectado por el $42 \%$ (55/131) de las células lácticas de leche de oveja y el 75\% (6/8) de las BAL de la CECT.

* $\quad$ El 56\% (73/131) de las BAL de leche de oveja y 50\% (4/8) pertenecientes a la CECT inhibieron por acción de los ácidos orgánicos a H. pylori NCTC11637. Mientras, $H$. pylori B6 solo fue afectado por los sobrenadantes del 8\% (11/131) de las cepas lácticas de leche de oveja y el $62.5 \%(5 / 8)$ de las cepas lácticas de la CECT.

* $\quad$ El 5.8\%, 7.2\%, 10.1\% y 7.2\% de las BAL aisladas de leche de oveja y de la CECT necesitaron de la presencia de las células para inhibir el crecimiento de las cepas de Salmonella S134, S58, S135 y S915, respectivamente.

* $\quad$ El $6.5 \%, 7.2 \%, 5.0 \%$ y $6.5 \%$ de las sustancias producidas a $\mathrm{pH} 4.5$ de las BAL estudiadas afectaron el crecimiento de las cepas de Salmonella S134, S58, S135 y S915, respectivamente. 
* El $11 \%$ y el $1.5 \%$ de las BAL de leche de oveja han inhibido por medio de las sustancias producidas a pH 7 el crecimiento de $H$. pylori NCTC11637 y B6, respectivamente. Aunque, los sobrenadantes de las $\mathrm{BAL}$ a $\mathrm{pH} 7$ no tienen ningún efecto frente a las cepas de Salmonella spp estudiadas.

* Las cepas L. acidophilus (903), L. casei (CECT475), L. delbrueckii delbrueckii (CECT286), L. paracasei paracasei (1010, CECT4022), L. pentosus (2O7, CECT4023), L. plantarum (Q2, Q3), L. rhamnosus (CECT278) y Lactococcus lactis subsp lactis $(103,1906)$ fueron las especies que presentaron mayores casos de inhibición frente a los patógenos H. pylori y Salmonella spp.

* Las sustancias producidas a pH 4.5 por las cepas L. brevis (2004) y L. rhamnosus (1203) afectaron el crecimiento y produjeron cambios morfológicos en $H$. pylori B6 pasando de formas espirales a $\mathrm{U}, \mathrm{V}$ y cocos en estado viable y no viable. Las cepas BAL de leche de oveja Guirra lograron disminuir la densidad del patógeno pero no lo erradicaron.

* En la caracterización genotípica de las cepas BAL con actividad antimicrobiana frente a $H$. pylori y Salmonella spp. mediante RAPDs mostró una elevada heterogeneidad incluso dentro de la misma especie. Las agrupaciones no mostraban asociación de acuerdo a los resultados de inhibición antimicrobiana, ni perfiles a especies.

* La capacidad de adhesión es dependiente de la cepa y no todas las BAL que presentaron actividad antimicrobiana frente a los patógenos estudiados tuvieron capacidad de adhesión a la mucina de cerdo en condiciones in vitro.

* El tratamiento de adhesión al policarbonato no es predictivo en todos los casos de la capacidad de adhesión de las BAL estudiadas. 
* Las cepas L. casei (CECT475), L. paracasei paracasei (1008, 1010, 2105, $4 \mathrm{O} 4$ y 2T4), L. pentosus (2O7), L. plantarum (1705, $3 \mathrm{O} 9$ y Q2) y Lactococcus lactis subsp lactis (1305B, 1906, 2011 y 1T4) presentaron porcentajes de adhesión superiores a 7.45\%; los cuales corresponden a una cantidad suficiente de bacterias $\left(10^{6} \mathrm{UFC} / \mathrm{ml}\right)$ que se adhieren y de esta manera colonizar y ejercer los efectos beneficiosos en el hospedador.

* El sistema LIVE/DEAD y el recuento en placa permitieron determinar la resistencia de algunas BAL aisladas de leche de oveja a las condiciones gastrointestinales. Todas las cepas BAL resultaron ser más sensibles a los jugos gástricos con valores de viabilidad entre 0 y 97\%; mientras que estos valores frente a condiciones intestinales estuvieron entre $16 \%$ y 94\%. La resistencia a las condiciones gastrointestinales dependió de la cepa ensayada.

* La cepa de leche de oveja L. paracasei (1010) en condiciones in vitro demostró poseer todas las características probióticas estudiadas como actividad antimicrobiana frente a patógenos, capacidad de adhesión a la mucina y tolerancia a las condiciones gastrointestinales a diferentes tiempos. Consideramos esta cepa de interés para posteriores estudios in vivo. 


\section{BIBLIOGRAFIA}

=


Adams, B.L., Bates, T.C., Oliver, J.D., 2003. Survival of Helicobacter pylori in a Natural Freshwater Environment. Applied and Environmental Microbiology, 69(12), págs.7462-7466.

Aguilar, F., Escolástica, L., 2003. Caracterización fenotípica y genotípica de estirpes de Salmonella Choleraesuis aisladas de ambientes marinos.

Aiba, Y., Nobuyuki, S., Kabir, A.M., Takagi, A., Koga, Y. 1998. Lactic acid-mediated suppression of helicobacter pylori by the oral administration of lactobacillus salivarus as a probiotic in a gnotobiotic murine model. The American Journal of gastroenterology, págs.2097-2101.

Alonso, J.L., Mascellaro, S., Moreno, Y., Ferrus, M.A., Hernández, J. 2002. Double-Staining method for differentiation of morphological changes and membrane integrity of Campylobacter coli cells. Applied and Environmental Microbiology, 68(10), págs.5151-5154.

Allgeyer, L.C., Miller, M.J., Lee, S.Y., 2010. Drivers of linking for yogurt drinks with prebiotics and probiotics. Journal of Food Science, 75(4), pág.S212-S219.

Andrighetto, C., Zampese, L., Lombardi, A., 2001. RAPD-PCR characterization of lactobacilli isolated from artisanal meat plants and traditional fermented sausages of Veneto region (italy). Letters in Applied Microbiology, 33, págs.26-30.

Angelov, A., Gotcheva, V., Kuncheva, R., Hritozova, T. 2006. Development of a new oatbased probiotic drink. International Journal of Food Microbiology, 112, págs.7580 .

Anselmi, S., Castillo, V., Gonzalez, K., Angel, G., Sathyn, R., Medina, Y., Marcel, J. 2007. Helicobacter pylori un camino al cáncer. Academia Biomédica digital. VITAE. Universidad Central de Venezuela. 
Arciero, J.C., Ermentrout, G.B., Upperman, J.S., Vodovotz, Y., Rubin, J.E. 2010. Using a mathematical model to analyze the role of probiotics and inflammation in necrotizing enterocolitis. PLoS ONE www.plosone.org, 5(4).

Armuzzi, A., Cermonini, F., Ojetti, V., Bartolozzi, F., Canducci, F., Candelli, M., Santarelli, L., Cammarota, G., De Lorenzo, A., Pola, P., Gasbarrini, G., Gasbarrini, A. 2001. Effect of Lactobacillus GG supplementation on antibiotic-associated gastrointestinal side effects during Helicobacter pylori eradication therapy: a pilot study. Digestion, 63, págs.1-7.

Asteri, I.A., Kittaki, N., Tsakalidou, E., 2010. The effect of wild lactic acid bacteria on the production of goat's milk soft cheese. International Journal of Dairy Technology, 63(2), págs.234-242.

Avila, J., Avila, M., Tovar, B., Brizuela, M., Perazzo, Y., Hernández, H. 2010. Capacidad probiótica de cepas del género Lactobacillus extraídas del tracto intestinal de animales de granja. Redalyc-Revistas científicas de América Latina, El caribe, España y Portugal, XX(2), págs.161-169.

Axelson, S., 1998. Lactic acid bacteria: classification and physiology. En Lactic Acid Bacteria.Microbiological and Functional Aspects. págs. 1-72.

Azaïs-Braesco, V., Bresson, J.L., Guarner, L., Corthier, G. 2010. Not all lactic acid bacteria are probiotics, but some are. British Journal of Nutrition, 103, págs.1079-1081.

Azevedo, N.F., Almeida, C., Cerqueira, L., Dias, S., Keevil, C.W., Vieira, M.J. 2007. Coccoid form of Helicobacter pylori as a morphological manifestation of cell adaptation to the environment. Appl. Environ. Microbiol, 73(10), págs.3423-3427.

Banks, J.M., 2000. Queso. En Tecnología de los productos lácteos. Zaragoza: Editorial Acribia, págs. 82-126. 
Barefoot, S.F., Klaenhammer, T.R., 1983. Deteccion an activity of lactacin B, a bacteriocin produced by Lactobacillus acidophilus. Applied and Environmental Microbiology, 45(6), págs.1808-1815.

Bathia, S.J., Kochar, N., Abraham, P., Nair, N.G., Mehta, A.P. 1989. Lactobacillus acidophilus inhibits growth of Campylobacter pylori in vitro. Journal of clinical microbiology, 27(10), págs.2328-2330.

Bauer, A.W., Kirby, W.M.M., Sherris, J.C., Turk, M. 1966. Antibiotic susceptibility testing by a standardized single disk method. Am J Clin Pathol, 45, págs.493-496.

Bautista, C.R., Arriola, M.T., Trejo, L., Ixta, O., Rojas, E., 2003. Comparación entre el efecto de Lactobacillus casei y el de una vacuna comercial en pollos contra la coccidiosis. Téc. Pecu. Méx., 41, págs.317-327.

Bazzoli, E., Zagari, R.M., Fossi, S., 1992. In vivo Helicobacter pylori clearance failure with lactobacillus acidophilus. Gastroenterology, 102(A38).

Beausoleil, M., Fortier, N., Guénette, S., L`Ecuyer, A., Savoie, M., Franco, M., Lachaîne, J., Weiss, K. 2007. Effect of a fermented milk combining Lactobacillus acidophilus CL1285 and Lactobacillus casei in the prevention of antibiotic-associated diarrhea:A randomized, double-blind, placebo-controlled trial. Can J Gastroenterol, 21(11).

Bennet, R.G., 1996. Treatment on relapsing Clostridium difficile diarrhoea with Lactobacillus GG. Nutr. Today, 31, pág.35S-38S.

Bernet, M.F., Brassart, D., Neeser, J.R., Servin, A.L., Hudault, S. 1994. Lactobacillus acidophilus La1 bind to cultured human intestinal cell lines and inhibits cellattachment and cell-invasion by enterovirulent bacteria. Gut, 35, págs.483-489. 
Berney, M., Hammes, F., Bosshard, F., Weilenmann, H.U., Egli, T. 2007. Assessment and Interpretation of Bacterial Viability by Using the LIVE/DEAD BacLight Kit in Combination with Flow Cytometry. Applied and Environmental Microbiology, 73(10), págs.3283-3290.

Berthier, F., Ehrlich, S.D., 1999. Genetic diversity within Lactobacillus sakei and Lactobacillus curvatus and design of PCR primers for its detection using randomly amplified polymorphic DNA. International Journal of Systematic Bacteriology, 49, págs.997-1007.

Bianchi, M.A., Del Rio, D., Pellegrini, N., Sansebastiano, G., Neviani, E., Brighenti, F. 2004. A fluorescence-based method for the detection of adhesive properties of lactic acid bacteria to Caco-2 cells. Letters in Applied Microbiology, 39, págs.301-305.

Boucher, I., Vadeboncoeur, C., Moineau, S., 2003. Characterization of genes involved in the metabolism of $\alpha$-Galactosides by Lactococcus raffinolactis. Applied and Environmental Microbiology, págs.4049-4056.

Bromberg, R., Moreno, I., López, Z., Delboni, R., De Oliveira, J. 2004. Isolation of bacteriocin-producing lactic acid bacteria from meat and meat products and its spectrum of inhibitory activity. Brazilia journal of microbiology, 35, págs.137-144.

Bunthof, C.J., Abee, T., 2002. Development of a Flow Cytometric Method To Analyze Subpopulations of Bacteria in Probiotic Products and Dairy Starters. Applied and Environmental Microbiology, 68(6), págs.2934-2942.

Burdock, G.A., Carabin, I.G., Griffiths, J.C., 2006. The importance of GRAS to the functional food and nutraceutical industries. Toxicology.

Di Cagno, R., Cardinali, G., Minervini, G., Antonielli, L., Giuseppe, R., Ricciuti, P., Gobbetti, M. 2010. Taxonomic structure of the yeasts and lactic acid bacteria 
microbiota of pineapple (Ananas comosus L. Merr.) and use of autochthonous starters for minimally processing. Food Microbiology, 27, págs.381-389.

Calderón, O., Padilla, C., Chaves, C., Villalobos, L., Arias, M.L., 2007. Evaluación del efecto del cultivo probiótico Lactobacillus rhamnosus adicionado a yogurt natural y con probióticos comerciales sobre poblaciones de Staphylococcus aureus, Escherichia coli O157:H7, Listeria monocytogenes y Salmonella enteritidis. Archivos latinoamericanos de nutrición, 57(1).

Candela, M., Perna, F., Carnevali, P., Vitali, B., Ciati, R., Gionchetti, P., Rizzello, F., Campieri, M., Brigidi, P. 2008. Interaction of probiotic Lactobacillus and Bifidobacterium strains with human intestinal epithelial cells: adhesion properties, competition against enteropathogens and modulation of IL-8 production. International Journal of Food Microbiology, págs.286-292.

Canducci, F., Armuzzi, A., Cremonini, F., Cammarota, G., Bartolozzi, F., Pola, P., Gasbarrini, G., Gasbarrini, A. 2000. A lyophilized and inactivated culture of Lactobacillus acidophilus increases Helicobaccer pylori eradication rates. Aliment. Pharmacol. Ther., 14, págs.1625-1629.

Casalta, E., Montel, M.E., 2008. Safety assessment of dairy microorganisms: The Lactococcus genus. International Journal of Food microbiology, 126(3), págs.271273.

Casalta, E., Sorba, J.M., Aigle, M., Ogier, J.C. 2009. Diversity and dynamics of the microbial community during the manufacture of Calenzana, an artisanal Corsican cheese. International Journal of Food Microbiology, 133, págs.243-251.

Cats, A., Kuipers, E.J., Bosschaert, M.A.R., Pot, R.G.J., Vandenbrouckegrauls, C.M.J.E., Kuster, J.G. 2003. Effect of frequent consumption of a Lactobacillus casei- 
containing milk drink in Helicobacter pylori-colonized subjects. Aliment. Pharmacol. Ther., 17, págs.429-435.

Cava, F., Cobas, G., 2003. Formas cocoides de Helicobacter pylori: viables odegenerativas.
Redalyc,
12(2).
Available
at:

http://redalyc.uaemex.mx/src/inicio/ArtPdfRed.jsp?iCve=203414593002.

Centeno, J.A., Fernández-García, E., Gaya, P., Tomillo, J., Medina, M., Nuñez, M. 2004.

Volatile compounds in cheeses made from raw ewe's milk ripened with a lactic culture. Journal of Dairy Research, 71, págs.380-384.

Cittelly D.M, Henao S.C., Martínez J.D, 2001. Helicobacter pylori in gastric cancer and peptic ulcer disease in a colombian population. Strain heterogeneity and antibody profiles. Helicobacter, 6(3), págs.199-206.

Colombo, E., Franzetti, L., Frusca, M., Scapellini, M. 2010. Phenotypic and Genotypic Characterization of Lactic Acid Bacteria Isolated from Artisanal Italian Goat Cheese. Journal of Food Protection, 73(4), págs.657-662.

Collado, M.C., 2004. Caracterización de cepas del género Bifidobacterium con carácter probiótico. Tesis Doctoral. Valencia: Universidad Politécnica de Valencia.

Collado, M.C., Hernández, M., 2007. Identification and differentiation of Lactobacillus, Streptococcus and Bifidobacterium species in fermented milk products with bifidobacteria. Microbiological research, 162, págs.86-92.

Collado, M.C., Moreno, Y., Cobo, J.M., Hernández, M., 2006. Microbiological evaluation and molecular characterization of bifidobacteria strains in commercial fermented milks. Eur Food Res Technol, 222, págs.112-117.

Compaire, C., 1976. Quesos, tecnología y control de calidad. 
De Cothi, G.A., Newbold, K.M., O’Connor, H.J., 1989. Campylobacter-like organisms and heterotopic gastric mucosa in Meckel's diverticula. J clin Pathol, 42, págs.132-134.

De Champs, C., Maroncle, N., Balestrino, D., Rich, C., Forester,C. 2003. Persistence of colonization of intestinal mucosa by probiotic strain Lactobacillus casei subsp. rhamnosus Lcr35, after oral consumption. J. Clin. Microbiol, 3, págs.1270-1273.

Chang, J.H., Shim, Y.Y., Cha, S.K., Chee, K.M. 2010. Probiotic characteristics of lactic acid bacteria isolated from kimchi. Journal of Applied Microbiology, 109, págs.220-230.

Charteris, W.P., Kelly, P.M., Morelli, L., Collins, J.K. 1998. Antibiotic suceptibility of potentially probiotic Bifidobacterium isolates from the human gastrointestinal tract. Applied Microbiology, 26, págs.333-337.

Danielsen, M., Wind, A., 2003. Susceptibility of Lactobacillus spp. to antimicrobial agents. Int. J. Food Microbiol, 82, págs.1-11.

Degnan, F., 2008. The US Food and Drug Administration and Probiotics: Regulatory Categorization. Clinical Infectious Diseases, 46, págs.133-136.

Deplancke, B., Gaskins, H.R., 2001. Microbial modulation of innate defense: goblet cells and the intestinal mucus layer. Am J Clin Nutr, 73(suppl), pág.1131S-1141S.

Dykes, G.A. , Von Holy, A., 1994. Strain typing in the genus Lactobacillus. Letters in Applied Microbiology, 19, págs.63-66.

Errecalde, J.E., 2004. Uso de antimicrobianos en animales de consumo. Incidencia del desarrollo de resistencias en salud publica. FAO.

Estrada, A.C., Gutiérrez, L.A., Montoya, O.I., 2005. Evaluación in vitro del efecto bactericida de cepas nativas de Lactobacillus sp. contra Salmonella sp. y Escherichia coli. Rev.Fac.Nal.Agr.Medellín, 58(1). 
FAO, 2007. Report on Functional food.

FAO, OMS, 2001. Informe de la consulta de expertos FAO/OMS sobre evaluación de las propiedades saludables y nutricionales de los probióticos en los alimentos, incluida la leche en polvo con bacterias vivas de ácido láctico.

Fayol-Messaoudi, D., Berger, C.N., Coconnier-Polter, M.H., Liévin, V., Servin, A.L. 2005. $\mathrm{pH}$, lactic acid and non-lactic acid dependent activities of probiotic lactobacilli against salmonella enterica serovar typhimurium. Applied and environmental microbiology, 71(10), págs.6008-6013.

Fenell, C., Michetti, P., 2003. Probiotics and Helicobacter pylori. Best Pract. Res. Clin. Gastroenterol, 17, págs.785-791.

Fernández, P., López, P., Corbí, A.L., Peláez, C., Requena, T. 2008. Probiotic strains: survival under simulated gastrointestinal conditions, in vitro adhesion to Caco-2 cells and effect on cytokine secretion. Eur Food Res Technol, 227, págs.1475-1484.

Fluit, A.C., 2005. Towards more virulent and antibiotic-resistant Salmonella? FEMS Immunol. Med. Microbiol, 43(1), págs.1-11.

Foligné, B., Dewulf, J., Breton, J., Claisse, O., Lonvaud-Funel, A., Pot, B. 2010. Probiotic properties of non-conventional lactic acid bacteria: Immunomodulation by Oenococcus oeni. International Journal of Food Microbiology, 140, págs.136-145.

Fooks, L.J., Fuller, R., Gibson, G.R., 1999. Prebiotics, probiotics and human gut microbiology. Int. Dairy J., 9, págs.53-61.

Francavilla, R., Lionetti, E., Castallaneta, S.P., Magistá, A.M., Maurogiovanni, G., Bucci, N., De canio, A., Indrio, F., Cavallo, L., Ierardi, E., Miniello, V.T. Inhibition of $H$. pylori by L. reuteri ATCC 55730 and Effect on EradicationTherapy: A Pilot Study. Helicobacter, 13, págs.127-134. 
Fukao, M., Tomita, H., Yakabe, T., Nomura, T., Ike, Y., Yajima, N. 2009. Assessment of Antibiotic Resistance in Probiotic Strain Lactobacillus brevis KB290. Journal of Food Protection, 72(9), págs.1923-1929.

Gamel, T.H., Abd el-Razek, A.M., Damir, A.A., 2008. Dried peeled roots of glossostemon bruguieri (moghat) as a potential functional food. Journal of Food Processing and Preservation, 34, págs.55-67.

Garai-Ibabe, G., Areizaga, J., Aznar, R., Elizaquivel, P., Prieto, A., Irastorza, A., Dueñas, M.T. 2010. Screening and selection of 2-Branched (1,3)- $\beta$-D-Glucan producing lactic acid bacteria and exopolysaccharide characterization. J. Agric. Food Chem., 58 , págs.6149-6156.

García, A., Henríquez, P., Retamal, C., Pineda, S., Delgado, C., Gonzalez, C. 2009. Propiedades probióticas de Lactobacillus spp aislados de biopsias gástricas de pacientes con y sin infección por Helicobacter pylori. Rev.Med.Chile, 137, págs.369-376.

Gardiner, G.E., Heinemann, C., Bruce, A.W., Beuerman, D., Reid, G. 2002. Persistence of Lactobacillus fermentum RC-14 and Lactobacillus rhamnosus GR-1 but Not L. rhamnosus GG in the Human Vagina as Demonstrated by Randomly Amplified Polymorphic DNA. Clinical and Diagnostic Laboratory Immunology, págs.92-96.

Gatti, M., Bernini, V., Lazzi, C., Neviani, E. 2006. Fluorescence microscopy for studying the viability of micro-organisms in natural whey starters. Letters in Applied Microbiology, 42, págs.338-343.

Gatti, M., Fornasari, M.E., Neviani., E., 2001. Differentiation of Lactobacillus delbrueckii subsp. bulgaricus and Lactobacillus delbrueckii subsp. lactis by SDS-PAGE of cellwall proteins. Lett. Appl. Microbiol., 32, págs.352-356. 
Gião, M.S., Azevedo, N.F., Wilks, A., Vieira, M.J., Keevil, C.W. 2010. Effect of Chlorine on Incorporation of Helicobacter pylori into Drinking Water Biofilms. Applied and Environmental Microbiology, 76(5), págs.1669-1673.

Gião, M.S., Azevedo, N.F., Wilks, S.A., Vieira, M.J., Keevil, C.W. 2008. Persistence of Helicobacter pylori in Heterotrophic Drinking-Water Biofilms. Applied and Environmental Microbiology, 74(19), págs.5898-5904.

Goderska, K., Czarnecki, Z., 2007. Characterization of selected strains from Lactobacillus acidophilus and Bifidobacterium bifidum. African Journal of Microbiology Research, 1(6), págs.65-78.

González, B.E., Jiménez, Z., Heredia, N.L., Villarreal, L., García, G., Gómez, M. 2006. Efecto de microorganismos probióticos sobre el crecimiento de Salmonella enteritidis var. Typhimurium. Ciencia UANL, 9(4), págs.365-374.

González, L., Sacristán, N., Arenas, R., Fresno, J.M., Tornadijo, M.E. 2010. Enzymatic activity of lactic acid bacteria (with antimicrobial properties) isolated from a traditional Spanish cheese. Food microbiology, 27, págs.592-597.

Goodwin, C.S., Armstrong, J.A., Chilvers, T., Peters, M., Collins, M.D., Sly, L., McConnell, W., Harper, E.S. 1989. Transfer of Campylobacter pylori and Campylobacter mustelae to Helicobacter gen. Nov and Helicobacter mustelae comb. Nov respectively. International Journal of Systematic and Evolutionary Microbiology, 39, págs.397-405.

Gotteland, M., Brunser, O., Cruchet, S., 2006. Probiotics in Controlling Gastric Colonization by $H$ pylori?: Inhibition of $H$. Pylori by Organic Acid and Bacteriocin-Producing Probiotics. Alimentary Pharmacology \& Therapeutics, 23(8), págs.1077-1086. 
Goyal, N., Dixit, K., Gandhi, D., 2008. Antimicrobial activity of probiotic Lactobacillus strains towards Salmonella enterica ser enteritidis in whey. The Internet Journal of Microbiology, 5(1).

Grangette, C., Müller-Alouf, H., Hols, P., Goudercourt, D., Delcour, J., Turneer, M., Mercenier, A. 2004. Enhanced mucosal delivery of antigen with cell wall mutants of lactic acid bacteria. Infection and Immunity, págs.2731-2737.

Guillemard, E., Tondu, F., Lacoin, F., Schrezenmeir, J. 2010. Consumption of a fermented dairy product containing the probiotic Lactobacillus casei DN-114001 reduces the duration of respiratory infections in the elderly in a randomised controlled trial infections in the elderly in a randomised controlled trial. British Journal of Nutrition. 103, págs. 58-68.

Hagi, T., Hoshino, T., 2009. Screening and characterization of Potential probiotic Lactic Acid Bacteria from cultured common Carp Intestine. Biosci. Biotechnol., 73(7), págs.1479-1483.

Hamilton-Miller, J.M., 2003. The role of probiotics in the treatment and prevention of Helicobacter pylori infection. International Journal Antimicrobial Agents, 22, págs.360-366.

Hammes, W.P., Bantleon, A., Mind, S., 1990. Drivers of linking for yogurt drinks with prebiotics and probiotics. FEMS Microbiology review, 87, págs.165-173.

Hansen, P.A., Lessel, E.F., 1971. Lactobacillus casei (Orla-Jensen) Comb. Nov. Int. J. Syst. Bacteriol, 21, págs.69-71.

Harun-ur-Rashid, M., Togo, K., Ueda, M., Miyamoto, T. 2007. Identification and characterization of dominant lactic acid bacteria isolated from traditional fermented milk Dahi in Bangladesh. World J Microbiol Biotechnol, 23, págs.125-133. 
Havelaar, A.H., Brul, S., De Jong, A., De Jonge, R., Zwietering, M.H., Ter Kuile, B.H. 2010. Future challenges to microbial food safety. International Journal of Food Microbiology, 139, pág.S79-S94.

He, F., Ouwehand, A.C., Isolauri, E., Hashimoto, H., Benno, Y., Salminen, S. 2001. Comparison of mucosal adhesion and species identification of bifidobacteria isolated from healthy and allergic infants. FEMS Immunology and Medical Microbiology, 30, págs.43-47.

Hernández, A., 2005. Lactococina 972: Caracterización genética, modo de acción y optimización de la producción en biorreactores. Tesis Doctoral. Oviedo: Universidad de Oviedo.

Hoefel, D., Grooby, W.L., Monis, P.T., Andrews, S., Saint, C.P. 2003. A comparative study of carboxyfluorescein diacetate and carboxyfluorescein diacetate succinimidyl ester as indicators of bacterial activity. Journal of Microbiological Methods, 52, págs.379- 388.

Holzapfel, W.H., Haberer, P., Geisen, R., Bjökroth, J., Schillinger, U. 2006. Taxonomy and important features of probiotic microorganisms in food and nutrition. Am. J. Clin. Nutr., 73, pág.365S-373S.

Holler, B.J., Steele, J.L., 1995. Characterization of Lactococci other than Lactococcus lactis for possible use as starter cultures. Int. Dairy Journal, 5, págs.275-289.

Huang, C.H., Lee, F.L., 2009. Development of novel species-specific primersfor species identification of the Lactobacillu scasei group based on RAPD fingerprints. www.interscience.wiley.com.

Huang, Y., Adams, M.C., 2004. In vitro assessment of the upper gastrointestinal tolerance of potential probiotic dairy propionibacteria. International Journal of Food Microbiology, 91, págs.253-260. 
Hudault, S., Liévin, V., Oise Bernet-Camard, M.F., Servin, A.L. 1997. Antagonistic Activity Exerted in vitro and in vivo by Lactobacillus casei (Strain GG) against Salmonella typhimurium C5 Infection. Applied and Environmental Microbiology, págs.513-518.

Hurtado, A., Reguant, C., Bordons, A., Rozès, N. 2010. Evaluation of a single and combined inoculation of a Lactobacillus pentosus starter for processing cv. Arbequina natural green olives. Food Microbiology, 27, págs.731-740.

Hussain, M.A., Rouch, D.A., Britz, M.L., 2009. Biochemistry of non-starter lactic acid bacteria isolate Lactobacillus casei GCRL163: Production of metabolites by stationary-phase cultures. International dairy journal, 19, págs.12-21.

Hütt, P. Shchepetova, J., Kullisaar, K., Loivukene, K., Kullisaar, T., Mikelsaar, M. 2005. Antagonistic activity of probiotic lactobacilli and bifidobacteria against entero- and uropathogens. Journal of Applied Microbiology. , 100, págs.1324-1332.

Hütt, P., Shchepetova, J., Lo ivukene, K., Kullisaar, T., Mikelsaar, M. 2006. Antagonistic activity of probiotic lactobacilli and bifidobacteria against entero- and uropathogens. Journal of applied Microbiology, 100, págs.1324-1332.

Hynönen, U., Åvall-Jääskeläinen, S., Palva, A., 2010. Characterization and separate activities of the two promoters of the Lactobacillus brevis S-layer protein gene. Appl Microbiol Biotechnol, 87, págs.657-668.

Ibourahema, C., Dauphin, R.D., Jacqueline, D., Thonart, P. 2008. Characterization of lactic acid bacteria isolated from poultry farms in Senegal. African Journal of Biotechnology, 7(12), págs.2006-2012.

Idoui, T., Boudjerda, J., Leghouchia, E., Karamb, N.E. 2009. Lactic acid bacteria from «Sheep's Dhan», a traditional butter from sheep's milk:Isolation, identification and major technological traits. Grasas y Aceites, 60(2), págs.177-183. 
Ikeda, T., Yasui, C., Hoshino, K., Arikawa, K., Nishikawa, Y. 2007. Influence of lactic acid bacteria on longevity of Caenorhabditis elegans and host defense against Salmonella enterica serovar enteritidis. Applied and Environmental Microbiology, págs.6404-6409.

Iñiguez-Palomares, C., Acevedo-Felix, E., 2006. Mecanismos de adhesión al tracto intestinal y antagonismo de Bifidobacterium. Revista Salud Pública y Nutrición RESPYN, $7(2)$.

Ishikawa, H., Kutsukake, E., Fukui, T., Sato, I., Shirai, T., Kurihara, T., Okada, N., Danbara, H., Toba, M., Kohda, N., Maeda, Y., Matsumoto, T. 2010. Oral administration of heat-killed lactobacillus plantarum strain b240 protected mice against salmonella enterica serovar typhimurium. Biosci. Biotechnol. Biochem, 74(7), págs.1338-1342.

Isolauri, E., Kirjavainen, P.V., Salminen, S., 2002. Probiotics: a role in the treatment of intestinal infection and inflammation. Gut., 50, págs.54-59.

Izquierdo, E., Medina, M., Ennahar, S., Marchioni, E., Sanz, Y. 2008. Resistance to Simulated Gastrointestinal Conditions and Adhesion to Mucus as Probiotic Criteria for Bifidobacterium longum Strains. Current Microbiology, 56, págs.613-618.

Jacobsen, C.N., Nielsen, V.R., Hayford, A.E., Moller, P.L., Michaelsen, K.F., Paerregaard, A., Sandström, B., Tvede, M., Jakobsen, M. 1999. Screening of Probiotic Activities of forty seven strains of Lactobacillus spp. By In vitro techniques and evaluation of the colonization ability of five selected strain in humans. Applied and Environmental Microbiology, 65(11), págs.4949-4956.

Jankovic, I., Sybesma, W., Phothirath, P., Ananta, E., Mercenier, A. 2010. Application of probiotic in food products - Challenges and new approaches. Current Opinion in Biotechnology, 21, págs.175-181. 
Jaramillo, D.P., 2007. Aptitud quesera de la leche de oveja guirra y efecto de la dieta sobre las características tecnológicas de la leche y el madurado del queso. Tesis Doctoral. Barcelona: Universidad Autónoma de Barcelona.

Jimenez, A.I., 2005. Supervivencia de Helicobacter pylori HBTC6 en disitntos microcosmos acuáticos. Caracterización del estado viable no cultivable (VNC). Tesis Doctoral. Valencia: Universidad Politécnica de Valencia.

Jiménez, B., 2008. Manejo dietético del estreñimiento crónico funcional. Especial referencia al beneficio de las bifidobacterias. Departamento de Medicina. Servicio Digestivo. Hospital Arnau de Vilanova. Valencia. Revista Alimentación y Salud, 15(2), págs.31-38.

Jones, D.M., D.M., Lessels A.M, A.M., Eldridge J., J., 1984. Campylobacter-like organisms on the gastric mucosa: culture, histological, and serological studies. J clin Pathol, 37, págs.1002-1006.

Kalliomäki, M., 2009. Probiotics, prebiotics and synbiotics: A hope or hype in allergy. Clinical \& Experimental Allergy, 40, págs.694-696.

Keohane, J., Ryan, K., Shanahan, F., 2009. Lactobacillus in the gastrointestinal tract. En Lactobacillus Molecular biology. From genomic to probiotic. págs. 9:169-181.

Kimoto, H., Ohmomo, S., Okamoto, T., 2002. Cholesterol Removal from Media by Lactococci. J. Dairy Sci., 85, págs.3182-3188.

Kinoshita, H., Wakahara, N., Watanabe, M., Kawasaki, T., Matsuo, H., Kawai, Y., Kitazawa, H., Ohnuma, S., Miura, K., Horri, A., Saito, T. 2008. Cell surface glyceraldehyde-3pjosphate dehydrogenase (GAPDH) of Lactobacillus plantarum LA 318 recognizes human A and B blood group antigens. Research in Microbiology, 159, págs.685691. 
Kirjavainen, P.V., Ouwehand, A.C., Isolauri, E., Salminen, S.J. 1998. The ability of probiotic bacteria to bind to human intestinal mucus. FEMS Microbiology Letters, 167, págs.185-189.

Koninkx, J.F.J.G., Tooten, P.C.J., Malago, J.J., 2010. Probiotic bacteria induced improvement of the mucosal integrity of enterocyte-like Caco-2 cells after exposure to Salmonella enteritidis 857. Journal of functional food, 2, págs.225-234.

Krieg, N.R., Holt, J.G., 1984. Bergey's Manual of Systematic Bacteriology Second., Baltimore USA: William \& Wilkns.

Laparra, J.M., Sanz, Y., 2009. Comparison of in vitro models to study bacterial adhesion to the intestinal epithelium. Letters in Applied Microbiology, 49, págs.695-701.

Laparra, J.M., Sanz, Y., 2010. Interactions of gut microbiota with functional food components and nutraceuticals. Pharmacological Research, 61, págs.219-225.

Lara-Villoslada, F., Sierra, S., Boza, J., Xaus, J., Olivares, M. 2007. Efectos beneficiosos en niños sanos del consumo de un producto lácteo que contiene dos cepas probióticas. Lactobacillus coryniformis CECT5711 y lactobacillus gasseri CECT5714. Nutr Hosp., 22(4), págs.496-502.

Leal, M.V., Baras, M., Ruiz-Barba, J.L., Floriano, B., Jimenez-Díaz, R. 1998. Bacteriocin productions and competitiveness of Lactobacillus plantarum LPCO10 in olive juice broth, a culture medium obtained from olives. International Journal of Food microbiology, págs.129-134.

Lee, B.J., Kim, J.S., Kang, Y.M., Lim, J.H., Kim, Y.M., Lee, M.S., Jeong, M.H., Ahn, C.B., Je, J.Y. 2010. Antioxidant activity and c-aminobutyric acid (GABA) content in sea tangle fermented by Lactobacillus brevis BJ20 isolated from traditional fermented foods. Food Chemistry, 122, págs.271-276. 
Lee, H.J., Orlovich, D.A., Tagg, J.R., Fawcett, J.P. 2009. Detection and Specific Enumeration of Multi-Strain Probioticsin the Lumen Contents and Mucus Layers of the Rat IntestineAfter Oral Administration. Probiotics \& Antimicro. Prot., 1, págs.113-120.

Lee, L., Salminen, S., 1995. The coming of age of probiotics. Trend. Food Sci. Tech, 6, págs.241-246.

Leyer, J.G., Li, S., Mubasher, M.E., Reifer, C., Ouwehand, A.C. Probiotic effects on cold and influenza-like symptom incidence and duration in children. Pediatrics. 2009. 124, págs. 172-179.

Li, H., Qiu, T., Gao, D., Cao, Y. 2010. Medium optimization for production of gammaaminobutyric acid by Lactobacillus brevis NCL912. Amino Acids, 38, págs.14391445.

Lilly, M., Stillwell, R., 1965. Probiotics: Growth-Promoting Factors Produced by Microorganisms. Science, 147(3659), págs.747 - 748.

Lin, D.C., 2003. Probiotics as functional food. Nutrition in clinical practice, 6, págs.497506.

Lin, W.H., Lin, C.K., Sheu, S.J., Hwang, C.F., Ye, W.T., Hwang, W.Z., Tsen, H.Y. 2009. Antagonistic activity of spent culture supernatants of lactic acid bacteria against helicobacter pylori growth and infection in human gastric epithelial AGS cells. Journal of food science, 74(6), pág.M225-M230.

Liu, G., Griffiths, M.W., Shang, N., Chen, S., Li, P. 2010. Applicability of Bacteriocinogenic Lactobacillus pentosus 31-1 as a Novel Functional Starter Culture or Coculture for Fermented Sausage Manufacture. Journal of Food Protection, 73(2), págs.292-298. 
Ljungh, A., Wadström, T., 2009. Lactobacillus. Molecular biology. From genomics to probiotics. History of probiotics and living drugs. En Lactobacillus Molecular biology. From genomic to probiotic.

Logan, N.A., 1994. Bacterial systematics Backwell Scientific Publications., Oxford.

Lorca, G.L., de Valdez, G., 2009. Lactobacillus stress responses. Lactobacillus Molecular biology. From genomic to probiotic, 6, págs.115-137.

Lorca, G.L., Wadström, T., Font de Valdez, G., Ljungh, A. 2001. Lactobacillus acidophilus Autolysins Inhibit Helicobacter pylori In Vitro. Current Microbiology, 42, págs.3944.

Lorenzo, N., 2008. Study of apoptotic deletion mediated by Bifidobacterium longum with construction of recombinant strains for Serpin encoding gene and phenotypes comparison in a pig cell model. Alma Mater Studiorum - Uniiversiittà dii Bollogna y Univerza v Mariboru - Maribor University.

Madrid, A., 1994. Nuevo manual de tecnología quesera A Madrid Vicente y Mundi-Prensa., Madrid.

Makras, L., Triantafyllou, V., Fayol-Messaoudi, D., Adriany, T., Zoumpopolou, G., Tsakalidou, E., Servin, A., De Vuyst, L. 2006. Kinetic analysis of antibacterial activity of probiotic lactobacilli towards Salmonella enterica serovar Typhimurium reveals a role for lactic acid and other inhibitory compounds. Research in Microbiology, 157, págs.241-247.

Mannua, L., Pabaa, A., Dagaa, E., Comuniana, R., Zanettib, S., Dupre, I., Sechib, L.A. 2003. Comparison of the incidence of virulence determinants and antibiotic resistance between Enterococcus faecium strains of dairy, animal and clinical origin. International Journal of Food Microbiology, 88, págs.291- 304. 
Maragkoudakis, P.A., Mountzouris, K.C., Psyrras, D., Cremonese, S., Fischer, J., Cantor, M.D., Tsakalidou, E. 2009. Functional properties of novel protective lactic acid bacteria and application in raw chicken meat against Listeria monocytogenes and Salmonella enteritidis. International Journal of Food microbiology, págs.219-226.

Markosyan, A., McCluskey, J.J., Wahl, T.I., 2009. Consumer Response to Information about a Functional Food Product: Apples Enriched with Antioxidants. Canadian Journal of Agricultural Economics, 57, págs.325-341.

Marteau, P., Minekus, M., Havenaar, R., Huis In't Veld, J.H.J. 1997. Survival of lactic acid bacteria in a dynamic model of the stomach and small intestine: Validation and the efects of bile. $J$ dairy Sci, 80, págs.1031-1037.

Marteau, P., Seksik, P., Jian, R., 2002. Probiotics and intestinal health effects: a clinical perspective. British Journal of Nutrition, 88, pág.S51-S57.

Martín, B., Corominas, L., Garriga, M., Aymerich, T. 2009. Identification and tracing of Enterococcus spp. by RAPD-PCR in traditional fermented sausages and meat environment. Journal of Applied Microbiology, 106, págs.66-77.

Martín, R., Delgado, S., Maldonado, A., Jiménez, E., Olivares, M., Fernández, L., Sobrino, O.J., Rodríguez, J.M. 2009. Isolation of lactobacilli from sow milk and evaluation of their probiotic potential. Journal of Dairy Research, 76, págs.418-425.

Martínez-Cuesta, M.C., Bengoechea, J., Rodríguez, B., Requena, T., Peláez, C. 2010. Control of late blowing in cheese by adding lacticin 3147-producing Lactococcus lactis IFPL 3593 to the starter. International dairy journal, págs.18-24.

Martín-Platero, A.M., Valdivia, E., Maqueda, M., Martínez-Bueno, M. 2009. Characterization and safety evaluation of enterococci isolated from Spanish goats' milk cheeses. International Journal of Food Microbiology, 132, págs.24-32. 
Masaake, M., Takafumi, a., Shin-nosuke, H., Keizo, T., Tadao, H., Dawn, I., Kenji, I., Kazuo, K., Hidemi, G., Michio, O. 2004. Effect of glycine on Helicobacter pylori In vitro. Antimicrobial agents and chemotherapy - American society for microbiology, págs.3782-3788.

Mattila-Sandholm, T. Blum, S., Collins, J.K., Crittenden, R., De Vos, W., Dunne, C., Fonden, R., Grenov, G., Isolauri, E., Kiely, B., Marteau, P. 1999. Probiotics: towards demonstrating efficacy. Trends Food Sci. Technol, 10, págs.393-399.

Mattila-Sandholm, T., Myllärinen, P., Crittenden, R., Mogensen, G., Fondén, R., Saarela, M. 2002. Technological challenges for future probiotic foods. International Dairy Journal, 12(2-3), págs.173-182.

Mazo, S.A., Arias, S.A., 2006. Eficacia y seguridad de leche fermentada por lactobacilos (kumis) en la recuperación nutricional de niños desnutridos y en el control de sus episodios de enfermedad diarreica. Rev. Fac. Nac. Salud Pública, 24(2).

McCray, S., 2003. Lactose intolerance: Considerations for the clinician. Practical Gastroenterology. Nutrition support in Gastroenterology, págs.21-39.

McLeod, A., Ludvig Nyquist, O., Snipen, L., Naterstad, K., Axelsson, L. 2008. Diversity of lactobacillus sakei strains investigated by phenotypic and genotypic methods. Systematic and Applied Microbiology, 31, págs.393-403.

Mejía, J.A., Chacón, Z., Guerrero, B., Rojas, J.A., López, G. 2007. Obtención de cepas de lactobacillus. Caracterización in vitro como potenciales probioticas. Revista cientifica, FCV-LUZ, 17(2), págs.178-185.

Metchnikoff, E., 1907. Lactic acid as inhibiting intestinal putrefaction. En In: The prolongation of life: Optimistic studies. London. 
Michetti, P., Dorta, G., Wiesel, P.H., Brassart, D., Verdu, E., Herranz, M., Felley, C., Porta, N., Rouvet, M., Blum, A.L., Corthésy-Theulaz, I. 1999. Effect of whey-based culture supernatant of Lactobacillus acidophilus (johnsonii) La1 on Helicobacter pylori infection in humans. Digestion, 60(3), págs.203-209.

Midolo, P.D., Lambed, J.R., Hull, R., Luo, F., Grayson, M.L. 1995. In vitro inhibition of Helicobacter pylori NCTC 11637 by organic acids and lactic acid bacteria. Journal of Applied Bacteriology, 79, págs.475-479.

Moher, D., Schulz, K.F., Altman, D.G., 2001. The consort statement: revised recommendations for improving the quality of reports of parallel group randomized trials. BMC Medical Research Methodology, http://www.biomedcentral.com/14712288/1/2.

De Moreno de LeBlanc, A., Castillo, N.A., Perdigon, G., 2010. Anti-infective mechanisms induced by a probiotic Lactobacillus strain against Salmonella enterica serovar Typhimurium infection. International Journal of Food Microbiology, 138, págs.223-231.

Moreno, Y., Ferrús, M.A., Alonso, J.L., Jiménez, A., Hernández, J. 2003. Use of fluorescent in situ hybridization to evidence the presence of Helicobacter pylori in water. Wat. Res., 37, págs.2251-2256.

Moreno, Y., Hernández, M., Collado, M.C., Hernández, E. 2000. Aplicación de fluorocromos para el estudio dela viabilidad de las Bacterias Ácido Lácticas (BAL) presentes en productos lácteos. Ars Pharmaceutica, 41(3), págs.287-292.

Moreno, Y., Piqueres, P., Alonso, J.L., Jiménez, A.I., González, A., Ferrús, M.A. 2007. Survival and viability of $H$. pylori after inoculation into clorinated drinking water. Water Research, 41(15), págs.3490-3496. 
Morono, Y., Takano, S., Miyanaga, K., Tanji, Y., Unno, H., Hori, K. 2004. Application of glutaraldehyde for the staining of esterase-active cells with carboxyfluorescein diacetate. Biotechnology Letters, 26, págs.379-383.

Mulabagal, V., Ngouajio, M., Zhang, Y., Gottumukkala, A.L., Nair, M.G. 2010. In vitro evaluation of red and green lettuce (Lactuca sativa) for functional food properties. Food Chemistry, 118, págs.300-306.

Murray, P.R., Rosenthal, K.S., Pfaller, M.A., 2006. Microbiología médica Quinta edición., Madrid - España.

Murry, A.C., Hinton, A., Morrison, H., 2004. Inhibition of Growth of Escherichia coli, Salmonella typhimurium, and Clostridia perfringens on Chicken Feed Media by Lactobacillus salivarius and Lactobacillus plantarum. International Journal of Poultry Science, 3(9), págs.603-607.

Myllyluoma, E., Ahonen, A.M., Korpela, R., Vapaatalo, H., Kankuri, E. 2008. Effects of multispecies probiotic combination on helicobacter pylori infection in vitro. Clinical and Vaccine Immunology, 15(9), págs.1472-1482.

Nagendra, G., 2001. Functional foods from probiotics and prebiotics. Food Tech., 11, págs.46-53.

Obregón, M.C., Cruchet, S., Díaz, E., Salazar, G., Gotteland, M. 2003. El consumo regular de Lactobacillus johnsonii La1 interfiere con la colonización gástrica por Helicobacter pylori. Revista chilena de nutrición, 30(3).

Olivares, M., Díaz-Ropero, M.P., Martín, R., Rodríguez, J.M., Xaus, J. 2006. Antimicrobial potential of four Lactobacillus strains isolated from breast milk. Journal of Applied Microbiology, 101(1), págs.72-79. 
Ouadghiri, M., Amar, M., Vancanneyt, M., Swings, J. 2005. Biodiversity of lactic acid bacteria in Moroccan soft white cheese (Jben). FEMS Microbiology Letters, 251, págs.267-271.

Ouoba, L.I., Nyanga-Koumou, C.A., Parkouda, C., Sawadogo, H., Kobawila, S.C., Keleke, S., Diawara, B., Louembe, D., Sutherland, J.P. 2009. Genotypic diversity of lactic acid bacteria isolated from African traditional alkaline-fermented foods. Journal of Applied Microbiology, 108, págs.2019-2029.

Pantoflickova, D., Corthésy-Theulaz, I., Dorta, G., Stolte, M., Isler, P., Rochat, F., Enslen, M., Blum, A.L. 2003. Favourable effects of regular intake of fermented milk containing Lactobacillus johnsonii on Helicobacter pylori associated gastritris. Aliment Pharmacol Ther, 18, págs.805-813.

Parkes, G.C., Sanderson, J.D., Whelan, K., 2009. Treating irritable bowel sydrome with probiotics: The evidence. Proceedings of the Nutrition Society, 69, págs.187-194.

Parsonnet, J., 1998. Helicobacter pylori. Infect. Dis. Clin. North Am., 12(18), págs.185-197.

Pascual, M.R., 2005. Enfermedades de origen alimentario: su prevención. Díaz de Santos, S.A., pág. 188 .

Pérez Elortondo, F.J., Aldámiz Echobarria, P., Albisu, M., Barcina, Y. 1998. Indigenous Lactic Acid Bacteria in Idiazábal Ewes'Milk Cheese. Int. Dairy Journal, 8, págs.725-732.

Pescuma, M., Hébert, E.M., Mozzi, F., Font de Valdez, G. 2010. Functional fermented whey-based beverage using lactic acid bacteria. International journal of food microbiology, 141, págs.73-81.

Pot, B., Tsakalidou, E., 2009. Taxonomy and metabolism of Lactobacillus. En Lactobacillus Molecular biology. From genomic to probiotic. 
Pregliasco, F., Anselmi, G., Fonte, L., Giussani, F., Schieppati, S., Soletti, L. 2008. A new chance of preventing winter diseases by the administration of synbiotic formulations. Journal of clinical gastroenterology. 42(3). S224-S233.

Pu, Z.Y., Dobos, M., Limsowtin, G.K.Y., Powell, I.B. 2002. Integrated polymerase chain reaction-based procedures for the detection and identification of species and subspecies of the Gram-positive bacterial genus Lactococcus. Journal of Applied Microbiology, 93, págs.353-361.

QPS, 2004. EFSA Scientific Colloquium Summary Report.

Quigley, E.M.M., 2010. Prebiotics and probiotics; Modifyng and mining the microbiota. Pharmacological Research, 61, págs.213-218.

Ramasamy, K., Abdullah, N., Wong, M., Karuthan, C., Wan Ho, Y. 2010. Bile salt desconjugation and cholesterol removal from media by Lactobacillus strains used as probiotics in chickens. $J$ Sci Food Agric, 90, págs.65-69.

Randazzo, C.L., Pitino, I., Ribbera, A., Caggia, C. 2010. Pecorino Cheese: Study of bacterial population and flavour compounds. Food Microbiology, 27, págs.363-374.

Del Re, B., Busetto, A., Vignola, G., Sgorbati, B., Palenzona, D. 1998. Autoaggregation and adhesion ability in a Bifidobacterium suis strain. Applied Microbiology, 27, págs.307-310.

Del Re, B., Sgorbati, B., Miglioli, M., Palenzona, D. 2000. Adhesion, autoaggregation and hydrophobicity of 13 strains of Bifidobacterium longum. Letters in Applied Microbiology, 31, págs.438-442.

Rodriguez, J.M., 2006. Microorganismos y salud. Bacterias lácticas y bifidobacterias. Editorial Complutense., Madrid. 
Rodriguez, P., Fernández, C., Centeno, J.A., Garabal, J.I. 2009. Antibiotic Resistance in Lactic Acid Bacteria and Micrococcaceae/Staphylococcaceae Isolates from Artisanal Raw Milk Cheeses, and Potential Implications on Cheese Making. Journal Of Food Science, 74(6), págs.284-293.

Rodríguez-Carvajal, M.A., Sánchez, J.I., Campelo, A.B., Martínez, B., Rodríguez, A., GilSerrano, A.M. 2008. Structure of the high-molecular weight exopolysaccharide isolated from Lactobacillus pentosus LPS26. Carbohydrate Research, 343, págs.3066-3070.

Rokka, S., Pihlanto, A., Korhonen, H., Joutsjoki, V. 2006. In vitro growth inhibition of helicobacter pylori by lactobacilli belonging to the lactobacillus plantarum group. 2006. Lett Appl Microbiol, 43(5), págs.508-513.

de Roos, N., Katan, M., 2000. Effects of probiotic bacteria on diarrhea, lipid metabolism, and carcinogenesis: a review of papers published between 1988 and 1998. Am J Clin Nutr, 71, págs.405-411.

Rosendale, D.I., Maddox, I.S., Miles, M.C., Rodier, M., Skinner, M., Sutherland, J. 2008. High-throughput microbial bioassays to screen potential New Zealand functional food ingredients intended to manage the growth of probiotic and pathogenic gut bacteria. International Journal of Food Science and Technology, 43, págs.22572267.

Saggioro, A., Caroli, M., Pasini, M., Bortoluzi, F., Girakdi, L., Pilone, G. 2005. Helicobacter pylori erradication with Lactobacillus reuteri. A double-blind placebo-controlled study. Digest. Liver Dis., 37, pág.88.

Salminen, M.K., Rautelin, H., Tynkkynen, S., Poussa, T., Saxelin, M., Valtonen, V., Järvinen, A. 2004. Lactobacillus bacteremia, clinical significance, and patient 
outcome, with special focus on probiotic L. rhamnosus GG. Clinical Infectious Diseases Society of America, 38, págs.62-69.

Salminen, S., Donohhue, D.C., 1996. Safety assessment of Lactobacillus strain GG (ATCC 53103). Nutr. Today, 31(1), pág.12S-15S.

Salminen, S., Nybom, S., Meriluoto, J., Collado, M.C., Vesterlund, S. 2010. Interaction of probiotics and pathogens - Benefits to human health? Current Opinion in Biotechnology, 21, págs.157-167.

Salminen, S., Ouwehand, A., Benno, Y., Lee, Y.K. 1999. Probiotics: how should they be defined? Trends Food Science e Technology, págs.107-110.

Sánchez, B., Saad, N., Schmitter, J.M., Bressollier, P., Urdaci, M.C. 2010. Adhesive Properties, Extracellular Protein Production, and Metabolism in the Lactobacillus rhamnosus GG Strain when Grown in the Presence of Mucin. J. Microbiol. Biotechnol., 20(6), págs.978-984.

Sanz, Y., Hernández, M., Ferrús, M.A., Hernández, J. 1998. Characterization of lactobacillus sake isolates from dry-cured sausages by restriction fragment lenght polymorphism analysis of the 16S rRNA gene. Journal of Applied Microbiology, 4, págs.600-606.

Sarika, A.R., Lipton, A.P., Aishwarya, M.S., 2010. Bacteriocin Production by a New Isolate of Lactobacillus rhamnosus GP1 under Different Culture Conditions. Advance Journal of Food Science and Technology, 2(5), págs.291-297.

Sarmiento, L.A., 2008. Influencia del consumo de sorbitol en la microbiota intestinal de un modelo animal. Doctoral. Valencia: Universidad Politécnica de Valencia.

Schultsz, C., Van Den Berg, F.M., Ten Kate, F.W., Tytgat, G.N.J., Dankert, J. 1999. The Intestinal Mucus Layer From Patients With Inflammatory Bowel Disease Harbors 
High Numbers of Bacteria Compared With Controls. Gastroenterology, 117, págs.1089-1097.

Servin, A.L., Coconnier, M.H., 2003. Adhesion of probiotic strains to the intestinalmucosa and interaction with pathogens. Best Practice \& Research Clinical Gastroenterology, 17(5), págs.741-754.

Sgouras, D., Maragkoudakis, P., Petraki, K., Martínez-González, B., Eriotou, E., Michopoulos, S., Kalantzopoukos, G., Tsakalidou, E., Mentis, A. 2004. In vitro and in vivo inhibition of Helicobacter pylori by Lactobacillus casei strain Shirota. Appl. Envirom. Microbiol, 70(1), págs.518-526.

Sgouras, D.N., Panayotopoulou, E.G., Martínez-González, B., Petraki, K., Michopoulos, S., Mentis. 2005. Lactobacillus johnsonii La1 Attenuates Helicobacter pyloriAssociated Gastritis and Reduces Levels of Proinflammatory Chemokines in C57BL/6 Mice. Clinical and Diagnostic Laboratory Immunology, 12(12), págs.1378-1386.

Sheu, B.S., Cheng, H.C., Kao, A.W., Wang, S.T., Yang, Y.J., Yang, H.B., Wu, J.J. 2006. Pretreatment with Lactobacillus and Bifidobacterium containing yogurt can improve the efficacy of quadruple therapy in eradicating residual Helicobacter pylori infection after failed triple therapy. Am J Clin Nutr, 83, págs.864- 869.

Sigrid, C.J., Tine, L.A., Desair, J., Marchal, K., Nagy, I. 2006. Strong antimicrobial activity of Lactobacillus rhamnosus GG against Salmonella typhimurium is due to accumulation of lactic acid. FEMS Microbiology Letters, 259(1), págs.89-96.

Smaoui, S., Elleuch, L., Bejar, W., Karray-Rebai, I., Ayadi, I., Mathieu, F., Bejar, S., Mellouli, L., Mathieu, F., Chouayekh. 2010. Inhibition of fungi and gram-negative bacteria by bacteriocin BacTN635 produced by Lactobacillus plantarum sp. TN635. Appl Biochem Biotechnol, 162, págs.1132-1146. 
Stackenbrant, E., Fowler, V.J., Woose, C.R., 1983. A phylogenetic analysis of lactobacilli, pediococcus pentosaceus and leuconostoc mesenteroides. Systematic and Applied Microbiology, 4, págs.326-337.

Suerbaum, S., Michetti, P., 2002. Helicobacter pylori Infection. $N$ Engl J Med, 347, págs.1175-1186.

Svec, P., Kukletová, M., Sedlácek, I., 2010. Comparative evaluation of automated ribotyping and RAPD-PCR for typing of Lactobacillus spp. Occurring in dental caries. Antonie Van Leewenhoek, 98, págs.85-92.

Tamminen, M., Joutsjoki, T., Sjöblom, M., Joutsen, M., Palva, A., Ryhänen, E.L., Joutsjoki, V. 2004. Screening of lactic acid bacteria from fermented vegetables by carbohydrate profiling and PCR-ELISA. Letters in Applied Microbiology, 39, págs.439-444.

Thirabunyanon, M., Boonprasom, P., Niamsup, P., 2009. Probiotic potential of lactic acid bacteria isolated from fermented dairy milks on antiproliferation of colon cancer cells. Biotechnol Lett, 31, págs.571-576.

Todorov, S.D., Dicks, L.M.T., 2009. Bacteriocin production by Pediococcus Pentosaceus isolated from marula (Scerocarya birrea). International Journal of Food microbiology, 132, págs.117-126.

Todorov, S.D., Dicks, M.T., 2005. Growth parameters influencing the production of Lactobacillus rhamnosus bacteriocins ST461BZ and ST462BZ. Annals of Microbiology, 55(4), págs.283-289.

Torriani, S., Zapparoli, G., Dellaglio, F., 1999. Use of PCR-Based methods for rapid differentiation of Lactobacillus delbrueckii subsp. bulgaricus and L. delbrueckii subsp. lactis. Applied and Environmental Microbiology, 65(10), págs.4351-4356. 
Tu, R.J., Wu, H.Y., Lock, Y.S., Chen, M.J. 2010. Evaluation of microbial dynamics during the ripening of a traditional Taiwanese naturally fermented ham. Food Microbiology, 27, págs.460-467.

Tuomola, E.M., Ouwehand, A.C., Salminen, S.J., 1999. Human ileostomy glycoproteins as a model for small intestinal mucus to investigate adhesion of probiotics. Letters in Applied Microbiology, 28, págs.159-163.

Tynkkynen, S., Satokari, R., Saarela, M., Mattila-Sandholm, T., Saxelin, M. 1999. Comparison of Ribotyping, Randomly Amplified Polymorphic DNA Analysis, and Pulsed-Field Gel Electrophoresis in Typing of Lactobacillus rhamnosus and L. casei Strains. Applied And Environmental Microbiology, págs.3908-3914.

Ushiyama, A., Tanaka, K., Aiba, Y., Shiba, T., Takagi, A., Mine, T., Koga, Y. 2003. Lactobacillus gasseri OLL2716 as probiotic in clarithromycin-resistant Helicobacter pylori infection. Journal of Gastroenterology and Hepatology, págs.986-991.

Vale, F.F., Vítor, J.M.B., 2010. Transmission pathway of Helicobacter pylori: Does food play a role in rural andurban areas? International Journal of Food Microbiology, 138, págs.1-12.

Van den Abbeele, P., Grootaert. C., Possemiers, S., Vertraete, W., Verbeken, K., Van de Wiele, T. 2009. In vitro model to study the modulation of the mucin-adhered bacterial community. Appl Microbiol Biotechnol, 83, págs.349-359.

Vandamme, P., De Ley, J., 1991. Proposal for a new family, Campylobacteriaceae. International Journal of Systematic Bacteriology, 41, págs.451-455.

Verdenelli, M.C., Ghelfi, F., Silvi, S., Orpianesi, C., Cecchini, C., Cresci, A. 2009. Probiotic properties of Lactobacillus rhamnosus and Lactobacillus paracasei isolated from human faeces. Eur J Nutr, 48, págs.355-363. 
Vesa, T.H., Marteau, P., Korpela, R., 2000. Lactose intolerance. J. Am. Coll. Nutr., 19, págs. $165-175$.

Vesterlund, S., Karp, M., Salminen, S., Ouwehand, A.C. 2006. Staphylococcus aureus adheres to human intestinal mucus but can be displaced by certainlactic acid bacteria. Microbiology letters, 152, págs.1819-1826.

Vicent, J.G., Veomett, R.C., Riley, R.F., 1959. Antibacterial activity associated with Lactobacillus acidophilus. J. Bacteriology, 78, págs.477-484.

Vilaichone, R.K., Mahachai, V., Tumwasorn, S., Nunthapisud, P., Kullavanij. 2002. Inhibitory effect of Lactobacillus acidophilus on Helicobacter pylori in peptic ulcer patients: in vitro study. J. Med. Assoc. Thai, 85, págs.79-84.

Villena, J., Racedo, S., Agüero, G., Alvarez, S. 2006. Yoghurt accelerates the recovery of defence mechanisms against Streptococcus pneumoniae in protein-mahourished mice. British Journal of Nutrition. 95, págs. 591-602.

De Vos, P., Garrity, G.M., Krieg, N.R., Ludwig, W., Rainey, F.A., Schleifer, K.H., Whitman, W.B. 2009. Bergey's Manual of Systematic Bacteriology second edition., Springer, Dordrecht, Heidelberg, London, New York.

De Vrese, M., Schrezenmeir, J. 2002. Probiotics and non-intestinal infectious conditions. British Journal of Nutrition. 88(1). págs. S59-S66.

Walker, A.W., Duffy, C.L., 1998. Diet and bacterial colonization:Role of probiotics and prebiotics. Journal Nutri. Biochem, 9, págs.668-675.

Walker, P., 2008. 10 years of functinal foods in Europe. International Journal for vitamin and nutrition research, 78 . 
Wang, B., Li, J., Li, Q., Zhang, H., Li, N. 2009. Isolation of adhesive strains and evaluation of the colonization and immune response by Lactobacillus plantarum $\mathrm{L} 2$ in the rat gastrointestinal tract. International Journal of Food microbiology, 132, págs.59-66.

Wang, B., Wei, H., Yuan, J., Li, Q., Li, Y., Li, N., Li, J. 2008. Identification of a Surface Protein from Lactobacillus reuteri JCM1081 That Adheres to Porcine Gastric Mucin and Human Enterocyte-Like HT-29 Cells. Current Microbiology, 57, págs.33-38.

Wang, W.M., Wang, K.Y., Li, S.N., Liu, C.S., Perng, D.S., Su, Y.C., Wu, D.C., Jan, C.M., Lai, C.H., Wang, T.N. 2004. Effects of ingesting Lactobacillus and Bifidobacterium containing yogurt in subjects with colonized Helicobacter pylori. The American Journal of Clinical Nutrition, 80(3), págs.737-741.

Warren, I., Lee, E.M., Marin, H.K., 2007. Probiotics for preventing and treating Nosocomial Infections. Chest on line, http://www.chestjournal.org/content/132/1/286.full.html.

Weiss, N., Schillinger, U., Kandler., O., 1983. Lactobacillus lactis, Lactobacillus leichmannii and Lactobacillus bulgaricus, subjective synonyms of Lactobacillus delbrueckii, and description of Lactobacillus delbrueckii subsp. lactis comb. nov. and Lactobacillus delbrueckii subsp. bulgaricus comb. nov. Syst. Appl. Microbiol., 4, págs.552-557.

Wilson, A.R., Sigee, D., Epton., H.A., 2005. Anti-bacterial activity of Lactobacillus plantarum strain SK1 against Listeria monocytogenes is due to lactic acid production. The society for Applied Microbiology, 99(6), págs.1516-1522.

Yamamoto, K., Katayama, T., 2004. The Adhesion of Lactic Acid Bacteria to Intestine and Their Glycosidases. Foods Food Ingredients J. Jpn., 209(9). 
Yuan Kun, L., 2006. Microbial biotechnology. Principles and applications Second., National University of Singapore.

Zapparoli, G., Reguant, C., Bordons, A., Torriani, S., Dellaglio, F. 2000. Genomic DNA Fingerprinting of Oenococcus oeni Strains by Pulsed-Field Gel Electrophoresis and Randomly Amplified Polymorphic DNA-PCR. Current Microbiology, 40, págs.351-355.

Zhang, J., Liu, G., Shang, N., Cheng, W., Chen, S., Li, P. 2009. Purification and Partial Amino Acid Sequence of Pentocin 31-1, an Anti-Listeria Bacteriocin Produced by Lactobacillus pentosus 31-1. Journal of Food Protection, 72(12), págs.2524-2529.

Zhou, J.S., Gopal, P.K., Gill, H.S., 2001. Potential probiotic lactic acid bacteria Lactobacillus rhamnosus (HN001), Lactobacillus acidophilus (HN017) and Bifidobacterium lactis (HN019) do not degrade gastric mucin in vitro. International Journal of Food Microbiology, 63, págs.81-90. 
ANEXOS

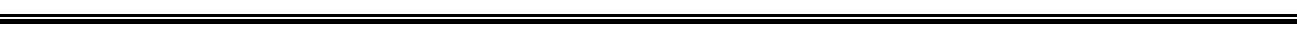




\section{ANEXO I.}

\section{MEDIOS DE CULTIVO}

Los medios de cultivo empleados fueron esterilizados a $121{ }^{\circ} \mathrm{C}$ durante 15 minutos en autoclave y atemperados a $50^{\circ} \mathrm{C}$ antes de verterlos en placas estériles.

Los medios líquidos fueron distribuidos en tubos de ensayo, esterilizados a $121{ }^{\circ} \mathrm{C}$ por un tiempo de 15 minutos, en autoclave y atemperados a temperatura ambiente y luego, almacenados en el refrigerador a $4^{\circ} \mathrm{C}$.

\section{MEDIOS DE CULTIVO SOLIDOS}

\section{Agar MRS (Scharlau ref. 01-135)}

Medio sólido para Lactobacillus. Composición para un litro de agua destilada:

\begin{tabular}{|l|c|}
\hline \multicolumn{1}{|l|}{ Peptona } & $10.00 \mathrm{~g}$ \\
\hline \hline Extracto de carne & $8.00 \mathrm{~g}$ \\
\hline \hline Extracto de levadura & $4.00 \mathrm{~g}$ \\
\hline \hline D $(+)$ Glucosa & $20.00 \mathrm{~g}$ \\
\hline Acetato sódico & $5.00 \mathrm{~g}$ \\
\hline Citrato triamónico & $2.00 \mathrm{~g}$ \\
\hline Sulfato de Magnesio & $0.20 \mathrm{~g}$ \\
\hline Sulfato de Manganesio & $0.05 \mathrm{~g}$ \\
\hline Sulfato dipotásico & $2.00 \mathrm{~g}$ \\
\hline \hline Polisorbato 80 & $1.00 \mathrm{ml}$ \\
\hline \hline Agar & $14.00 \mathrm{~g}$ \\
\hline pH final aproximado & $6.2 \pm 0.2$ \\
\hline
\end{tabular}




\section{Agar Sangre de Caballo}

Columbia Blood Agar Base (Scharlau ref 01-034). Composición para un litro de agua destilada:

\begin{tabular}{|l|c|}
\hline Peptona de caseina & $12.00 \mathrm{~g}$ \\
\hline \hline Peptona de carne & $11.00 \mathrm{~g}$ \\
\hline \hline Almidón & $1.50 \mathrm{~g}$ \\
\hline \hline Cloruro de sodio & $5.00 \mathrm{~g}$ \\
\hline \hline Agar & $15.00 \mathrm{~g}$ \\
\hline \hline $\mathrm{pH}$ final aproximado & $7.3 \pm 0.2$ \\
\hline
\end{tabular}

$10 \%$ de sangre desfibrinada de caballo (Oxoid ref. SR0050C)

El agar base se resuspende en agua destilada y se esteriliza en autoclave a $121^{\circ} \mathrm{C}$ durante 15 minutos, luego, se atempera el medio a $50{ }^{\circ} \mathrm{C}$ y se adiciona la sangre desfibrinada de caballo asépticamente, se homogeniza el medio y se distribuye en placas estériles.

\section{Agar PC (Scharlau 01-161)}

Composición para un litro de agua destilada:

\begin{tabular}{|l|c|}
\hline Peptona caseina & $5.0 \mathrm{~g}$ \\
\hline Extracto de levadura & $2.5 \mathrm{~g}$ \\
\hline Dextrosa & $1.0 \mathrm{~g}$ \\
\hline \hline Agar & $15.0 \mathrm{~g}$ \\
\hline
\end{tabular}


Agar TSA (Merck 733)

Triptose Soy Agar - Agar Soja Triptosa. Composición para un litro de agua destilada:

\begin{tabular}{|l|c|}
\hline Peptona de Caseína & $15.00 \mathrm{~g}$ \\
\hline Peptona de harina de soja & $5.0 \mathrm{~g}$ \\
\hline Cloruro sódico & $5.0 \mathrm{~g}$ \\
\hline Agar & $15.00 \mathrm{~g}$ \\
\hline $\mathrm{pH}$ final aproximado & $7.3 \pm 0.2$ \\
\hline
\end{tabular}

MEDIOS DE CULTIVO SEMISOLIDOS

Agar nutriente - Semisólido (Difco ref 234000)

Composición referida a un litro de agua destilada:

\begin{tabular}{|l|c|}
\hline Extracto de res & $3.0 \mathrm{~g}$ \\
\hline \hline Peptona & $5.0 \mathrm{~g}$ \\
\hline \hline Agar & $7.0 \mathrm{~g}$ \\
\hline
\end{tabular}




\section{MEDIOS DE CULTIVO LIQUIDOS}

\section{Caldo Brucella (Difco ref 211088)}

Composición referida a un litro de agua destilada:

\begin{tabular}{|l|c|}
\hline Caseína digerida por enzimas & $10.0 \mathrm{~g}$ \\
\hline \hline Tejido animal digerido por enzimas & $10.0 \mathrm{~g}$ \\
\hline \hline Dextrosa & $1.0 \mathrm{~g}$ \\
\hline \hline Extracto de levadura & $2.0 \mathrm{~g}$ \\
\hline \hline Cloruro sodio & $0.1 \mathrm{~g}$ \\
\hline
\end{tabular}


ANEXO 2.

\section{REACTIVOS Y SOLUCIONES}

\section{RESUSPENSION SALMONELLA}

Tampón Fosfato Salino (PBS) 3X (solución de almacenaje)

\begin{tabular}{|l|l|}
\hline COMPUESTO & CANTIDAD \\
\hline \hline $\mathrm{NaCl}$ & $22.8 \mathrm{~g}$ \\
\hline $\mathrm{NaH}_{2} \mathrm{PO}_{4}$ & $3 \mathrm{~g}$ \\
\hline \hline $\mathrm{Na}_{2} \mathrm{HPO}_{4}$ & $2.88 \mathrm{~g}$ \\
\hline \hline Agua destilada & $1 \mathrm{~L}$ \\
\hline \hline $\mathrm{pH}$ & 7.5 \\
\hline
\end{tabular}

Las sales se disuelven por separado. Luego, se esteriliza a $115^{\circ} \mathrm{C}, 15 \mathrm{~min}$.

\section{PBS 1X}

Diluir 3 veces el tampón PBS $3 X$ en agua destilada. Esterilizar a $121^{\circ} \mathrm{C}, 15$ min. 


\section{INCUBACION DE LAS CEPAS}

\section{Sobres generadores de microaerofilia (CampyGen, Oxoid ref. CN0035A)}

El sobre de microaerobiosis se introduce en una jarra de $3.5 \mathrm{~L}$ con placas y se cierra lo más pronto posible, el oxígeno contenido es absorbido, simultáneamente, se genera dióxido de carbono produciendo las condiciones de microaerobiosis apropiadas ( $85 \%$ de $\mathrm{N}_{2}$, $10 \%$ de $\mathrm{CO}_{2}$ y $5 \%$ de $\mathrm{O}_{2}$ ). El componente activo de cada sobre es ácido ascórbico.

\section{Suplemento de anaerobiosis (Anaerogen, Oxoid ref. AN0035A)}

Se introduce un sobre por jarra de $3.5 \mathrm{~L}$, la cual se cierra y es optima para el crecimiento de las bacterias acidolácticas. 
Anexo III

\section{ANEXO 3.}

Tablas ID API 50CHL.

Resultados de análisis bioquímicos de las cepas CECT y aisladas de leche de oveja Guirra. (+) Resultado positivo: Fermentación completa del azúcar. (-) Resultado negativo: Azúcar sin fermentar. (d) Fermentación débil. Las líneas sombreadas muestran las cepas con el mismo resultado en toda la colección. Las líneas no sombreadas presentan los resultados en los que hay diferencia en las cepas analizadas. 


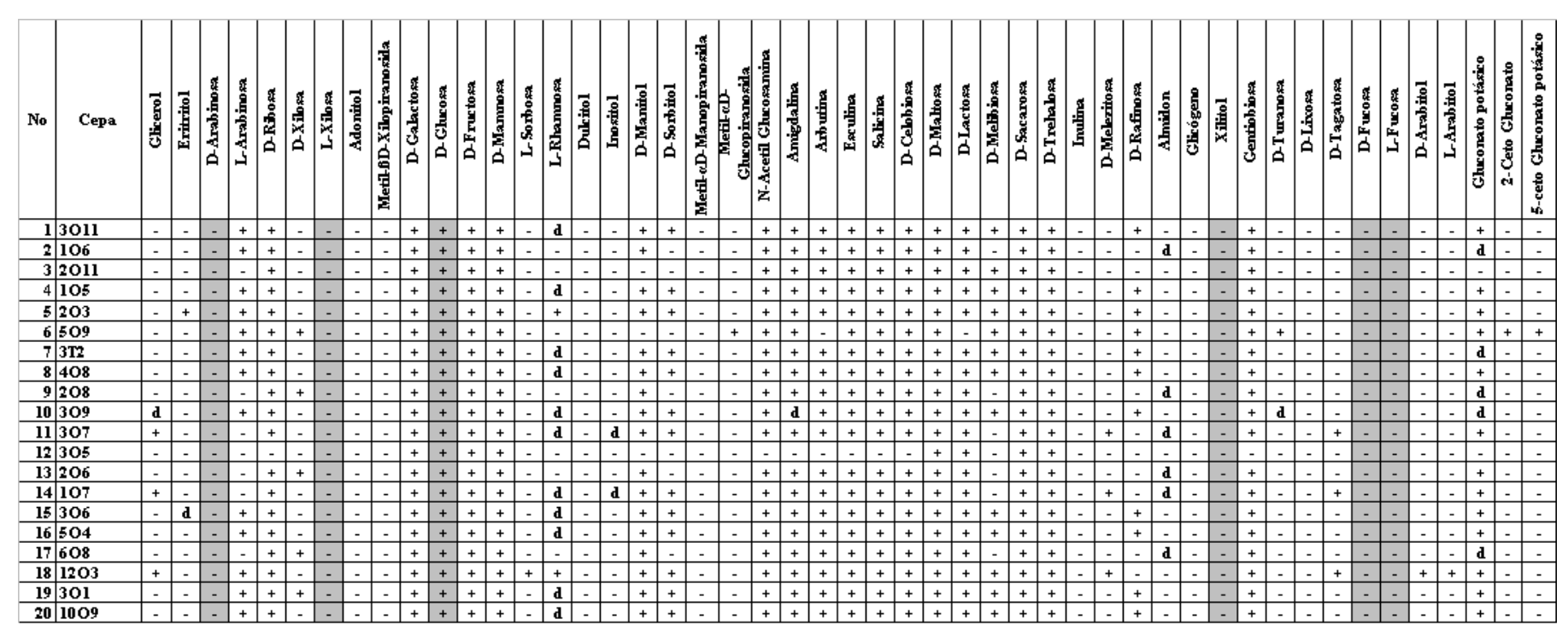

236 


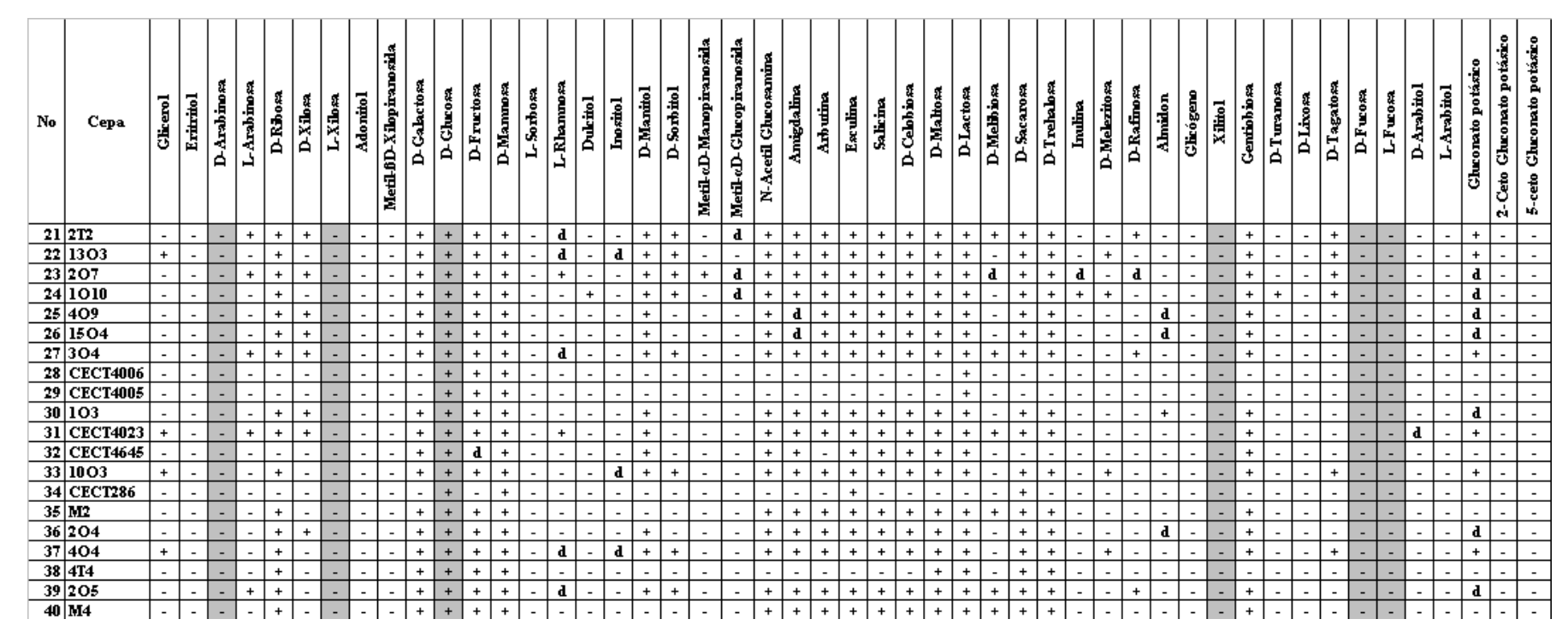




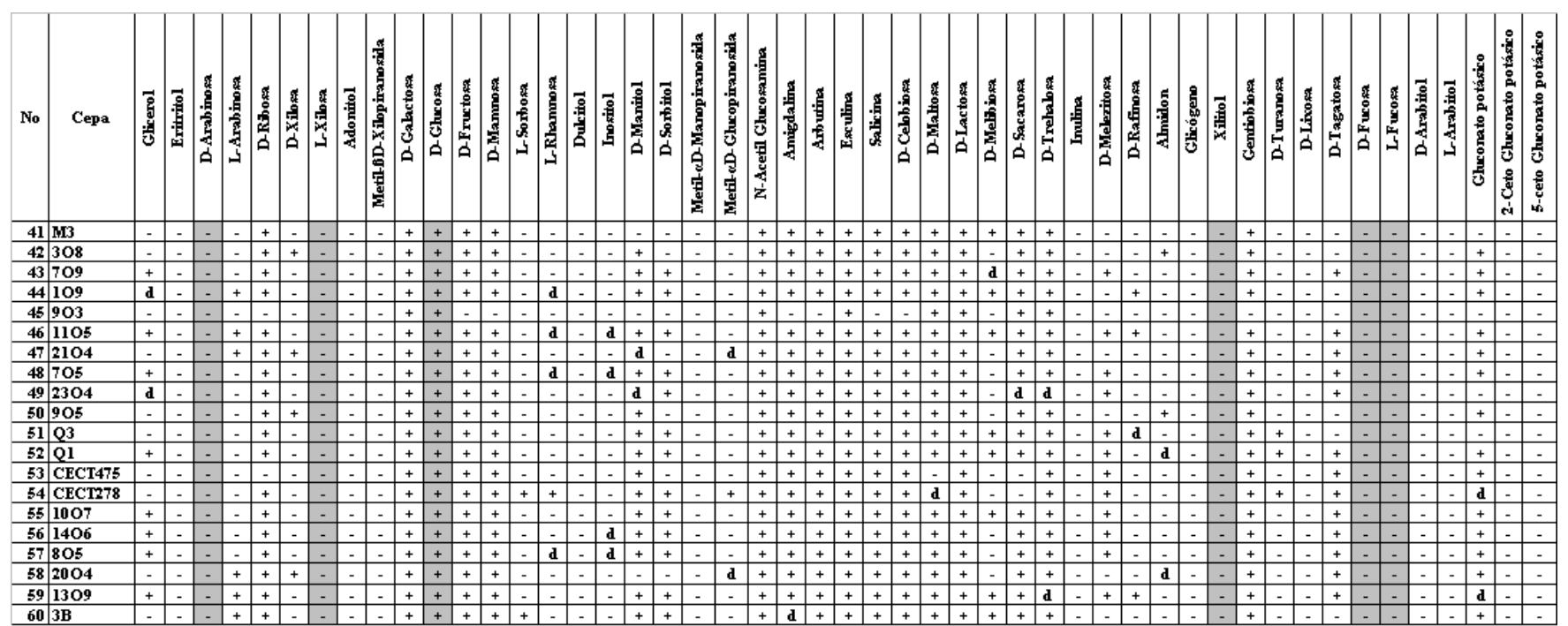




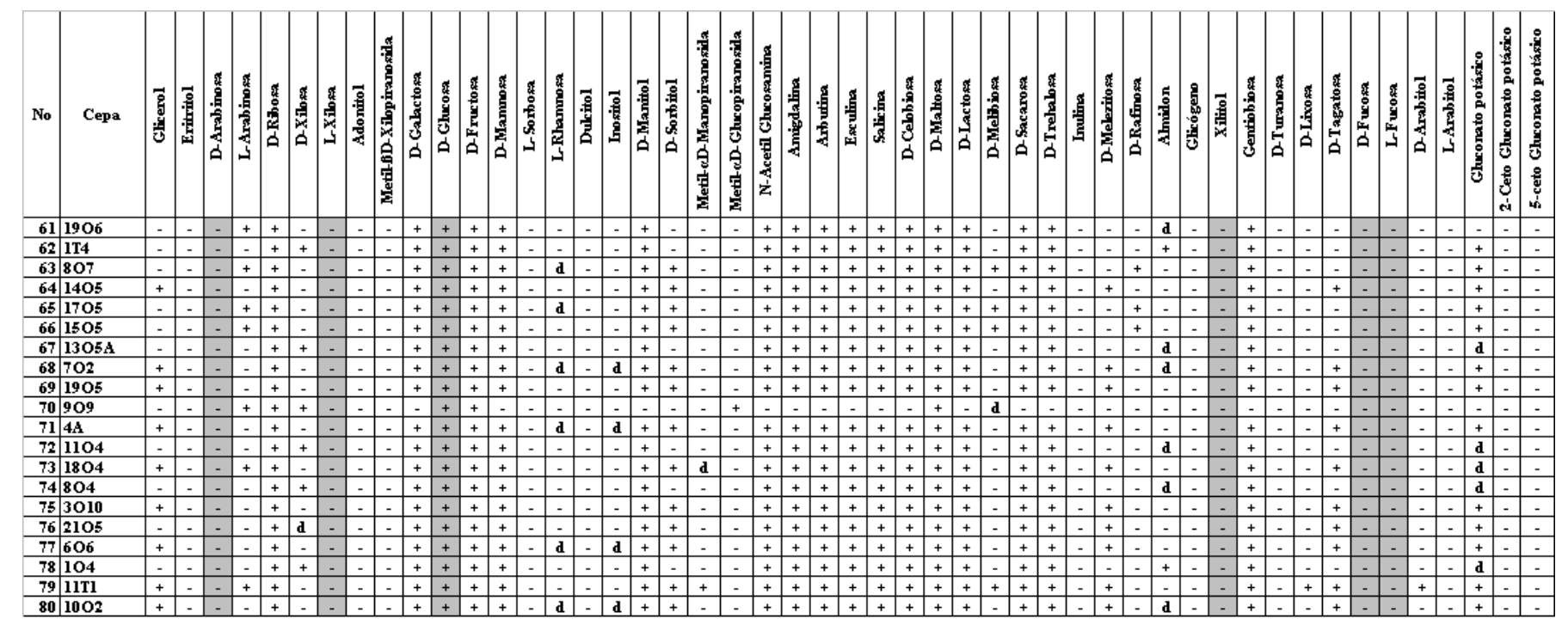




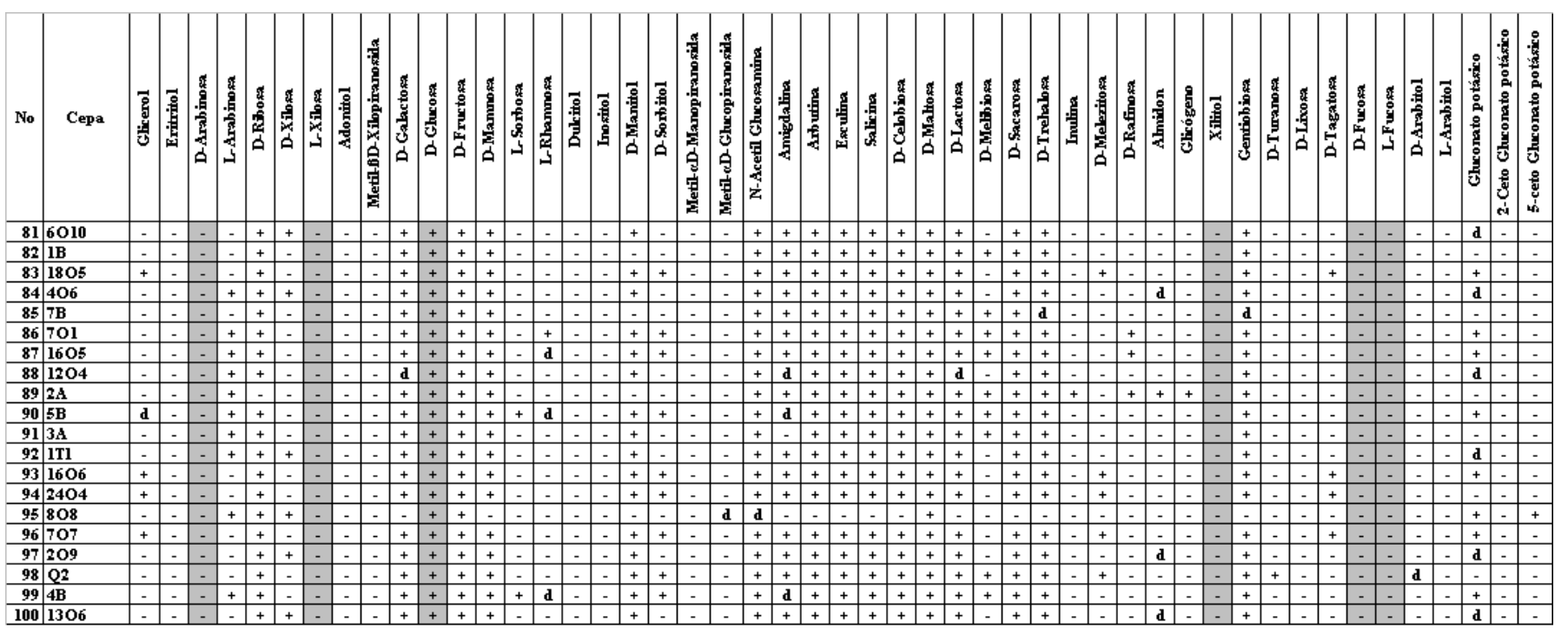

240 


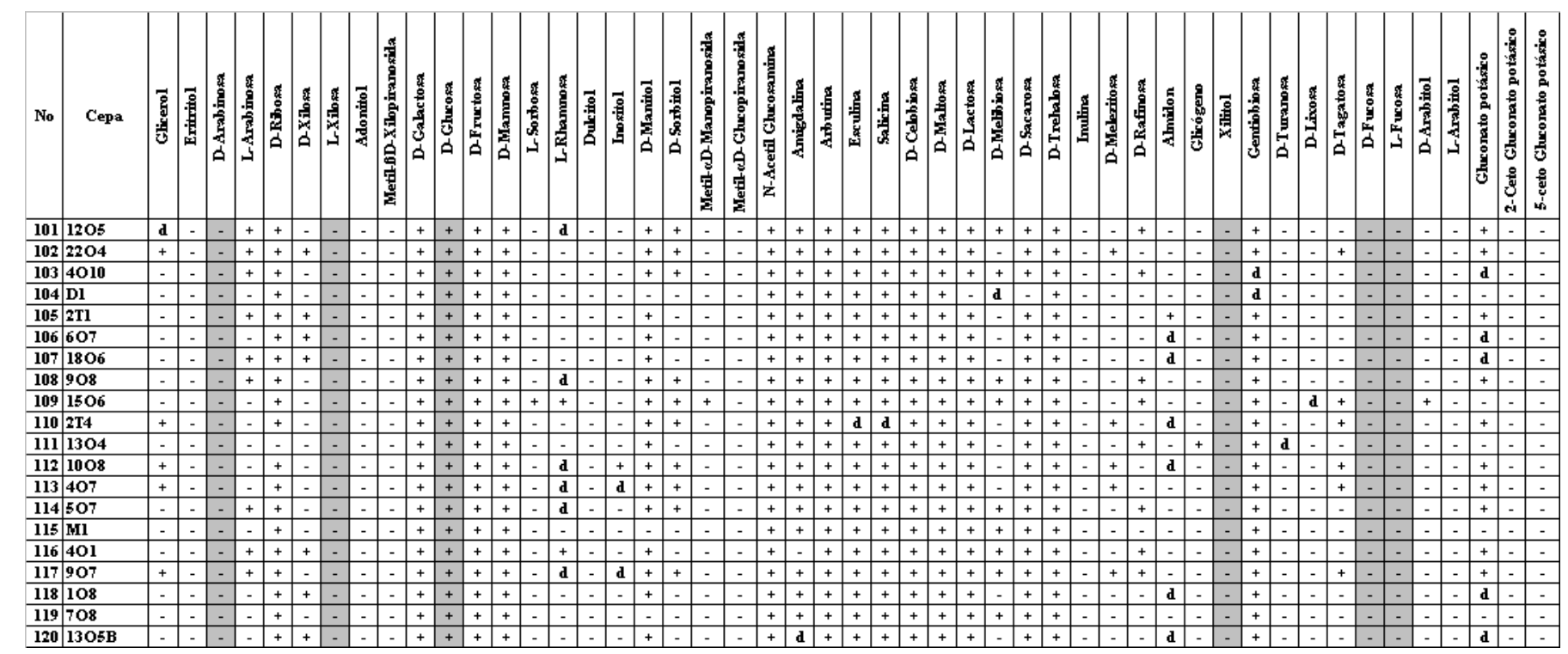


Anexo IV

\section{ANEXO 4.}

ACTIVIDAD ANTIMICROBIANA DE LAS BAL FRENTE A Helicobacter pylori y Samonella spp. 


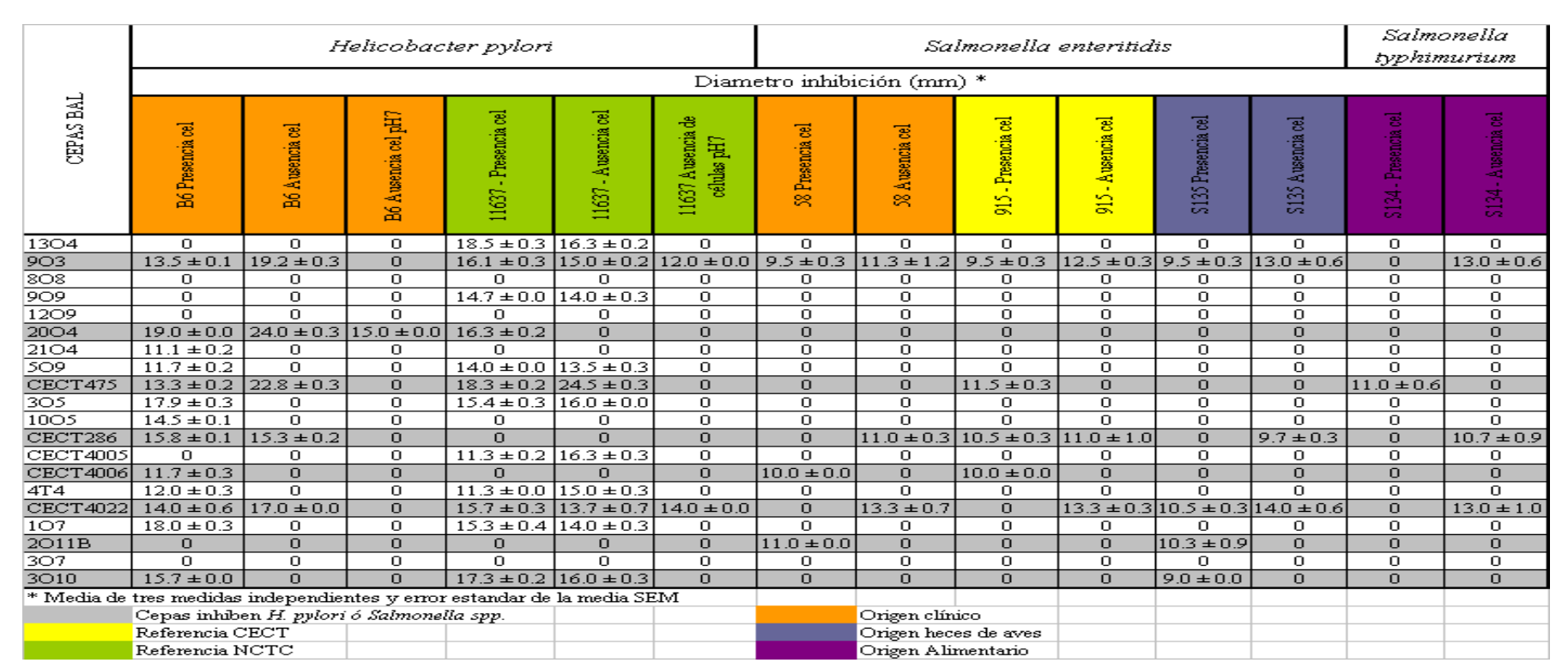




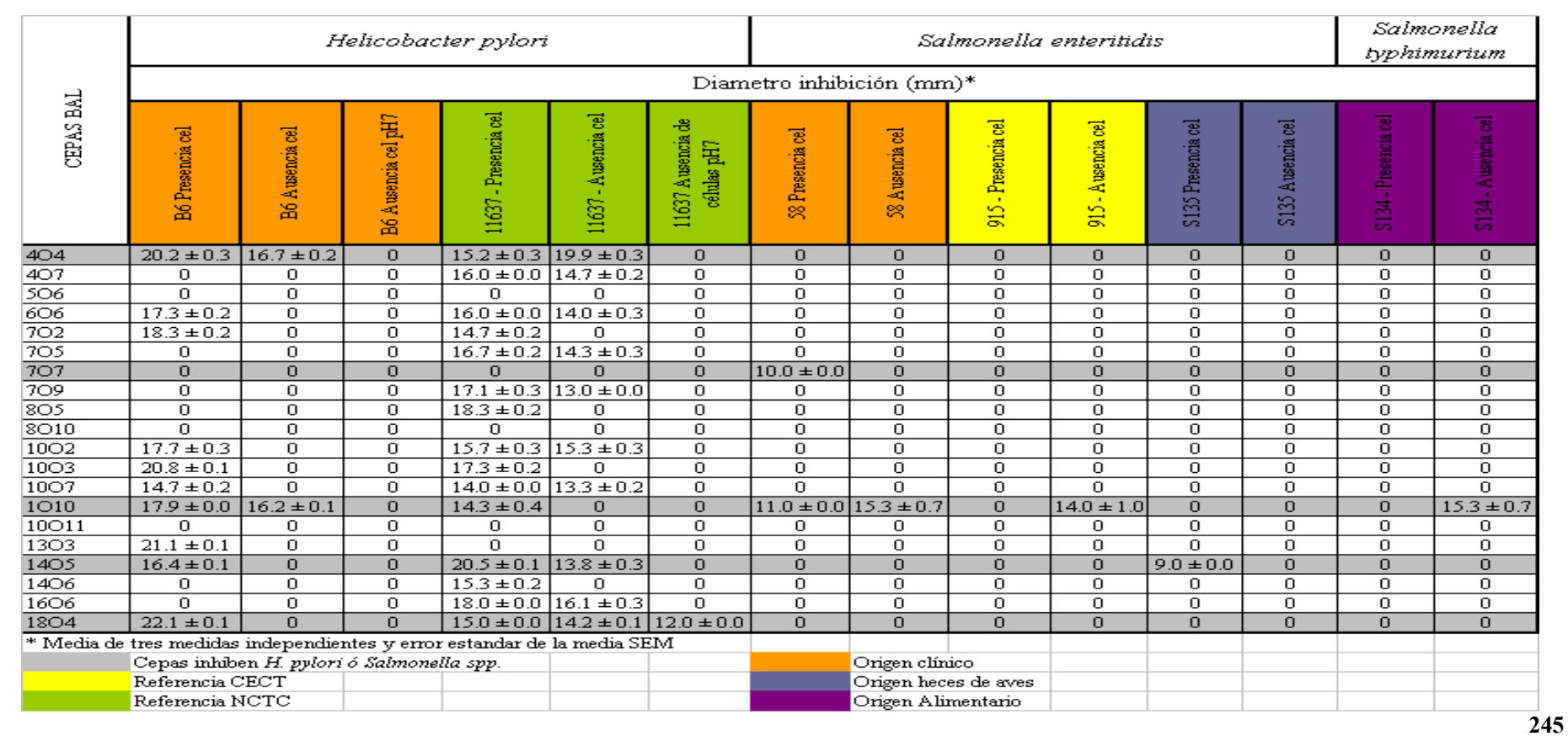




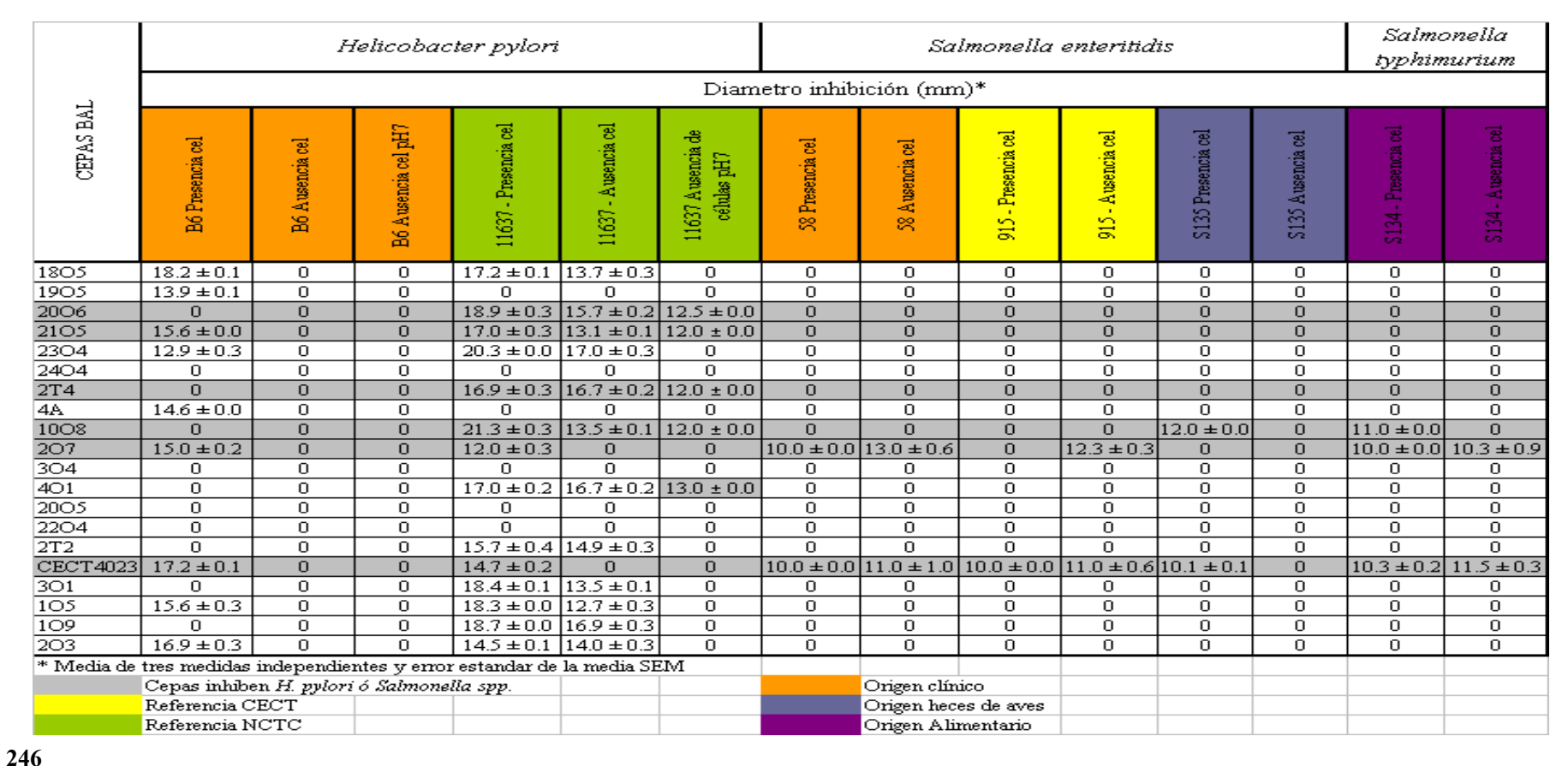


Anexo IV

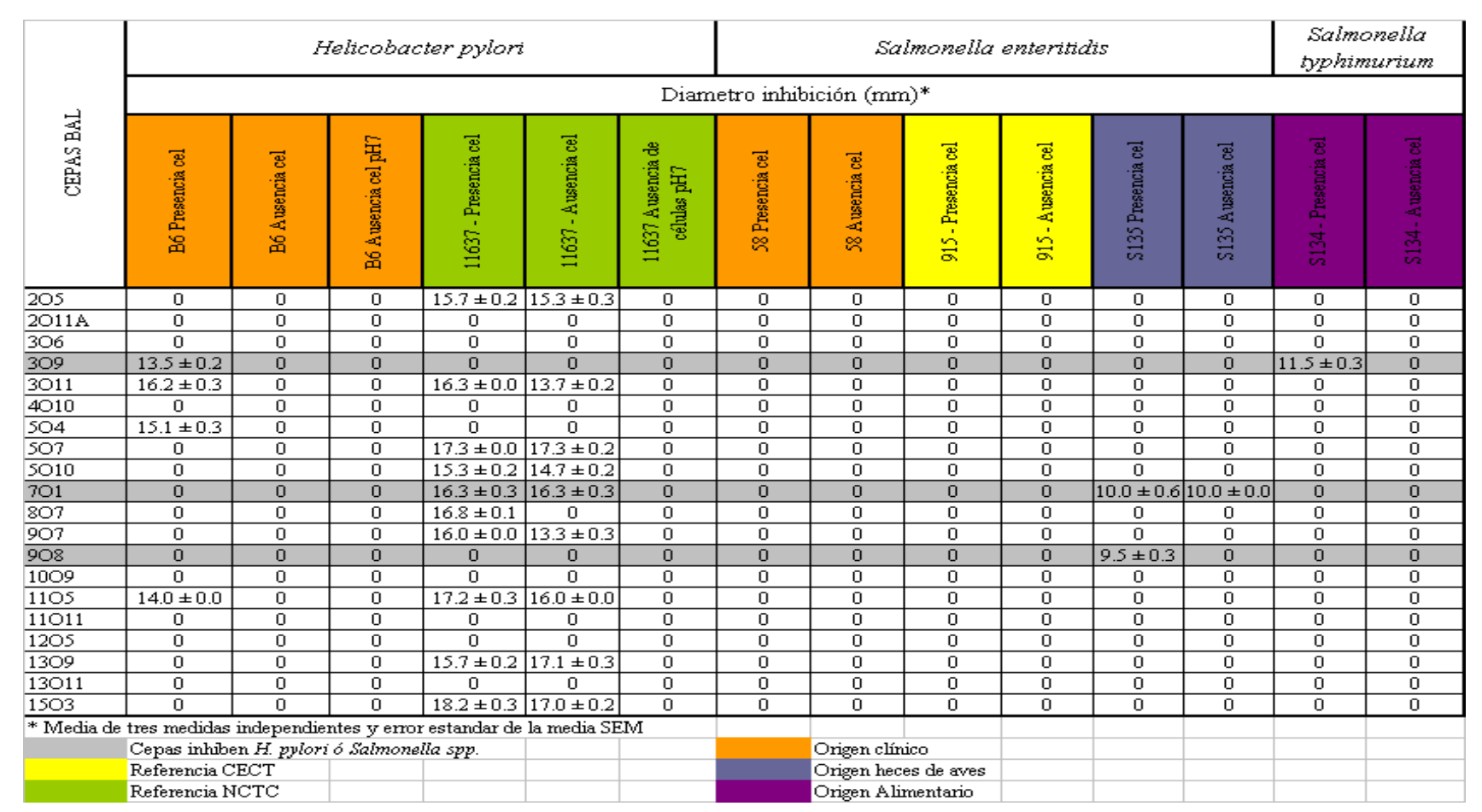




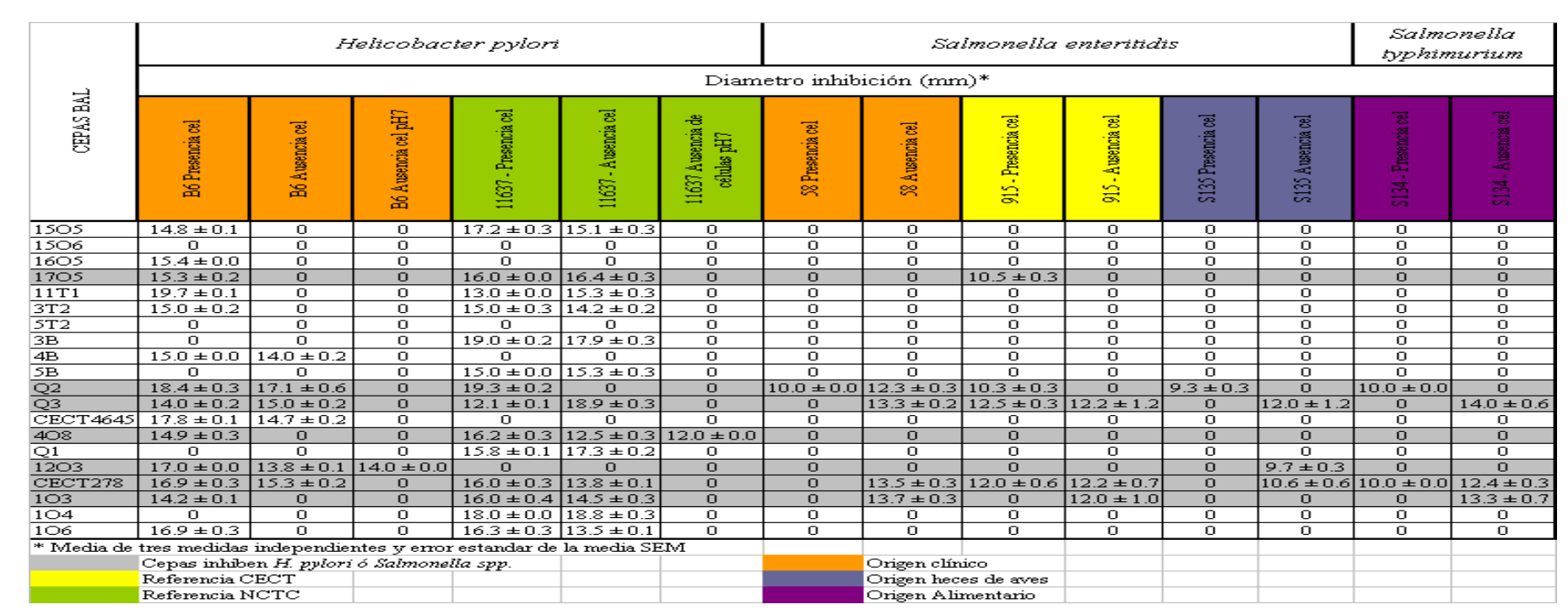


Anexo IV

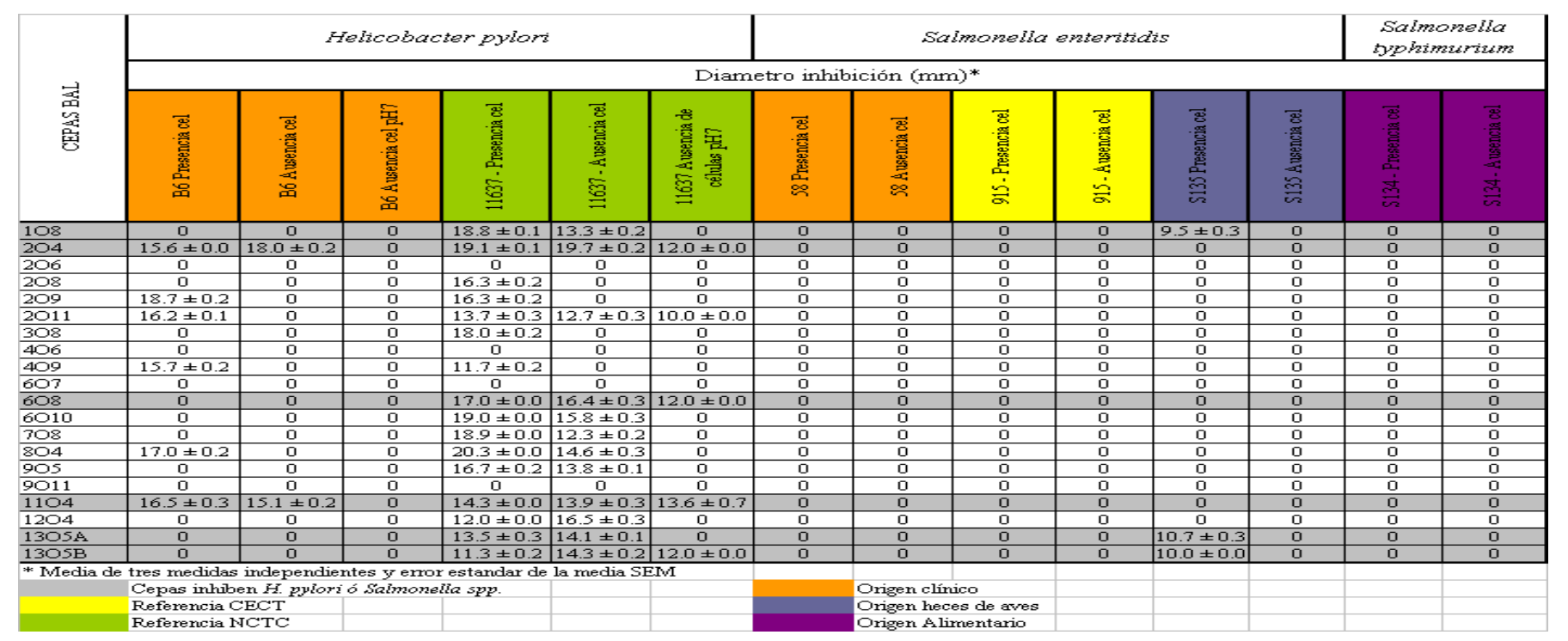




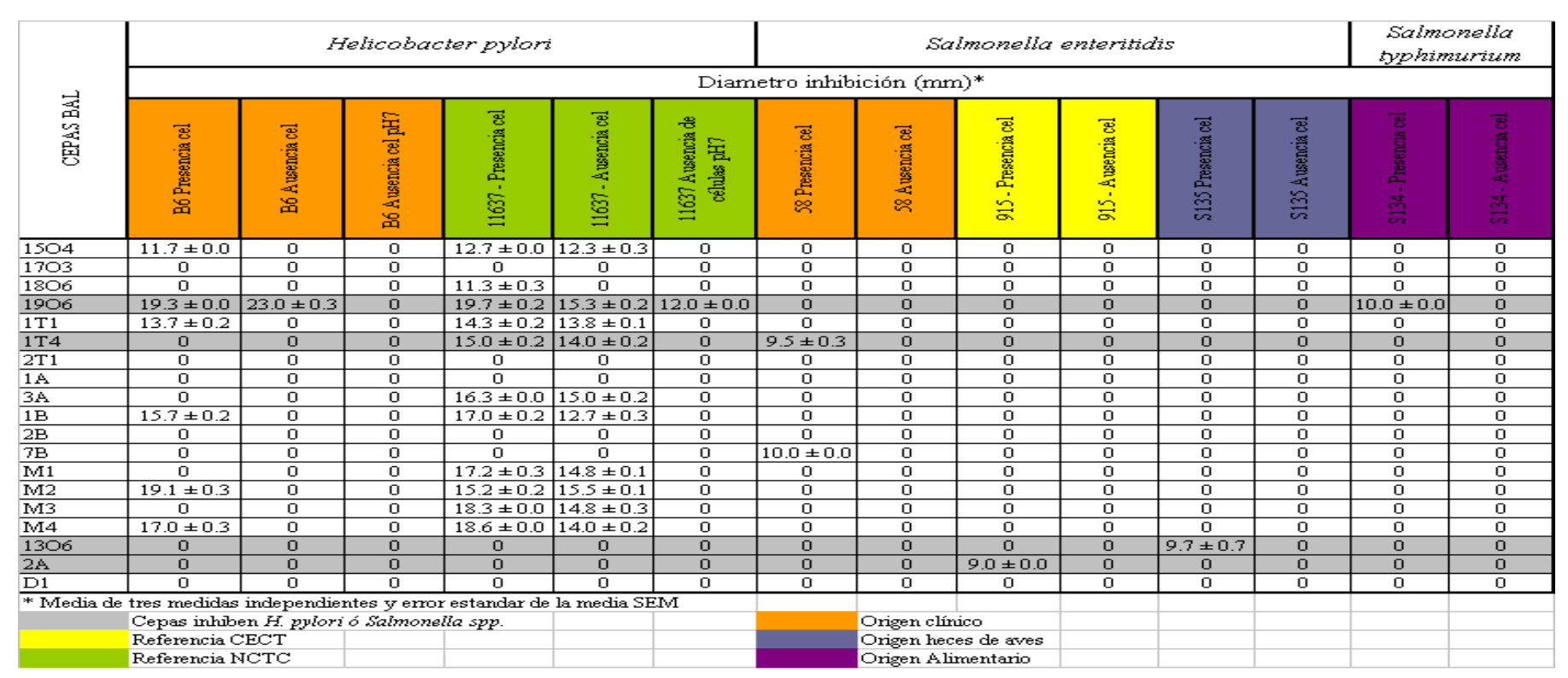




\section{CONGRESOS Y PUBLICACIONES}

AUTORES: Claudia Milena Amorocho, Ana Jiménez, Yolanda Moreno, Jorge García, María Antonia Ferrús y Manuel Hernández.

TITULO:"in vitro" effect of lactic acid bacteria isolated from Guirra sheep against Helicobacter pylori.

TIPO DE PARTICIPACIÓN: Poster

CONGRESO: Food Microbiology Conference

PUBLICACIÓN: Memorias Congreso

LUGAR DE CELEBRACIÓN: Aberdeen, Escocia

$A \tilde{N} O: 2008$

AUTORES: Claudia Milena Amorocho, Ana Jiménez, Yolanda Moreno, Jorge García, María Antonia Ferrús y Manuel Hernández.

TITULO CAPITULO: Effect "in vitro" of lactic acid bacteria isolated from "guirra" sheep against Salmonella spp. Págs 403-407.

TITULO LIBRO: "Microorganisms in Industry and Environment. From scientific and industrial research to consumer products"

TIPO DE PARTICIPACIÓN: Poster y Artículo

CONGRESO: III International Conference on Environmental, Industrial and Applied Microbiology. BioMicroworld Conference

PUBLICACIÓN: Aceptado para publicación. ISBN-13: 978-981-4322-10-2

LUGAR DE CELEBRACIÓN: Lisboa, Portugal

$A \tilde{N} O: 2009$ 
AUTORES: Claudia Milena Amorocho, Ana Jiménez, Yolanda Moreno, María Antonia Ferrús y Manuel Hernández.

TITULO: Survival to simulated gastrointestinal transit of lactic acid bacteria with antimicrobial activity

TIPO DE PARTICIPACIÓN: Poster

CONGRESO: IAFP European Symposium

PUBLICACIÓN: Memorias Congreso

LUGAR DE CELEBRACIÓN: Dublin,Irlanda

$A \tilde{N} O: 2010$

AUTORES: Claudia Milena Amorocho, Yolanda Moreno, Jorge García y Manuel Hernández.

TITULO: Phenotypic and molecular characterization of probiotic lactic acid bacteria (LAB) isolated from guirra sheep milk

TIPO DE PARTICIPACIÓN: Poster

CONGRESO: IDF International Symposium on sheep, goat and other no-cow milk

PUBLICACIÓN: Memorias Congreso

LUGAR DE CELEBRACIÓN: Atenas, Grecia

$A \tilde{N} O: 2011$ 
AUTORES: Claudia Milena Amorocho, Yolanda Moreno, Ana Jiménez y Manuel Hernández.

TITULO: In vitro adhesion of lactic acid bacteria (LAB) isolated from guirra sheep milk TIPO DE PARTICIPACIÓN: Poster

CONGRESO: IDF International Symposium on sheep, goat and other no-cow milk

PUBLICACIÓN: Memorias Congreso

LUGAR DE CELEBRACIÓN: Atenas, Grecia

$A \tilde{N} O: 2011$ 